\title{
Precipitation and Hardening in Magnesium Alloys
}

\begin{abstract}
JIAN-FENG NIE
Magnesium alloys have received an increasing interest in the past 12 years for potential applications in the automotive, aircraft, aerospace, and electronic industries. Many of these alloys are strong because of solid-state precipitates that are produced by an age-hardening process. Although some strength improvements of existing magnesium alloys have been made and some novel alloys with improved strength have been developed, the strength level that has been achieved so far is still substantially lower than that obtained in counterpart aluminum alloys. Further improvements in the alloy strength require a better understanding of the structure, morphology, orientation of precipitates, effects of precipitate morphology, and orientation on the strengthening and microstructural factors that are important in controlling the nucleation and growth of these precipitates. In this review, precipitation in most precipitation-hardenable magnesium alloys is reviewed, and its relationship with strengthening is examined. It is demonstrated that the precipitation phenomena in these alloys, especially in the very early stage of the precipitation process, are still far from being well understood, and many fundamental issues remain unsolved even after some extensive and concerted efforts made in the past 12 years. The challenges associated with precipitation hardening and age hardening are identified and discussed, and guidelines are outlined for the rational design and development of higher strength, and ultimately ultrahigh strength, magnesium alloys via precipitation hardening.
\end{abstract}

DOI: $10.1007 / \mathrm{s} 11661-012-1217-2$

(C) The Minerals, Metals \& Materials Society and ASM International 2012

\section{INTRODUCTION}

MAGNESIUM is the lightest of all commonly used structural metals, with a density approximately two thirds that of aluminum and one quarter that of steels. Magnesium is an abundant element, comprising $2.7 \mathrm{pct}$ of the Earth's crust, and it is available commercially with purity exceeding 99.8 pct. Magnesium has a relatively low melting temperature and high specific heat. Hence, magnesium and its alloys may, thus, be readily cast to near-net shape by conventional casting methods. Because of such attractive features, magnesium alloys have received considerable research over the last decade for potentially wider and larger applications in the automotive, aircraft, aerospace, and 3C (computer, communication, and consumer electronic product) industries. The annual production rate of magnesium metal was approximately 450,000 tons in 2001 and reached $\sim 720,000$ tons in 2008. Despite the considerable efforts made thus far, the adoption of magnesium alloys in engineering applications remains limited compared with that achieved for aluminum alloys. One important technical reason is that there are limited magnesium alloys for designers to select from for specific applications, and within these limited choices, the most cost-effective magnesium alloys have inadequate properties such as yield strength, creep-resistance, formability, and corrosion resistance. The accumulated

JIAN-FENG NIE, Professor, is with the Department of Materials Engineering, Monash University, Clayton, VIC 3800, Australia. Contact e-mail: Jianfeng.nie@monash.edu

Manuscript submitted February 1, 2012.

Article published online July 21, 2012 empirical experience, rather than basic understanding, provides the tools for practical design and development of magnesium alloys with better mechanical and chemical properties.

Many magnesium casting and wrought alloys achieve their useful mechanical properties via age hardening, which involves (1) solution treatment at a relatively high temperature within the $\alpha-\mathrm{Mg}$ single-phase region, (2) water quenching to obtain a supersaturated solid solution of alloying elements in magnesium, and (3) subsequent aging at a relatively low temperature to achieve a controlled decomposition of the supersaturated solid solution into a fine distribution of precipitates in the magnesium matrix. The decomposition of the supersaturated solid solution often involves the formation of a series of metastable or equilibrium precipitate phases that have a different resistance to dislocation shearing. Therefore, the control of the precipitation is important if the maximum precipitation strengthening effect is to be achieved.

Attempts to improve the age-hardening response of magnesium alloys inevitably requires an in-depth understanding of precipitation, precipitation hardening, and microstructural factors that are most important in controlling the precipitation of strengthening phases and the strength of precipitation-hardenable alloys. For precipitation-hardened magnesium alloys, their microstructures often contain a distribution of plate-shaped or lath-rodshaped precipitates of intermediate or equilibrium phases formed parallel or normal to the basal plane of the magnesium matrix phase. In the last century, the crystal structure, composition, and orientation relationship of these precipitates have been characterized primarily using conventional transmission electron microscopy (TEM) 
and electron diffraction. As a consequence of the resolution and limitation of these techniques, the characteristic features of some precipitate phases and the precipitation sequence in many alloys were not clearly established. In the first decade of this century, with the assistance of highresolution transmission electron microscopy, particularly atomic-resolution high-angle annular dark-field scanning transmission electron microscopy (HAADF-STEM), and three-dimensional atom probe (3DAP), some puzzles on the structure and composition of precipitate phases in some existing magnesium alloys have been solved. These modern characterization facilities also greatly facilitate the identification of precipitates in magnesium alloys that are developed in recent years. Such knowledge on the crystallography of precipitate phases provides the basis for the understanding of the formation and strengthening mechanisms of the precipitate phases and, more importantly, for the rational alloy design in practice.

The purpose of this article is to provide a comprehensive review of the literature on precipitation and hardening in most, if not all, age-hardenable magnesium alloys. Because a few books on magnesium alloys ${ }^{[1-4]}$ and some review articles on precipitation in magnesium alloys ${ }^{[5-8]}$ and particle hardening ${ }^{[9-12]}$ are already in the literature, the emphasis of this article will be focused on (1) the structure, morphology, and orientation of precipitates, precipitation sequence and hardening response in each of the major alloy systems; (2) the effects of precipitate shapes on strengthening; and (3) the rational design of microstructures for larger agehardening response and therefore higher strength. Some unsolved issues that require additional research are also highlighted and discussed.

\section{PRECIPITATION AND AGE-HARDENING RESPONSE}

\section{A. Mg-Al-Based Alloys}

\section{Precipitation}

The magnesium-rich side of the $\mathrm{Mg}$-Al binary phase diagram includes equilibrium solid phases $\alpha-\mathrm{Mg}$ and $\beta$ $\mathrm{Mg}_{17} \mathrm{Al}_{12}$, as well as a eutectic temperature of $710 \mathrm{~K}$ $\left(437{ }^{\circ} \mathrm{C}\right)$. The $\beta$ phase has a body-centered cubic structure (space group $\mathrm{I} \overline{4} 3 \mathrm{~m}$ ) with the lattice parameter $a \sim 1.06 \mathrm{~nm} .{ }^{[13]}$ The equilibrium solid solubility of $\mathrm{Al}$ in $\alpha-\mathrm{Mg}$ is 11.8 at. pct (12.9 wt pct) at the eutectic temperature, and it decreases to approximately 3.3 at. pct at $473 \mathrm{~K}\left(200^{\circ} \mathrm{C}\right) .{ }^{[14]}$ The equilibrium volume fraction of precipitates achievable in the $\mathrm{Mg}$-Al alloys aged at $473 \mathrm{~K}\left(200^{\circ} \mathrm{C}\right)$ can reach a substantially large value of 11.4 pct. This thermodynamic feature provides a unique opportunity for generating a large volume fraction of precipitates by using conventional aging treatments, i.e., solution treatment at approximately $692 \mathrm{~K}\left(420{ }^{\circ} \mathrm{C}\right)$, followed by water quench and subsequent aging at a temperature in the range of $373 \mathrm{~K}$ to $573 \mathrm{~K}\left(100{ }^{\circ} \mathrm{C}\right.$ to $300{ }^{\circ} \mathrm{C}$ ). Unfortunately, during the isothermal aging treatment in the temperature range $373 \mathrm{~K}$ to $573 \mathrm{~K}$ $\left(100{ }^{\circ} \mathrm{C}\right.$ to $300{ }^{\circ} \mathrm{C}$ ), the precipitation process seems to involve solely the formation of the equilibrium $\beta$ phase (Table I). Although the $\beta$ precipitates are resistant to dislocation shearing ${ }^{[15,16]}$ their distribution is relatively coarse, presumably because of the relatively high diffusion rate of $\mathrm{Al}$ atoms in the solid matrix of magnesium and a possibly high concentration of vacancies in the $\alpha$ $\mathrm{Mg}$ matrix. Consequently, the age-hardening response of $\mathrm{Mg}-\mathrm{Al}$ alloys ${ }^{[15,17-20]}$ is not as appreciable as expected (Figure 1(a)). ${ }^{[19,20]}$

Previous studies ${ }^{[16,21]}$ revealed that the precipitation of the equilibrium $\beta$ phase occurs both discontinuously and continuously. The discontinuous precipitation is also known as cellular precipitation, and in this reaction, the supersaturated solid solution $\alpha^{\prime}$ phase decomposes into the $\beta$ phase and an $\alpha$ phase that is structurally identical to the $\alpha^{\prime}$ phase but has a less saturated concentration of aluminum. The discontinuous precipitation initiates in grain boundaries and expands toward the grain center in a cellular form. ${ }^{[22]}$ The cell comprises a lamellar structure of $\beta$ and $\alpha$ phases, and the cell interface separating $\alpha$ and $\alpha^{\prime}$ is a high angle boundary. The continuous precipitation occurs inside the grains. The continuous and discontinuous precipitations occur simultaneously and compete with each other during isothermal aging of $\mathrm{Mg}-\mathrm{Al}$ alloys. Duly et al. ${ }^{[23-25]}$ reported that the continuous precipitation is favored at both high and low aging temperatures and that discontinuous precipitation dominates the microstructure at intermediate temperatures. They proposed that the disappearance of discontinuous precipitation at high aging temperatures is caused by the volume diffusion of solute that prevents the nucleation and growth of the cellular colonies and that the absence of discontinuous precipitation at low aging temperatures is the result of a lower driving force, which is caused by the occurrence of continuous precipitation in the early stage of aging treatment.

A more recent study of a binary $\mathrm{Mg}-9$ wt pet Al alloy and alloy AZ91 ${ }^{[26]}$ indicates that in the binary $\mathrm{Mg}-9$ wt pct Al alloy samples aged at $423 \mathrm{~K}\left(150^{\circ} \mathrm{C}\right)$ or cooled from the solution temperature to room temperature, only discontinuous precipitates are observed, whereas that only continuous precipitates form when the binary and the AZ91 alloys are aged at $623 \mathrm{~K}\left(350^{\circ} \mathrm{C}\right)$. It is also found that both discontinuous and continuous precipitates form when the alloys are aged at intermediate temperatures of $473 \mathrm{~K}$ or $523 \mathrm{~K}\left(200{ }^{\circ} \mathrm{C}\right.$ or $\left.250{ }^{\circ} \mathrm{C}\right)$. It was proposed $^{[26]}$ that whether discontinuous precipitation occurs also depends on the concentration of vacancies in addition to the aging temperature.

For most continuous precipitates and discontinuous precipitates of the $\beta$ phase in the lamellar structure, they were initially reported to adopt the exact Burgers orientation relationship, i.e., $(011)_{\beta} / /(0001)_{\alpha},[1 \overline{1} 1]_{\beta} / /[2 \overline{1} \overline{1} 0]_{\alpha} \cdot{ }^{[27]} \quad$ Subsequent transmission electron microscopy studies ${ }^{[28,29]}$ indicate that the orientation relationship is actually near the Burgers. The $\beta$ precipitates in this orientation relationship have a plate morphology, with their broad surface parallel to $(0001)_{\alpha}$ (Figures 1(b) and (c)). Although the $\beta$ plates in this orientation relationship are often described as incoherent, ${ }^{[7,8,30]}$ ample experimental evidence demonstrates that the equilibrium $\beta$ phase is in fact not incoherent. Apart from the apparent lattice matching between the $\beta$ phase and surrounding matrix phase in 
Table I. Part of the Whole Precipitation Sequence in Individual Magnesium Alloy Systems

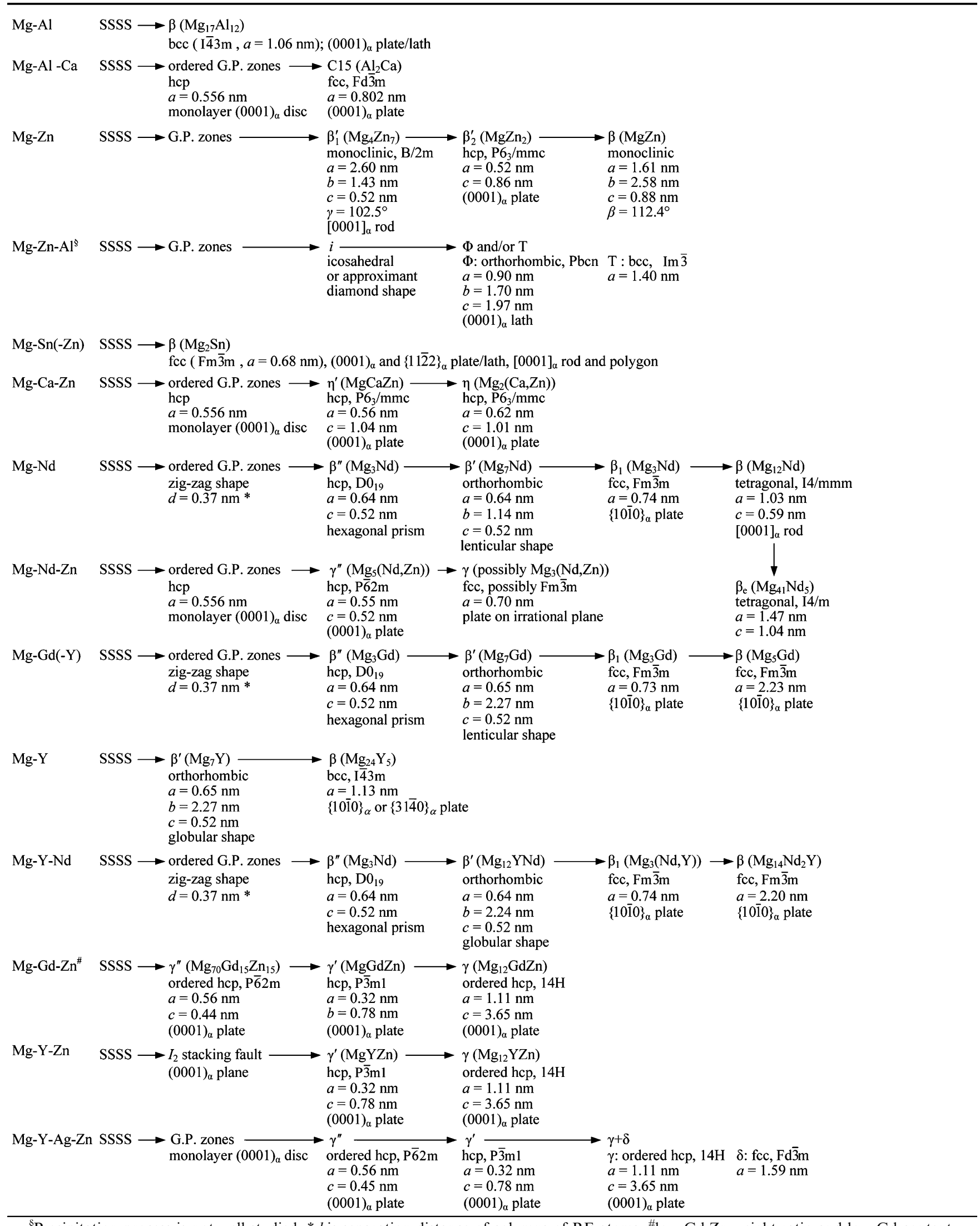

${ }^{\S}$ Precipitation process is not well studied; * $d$ is separation distance of columns of RE atoms; ${ }^{*}$ low Gd:Zn weight ratio and low Gd content. 
the plate broad surface, or habit plane, the lattice matching is also found in interfaces defining the major and minor side facets of individual $\beta$ plates. ${ }^{[28,29,31]}$

Despite the irrational orientation of these side facets with respect to both precipitate and matrix lattices, the major and minor side facets (Figure 2(a)) are invariably parallel to the moire fringes defined by the intersection of $(1 \overline{1} 00)_{\alpha}$ and $(0 \overline{3} 3)_{\beta}$, and of $(10 \overline{10})_{\alpha}$ and $(4 \overline{1} 1)_{\beta}$,

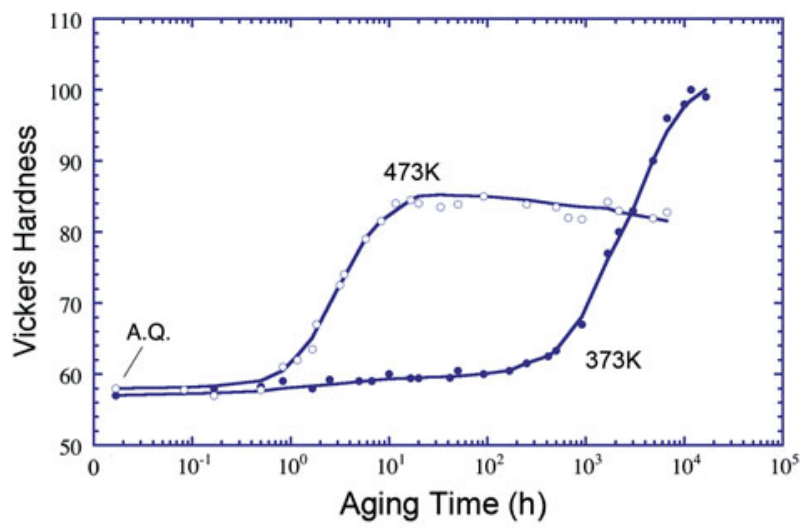

(a)

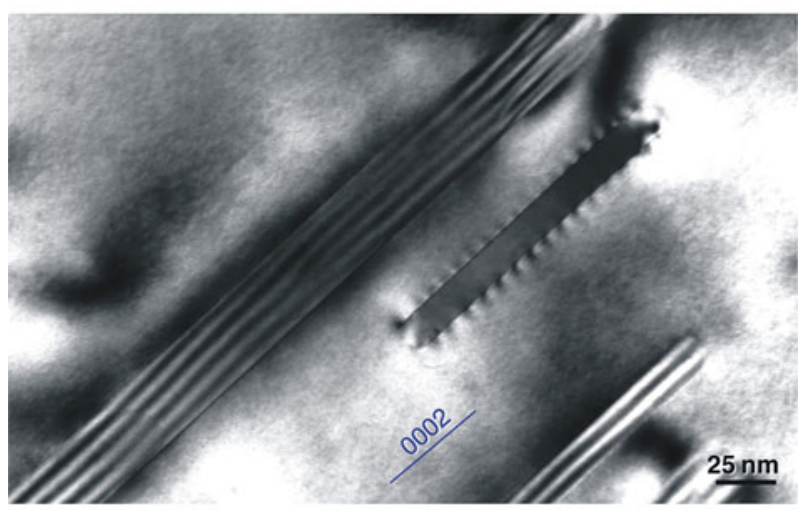

(b)

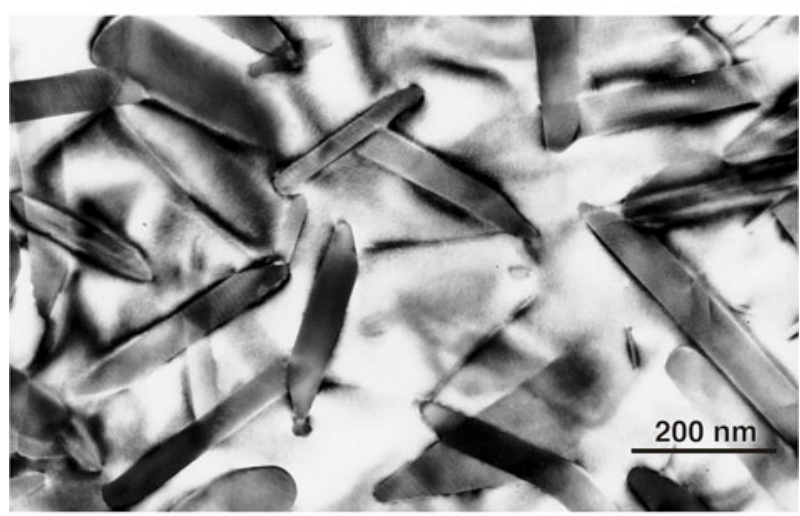

(c)

Fig. 1-(a) Isothermal aging curves of magnesium alloy AZ91 at $373 \mathrm{~K}$ and $473 \mathrm{~K}\left(100{ }^{\circ} \mathrm{C}\right.$ and $200{ }^{\circ} \mathrm{C}$ ) (adapted and reproduced from Refs. [19] and [20]). ( $b$ and $c$ ) Transmission electron micrographs showing the distribution and morphology of $\beta$ precipitates in samples aged for $8 \mathrm{~h}$ at $473 \mathrm{~K}\left(200{ }^{\circ} \mathrm{C}\right)$. Electron beam is parallel to $[2 \overline{1} 10]_{\alpha}$ in (b) and $[0001]_{\alpha}$ in (c). (b) is reproduced from Refs. [29] and [20], and (c) is from Ref. [20]. respectively. Figure 2(a) shows the major side facet of a thin $\beta$ plate that is embedded in the matrix phase. This major interface is parallel to the moire fringes resulting

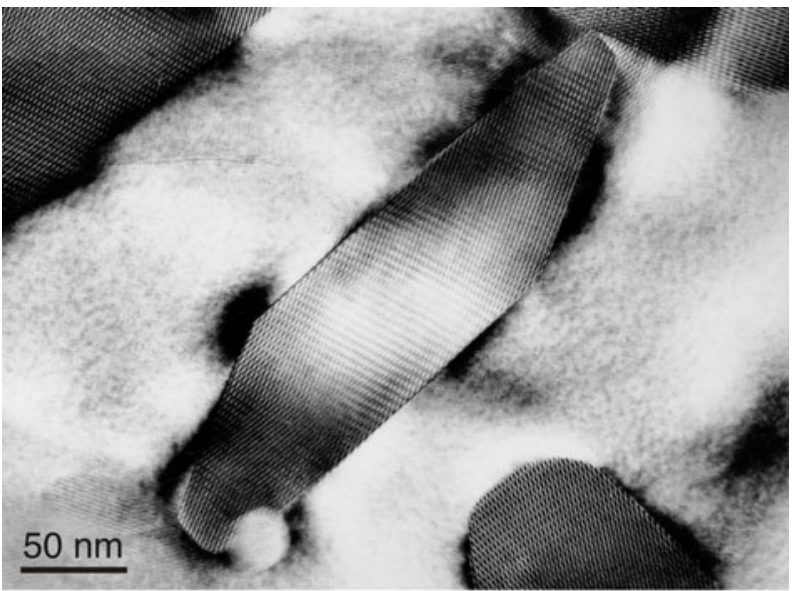

(a)

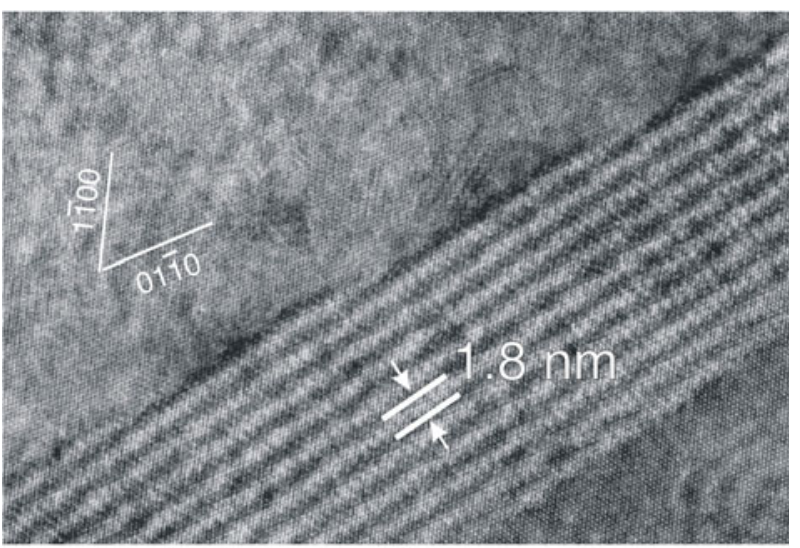

(b)

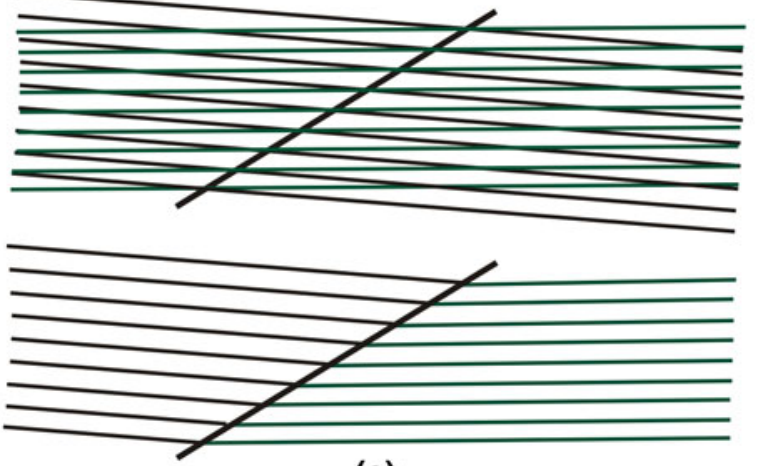

(c)

Fig. 2-(a) $[0001]_{\alpha}$ Transmission electron micrograph showing the parallelogram shape of $\beta$ precipitates in AZ91 (adapted and reproduced from Refs. [29] and [20]). (b) High-resolution transmission electron micrograph showing the major planar interface of $\beta$ precipitate such as that shown in (a); the planar interface is indicated by moiré planes (reproduced from Ref. [33]). (c) Schematic diagram showing the orientation relationship between two sets of lattice planes, e.g., $\{1 \overline{1} 00\}_{\alpha}$ and $(0 \overline{3} 3)_{\beta}$, and their resultant moiré plane, which corresponds to shown in (b). This diagram demonstrates the coherent matching of the two sets of lattice planes within the moiré plane. ${ }^{[34]}$ 
from the overlapping of the $(1 \overline{1} 00)_{\alpha}$ and $(0 \overline{3} 3)_{\beta}$ planes (Figure 2(c)), and it contains some ledges whose unit height is defined by the interplanar spacing of the moire fringes. The migration of this interface in its normal direction seems to involve the formation and later gliding of moiré ledges within the interface plane. ${ }^{[32,33]}$ These observations suggest the existence of commensurate matching of $(1 \overline{1} 00)_{\alpha}$ and $(0 \overline{3} 3)_{\beta}$ planes ${ }^{[2,33,34]}$ in the major facet interface, and of $(1010)_{\alpha}$ and $(4 \overline{1} 1)_{\beta}$ in the minor facet interface. This commensurate matching, together with the fact that $(0 \overline{3} 3)_{\beta}$ and $(4 \overline{1} 1)_{\beta}$ are the closest-packed planes in the $\beta$ lattice and $\{1100\}_{\alpha}$ is the near closest-packed plane in the magnesium lattice, suggests that the major and minor side facets of each $\beta$ plate have relatively low interfacial energies.

Apart from the near Burgers orientation relationship, two other orientation relationships have also been reported for the $\beta$ phase, ${ }^{[19,27,29,35,36]}$ namely $(1 \overline{1} 0)_{\beta} / /$ $(1 \overline{1} 00)_{\alpha}, \quad[111]_{\beta} / /[0001]_{\alpha}$ and $(1 \overline{1} 0)_{\beta} \sim / /(1 \overline{1} 00)_{\alpha}$, $[11 \overline{5}]_{\beta} \sim / /[0001]_{\alpha}$. For the former orientation relationship, the $\beta$ precipitates have a rod shape with their long axes parallel to $[0001]_{\alpha}$. The $[0001]_{\alpha}$ rods have a hexagonal cross section, with the bounding facets parallel to $\{1 \overline{1} 00\}_{\alpha} / /\{\overline{3} 30\}_{\beta}$. For the latter orientation relationship, the $\beta$ precipitates develop a rod shape with their long axes inclined with respect to the $[0001]_{\alpha}$ direction. Although these rods are more effective than the $(0001)_{\alpha}$ in impeding dislocation gliding on the basal plane, only a small fraction of them exists in the microstructure. It is currently unclear how to promote the rod-shape precipitates at the expenses of the $(0001)_{\alpha}$ plates. Such an effort inevitably requires an in-depth understanding of the transformation strains associated with each of the orientation relationships and the activation energy barrier to nucleation.

\section{Effects of cold work and alloying additions}

Cold work after solution treatment and prior to aging, microalloying, and macroalloying additions to $\mathrm{Mg}-\mathrm{Al}$ alloys do not seem to produce a significant enhancement in the age-hardening response. Clark reported ${ }^{[15]}$ that cold work after solution treatment and prior to aging of a Mg-9 wt pet Al alloy could increase the age-hardening response. The enhanced aging kinetics and the maximum hardness is attributable to a high number density of dislocations and twins in the cold-worked samples before aging and heterogeneous nucleation of $\beta$ precipitates on such lattice defects. It was noted that the density of precipitates formed at the twin interface and within twins is higher than that in the untwinned matrix regions. The preferential precipitation within twins may be attributed to the presence of stacking faults ${ }^{[37]}$ and a higher density of dislocations within the twins. ${ }^{[38]}$

The effects of microalloying additions on precipitation and age hardening of magnesium alloy AZ91 were studied by Bettles et al. ${ }^{[18]}$ They added, separately, 0.1 at. pet $\mathrm{Li}, \mathrm{B}, \mathrm{Ca}, \mathrm{Ti}, \mathrm{Sr}, \mathrm{Ag}, \mathrm{Mo}, \mathrm{Ba}, \mathrm{Pb}$, or 0.05 at. pet $\mathrm{Si}$ to AZ91. Even though the additions of such microalloying elements could influence the kinetics of precipitation and hardening, they did not lead to any appreciable increase in the maximum hardness values of the alloys (Figure 3). Therefore, it was speculated that the individual additions of these elements did not increase the nucleation rate of the $\beta$ phase or result in the formation of any new precipitate phases that can further enhance the age-hardening response.

The macroalloying addition of $\mathrm{Ca}$ to $\mathrm{Mg}-\mathrm{Al}$ alloys has been shown to improve the creep resistance. ${ }^{[39,40]}$ It is commonly reported in the early studies that the added $\mathrm{Ca}$ atoms react with $\mathrm{Al}$ atoms to form $\mathrm{Al}_{2} \mathrm{Ca}$ that has a $\mathrm{C} 15$ structure (space group $\mathrm{Fd} \overline{3} \mathrm{~m}, a=0.802 \mathrm{~nm}$ ), ${ }^{[39]}$ $(\mathrm{Mg}, \mathrm{Al})_{2} \mathrm{Ca}$ of a $\mathrm{C} 14$ structure, ${ }^{[40]}$ or a mixture of the two Laves phases during casting. In a subsequent study, ${ }^{[41]}$ it was reported that the intermetallic phase formed in the Mg-Al-Ca alloys has in fact a C36 structure $(a=0.584 \mathrm{~nm}, \quad c=1.897 \mathrm{~nm})$. This C36 Laves phase has now been confirmed in many recent studies to exist as an equilibrium phase in the $\mathrm{Mg}-\mathrm{Al}-\mathrm{Ca}$ system (Figure 4). ${ }^{[42]}$ For a long time, it has been generally accepted that the $\mathrm{Mg}-\mathrm{Al}-\mathrm{Ca}$ alloys are not age hardenable. However, a paper published in 2005 ${ }^{[43]}$ reported the precipitation of $\mathrm{C} 15$ when a high-pressure die-cast $\mathrm{Mg}-4.5 \mathrm{Al}-3.0 \mathrm{Ca}-0.14 \mathrm{Sr}-0.25 \mathrm{Mn}$ (wt pet) alloy,

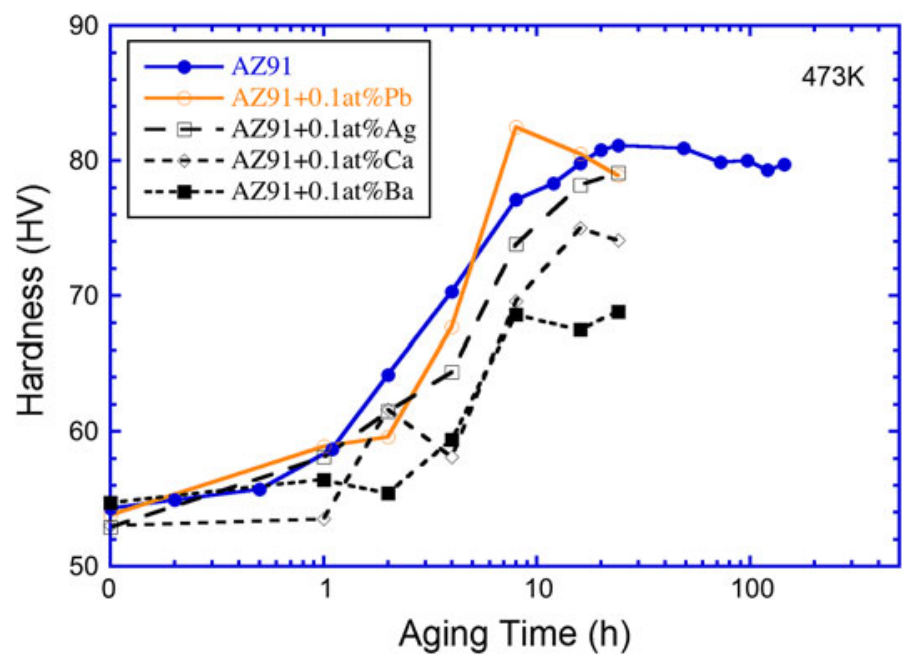

Fig. 3-Effects of microalloying additions on the age-hardening response of AZ91 at $473 \mathrm{~K}\left(200{ }^{\circ} \mathrm{C}\right)$. 
designated AXJ530, is aged at $573 \mathrm{~K}\left(300^{\circ} \mathrm{C}\right)$. The $\mathrm{C} 15$ precipitates form as plates on $(0001)_{\alpha}$, with the following orientation relationship with the matrix phase: $(111)_{\mathrm{C} 15}$ $/ /(0001)_{\alpha}$ and $[10 \overline{1}]_{C 15} / /[10 \overline{1} 0]_{\alpha}$. In a subsequent study, ${ }^{[4]}$ it was reported that the same alloy exhibits an age-hardening phenomenon when it is aged at $448 \mathrm{~K}$ to $523 \mathrm{~K}\left(175{ }^{\circ} \mathrm{C}\right.$ to $\left.250{ }^{\circ} \mathrm{C}\right)$ and that this age-hardening response is caused by the precipitation of the $\mathrm{C} 15$ plates. In a very recent study ${ }^{[45]}$ of $\mathrm{Mg}-2 \mathrm{Al}-2 \mathrm{Ca}$ and $\mathrm{Mg}-2 \mathrm{Al}-$ 2Ca-0.3Mn (wt pct) alloys, which were produced by permanent mold casting and creep tested at $448 \mathrm{~K}$ and $473 \mathrm{~K}\left(175{ }^{\circ} \mathrm{C}\right.$ and $\left.200{ }^{\circ} \mathrm{C}\right)$ under $50 \mathrm{MPa}$, the $\mathrm{C} 15$ plates were observed to form in the as-cast microstructures of the two alloys, and ordered G.P. zones form on the basal plane of the matrix phase in the crept samples. These ordered G.P. zones were inferred to be similar to those observed in $\mathrm{Mg}-\mathrm{RE}-\mathrm{Zn}$ and $\mathrm{Mg}-\mathrm{Ca}-\mathrm{Al}$ alloys, which will be described in Section II-D, and their number density in the Mn-containing alloy is higher than that in the Mn-free alloy.

\section{B. Mg-Zn Based Alloys}

\section{Phase equilibria and precipitation}

The magnesium-rich side of the $\mathrm{Mg}$ - $\mathrm{Zn}$ binary phase diagram is more complex than that of the $\mathrm{Mg}$-Al binary phase diagram. The eutectic temperature is $613 \mathrm{~K}$ $\left(340{ }^{\circ} \mathrm{C}\right)$, and the maximum solid solubility of $\mathrm{Zn}$ in magnesium is $6.2 \mathrm{wt}$ pct (or 2.4 at. pct) at the eutectic temperature. ${ }^{[14]}$ The eutectic reaction is such that the liquid phase solidifies into a mixture of $\alpha-\mathrm{Mg}$ and $\mathrm{Mg}_{7} \mathrm{Zn}_{3}$ phases. The $\mathrm{Mg}_{7} \mathrm{Zn}_{3}$ phase has an orthorhombic structure (space group Immm, $a=1.4083 \mathrm{~nm}$, $b=1.4486 \mathrm{~nm}$, and $c=1.4025 \mathrm{~nm}^{[46]}$, and it is thermodynamically stable only at temperatures above $598 \mathrm{~K}$ $\left(325^{\circ} \mathrm{C}\right)$. At temperatures at and below $598 \mathrm{~K}\left(325^{\circ} \mathrm{C}\right)$, the $\mathrm{Mg}_{7} \mathrm{Zn}_{3}$ phase decomposes, via an eutectoid

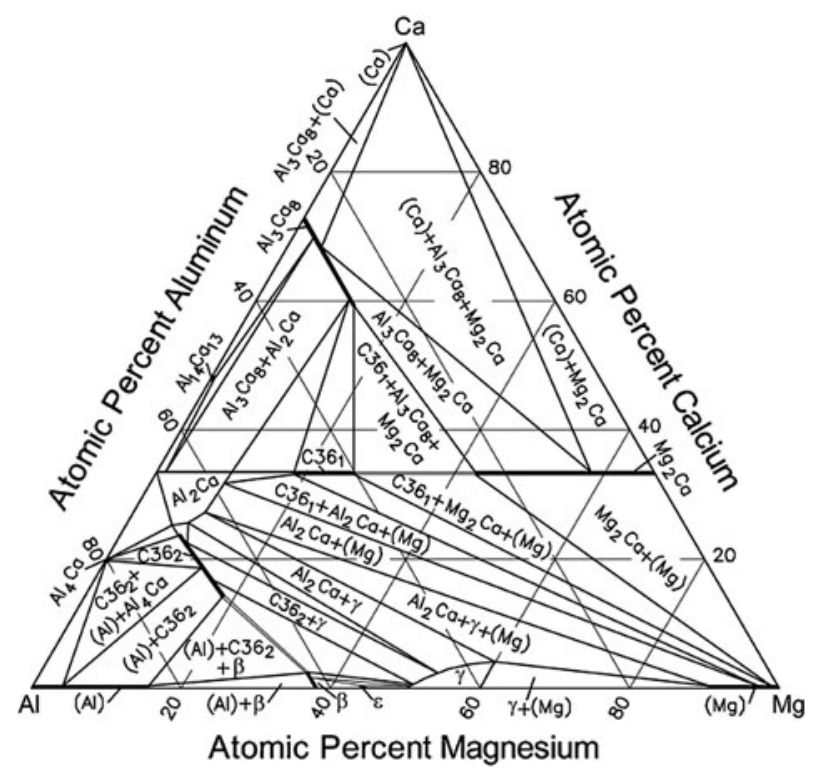

Fig. 4-Isothermal section of the $\mathrm{Mg}$ - $\mathrm{Al}-\mathrm{Ca}$ ternary phase diagram at $673 \mathrm{~K}\left(400{ }^{\circ} \mathrm{C}\right)$ (reproduced from Ref. [42]). The $\gamma$ phase in the diagram is the $\beta$ - $\mathrm{Mg}_{17} \mathrm{Al}_{12}$ phase in the present paper. reaction, into $\alpha-\mathrm{Mg}$ and $\mathrm{MgZn}$. The intermetallic phase that is in equilibrium with $\alpha-\mathrm{Mg}$ at temperatures below $598 \mathrm{~K}\left(325^{\circ} \mathrm{C}\right)$ is $\mathrm{MgZn}$. The structure of this intermetallic phase was not unambiguously established before 2006, even though the $\mathrm{Mg}-\mathrm{Zn}$ based alloys have received considerable attention in the past 10 years. Based on the X-ray diffraction results, Khan ${ }^{[47]}$ proposed a rhombohedral structure for the MgZn phase and expressed the lattice parameters in a hexagonal version, with $a=$ $2.569 \mathrm{~nm}$ and $c=1.8104 \mathrm{~nm}$. However, this rhombohedral structure has so far not been confirmed by the others. A recent study made by transmission electron microscopy and electron microdiffraction ${ }^{[48]}$ suggests that the $\mathrm{MgZn}$ phase has a base-centered monoclinic structure $(a=1.610 \mathrm{~nm}, b=2.579 \mathrm{~nm}, c=$ $0.880 \mathrm{~nm}, \beta=112.4 \mathrm{deg})$.

During heat treatments of a $\mathrm{Mg}-8$ wt pet $\mathrm{Zn}$ alloy at temperatures below $598 \mathrm{~K}\left(325^{\circ} \mathrm{C}\right)$, it was observed ${ }^{[48]}$ that the primary intermetallic particles of the $\mathrm{Mg}_{7} \mathrm{Zn}_{3}$ phase that had formed during the solidification process decompose into a divorced lamellar structure of $\alpha-\mathrm{Mg}$ and $\mathrm{Mg}_{4} \mathrm{Zn}_{7}$. The $\mathrm{Mg}_{4} \mathrm{Zn}_{7}$ phase is metastable, and it gradually replaced by the equilibrium phase $\mathrm{MgZn}$ after prolonged heat treatment. The $\mathrm{Mg}_{4} \mathrm{Zn}_{7}$ phase has a base-centered monoclinic structure and the following orientation relationship: $[001]_{\mathrm{Mg}_{4} \mathrm{Zn}_{7}} \sim / /[0001]_{\alpha}$ and $(630)_{\mathrm{Mg}_{4} \mathrm{Zn}_{7}} \sim / /(01 \overline{10})_{\alpha \cdot}{ }^{[48]}$ The structure of this metastable $\mathrm{Mg}_{4} \mathrm{Zn}_{7}$ phase is identical to that of the equilibrium $\mathrm{Mg}_{4} \mathrm{Zn}_{7}$ phase (space group $\mathrm{B} / 2 \mathrm{~m}, a=$ $2.596 \mathrm{~nm}, b=1.428 \mathrm{~nm}, c=0.524 \mathrm{~nm}, \gamma=102.5 \mathrm{deg}$ ) in the $\mathrm{Mg}-\mathrm{Zn}$ system $^{[49,50]}$ rather than the triclinic structure $(a=1.724 \mathrm{~nm}, \quad b=1.445 \mathrm{~nm}, \quad c=0.520 \mathrm{~nm}$, $\alpha=96 \mathrm{deg}, \quad \beta=89 \mathrm{deg}, \gamma=138 \mathrm{deg}$ ) assumed for the $\mathrm{Mg}_{2} \mathrm{Zn}_{3}$ phase by Gallot and Graf ${ }^{51]}$ and adopted by the others. ${ }^{[6,8,31]}$ Even though it is still unclear whether the monoclinic phase $\mathrm{Mg}_{4} \mathrm{Zn}_{7}$ is actually identical to the $\mathrm{Mg}_{2} \mathrm{Zn}_{3}$ phase, it is commonly accepted $^{[52]}$ that these two phases are the same, as only one intermetallic phase exists at compositions close to $\mathrm{Mg}-(60-63.6)$ at. pet $\mathrm{Zn}$ in the $\mathrm{Mg}-\mathrm{Zn}$ binary phase diagram.

The equilibrium solid solubility of $\mathrm{Zn}$ in magnesium decreases substantially with temperature, and the controlled decomposition of the supersaturated solid solution of $\mathrm{Zn}$ in magnesium can produce an age-hardening effect. $^{[52-56]}$ The aging curves of two binary $\mathrm{Mg}-\mathrm{Zn}$ alloys are provided in Figure 5(a). Depending on the alloy composition and aging temperatures, it is commonly accepted in the literature ${ }^{[6,8,30]}$ that the decomposition of the supersaturated solid-solution matrix phase reportedly involves the formation of G.P. zones, $\beta_{1}^{\prime}\left(\mathrm{MgZn}_{2}\right), \beta_{2}^{\prime}\left(\mathrm{MgZn}_{2}\right)$, and $\beta\left(\mathrm{Mg}_{2} \mathrm{Zn}_{3}\right)$. The formation of G.P. zones, which are described as coherent disks formed on $(0001)_{\alpha}$, has not been supported by direct experimental evidence so far. Although G.P. zones, together with $\mathrm{Zn}$ clusters and G.P.1 zones, were reported in recent studies ${ }^{[57,58]}$ to form in a $\mathrm{Mg}$ 2.8 at. pet $\mathrm{Zn}$ alloy aged at temperatures $295 \mathrm{~K}$, $343 \mathrm{~K}, 371 \mathrm{~K}$, and $433 \mathrm{~K}\left(22{ }^{\circ} \mathrm{C}, 70{ }^{\circ} \mathrm{C}, 98{ }^{\circ} \mathrm{C}\right.$, and $160{ }^{\circ} \mathrm{C}$ ), no compelling experimental evidence was provided to support the existence of such $\mathrm{Zn}$ clusters and G.P. zones. The hardness values reported in this 


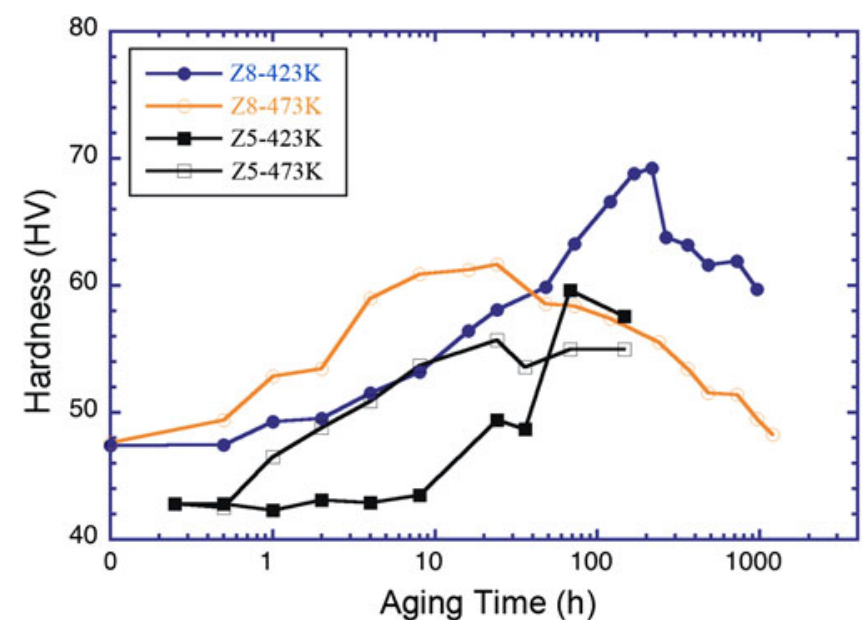

(a)

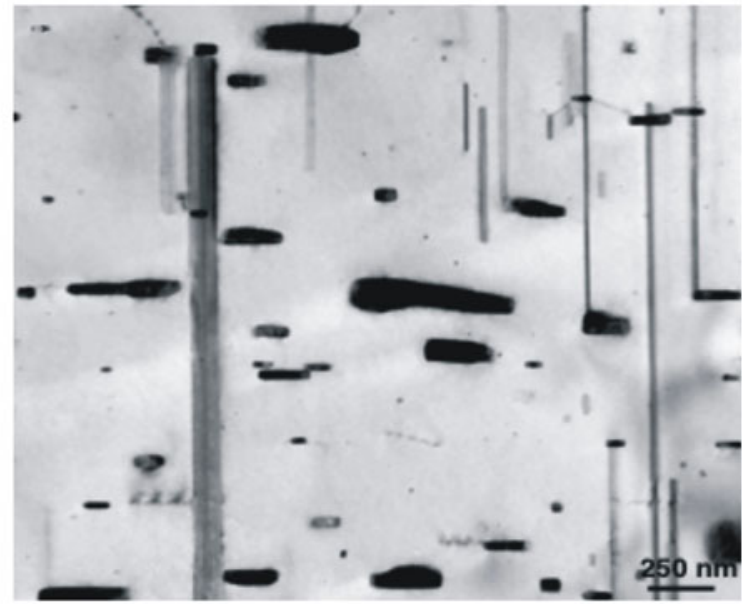

(b)

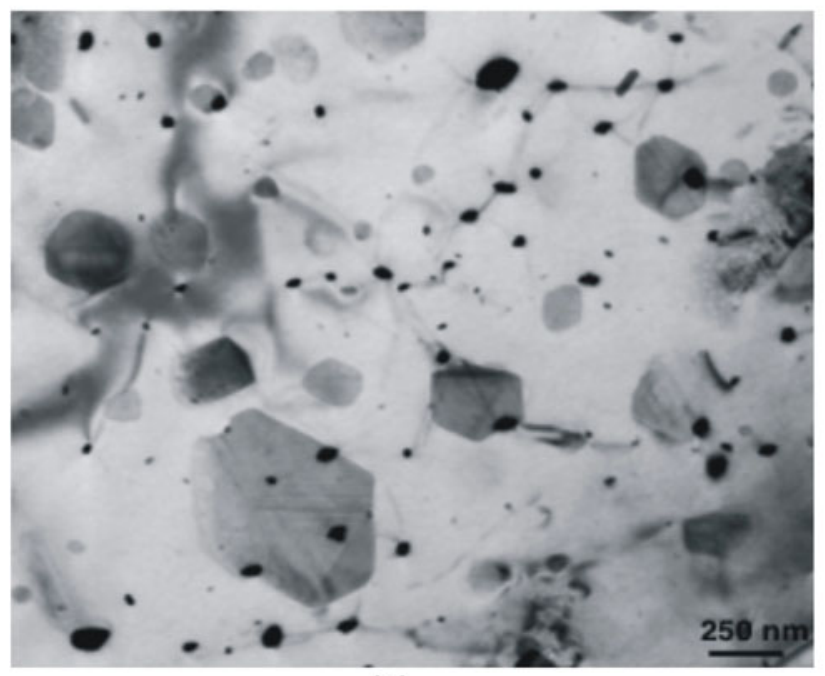

(c)

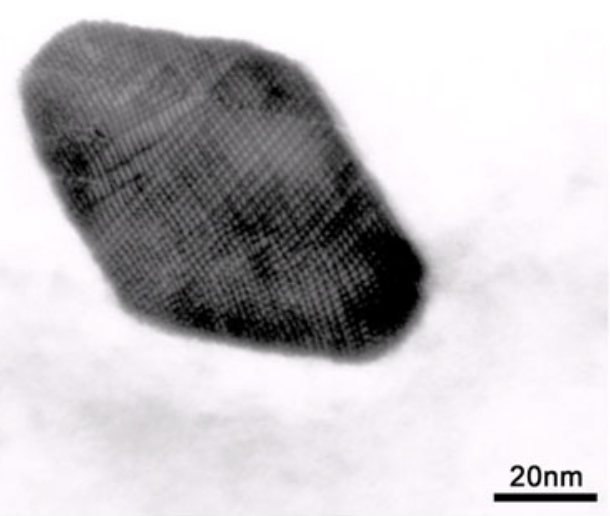

(d)

Fig. 5- (a) Age-hardening response of Mg-8 wt pet $\mathrm{Zn}$ and $\mathrm{Mg}-5$ wt pet $\mathrm{Zn}$ alloys at $423 \mathrm{~K}$ and $473 \mathrm{~K}\left(150{ }^{\circ} \mathrm{C}\right.$ and $\left.200{ }^{\circ} \mathrm{C}\right)$. ( $b$ and $\left.c\right)$ Transmission electron micrographs showing [0001] $]_{\alpha}$ rods and $(0001)_{\alpha}$ plates in $\mathrm{Mg}-8 \mathrm{Zn}$ alloy aged for $1000 \mathrm{~h}$ at $473 \mathrm{~K}\left(200{ }^{\circ} \mathrm{C}\right)$. (d) The cross section of a [0001] $]_{\alpha}$ rod of $\mathrm{Mg}_{4} \mathrm{Zn}_{7}$ and the substructure within this precipitate. Electron beam is parallel to [21̄10] $]_{\alpha}$ in (b) and [0001] in (c and d). (c) is adapted from Ref. [65].

work are also unrealistically high compared with those reported by the others. Further careful characterization in the future using 3DAP and atomic-resolution HAADF-STEM, as well as an in-depth analysis of these characterization results, are necessary before the notion of G.P. zones and clusters is formally accepted in the precipitation sequence of $\mathrm{Mg}-\mathrm{Zn}$ alloys.

The metastable phase $\beta_{1}^{\prime}$, which is also described as $\mathrm{MgZn}^{\prime},{ }^{[52,59]}$ forms as $[0001]_{\alpha}$ rods, whereas the metastable phase $\beta_{2}^{\prime}$ forms as $(0001)_{\alpha}$ plates. Based on observations from X-ray diffraction and selected-area electron diffraction (SAED) patterns, both $\beta_{1}^{\prime}$ and $\beta_{2}^{\prime}$ phases were suggested to have a hexagonal structure $(a=0.520 \mathrm{~nm}, c=0.857 \mathrm{~nm})^{[56,60-63]}$ that is identical to that of $\mathrm{MgZn}_{2}$ (space group $\mathrm{P} 6_{3} / \mathrm{mmc}, \quad a=$ $0.5221 \mathrm{~nm}, \quad c=0.8567 \mathrm{~nm}) .{ }^{[64]}$ Another hexagonal structure $(a=0.556 \mathrm{~nm}, c=0.521 \mathrm{~nm})$ was also reported for $\beta_{1}^{\prime},{ }^{[59]}$ but it has not been confirmed so far. The orientation relationships for these two precipitate phases are that $[0001]_{\beta_{1}^{\prime}} / /[11 \overline{2} 0]_{\alpha}$ and $(11 \overline{2} 0)_{\beta_{1}^{\prime}} / /$ $(0001)_{\alpha}$ between $\beta_{1}^{\prime}$ and $\alpha-\mathrm{Mg},{ }^{[60-62]}$ and $(0001)_{\beta_{2}^{\prime}} / /$ $\underset{\alpha-M g}{(0001)_{\alpha}{ }^{[56,60]}}$ and $[11 \overline{2} 0]_{\beta_{2}^{\prime}} / /[10 \overline{1} 0]_{\alpha}$ between $\beta_{2}^{\prime}$ and

A recent electron microscopy study of precipitate phases in a $\mathrm{Mg}-8 \mathrm{wt}$ pct $\mathrm{Zn}$ alloy aged at $473 \mathrm{~K}$ $\left(200{ }^{\circ} \mathrm{C}\right)^{[65]}$ indicates that the precipitate structures and orientation relationships are more complicated than those reported in early studies. Figures 5(b) through (d) show precipitates typical of $\mathrm{Mg}-8$ wt pct $\mathrm{Zn}$ samples aged for 1000 hours at $473 \mathrm{~K}\left(200{ }^{\circ} \mathrm{C}\right)$. Most precipitates are $\beta_{1}^{\prime}$ rods/laths, whereas a fraction of $\beta_{2}^{\prime}$ plates is also visible in the microstructure. Electron microdiffraction patterns obtained from the $\beta_{1}^{\prime}$ rods indicate that, contrary to the traditional view, they have a basecentered monoclinic structure $(a=2.596 \mathrm{~nm}$, $b=1.428 \mathrm{~nm}, c=0.524 \mathrm{~nm}, \gamma=102.5 \mathrm{deg})$ that is similar to that of $\mathrm{Mg}_{4} \mathrm{Zn}_{7}$, and that the orientation relationship is such that $[001]_{\beta_{1}^{\prime}} \sim / /[0001]_{\alpha}$ and $(630)_{\beta_{1}^{\prime}}$ $\sim / /(01 \overline{1} 0)_{\alpha}$. This orientation relationship is identical to that observed between $\mathrm{Mg}_{4} \mathrm{Zn}_{7}$ and $\alpha-\mathrm{Mg}$ phases in 
the eutectoid reaction within primary particles of the $\mathrm{Mg}_{7} \mathrm{Zn}_{3}$ phase. The proposed crystal structure and the orientation relationship are subsequently confirmed in separate studies on precipitates in Mg-Zn-Y alloys. ${ }^{[66-68]}$ In these latest electron microscopy studies, it is revealed that the $\mathrm{Mg}_{4} \mathrm{Zn}_{7}$ phase has a complex substructure and planar defects elongated along the long axis of $\beta_{1}^{\prime}$ rods (Figure 5(d)). In a very recent study, ${ }^{[69]}$ it was reported that the $\beta_{1}^{\prime}$ rods contain a mixture of $\mathrm{Mg}_{4} \mathrm{Zn}_{7}$ and $\mathrm{MgZn}_{2}$ phases that have the following orientation relationship: $[010]_{\mathrm{Mg}_{4} \mathrm{Zn}_{7}} / /[0001]_{\mathrm{MgZn}_{2}}$ and

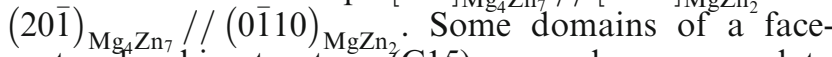
centered cubic structure $(\mathrm{C} 15)$ were also proposed to exist inside the $\beta_{1}^{\prime}$ rods. It is unclear currently whether any in situ transformation from one structure to the other occurs within the $\beta_{1}^{\prime}$ rods. It seems necessary to employ atomic-resolution HAADF-STEM to resolve the complex substructure of the $\beta_{1}^{\prime}$ rods. A small fraction of the $\beta_{1}^{\prime}$ phase was also found ${ }^{[65]}$ to adopt a rarely reported blocky shape and a different orientation relationship with the $\alpha-\mathrm{Mg}$ phase, e.g., $[001]_{\beta_{1}^{\prime}} \sim / /$ $[10 \overline{1} 0]_{\alpha}$ and $(250)_{\beta_{1}^{\prime}} \sim / /(0001)_{\alpha}$.

All recent studies have confirmed that the $\beta_{2}^{\prime}$ phase has the $\operatorname{MgZn}_{2}$ structure $(a=0.523 \mathrm{~nm}, c=0.858 \mathrm{~nm})$ and the orientation relationship reported in early studies. Similar to $\beta_{1}^{\prime}$ rods, the $\beta_{2}^{\prime}$ plates also have a complex substructure of domains and planar defects. ${ }^{[65]}$ Most particles of the $\beta_{2}^{\prime}$ phase adopt a plate morphology, but a small fraction of the $\beta_{2}^{\prime}$ phase also exists as laths with their long axis parallel to $[0001]_{\alpha}$. These $\beta_{2}^{\prime}$ laths can be distinguished from the $\beta_{1}^{\prime}$ rods from their morphology because their cross section has a larger aspect ratio and appear as a near parallelogram shape with the broad surface parallel to $\{10 \overline{1} 0\}_{\alpha}$. The orientation relationship between these $\beta_{2}^{\prime}$ laths and $\alpha-\mathrm{Mg}$ is that $[11 \overline{2} 0]_{\beta_{2}^{\prime}} / /[0001]_{\alpha}$ and $(0001)_{\beta_{2}^{\prime}} / /(11 \overline{2} 0)_{\alpha}$. This orientation relationship is clearly different from that associated $\beta_{2}^{\prime}$ plates but identical to that reported for $\beta_{1}^{\prime}$ rods in early studies. ${ }^{[60-62]} \mathrm{A}$ few $\beta_{2}^{\prime}$ laths with a rarely reported orientation relationship $[11 \overline{2} 0]_{\beta_{2}^{\prime}} / /[0001]_{\alpha}$ and $(1 \overline{1} 06)_{\beta_{2}^{\prime}} / /(\overline{1} 010)_{\alpha}$ were also found. ${ }^{[65]}$ The broad surface of these laths is $\sim 6 \mathrm{deg}$ from the nearest $\{10 \overline{1} 0\}_{\alpha}$ plane instead of being parallel to $\{10 \overline{1} 0\}_{\alpha}$.

Surprisingly, the structure and composition of the equilibrium $\beta$ phase have long been accepted as those of the $\mathrm{Mg}_{2} \mathrm{Zn}_{3}$ phase, i.e., the triclinic structure $(a=1.724 \mathrm{~nm}, b=1.445 \mathrm{~nm}, \quad c=0.520 \mathrm{~nm}, \alpha=$ $96 \mathrm{deg}, \quad \beta=89 \mathrm{deg}, \gamma=138 \mathrm{deg}$ ) and the $\mathrm{Mg}_{2} \mathrm{Zn}_{3}$ composition, even though the alloy composition lies in the $(\alpha-\mathrm{Mg}+\mathrm{MgZn})$ two-phase field. Based on the Mg$\mathrm{Zn}$ binary phase diagram and a more recent electron microscopy study, it seems appropriate to suggest that the equilibrium $\beta$ phase has a $\mathrm{MgZn}$ composition and a base-centered monoclinic structure $(a=1.610 \mathrm{~nm}$, $b=2.579 \mathrm{~nm}, c=0.880 \mathrm{~nm}, \beta=112.4 \mathrm{deg}$ ).

Recent studies indicate clearly that the precipitation sequence in $\mathrm{Mg}-\mathrm{Zn}$ alloys containing 4 to 9 wt pet $\mathrm{Zn}$ and aged isothermally at $393 \mathrm{~K}$ to $533 \mathrm{~K}\left(120{ }^{\circ} \mathrm{C}\right.$ to $\left.260{ }^{\circ} \mathrm{C}\right)$ is different from that accepted traditionally. ${ }^{[6-8]}$
The probable precipitation sequence in the $\mathrm{Mg}-\mathrm{Zn}$ alloys is provided in Table I. Although some detailed information has been gained in recent years, with the help of advanced characterization facilities, on the structure and morphology of precipitates in $\mathrm{Mg}$-Zn based alloys, there still is a lack of reports in the literature that elucidate the details of the full precipitation process and provide some insightful understanding of the nucleation and growth behaviors of the precipitate phases in this group of alloys. For example, why do the structures of the metastable $\beta_{1}^{\prime}$ and $\beta_{2}^{\prime}$ phases resemble closely those of the $\mathrm{Mg}_{4} \mathrm{Zn}_{7}$ and $\mathrm{MgZn}_{2}$ phases that exist as equilibrium phases in the $\mathrm{Mg}$ Zn binary phase diagram? If an in situ structural transformation from $\mathrm{Mg}_{4} \mathrm{Zn}_{7}$ to $\mathrm{MgZn}_{2}$ exists within the $\beta_{1}^{\prime}$ rods, then why does the $\mathrm{MgZn}_{2}$ phase also form prior to or simultaneously with the $\mathrm{Mg}_{4} \mathrm{Zn}_{7}$ phase?

\section{Effects of alloying additions}

Because the age-hardening response of binary $\mathrm{Mg}-\mathrm{Zn}$ alloys is limited, efforts have been made in the past to improve the age-hardening response of $\mathrm{Mg}-\mathrm{Zn}$ alloys via macroalloying and microalloying additions. Examples of macroalloying additions include $\mathrm{Cu},{ }^{[5,70]} \mathrm{Co}^{[71]}$ and $\mathrm{Ba}^{[72]}$ (Figure 6(a)). In these alloys, the solution treatment temperature can be increased from $593 \mathrm{~K}$ to $608 \mathrm{~K}$ $\left(320{ }^{\circ} \mathrm{C}\right.$ to $335{ }^{\circ} \mathrm{C}$ ), typically used for $\mathrm{Mg}$ - Zn binary alloys, to $703 \mathrm{~K}$ to $713 \mathrm{~K}\left(430{ }^{\circ} \mathrm{C}\right.$ to $\left.440{ }^{\circ} \mathrm{C}\right)$ for $\mathrm{Mg}$ - Zn$X(X=\mathrm{Cu}, \mathrm{Ba}$, and $\mathrm{Co})$ alloys without causing any local melting of the casting alloys (Figures 6(b) and (c)). This might be the result of a substantially increased eutectic temperature in the $\mathrm{Mg}-\mathrm{Zn}-X$ alloys. The use of a much higher temperature for the solution treatment allows more $\mathrm{Zn}$ atoms to be dissolved into the magnesium matrix after the solution treatment and possibly more vacancies to be achieved after the water quench. The higher concentrations of $\mathrm{Zn}$ atoms and vacancies can result in an enhanced age-hardening response during the isothermal aging treatment. A comparison of the aging curves of $\mathrm{Mg}-8 \mathrm{Zn}$ and $\mathrm{Mg}-8 \mathrm{Zn}-1 \mathrm{Co}$ (wt pet) alloys (Figures 6(a) and 5(a)) indicates that the maximum hardness value achievable at $473 \mathrm{~K}\left(200{ }^{\circ} \mathrm{C}\right)$ is increased by approximately 18 pct and that the aging time needed to achieve the maximum hardness is reduced from $\sim 24$ hours to $\sim 3$ hours. Another comparison of microstructures of peak-aged samples of these two alloys (Figures 6(d) through $(\mathrm{g})$ ) reveals the increased maximum hardness is associated with a denser distribution of precipitates in the $\mathrm{Mg}-8 \mathrm{Zn}-1 \mathrm{Co}$ (wt pct) alloy.

In contrast to macroalloying additions, microalloying additions to $\mathrm{Mg}-\mathrm{Zn}$ alloys generally cannot raise the eutectic temperature, and thus, they do not permit higher temperatures to be used for the solution treatment. ${ }^{[73-77]}$ However, the additions of appropriate alloying elements can equally result in a substantial enhancement in age-hardening response, as demonstrated in Figure 7(a). ${ }^{[75,77]}$ The additions of 0.1 to 0.35 wt pet $\mathrm{Ca}$ to $\mathrm{Mg}-(4-6) \mathrm{Zn}$ alloys, ${ }^{[7-80]}$ the addition of $\mathrm{Ag}$, or the combined addition of $\mathrm{Ag}$ and $\mathrm{Ca}$ to a Mg-6 wt pet Zn alloy ${ }^{[75,76,81-85]}$ can result in a significant enhancement in age-hardening response and tensile yield strength (Table II). The improved age-hardening 


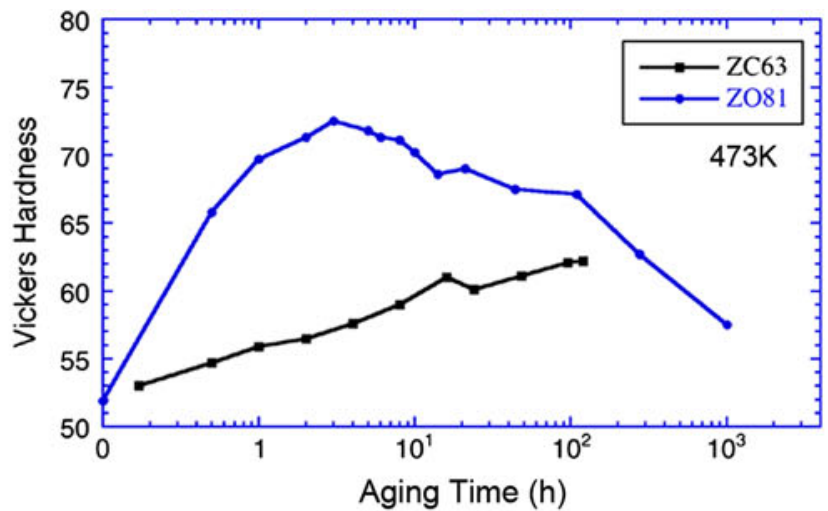

(a)

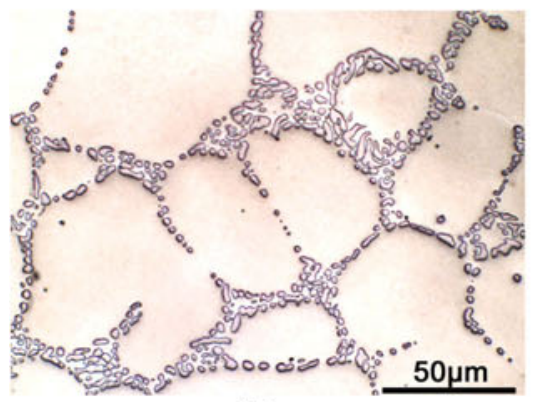

(b)

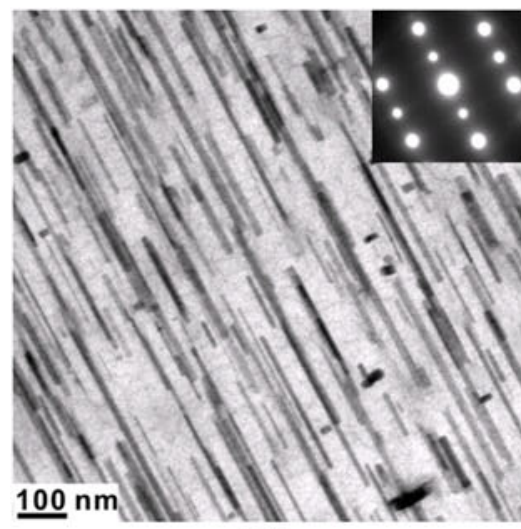

(d)

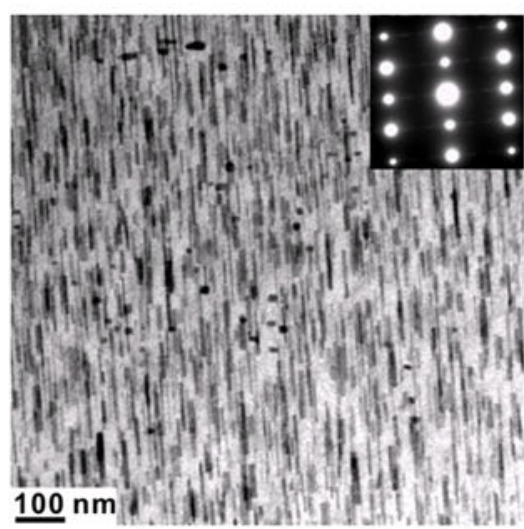

(f)

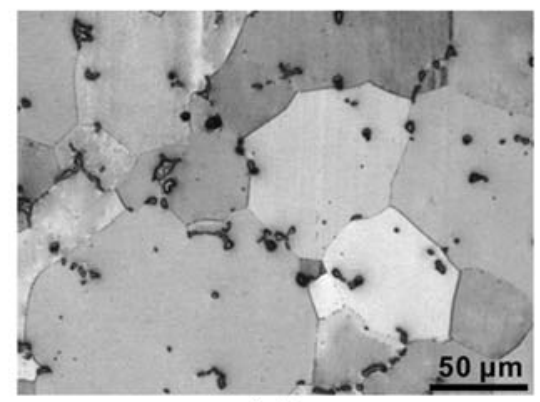

(c)

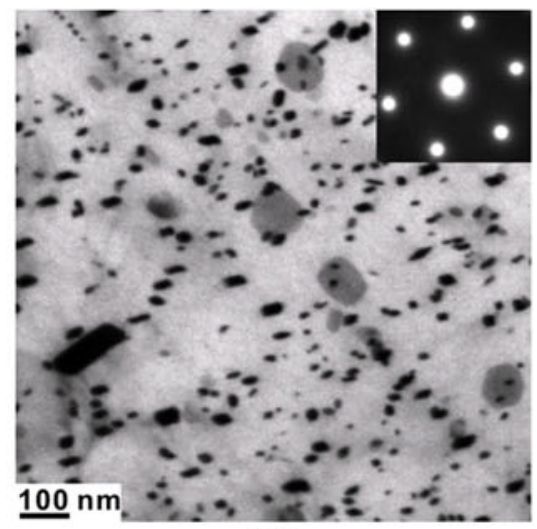

(e)

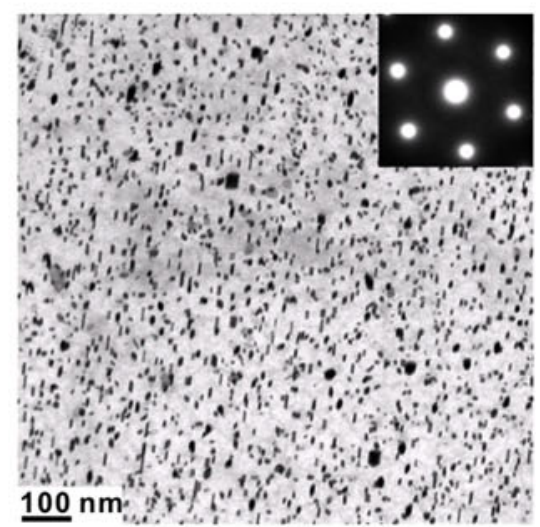

(g)

Fig. 6- (a) Effects of macroalloying additions of $\mathrm{Cu}$ and $\mathrm{Co}$ on age-hardening response of $\mathrm{Mg}-\mathrm{Zn}$ alloys at $473 \mathrm{~K}\left(200{ }^{\circ} \mathrm{C}\right)$. $(b$ and $c)$ Reflected light micrographs showing retained intermetallic particles in solution treated ZC63 and ZO81 alloys respectively. ( $d$ through $g$ ) Transmission electron micrographs showing distribution of precipitates in ( $\mathrm{d}$ and e) $\mathrm{Mg}-8 \mathrm{Zn}$ alloy, and $(f$ and $g$ ) Mg-8Zn-1Co alloy. (c through g) are adapted from Ref. [71]. 
response is associated with a refined distribution of rod-shaped precipitates (Figures $7(\mathrm{~b})$ and (c) ${ }^{[76,77]}$ and Figure 8). ${ }^{[78]}$ The analysis of 3DAP data suggests the cosegregation of $\mathrm{Ca}$ and $\mathrm{Zn}$ atoms in the preprecipitation stage. The Ag atoms do not associate with the $\mathrm{Ca}$ / $\mathrm{Zn}$ clusters and are uniformly distributed in the magnesium matrix phase before they segregate to precipitates that form in the peak-aged condition. Because the combined addition of $\mathrm{Ca}$ and $\mathrm{Ag}$ leads to the largest increment in the maximum hardness, it is unclear how the $\mathrm{Ca}$ and $\mathrm{Ag}$ atoms facilitate the nucleation rate of the precipitates. A more thorough characterization of the distribution of the $\mathrm{Ca}$ and $\mathrm{Ag}$ atoms and of the structure and orientation relationships of the precipitates, as well as considerations of solute-vacancy binding energies in magnesium, ${ }^{[86,87]}$ are all required if the precise role of $\mathrm{Ca}$ and $\mathrm{Ag}$ in the nucleation is to be revealed.

Some other studies indicate that macroadditions of $\mathrm{RE}$ elements ${ }^{[56,88]}$ and microalloying additions of $\mathrm{Sn}$ and $\mathrm{In}^{[89]}$ to $\mathrm{Mg}-\mathrm{Zn}$ alloys have little effect on the agehardening response. A commercial magnesium alloy developed from the Mg-Zn-RE system is ZE41, Mg-4.2 wt pet $\mathrm{Zn}-1.3$ wt pet RE-0.7 wt pet $\mathrm{Zr}$ (where $\mathrm{RE}$ represents rare-earth misch-metal). This alloy is often fabricated in the T5, instead of T6, condition for applications in helicopter transmission housings. The most commonly studied alloying addition in recent years seems to be $\mathrm{Y}$. The additions of $\mathrm{Y}$ to $\mathrm{Mg}$ - $\mathrm{Zn}$ alloys led to the formation of relatively large particles of a quasicrystalline phase. ${ }^{[00,91]}$ The formation of such quasicrystalline particles does not contribute much to the alloy strength, and therefore, the $\mathrm{Mg}-\mathrm{Zn}-\mathrm{Y}$ alloys are generally extruded to achieve finer magnesium grains for strengthening purpose ${ }^{[92-94]}$ (Table II).

\section{Mg-Zn-Al-Based Alloys}

$\mathrm{Mg}-\mathrm{Zn}-\mathrm{Al}$ based alloys, with the $\mathrm{Zn}: \mathrm{Al}$ weight ratio in the range 1:1 to 3:1, have received some interest in the last 15 years for developing casting alloys for elevated temperature applications. Although the Mg-Zn-Al ternary phase diagram is relatively well established compared with other Mg-based ternary phase diagrams, ${ }^{[95-98]}$ the identities of the equilibrium intermetallic phases in the $\mathrm{Mg}-\mathrm{Zn}-\mathrm{Al}$ alloys are still controversial. Based on $X$-ray diffraction observations, the equilibrium intermetallic phase in the $\mathrm{Mg}-\mathrm{Zn}-\mathrm{Al}$ alloys has been determined ${ }^{[99-101]}$ to be the $T$ phase that has an atomic composition of $\mathrm{Mg}_{32}(\mathrm{Al}, \mathrm{Zn})_{49}$ and a body-centered cubic structure (space group $\operatorname{Im} \overline{3}, a \sim 1.4 \mathrm{~nm}^{[102]}$ ). In contrast, the equilibrium intermetallic phase in the Mg-8 wt pct $\mathrm{Zn}-(4-8)$ wt pet Al alloys has been found ${ }^{[103]}$ to the $\phi$ phase. For the $\mathrm{Mg}-8 \mathrm{wt}$ pct $\mathrm{Zn}-(4-8)$ wt pet $\mathrm{Al}$ alloys, the latest version of the $\mathrm{Mg}-\mathrm{Zn}-\mathrm{Al}$ isothermal section at $593 \mathrm{~K}\left(320^{\circ} \mathrm{C}\right)^{[97,98]}$ (Figure 9) indicates that the equilibrium intermetallic phase is $\phi$ instead of $T$ (or $\tau$ in the Figure 9). The $\phi$ phase was originally reported to have a composition of $\mathrm{Mg}_{5} \mathrm{Al}_{2} \mathrm{Zn}_{2}{ }^{[104]}$ and a primitive orthorhombic structure $(a=0.8979 \mathrm{~nm}, b=1.6988 \mathrm{~nm}$, and $c=1.9340 \mathrm{~nm}))^{[105]}$ A subsequent study using transmission electron microscopy and convergent-beam electron diffraction ${ }^{[106]}$

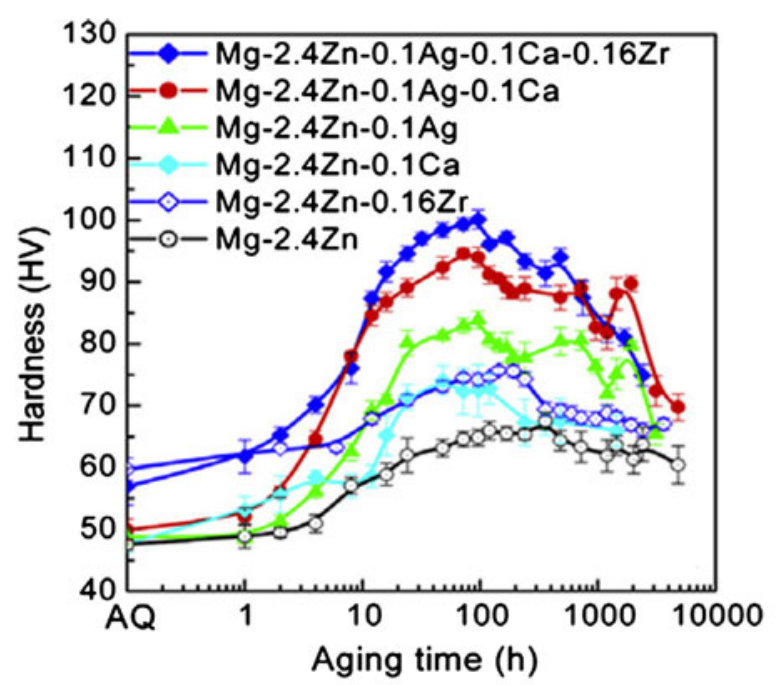

(a)

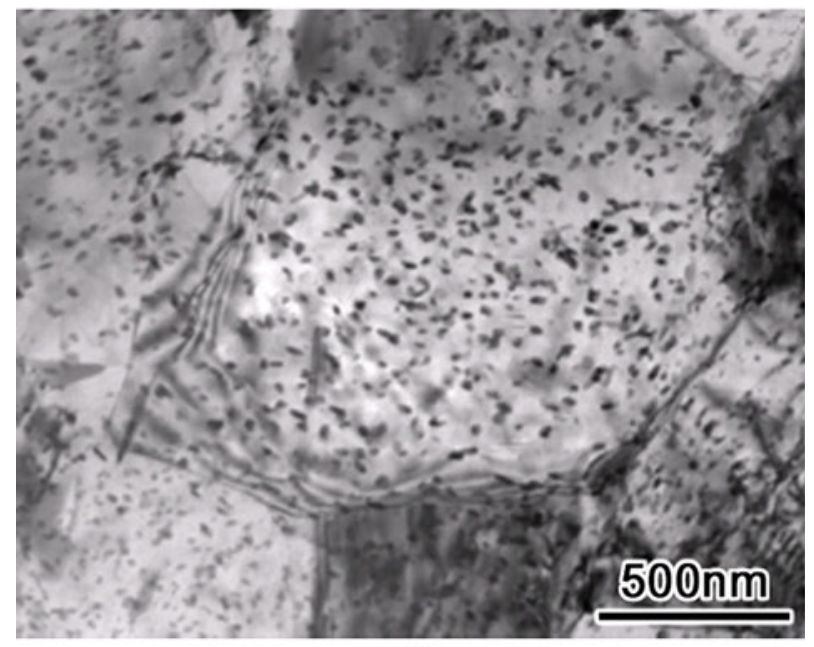

(b)

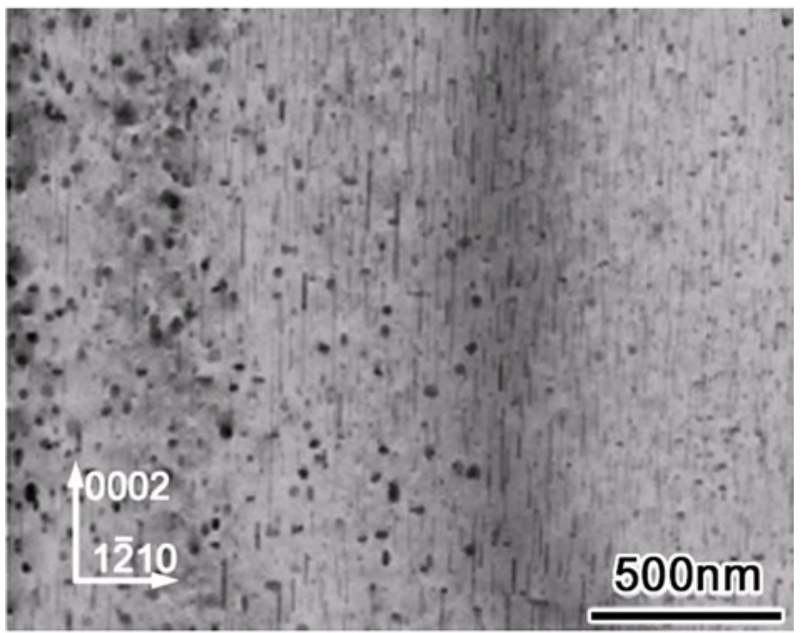

(c)

Fig. 7-(a) Age-hardening response of microalloyed $\mathrm{Mg}$ 2.4 at. pct $\mathrm{Zn}$ during isothermal aging at $433 \mathrm{~K}\left(160^{\circ} \mathrm{C}\right)$ (reproduced from Refs. [75] and [77]). ( $b$ and $c$ ) Transmission electron micrographs showing distribution of precipitates in extruded and peak-aged samples of $\mathrm{Mg}-2.4 \mathrm{Zn}-0.1 \mathrm{Ag}-0.1 \mathrm{Ca}-0.16 \mathrm{Zr}$ (at. pct) alloy (reproduced from Refs. [76] and [77]). 
Table II. Tensile Properties at Room Temperature of Magnesium Casting and Wrought Alloys

\begin{tabular}{|c|c|c|c|c|c|}
\hline \multirow[b]{2}{*}{ Alloy } & \multirow[b]{2}{*}{ Composition (wt pct) } & \multirow[b]{2}{*}{ Testing Condition } & \multicolumn{3}{|c|}{ Tensile Properties } \\
\hline & & & UTS (MPa) & YS (MPa) & $E(p c t)$ \\
\hline \multicolumn{6}{|l|}{ Casting Alloys } \\
\hline AZ91 & $\mathrm{Mg}-8.7 \mathrm{Al}-0.7 \mathrm{Zn}-0.1 \mathrm{Mn}$ & $\mathrm{T} 6$ & 200 & 120 & 2 \\
\hline ZK61 & $\mathrm{Mg}-6 \mathrm{Zn}-0.7 \mathrm{Zr}$ & T6 & 310 & 195 & 10 \\
\hline ZC63 & $\mathrm{Mg}-6 \mathrm{Zn}-2.7 \mathrm{Cu}-0.3 \mathrm{Mn}$ & T6 & 210 & 125 & 4 \\
\hline ZA85 & $\mathrm{Mg}-7.7 \mathrm{Zn}-4.9 \mathrm{Al}-0.3 \mathrm{Mn}$ & T6 & 195 & 138 & 2 \\
\hline QE22 & $\mathrm{Mg}-2.5 \mathrm{Ag}-2.1 \mathrm{Di}-0.7 \mathrm{Zr}$ & T6 & 260 & 195 & 3 \\
\hline WE54 & $\mathrm{Mg}-5.2 \mathrm{Y}-3 \mathrm{RE}-0.7 \mathrm{Zr}$ & T6 & 280 & 205 & 4 \\
\hline WE43 & $\mathrm{Mg}-4 \mathrm{Y}-3.4 \mathrm{RE}-0.7 \mathrm{Zr}$ & T6 & 250 & 180 & 7 \\
\hline MRI201S & & T6 & 260 & 170 & 6 \\
\hline MEZ & $\mathrm{Mg}-2.5 \mathrm{RE}-0.5 \mathrm{Zn}$ & T6 & 108 & 76 & 2 \\
\hline NEZ & $\mathrm{Mg}-3 \mathrm{Nd}-0.5 \mathrm{Zn}$ & T6 & 165 & 114 & 2 \\
\hline EV31 & $\mathrm{Mg}-3 \mathrm{Nd}-2 \mathrm{Gd}-0.6 \mathrm{Zn}-0.5 \mathrm{Zr}$ & T6 & 292 & 178 & 7 \\
\hline VZ61 & $\mathrm{Mg}-6 \mathrm{Gd}-1 \mathrm{Zn}-0.6 \mathrm{Zr}$ & T6 & 220 & 127 & 12 \\
\hline XZE111 & $\mathrm{Mg}-1 \mathrm{Ca}-1 \mathrm{Zn}-1 \mathrm{Nd}-0.6 \mathrm{Zr}$ & T6 & 227 & 153 & 7 \\
\hline VW114 & $\mathrm{Mg}-11.3 \mathrm{Gd}-3.8 \mathrm{Y}-0.7 \mathrm{Zr}$ & T6 & 330 & 300 & 2 \\
\hline VWZ1142 & $\mathrm{Mg}-11.1 \mathrm{Gd}-4.1 \mathrm{Y}-1.7 \mathrm{Zn}-0.5 \mathrm{Zr}$ & T6 & 361 & 231 & 4 \\
\hline VE112 & $\mathrm{Mg}-11 \mathrm{Gd}-2 \mathrm{Nd}-0.5 \mathrm{Zr}$ & T6 & 350 & 230 & 2 \\
\hline VQ182 & $\mathrm{Mg}-18.2 \mathrm{Gd}-1.9 \mathrm{Ag}-0.3 \mathrm{Zr}$ & T6 & 414 & 293 & 2 \\
\hline VW102 & $\mathrm{Mg}-10 \mathrm{Gd}-2 \mathrm{Y}-0.5 \mathrm{Zr}$ & T6 & 362 & 239 & 5 \\
\hline \multicolumn{6}{|c|}{ Extrusion Alloys } \\
\hline $\mathrm{AX} 43$ & $\mathrm{Mg}-3.5 \mathrm{Al}-3.3 \mathrm{Ca}-0.4 \mathrm{Mn}$ & $\mathrm{F}$ & 420 & 410 & 6 \\
\hline ZK60 & $\mathrm{Mg}-6 \mathrm{Zn}-0.6 \mathrm{Zr}$ & $\mathrm{F}$ & 310 & 250 & 3 \\
\hline ZX51 & $\mathrm{Mg}-4.7 \mathrm{Zn}-0.5 \mathrm{Ca}$ & $\mathrm{F}$ & 329 & 291 & 16 \\
\hline ZXK601 & $\mathrm{Mg}-5.7 \mathrm{Zn}-0.2 \mathrm{Ca}-0.8 \mathrm{Zr}$ & $\mathrm{F}$ & 357 & 310 & 18 \\
\hline \multirow[t]{2}{*}{ ZQX6 } & $\mathrm{Mg}-6 \mathrm{Zn}-0.4 \mathrm{Ag}-0.2 \mathrm{Ca}-0.6 \mathrm{Zr}$ & $\mathrm{F}$ & 351 & 289 & 17 \\
\hline & & T6 & 355 & 325 & 14 \\
\hline XZ11 & $\mathrm{Mg}-1 \mathrm{Ca}-1 \mathrm{Zn}-0.6 \mathrm{Zr}$ & $\mathrm{F}$ & 314 & 306 & 17 \\
\hline WE43 & $\mathrm{Mg}-4 \mathrm{Y}-3 \mathrm{Nd}-0.5 \mathrm{Zr}$ & T6 & 245 & 160 & 6 \\
\hline WE54 & $\mathrm{Mg}-5.3 \mathrm{Y}-3.5 \mathrm{Nd}-0.5 \mathrm{Zr}$ & T5 & 300 & 200 & 10 \\
\hline \multirow[t]{2}{*}{ Elektron 675} & $\mathrm{Mg}-6 \mathrm{Y}-7 \mathrm{Gd}-0.5 \mathrm{Zr}$ & $\mathrm{T} 6$ & 275 & 190 & 10 \\
\hline & & T5 & 410 & 310 & 9 \\
\hline \multirow[t]{3}{*}{ VK14 } & $\mathrm{Mg}-14 \mathrm{Gd}-0.5 \mathrm{Zr}$ & $\mathrm{F}$ & 295 & 190 & 20 \\
\hline & & T6 & 446 & 305 & 7 \\
\hline & & $\mathrm{T} 8$ & 482 & 445 & 2 \\
\hline VZ142 & Mg-14Gd-2.3Zn & $\mathrm{F}$ & 380 & 345 & - \\
\hline WZ75 & $\mathrm{Mg}-6.7 \mathrm{Y}-4.9 \mathrm{Zn}$ & $\mathrm{F}$ & 425 & 390 & 5 \\
\hline \multirow[t]{2}{*}{ VWZ1062 } & $\mathrm{Mg}-10 \mathrm{Gd}-5.7 \mathrm{Y}-1.6 \mathrm{Zn}-0.7 \mathrm{Zr}$ & $\mathrm{F}$ & 461 & 419 & 4 \\
\hline & & T5 & 542 & 473 & 8 \\
\hline ZW51 & $\mathrm{Mg}-5 \mathrm{Zn}-0.9 \mathrm{Y}-0.2 \mathrm{Zr}$ & $\mathrm{F}$ & 363 & 317 & - \\
\hline \multicolumn{6}{|c|}{ Sheet/Plate Alloys } \\
\hline ZM61 & $\mathrm{Mg}-6 \mathrm{Zn}-1 \mathrm{Mn}$ & $\mathrm{T} 6$ & 310 & 256 & 16 \\
\hline ZAM631 & $\mathrm{Mg}-6 \mathrm{Zn}-3 \mathrm{Al}-1 \mathrm{Mn}$ & T6 & 360 & 319 & 6 \\
\hline ZQX610 & $\mathrm{Mg}-6.3 \mathrm{Zn}-0.5 \mathrm{Ag}-0.2 \mathrm{Ca}-0.1 \mathrm{Zr}$ & T6 & 342 & 316 & 17 \\
\hline VWZ1142 & $\mathrm{Mg}-11 \mathrm{Gd}-4 \mathrm{Y}-1.7 \mathrm{Zn}-0.5 \mathrm{Zr}$ & T6 & 455 & 375 & 10 \\
\hline
\end{tabular}

confirms the primitive orthorhombic unit cell and lattice parameters proposed in the early studies, and it indicates that the $\phi$ phase has a space group of $\mathrm{Pbcm}$ and a composition of $\mathrm{Mg}_{21}(\mathrm{Zn}, \mathrm{Al})_{17}$.

For $\mathrm{Mg}-\mathrm{Zn}-\mathrm{Al}$ alloys with compositions lying in the $(\alpha-\mathrm{Mg}+\phi)$ two-phase field and produced by high-pressure die casting or permanent mold casting, recent studies using TEM and convergent-beam electron diffraction patterns ${ }^{[107,108]}$ indicate that primary intermetallic particles in the as-cast condition have a quasi-crystalline structure (point group of $m \overline{3} \overline{5}$, quasi-lattice parameter $\sim 0.515 \mathrm{~nm}$ ) and a composition of approximately $\mathrm{Mg}_{55} \mathrm{Al}_{19} \mathrm{Zn}_{26}$. The quasi-lattice parameter is very close to those of icosahedral phases formed in rapidly solidified $\mathrm{Mg}_{32} \mathrm{Al}_{17} \mathrm{Zn}_{32}{ }^{[109]}$ and $\mathrm{Mg}_{32}(\mathrm{Al}, \mathrm{Zn}, \mathrm{Cu})_{49}{ }^{[110]}$ intermetallic alloys, but it is smaller than the that $(0.528 \mathrm{~nm})$ reported for the icosahedral $\mathrm{Mg}_{38.5} \mathrm{Al}_{52} \mathrm{Zn}_{9.5}$ phase in Al-Mg-Zn alloys. ${ }^{[11]}$ Even though the equilibrium $T$ phase is often regarded as the crystalline approximant of the icosahedral phase, ${ }^{[112]}$ the metastable quasi-crystalline phase does not transform to the $T$ phase after prolonged heating at elevated temperatures such as $598 \mathrm{~K}\left(325^{\circ} \mathrm{C}\right)$. Instead, the quasi-crystalline particles are gradually replaced by the $\phi$ phase without any intermediate phases formed between them. Given that the composition of the Mg- 8 wt pet $\mathrm{Zn}-4$ wt pet 


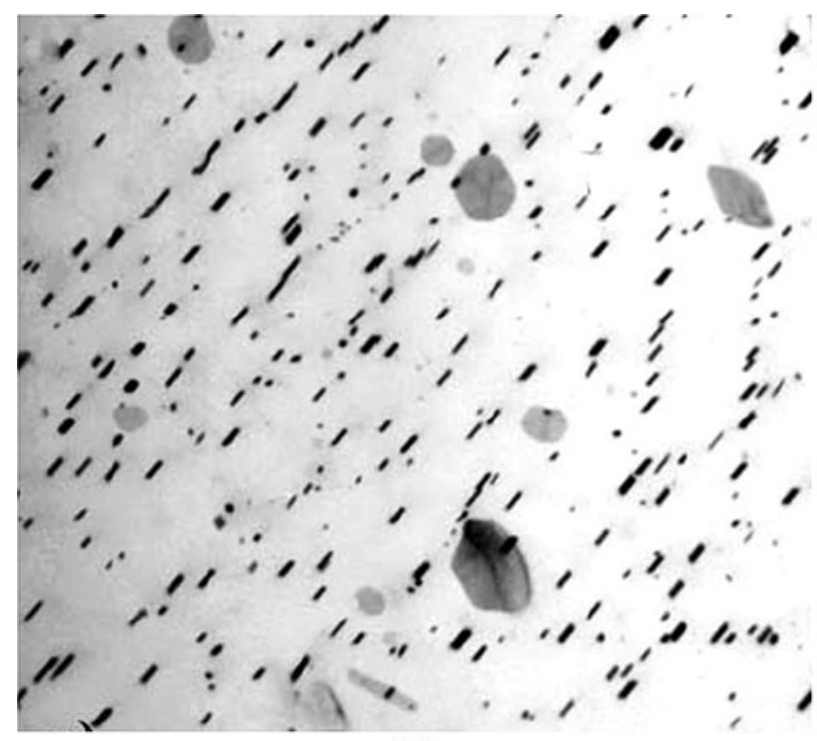

(a)

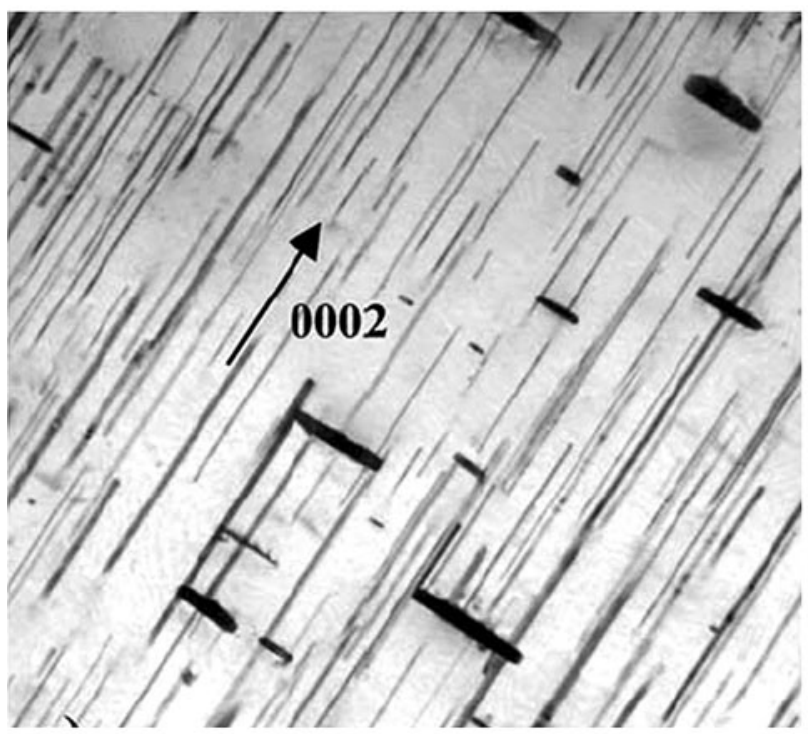

(c)

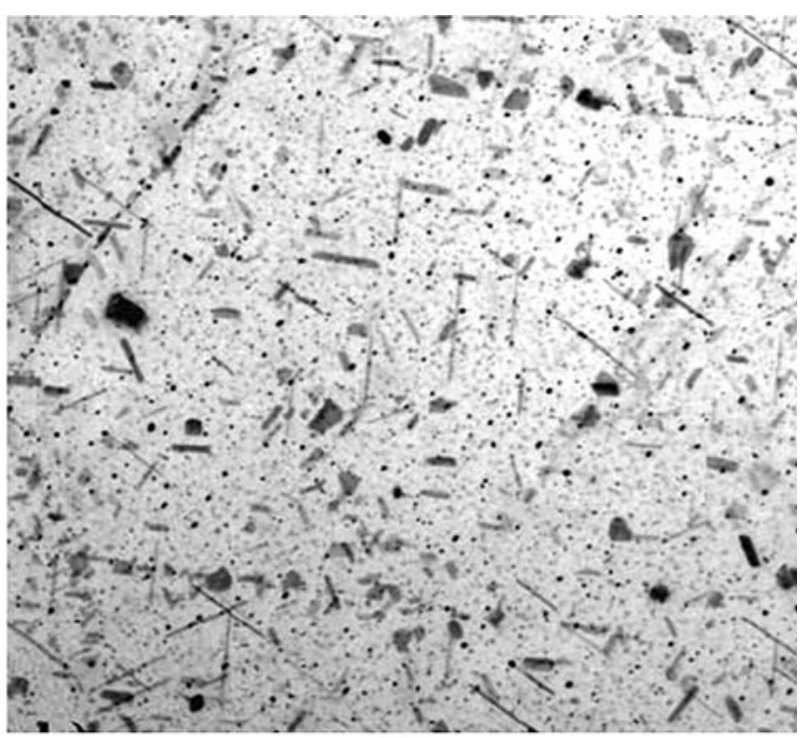

(b)

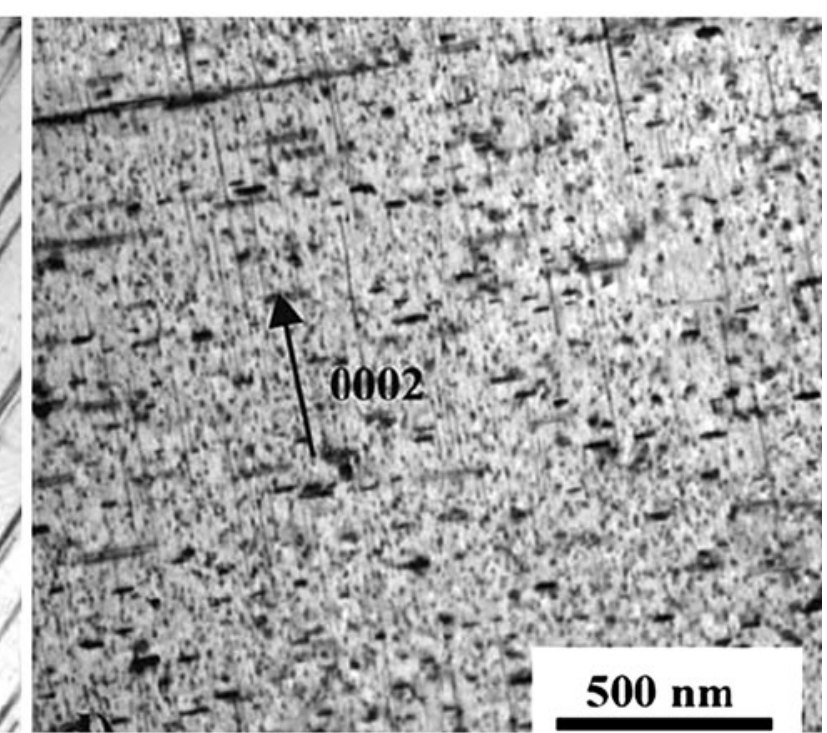

(d)

Fig. 8-Transmission electron micrographs showing distribution of precipitates in $(a$ and $c) \mathrm{Mg}-4 \mathrm{wt}$ pct $\mathrm{Zn}$, and $(b$ and $d)$ Mg-4 wt pct $\mathrm{Zn}-0.35 \mathrm{wt}$ pct $\mathrm{Ca}$ alloys. Electron beam is parallel to [0001] $]_{\alpha}$ in (a and b) and $[2110]$ in $(\mathrm{c}$ and $d$ ). The samples are solution treated at $618 \mathrm{~K}$ $\left(345^{\circ} \mathrm{C}\right)$ for $2 \mathrm{~h}$, ramped to $803 \mathrm{~K}\left(530^{\circ} \mathrm{C}\right)$ in $2 \mathrm{~h}$, and then at $803 \mathrm{~K}\left(530{ }^{\circ} \mathrm{C}\right)$ for $12 \mathrm{~h}$, water quenched and aged at $450 \mathrm{~K}\left(177{ }^{\circ} \mathrm{C}\right)$ for $28.9 \mathrm{~h}$. Reproduced from Ref. [78].

Al alloy is in the $(\alpha-\mathrm{Mg}+\phi)$ two-phase field, the replacement of the quasi-crystalline phase by the equilibrium $\phi$ phase is not surprising at all. The icosahedral phase has a composition closer to that of the $\phi$ phase than to the $T$ phase, and the $\phi$ unit cell has icosahedral clusters. ${ }^{[105,106]}$ The transformation from a metastable icosahedral phase to a nonapproximant crystalline phase has been observed in a $\mathrm{Mg}_{65} \mathrm{Zn}_{25} \mathrm{Y}_{10}$ intermetallic alloy. ${ }^{[113]}$

The aging curves of $\mathrm{Mg}-8 \mathrm{Zn}, \mathrm{Mg}-8 \mathrm{Zn}-4 \mathrm{Al}$, and $\mathrm{Mg}$ $8 \mathrm{Zn}-8 \mathrm{Al}$ (wt pct) alloys, which are solution treated for 4 hours at $598 \mathrm{~K}\left(325^{\circ} \mathrm{C}\right)(\mathrm{Mg}-8 \mathrm{Zn}$ and $\mathrm{Mg}-8 \mathrm{Zn}-4 \mathrm{Al})$ and $623 \mathrm{~K}\left(350{ }^{\circ} \mathrm{C}\right)(\mathrm{Mg}-8 \mathrm{Zn}-8 \mathrm{Al})$, water quenched, and aged at $473 \mathrm{~K}$ and $423 \mathrm{~K}\left(200{ }^{\circ} \mathrm{C}\right.$ and $\left.150{ }^{\circ} \mathrm{C}\right)$, are provided in Figures 10(a) and (b). ${ }^{[114]}$ The age-hardening response is significantly enhanced by ternary addition of 4 to $8 \mathrm{wt}$ pet $\mathrm{Al}$ to the $\mathrm{Mg}-8 \mathrm{Zn}$ alloy. The maximum hardness values achieved in the Mg-8Zn$8 \mathrm{Al}$ alloy are considerably higher than those obtained in Mg-6 wt pet Zn-3 wt pet Cu (ZC63), Mg-8 wt pet Zn1 wt pet Co (ZO81) (Figure 6(a)), and Mg-8 wt pet $\mathrm{Zn}$ 1.5 wt pet $\mathrm{RE}^{[56]}$ alloys. The quaternary addition of 0.5 wt pet $\mathrm{Ca}$ to $\mathrm{Mg}-8$ wt pet $\mathrm{Zn}-4$ wt pet $\mathrm{Al}$ alloy does not lead to any enhancement in age-hardening response (Figure 10(c)), and an increase in the Ca content from $0.5 \mathrm{wt}$ pct to $1.0 \mathrm{wt}$ pct causes a reduced age-hardening response (Figures 10(c) and (d)), even though the $\mathrm{Ca}$ addition retards the overaging of the alloys. ${ }^{[15]}$

The effects of preaging on the age-hardening response of a Mg-6Zn-3Al-1Mn (wt pet) alloy were studied by 


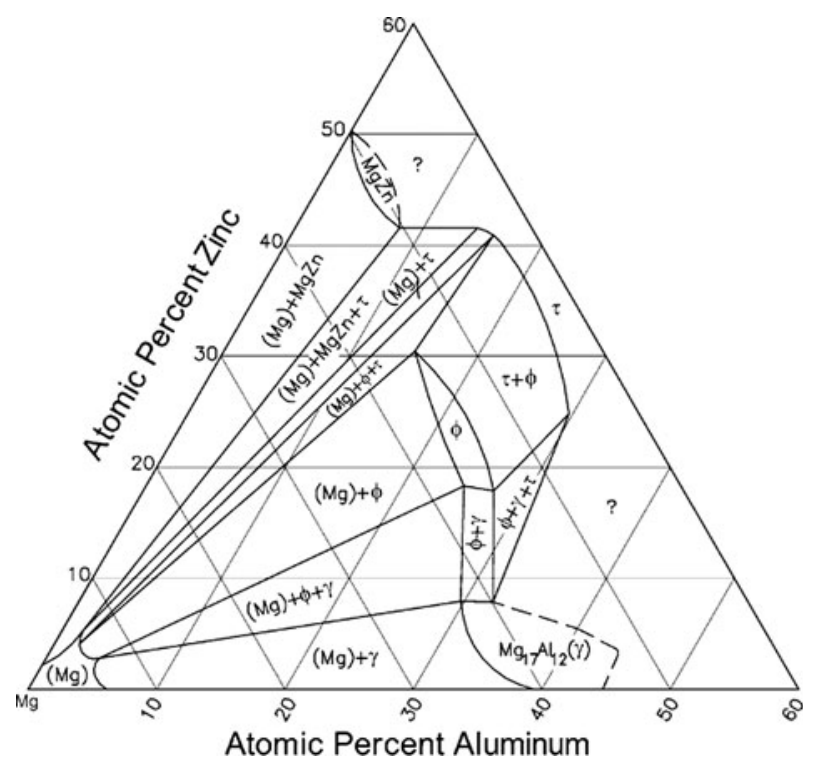

Fig. 9-Isothermal section of the $\mathrm{Mg}-\mathrm{Zn}$-Al ternary phase diagram at $593 \mathrm{~K}\left(320{ }^{\circ} \mathrm{C}\right)$ (reproduced from Ref. [98]). The $\gamma$ phase in the diagram is the $\beta-\mathrm{Mg}_{17} \mathrm{Al}_{12}$ phase in the present paper.
Oh-ishi et al. ${ }^{[16]}$ Their alloy was aged initially at $343 \mathrm{~K}$ $\left(70{ }^{\circ} \mathrm{C}\right)$ for 48 hours and followed by subsequent aging at $423 \mathrm{~K}\left(150{ }^{\circ} \mathrm{C}\right)$. It was found that the preaging enhances the age-hardening response at $423 \mathrm{~K}\left(150{ }^{\circ} \mathrm{C}\right)$ and that the double-aged microstructure contains a finer distribution of precipitates. The sheet of this alloy, produced by twin-roll casting and hot rolling, exhibits a tensile yield strength of $319 \mathrm{MPa}$ (Table II) after it is preaged at $343 \mathrm{~K}\left(70{ }^{\circ} \mathrm{C}\right)$ for 24 hours and then aged at $423 \mathrm{~K}\left(150{ }^{\circ} \mathrm{C}\right)$ for 24 hours. ${ }^{[117]}$

In a separate study of a $\mathrm{Mg}-2.4$ at. pct $\mathrm{Zn}-2$ at. pet $\mathrm{Al}$ (Mg-6.2 wt pet $\mathrm{Zn}-2.1$ wt pet Al) alloy, it was reported ${ }^{[84]}$ that the combined addition of 0.1 at. pct $\mathrm{Ag}$ and 0.1 at. pet $\mathrm{Ca}$ to this alloy could lead to a significant enhancement of the aging response at $433 \mathrm{~K}\left(160{ }^{\circ} \mathrm{C}\right)$ and that the maximum hardness achievable was raised by approximately 27 pct, from $\sim 75 \mathrm{VHN}$ in the $\mathrm{Mg}$ $2.4 \mathrm{Zn}-2 \mathrm{Al}$ alloy to $\sim 95 \mathrm{VHN}$ in the $\mathrm{Mg}-2.4 \mathrm{Zn}-2 \mathrm{Al}-$ $0.1 \mathrm{Ag}-0.1 \mathrm{Ca}$ alloy. The maximum hardness value does not change when the $\mathrm{Al}$ content in the alloy is increased or decreased by 1 at. pct, and it remains unchanged even when the $\mathrm{Al}$ content is reduced to zero. These observations suggest that the age-hardening response of the

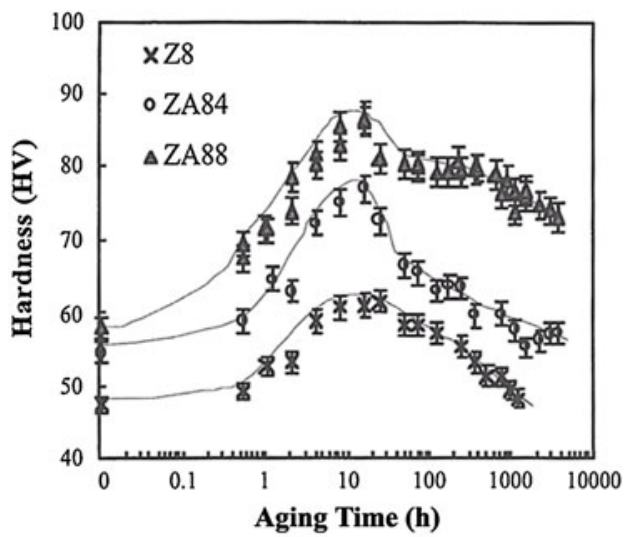

(a)

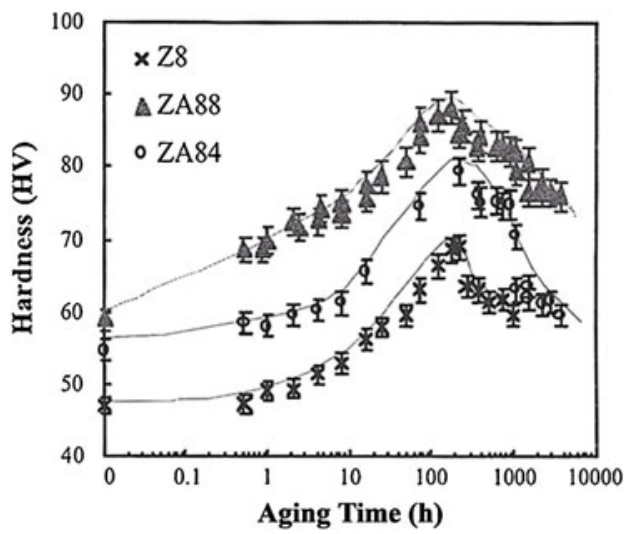

(b)

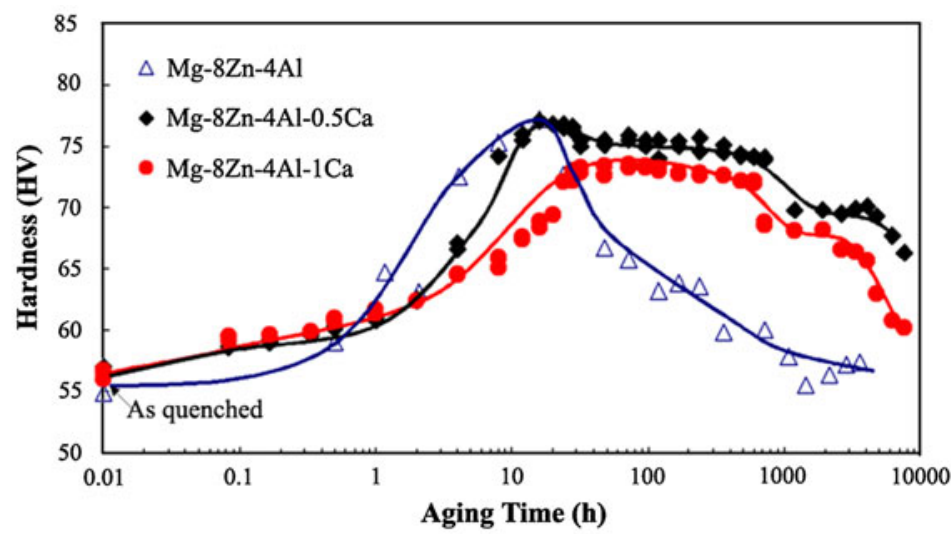

(c)

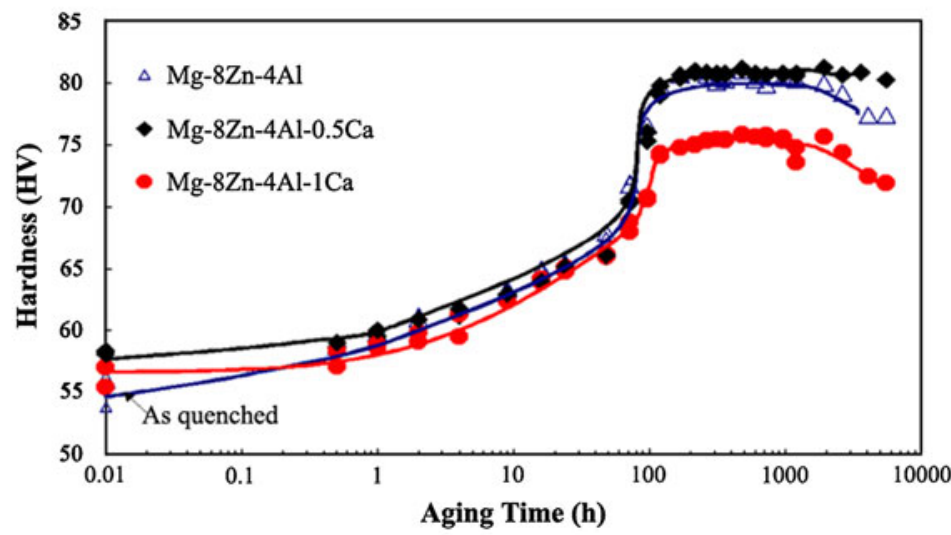

(d)

Fig. 10-Age-hardening response of Mg-8Zn, Mg-8Zn-4Al, and $\mathrm{Mg}-8 \mathrm{Zn}-8 \mathrm{Al}$ (wt pct) alloys during isothermal aging at (a) $473 \mathrm{~K}\left(200{ }^{\circ} \mathrm{C}\right)$ and (b) $423 \mathrm{~K}\left(150{ }^{\circ} \mathrm{C}\right)$. Reproduced from Ref. [114]. Effects of Ca additions on the age-hardening response of Mg-8Al-4Zn (wt pet) alloy at (c) $473 \mathrm{~K}\left(200^{\circ} \mathrm{C}\right)$ and $(d) 423 \mathrm{~K}\left(150^{\circ} \mathrm{C}\right)$. Reproduced from Ref. [115]. 
$\mathrm{Mg}-\mathrm{Zn}-\mathrm{Al}-\mathrm{Ag}-\mathrm{Ca}$ alloys is similar to that of the $\mathrm{Mg}-\mathrm{Zn}$ $\mathrm{Ag}-\mathrm{Ca}$ alloys that is shown in Figure 7(a).

Whereas the Mg-Zn-Al alloys exhibit a substantial age-hardening response during isothermal aging in the temperature range $373 \mathrm{~K}$ to $473 \mathrm{~K}\left(100{ }^{\circ} \mathrm{C}\right.$ to $\left.200{ }^{\circ} \mathrm{C}\right)$, the solid-state precipitates formed in these alloys have not been characterized in detail. Figure 11 shows microstructure typical of a Mg-8 wt pet $\mathrm{Zn}-8$ wt pet $\mathrm{Al}$ alloy, homogenized and solution treated for 122 hours at $598 \mathrm{~K}\left(325^{\circ} \mathrm{C}\right)$, water quenched, and then aged for 120 hours at $473 \mathrm{~K}\left(200{ }^{\circ} \mathrm{C}\right)$. The microstructure contains predominantly a dispersion of rhombic precipitates. These precipitates seem to distribute heterogeneously throughout the magnesium matrix phase, distributing along lines that are approximately parallel to $\langle 10 \overline{1} 0\rangle_{\alpha}$ directions when the microstructure is viewed in the $[0001]_{\alpha}$ direction. Electron microdiffraction patterns obtained from such precipitates are indicative of a icosahedral structure with a quasi-lattice parameter of approximately $0.52 \mathrm{~nm}$, instead of the $T$ phase that has been reported for most solid-state precipitates formed in a high-pressure die cast Mg-8 wt pet Zn-5 wt pet Al alloy. ${ }^{[118]}$ Currently, there is a lack of convergent beam electron diffraction patterns to establish unambiguously whether these precipitates have a perfect icosahedral symmetry or are a crystalline approximant with a very large unit cell parameter, but atomic-resolution transmission electron microscopy does not reveal any periodic crystal structure or nanoscale twins existing within such particles.

The orientation relationship between the rhombic precipitates and the matrix phase is that $(8 / 13,5 / 8$, $\overline{3} / \overline{5})_{i} / /(\overline{2} 110)_{\alpha}$ and $[5 \text {-fold }]_{i} / /[0001]_{\alpha}$. The facets of the rhombic precipitate are not parallel, or close to parallel, to any of the close-packed planes of the two phases (Figure 11(d)). However, it was found ${ }^{[119]}$ that the two rhombic interfaces are exactly parallel to the moiré planes defined by the intersection of $(3 / 5,8 / 13, \overline{5} / \overline{8})_{i}$ and $(1 \overline{1} 00)_{\alpha}$ planes, and the $(\overline{10} / \overline{6}, 0 / 0,0 / 0)_{i}^{i}$ and $(01 \overline{10})_{\alpha}$ planes, respectively. This observation indicates that the $(3 / 5,8 / 13, \overline{5} / \overline{8})_{i}$ and $(\overline{1} 100)_{\alpha}$ planes are fully coherent within one of the

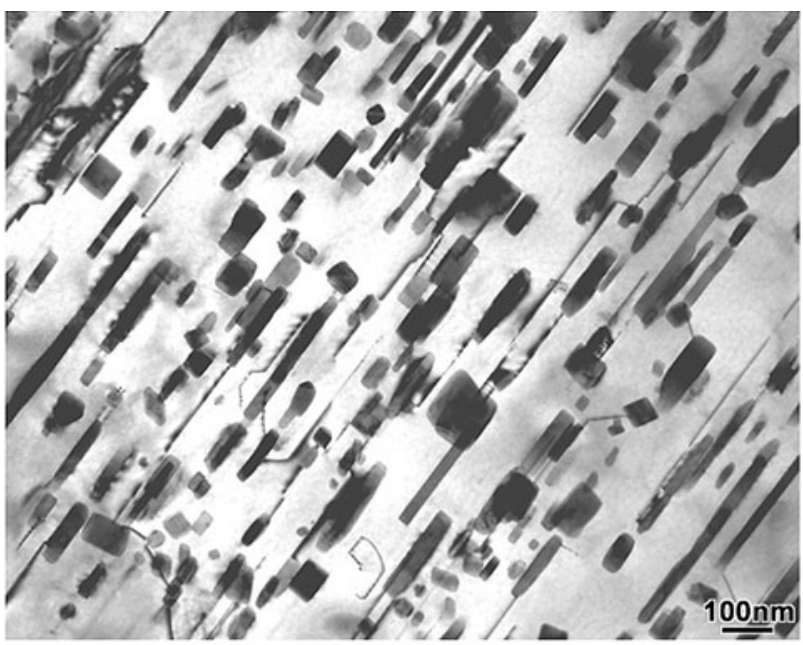

(a)

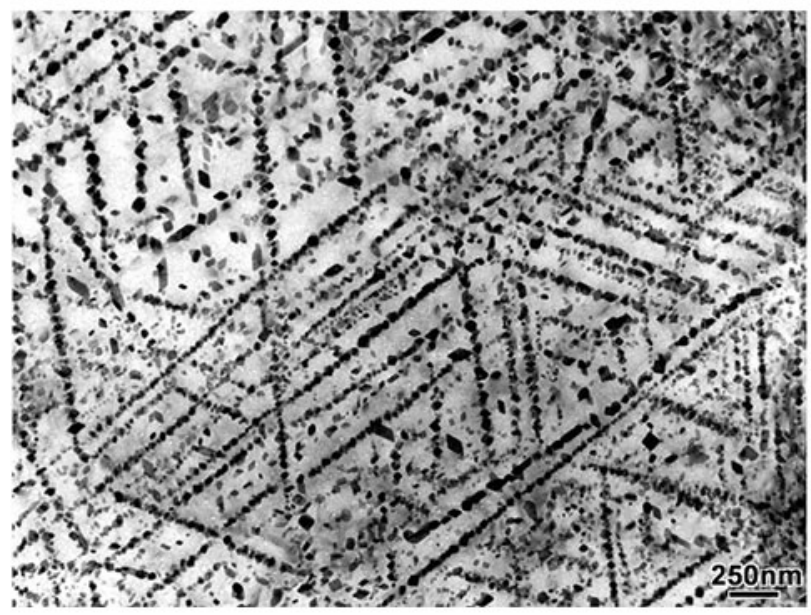

(b)

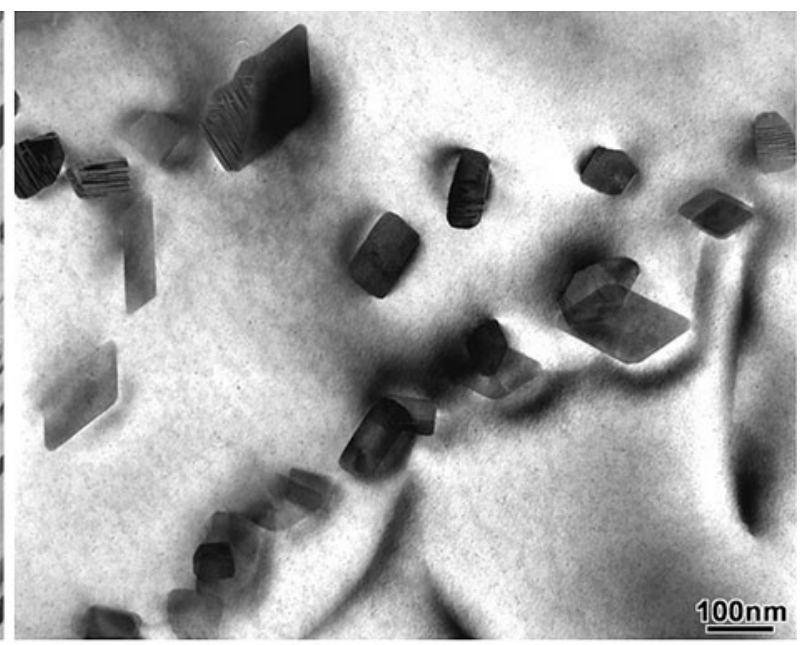

(c)

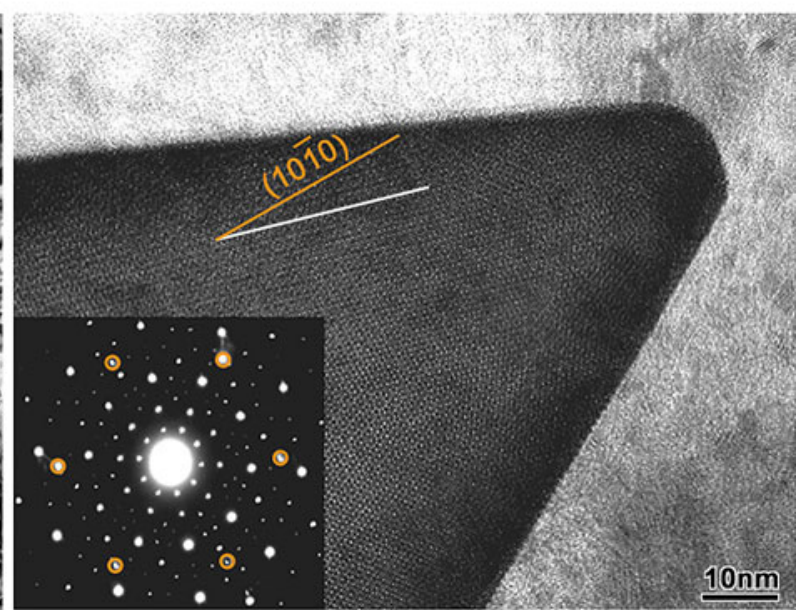

(d)

Fig. 11-Transmission electron micrographs showing distribution and morphology of precipitates in a $\mathrm{Mg}-8$ wt pet $\mathrm{Zn}-8$ wt pet Al alloy aged at $473 \mathrm{~K}\left(200^{\circ} \mathrm{C}\right)$ for $120 \mathrm{~h}$. Electron beam is parallel to $[2 \overline{1} 10]_{\alpha}$ in $(a)$ and $[0001]_{\alpha}$ in $(b$ through $d)$. 
precipitate-matrix interfaces, whereas that the $(\overline{1} \overline{0} / \overline{6}, 0 / 0,0 / 0)_{i}$ and $(01 \overline{1} 0)_{\alpha}$ planes are also fully coherent within another precipitate-matrix interface. Note that $(3 / 5,8 / 13, \overline{5} / \overline{8})_{i}$ and $(\overline{1} \overline{0} / \overline{6}, 0 / 0,0 / 0)_{i}$ are the closest-packed planes in the icosahedral phase, and $\{01 \overline{1} 0\}_{\alpha}$ is a near closest-packed plane in the matrix phase. Some of the icosahedral particles also have a truncated rectangular or square shape when viewed in the $[0001]_{\alpha}$ orientation, and these icosahedral particles have another orientation relationship with the matrix phase: $(8 / 13,5 / 8, \overline{3} / \overline{5})_{i} / /(1 \overline{1} 00)_{\alpha}$ and $[2 \text {-fold }]_{i} / /$ $[0001]_{\alpha}$. Inspection of images of the icosahedral particles projected along the $[0001]_{\alpha}$ direction also reveal that some of them contain a high density of planar defects or polycrystalline aggregates. But the crystallography of such defects is unclear.

The microstructure of $\mathrm{Mg}-8$ wt pet $\mathrm{Zn}-8$ wt pct $\mathrm{Al}$ alloy samples aged for 120 hours at $473 \mathrm{~K}\left(200{ }^{\circ} \mathrm{C}\right)$ also has a small fraction of relatively coarse, lath-shaped $\phi$ precipitates that have the following orientation relationship with the matrix: $(002)_{\phi} / /(0002)_{\alpha}$, $[010]_{\phi} / /[10 \overline{10}]_{\alpha}$. The broad surface of these $\phi$ laths is parallel to $(0001)_{\alpha}$. In addition to the precipitates of the equilibrium $\phi$ phase, some precipitates of the equilibrium phase $\beta$ - $\mathrm{Mg}_{17} \mathrm{Al}_{12}$ are also found in samples aged for 120 hours at $473 \mathrm{~K}\left(200{ }^{\circ} \mathrm{C}\right)$. The orientation relationship and morphology of these $\beta$ precipitates are similar to those observed in $\mathrm{Mg}-\mathrm{Al}$ binary alloys. Although there is no doubt that the precipitation sequence in the $\mathrm{Mg}-8$ wt pet $\mathrm{Zn}-8$ wt pet $\mathrm{Al}$ alloys and alloys of similar compositions involves the formation of metastable icosahedral phase and the equilibrium $\phi$ and $\beta$ phase (Table I), the actual precipitation sequence in such alloys is more complex and, therefore, requires detailed characterization using advanced imaging and diffraction techniques in the future. For example, some relatively coarse particles that have a point group perfectly consistent with that of the $T$ phase (space group $\mathrm{I} \overline{3} \mathrm{~m}, a=1.42 \mathrm{~nm}$ ) are occasionally observed in the sample aged for 120 hours at $473 \mathrm{~K}\left(200^{\circ} \mathrm{C}\right)$. The orientation relationship between these cubic precipitates and the matrix phase is such that $(002)_{T} / /(10 \overline{10})_{\alpha}$ $[100]_{T} / /[0001]_{\alpha}$. The $T$ phase precipitates were also reported to form during isothermal aging at $443 \mathrm{~K}$ $\left(170{ }^{\circ} \mathrm{C}\right)$ of high-pressure die cast $\mathrm{Mg}-8 \mathrm{wt}$ pct Zn-4.8 wt pet Al-0.3 wt pet Mn (designated ZA85). ${ }^{[18]}$ Whereas the $T$ phase is an equilibrium phase in the ternary $\mathrm{Mg}-\mathrm{Zn}-\mathrm{Al}$ phase diagram, it is difficult to assess whether this phase is an equilibrium phase in the Mg-8 wt pet Zn-8 wt pet Al ternary alloy because three equilibrium phases, $\alpha-\mathrm{Mg}, \phi$, and $\beta$ - $\mathrm{Mg}_{17} \mathrm{Al}_{12}$, have already been detected in this alloy.

In Mg-6.2Zn-2.1 Al (wt pct) alloy and those of similar compositions, it has been reported that the precipitation sequence is similar to that in $\mathrm{Mg}-\mathrm{Zn}$ binary alloys. ${ }^{[84]}$ However, it was reported ${ }^{[16]}$ in a separate study that the addition of 3 wt pet $\mathrm{Al}$ to a Mg-6 wt pet Zn$1 \mathrm{wt}$ pct Mn alloy leads to a change in precipitate morphology. The basal plates formed in the Al-free alloy are replaced by cuboidal precipitates in the Al-containing alloy. In addition, spherical G.P. zones enriched in $\mathrm{Zn}$ also reportedly form in the Al-containing alloy after the alloy is aged at $343 \mathrm{~K}\left(70{ }^{\circ} \mathrm{C}\right)$. These G.P. zones reportedly act as heterogeneous nucleation sites for the metastable phases that precipitate during subsequent aging at $423 \mathrm{~K}\left(150^{\circ} \mathrm{C}\right)$, resulting in a finer distribution of precipitates.

\section{Mg-Ca-Based Alloys}

The Mg-Ca system has some potential for developing precipitation-hardenable alloys. The equilibrium solid solubility of $\mathrm{Ca}$ in magnesium is 0.82 at. pct (1.35 wt pct) at the eutectic temperature of $789.5 \mathrm{~K}$ $\left(516.5^{\circ} \mathrm{C}\right)$, and it is approximately zero at $473 \mathrm{~K}$ $\left(200{ }^{\circ} \mathrm{C}\right) .{ }^{[14]}$ The equilibrium intermetallic phase at the $\mathrm{Mg}$-rich end of the $\mathrm{Mg}-\mathrm{Ca}$ phase diagram is $\mathrm{Mg}_{2} \mathrm{Ca}$ that has a crystal structure (space group $\mathrm{P} 6_{3} / \mathrm{mmc}, a=$ $0.623 \mathrm{~nm}, c=1.012 \mathrm{~nm}$ ) similar to that of the magnesium matrix phase $\left(\mathrm{P} 6_{3} / \mathrm{mmc}, a=0.321 \mathrm{~nm}, c=\right.$ $0.521 \mathrm{~nm}) .{ }^{[13]}$ This similarity in crystal structure may result in a higher nucleation rate and, hence, a higher number density of precipitates in $\mathrm{Mg}-\mathrm{Ca}$ alloys. Assuming that the precipitates formed during isothermal aging at $473 \mathrm{~K}\left(200{ }^{\circ} \mathrm{C}\right)$ have a $\mathrm{Mg}_{2} \mathrm{Ca}$ composition, the maximum volume fraction of precipitates achievable at $473 \mathrm{~K}\left(200{ }^{\circ} \mathrm{C}\right)$ is calculated to be approximately $2.2 \mathrm{pct}$ for a $\mathrm{Mg}-1$ wt pct $\mathrm{Ca}$ alloy, which is adequate to yield required strength. An example is the conventional precipitation-hardenable Al-0.6 wt pet Si-1.0 wt pet $\mathrm{Mg}$ (6061) wrought alloy. The volume fraction of solid-state precipitates is approximately 2 pct in this alloy. However, a tensile yield strength of $275 \mathrm{MPa}$ is achieved in the $\mathrm{T} 6$ condition. ${ }^{[8]}$ Because $\mathrm{Ca}$ has a low density $\left(1.55 \mathrm{~g} / \mathrm{cm}^{3}\right), \mathrm{Mg}-\mathrm{Ca}$ alloys have the added advantage of preserving the low density of magnesium, and the addition of $\mathrm{Ca}$ can also reduce the flammability of molten magnesium and improve the oxidation and corrosion resistance of magnesium. ${ }^{[1]}$ Therefore, efforts have been made in the past 15 years to develop precipitation-hardenable alloys based on the $\mathrm{Mg}-\mathrm{Ca}$ system. ${ }^{[76,120-124]}$

A study made by Nie and Muddle ${ }^{[120]}$ indicates that the $\mathrm{Mg}-1$ wt pet $\mathrm{Ca}$ alloy exhibits only a moderate agehardening response during isothermal aging at $473 \mathrm{~K}$ $\left(200{ }^{\circ} \mathrm{C}\right)$. However, they noticed that the addition of 1 wt pet of $\mathrm{Zn}$ to the binary alloy led to a substantial increase in peak hardness and an accelerated rate of aging. A subsequent study ${ }^{[121]}$ indicates that the quaternary addition of $1 \mathrm{wt}$ pet $\mathrm{Nd}$ to the $\mathrm{Mg}-1 \mathrm{Ca}-1 \mathrm{Zn}-0.6 \mathrm{Zr}$ (wt pct) alloy can lead to a subsequent increase in the maximum hardness and strength (Figure 12(a)). The resultant $\mathrm{Mg}-1 \mathrm{Ca}-1 \mathrm{Zn}-1 \mathrm{Nd}-0.6 \mathrm{Zr}$ (wt pct) alloy exhibits a tensile yield strength of $153 \mathrm{MPa}$ at room temperature (Table II) and $135 \mathrm{MPa}$ at $423 \mathrm{~K}\left(150{ }^{\circ} \mathrm{C}\right) .{ }^{[121]} \mathrm{A}$ comparison of the microstructures of these alloys indicates that the significant increase in maximum hardness and strength is associated with a refined distribution and improved thermal stability of basal precipitate plates (Figure 12(b)). The crystallographic features of these basal plates and their electron diffraction patterns resemble closely those formed in $\mathrm{Mg}-\mathrm{Nd} /$ $\mathrm{Ce}-\mathrm{Zn}$ alloys. However, it remains to be unambiguously established whether the precipitates in the $\mathrm{Mg}-\mathrm{Ca}-\mathrm{Zn}$ 


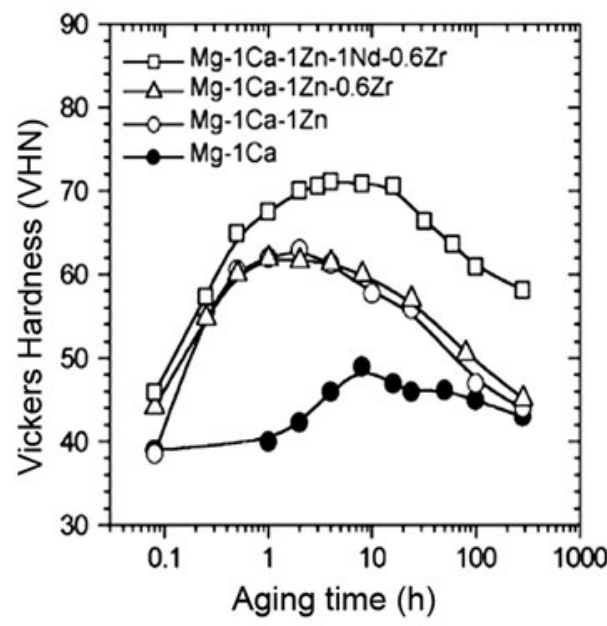

(a)

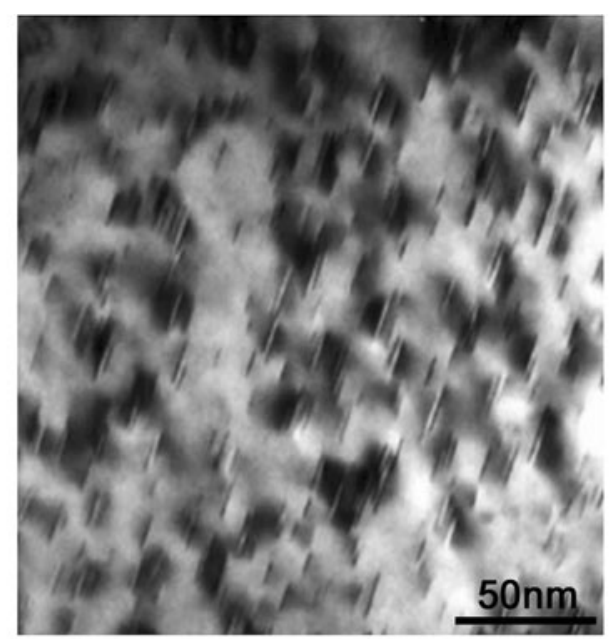

(b)

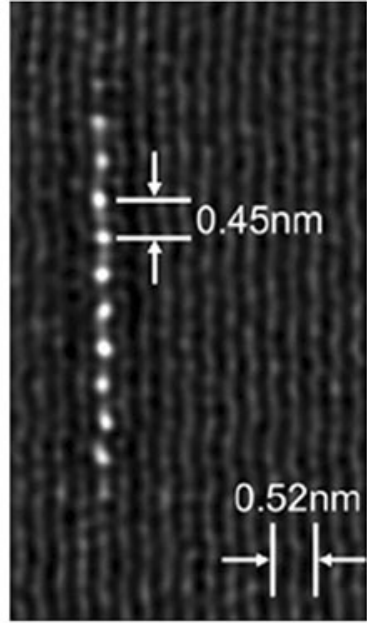

(c)

Fig. 12-(a) Aging curves of Mg-Ca based alloys at $473 \mathrm{~K}\left(200{ }^{\circ} \mathrm{C}\right)$. (b) Transmission electron micrograph showing the distribution of basal precipitate plates in Mg-1Ca-1Zn-1Nd-0.6Zr (wt pct) alloy aged for $1000 \mathrm{~h}$ at $473 \mathrm{~K}\left(200{ }^{\circ} \mathrm{C}\right)$. (c) Atomic-resolution HAADF-STEM image showing ordered G.P. zones in a Mg-0.3Ca-0.6Zn (at. pct) alloy. (a) and (b) are reproduced from Ref. [121], and (c) is from Ref. [76].

and $\mathrm{Mg}-\mathrm{Nd} / \mathrm{Ce}-\mathrm{Zn}$ alloys are structurally identical to each other. An improved understanding on this aspect can facilitate the optimization of alloy composition for improved thermal stability and creep resistance.

In the as-cast microstructure of the $\mathrm{Mg}-1 \mathrm{Ca}-1 \mathrm{Zn}(\mathrm{wt}$ pct) alloy, the primary intermetallic phase has a composition of $\mathrm{Mg}_{69.4} \mathrm{Ca}_{27} \mathrm{Zn}_{3.6}$ and a hexagonal crystal structure (point group 6/mmm, $a \sim 0.61 \mathrm{~nm}, c \sim 1.02 \mathrm{~nm}$ ) that seems isomorphous with $\mathrm{Mg}_{2} \mathrm{Ca}$. Two types of solidstate precipitate phases are observed in the as-cast microstructure: a hexagonal phase with $a=0.623 \mathrm{~nm}$, $c=1.012 \mathrm{~nm}$, and a hexagonal phase with $a=$ $0.556 \mathrm{~nm}, c=1.042 \mathrm{~nm} .{ }^{[120]}$ Both precipitate phases form as thin plates on $(0001)_{\alpha}$, and they have identical orientation relationships with respect to the matrix phase: $(0001)_{\mathrm{p}} / /(0001)_{\alpha},[2 \overline{1} \overline{1} 0]_{\mathrm{p}} / /[10 \overline{1} 0]_{\alpha}$. However, the latter hexagonal phase, i.e., the one with $a=0.556 \mathrm{~nm}$, $c=1.042 \mathrm{~nm}$, has a much more uniform distribution than the former hexagonal phase. It was argued ${ }^{[120]}$ that for the observed orientation relationships between precipitate and matrix phases, a lattice parameter of $a=0.556 \mathrm{~nm}$ permits a perfect lattice matching between precipitate and matrix phases in the habit plane, and this improved lattice matching gives rise to a higher nucleation rate and consequently an enhanced age-hardening response in the $\mathrm{Mg}-\mathrm{Ca}-\mathrm{Zn}$ alloy. It was suggested ${ }^{[120]}$ also that an incorporation of $\mathrm{Zn}$ atoms into the $\mathrm{Mg}_{2} \mathrm{Ca}$ unit cell can change the lattice parameters and, therefore, reduce the lattice misfit between the precipitate and magnesium matrix phases within the $(0001)_{\alpha}$ habit plane.

A subsequent study of microstructures of a $\mathrm{Mg}$ 0.3 at. pct $\mathrm{Ca}-0.3$ at. pct $\mathrm{Zn}$ alloy aged for different times at $473 \mathrm{~K}\left(200{ }^{\circ} \mathrm{C}\right)^{[124]}$ indicate the following precipitation sequence: monolayers of G.P. zones on $(0001)_{\alpha}$, larger $(0001)_{\alpha}$ plates of an unidentified phase, and rectangular $\mathrm{Mg}_{2} \mathrm{Ca}(\mathrm{Zn})$ phase. Each G.P. zone was reported to contain approximately 18 at. pct $\mathrm{Ca}$ and
8 at. pct $\mathrm{Zn}$. Two orientation relationships were reported for the $\mathrm{Mg}_{2}(\mathrm{Ca}, \mathrm{Zn})$ phase: $(0001)_{\mathrm{p}} / /(0001)_{\alpha}$, $[\overline{1} 2 \overline{1} 0]_{\mathrm{p}} / /[01 \overline{1} 0]_{\alpha}$, and $(0001)_{\mathrm{p}} / /[01 \overline{1} 0]_{\alpha},[\overline{1} 2 \overline{1} 0]_{\mathrm{p}} / /$ $[2 \overline{1} \overline{1} 0]_{\alpha}$. In a separate but more recent study of precipitation- and age-hardening response at $473 \mathrm{~K}\left(200^{\circ} \mathrm{C}\right)$ of $\mathrm{Mg}-0.3$ at. pct $\mathrm{Ca}-\mathrm{Zn}$ alloys, ${ }^{[76]}$ it was reported that the maximum age-hardening response is obtained when the $\mathrm{Zn}$ content is 0.6 at. pct. Any increase or decrease in the $\mathrm{Zn}$ content in the alloy diminishes the age-hardening response. In this recent study, ${ }^{[76]}$ HAADF-STEM was employed to characterize the precipitates in the $\mathrm{Mg}-0.3$ at. pet $\mathrm{Ca}-0.6$ at. pet $\mathrm{Zn}$ alloy aged for different times at $473 \mathrm{~K}\left(20{ }^{\circ} \mathrm{C}\right) .{ }^{[76]}$ It was found that monolayer G.P. zones (Figure 12(c)) were responsible for the age hardening and that these G.P. zones had an ordered structure that is identical to that in Mg-RE-Zn alloys. ${ }^{[125]}$ The total atomic concentration of $\mathrm{Ca}$ and $\mathrm{Zn}$ atoms in each ordered G.P. zone is $\sim 33$ pct. These ordered G.P. zones are thermally stable and still dominate the microstructure after overaging (16 hours) at $473 \mathrm{~K}\left(200{ }^{\circ} \mathrm{C}\right)$.

An increase in the $\mathrm{Zn}$ content from 0.6 at. pct to 1.6 at. pet in the $\mathrm{Mg}-0.3$ at. pet $\mathrm{Ca}$ alloy leads to a change in the precipitation sequence. It was reported ${ }^{[76]}$ that the precipitation reaction in the $\mathrm{Mg}-0.3$ at pct Ca-1.6 at. pet $\mathrm{Zn}$ alloy at $473 \mathrm{~K}\left(200{ }^{\circ} \mathrm{C}\right)$ included the formation of $[0001]_{\alpha}$ rods of metastable $\beta_{1}^{\prime}-\mathrm{Mg}_{4} \mathrm{Zn}_{7}$ phase, $(0001)_{\alpha}$ plates of the equilibrium $\mathrm{Mg}_{6} \mathrm{Ca}_{2} \mathrm{Zn}_{3}$ phase (space group P $\overline{3} 1 \mathrm{c}, a=0.97 \mathrm{~nm}, c=1.0 \mathrm{~nm}$ ), and laths of an unknown phase. The broad surface of these laths is parallel to $(0001)_{\alpha}$ and their long axis is parallel to $[2 \overline{1} 10]_{\alpha}$ and $[10 \overline{1} 0]_{\alpha}$. The orientation relationship between the $\mathrm{Mg}_{6} \mathrm{Ca}_{2} \mathrm{Zn}_{3}$ phase and the magnesium matrix is such that $(0001)_{\mathrm{p}} / /(0001)_{\alpha}$, $[10 \overline{1} 0]_{\mathrm{p}} / /[10 \overline{1} 0]_{\alpha}$. The $\mathrm{Mg}_{6} \mathrm{Ca}_{2} \mathrm{Zn}_{3}$ phase was originally reported to form as cuboidal particles in melt-spun ribbons of a Mg-6 wt pet $\mathrm{Zn}-1.5$ wt pet Ca alloy. ${ }^{[126]}$ These cuboidal precipitates reportedly adopt two 
orientation relationships: $(11 \overline{2} 0)_{\mathrm{p}} / /(0001)_{\alpha},[0001]_{\mathrm{p}} / /$ $[11 \overline{2} 0]_{\alpha}$, and $(11 \overline{2} 0)_{\mathrm{p}} / /(0001)_{\alpha},[0001]_{\mathrm{p}} / /[21 \overline{3} 0]_{\alpha} \cdot{ }^{[127]}$

Although it has been demonstrated that additions of $\mathrm{Zn}$ and $\mathrm{Nd}$ can enhance the age-hardening response of $\mathrm{Mg}-\mathrm{Ca}$ alloys, the effects of other alloying elements have received little attention. As discussed in the Section II-A, the high-pressure die-cast $\mathrm{Mg}-\mathrm{Al}-\mathrm{Ca}-\mathrm{Sr}$ (AXJ530) alloy exhibits some age hardening when they are aged at $448 \mathrm{~K}$ to $523 \mathrm{~K}\left(175^{\circ} \mathrm{C}\right.$ to $\left.250{ }^{\circ} \mathrm{C}\right),{ }^{[44]}$ and this age hardening is associated with the formation of $(0001)_{\alpha}$ precipitate plates of $\mathrm{Al}_{2} \mathrm{Ca}$ phase (space group $\mathrm{Fd} \overline{3} \mathrm{~m}, \quad a=0.802 \mathrm{~nm}$ ). The total concentration of ternary and quaternary alloying elements such as $\mathrm{Ca}$ and $\mathrm{Sr}$ in this AXJ530 alloy is high for the purpose of castability and creep resistance, whereas the potential of developing dilute precipitation-hardenable alloys based on the $\mathrm{Mg}$-Al-Ca system was not explored. In a very recent study, ${ }^{[123]}$ it was demonstrated that the ternary addition of an appropriate amount of $\mathrm{Al}$ ( 0.3 wt pct) to a $\mathrm{Mg}-0.5$ wt pet Ca alloy can remarkably enhance the age-hardening response at $473 \mathrm{~K}\left(200{ }^{\circ} \mathrm{C}\right)$ (Figure 13(a)). The maximum age-hardening response achievable at the aging temperature is reduced if the $\mathrm{Al}$ content in the Mg-Ca-Al alloy is higher or lower than 0.3 wt pct. The peak-aged microstructure contains a dense distribution of nanoscale precipitate plates on $(0001)_{\alpha}$. Based on the monolayer thickness of these precipitate plates, the enrichment of $\mathrm{Ca}$ in these particles and the selected-area electron diffraction patterns recorded matrix regions containing such precipitates. These precipitate plates are inferred ${ }^{[123]}$ to be ordered G.P. zones such as those observed in the $\mathrm{Mg}-\mathrm{Ca}-\mathrm{Zn}$ and $\mathrm{Mg}-\mathrm{RE}-\mathrm{Zn}$ alloys. The concentrations of $\mathrm{Ca}$ and $\mathrm{Al}$ atoms in the G.P. zone, measured from 3DAP, are approximately 6 at. pct and 7 at. pct, respectively.

The ordered G.P. zones are gradually replaced by $(0001)_{\alpha}$ plates of the equilibrium phase $\mathrm{Al}_{2} \mathrm{Ca}$ with continued aging at $473 \mathrm{~K}\left(200{ }^{\circ} \mathrm{C}\right)$. The formation of the relatively larger basal plates of the $\mathrm{Al}_{2} \mathrm{Ca}$ phase (Figure 11(b)) was reported to cause the overaging of the alloy. The orientation relationship between the $\mathrm{Al}_{2} \mathrm{Ca}$ plates and the magnesium matrix phase is such that $(111)_{\mathrm{p}} / /(0001)_{\alpha}$ and $[01 \overline{1}]_{\mathrm{p}} / /[0 \overline{1} 10]_{\alpha}$, which is identical to that associated with the $\mathrm{Al}_{2} \mathrm{Ca}$ plates formed in AXJ530 alloy. ${ }^{[43]}$

The occurrence of the age-hardening phenomenon in the $\mathrm{Mg}-\mathrm{Ca}-\mathrm{Al}$ system offers the potential for developing a precipitation-hardenable wrought alloy. ${ }^{[123]}$ In 2011, an unusual $\mathrm{Mg}-3.5 \mathrm{Al}-3.3 \mathrm{Ca}-0.4 \mathrm{Mn}$ (wt pct) extrusion alloy was developed. In the as-extruded condition, this alloy exhibits a tensile yield strength of $410 \mathrm{MPa}$, together with an elongation to fracture of $5.6 \mathrm{pct}^{[128]}$ (Table II). Among the RE-free magnesium alloys, the strength level achieved in this alloy is exceptionally impressive, and this is attributed to the formation of plate-shaped and spherical-shaped precipitates, basal texture, and refined grain size of magnesium. The identities of the two types of precipitates were not verified, but they were assumed ${ }^{[128]}$ to be identical to those formed in $\mathrm{Mg}-0.5 \mathrm{Ca}-0.3 \mathrm{Al}$ (wt pct) ${ }^{[123]}$ and Mg-6Al-3.2Ca-0.5Mn (wt pet) ${ }^{[129]}$ alloys.

\section{E. Mg-Sn-Based Alloys}

$\mathrm{Mg}-\mathrm{Sn}$-based alloys have received some attention in recent years for developing casting and wrought alloy products. ${ }^{[77,130-132]}$ The Mg-Sn binary system itself is ideal for developing precipitation-hardenable alloys. ${ }^{[133]}$ The maximum equilibrium solid solubility of $\mathrm{Sn}$ in $\alpha-\mathrm{Mg}$ is approximately 3.35 at. pct (or $14.5 \mathrm{wt}$ pct) at the eutectic temperature $834 \mathrm{~K}\left(561{ }^{\circ} \mathrm{C}\right)$, and it decreases to approximately 0.1 at. pct at $473 \mathrm{~K}\left(200{ }^{\circ} \mathrm{C}\right) \cdot{ }^{[14]}$ The equilibrium volume fraction of precipitates obtainable at $473 \mathrm{~K}\left(200{ }^{\circ} \mathrm{C}\right)$ is approximately 4.7 pct for a $\mathrm{Mg}-7 \mathrm{wt}$ pet $\mathrm{Sn}$ alloy. The equilibrium intermetallic phase in the $\mathrm{Mg}$-Sn binary alloys is $\beta-\mathrm{Mg}_{2} \mathrm{Sn}$ (space group $F \mathrm{~m} \overline{3} \mathrm{~m}, a=0.68 \mathrm{~nm}$ ). It is rather unfortunate that during isothermal aging treatments in the temperature range of $433 \mathrm{~K}$ to $573 \mathrm{~K}\left(160{ }^{\circ} \mathrm{C}\right.$ to $\left.300{ }^{\circ} \mathrm{C}\right)$, the precipitation process in the $\mathrm{Mg}$-Sn binary alloys does not involve the formation of any metastable precipitate phases. The precipitates formed during the aging process are generally much coarser than the precipitates in other precipitation-hardenable magnesium alloys. Therefore,

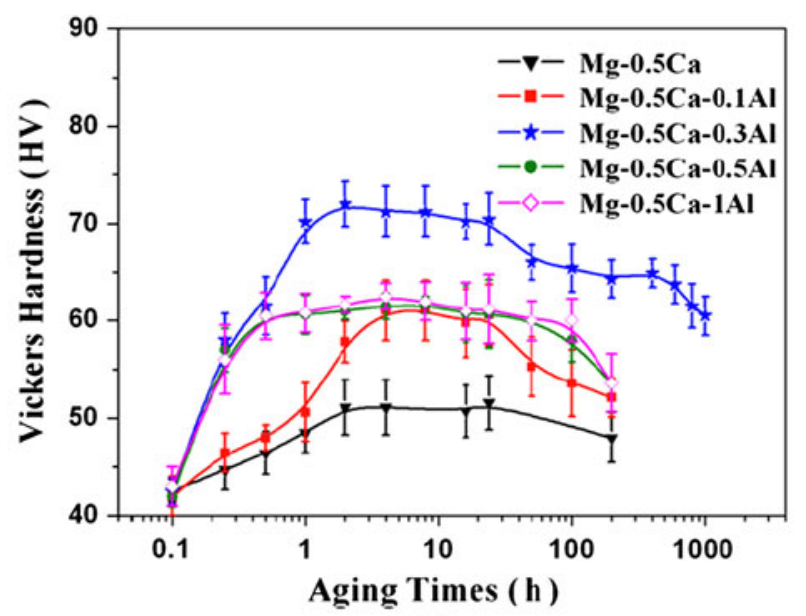

(a)

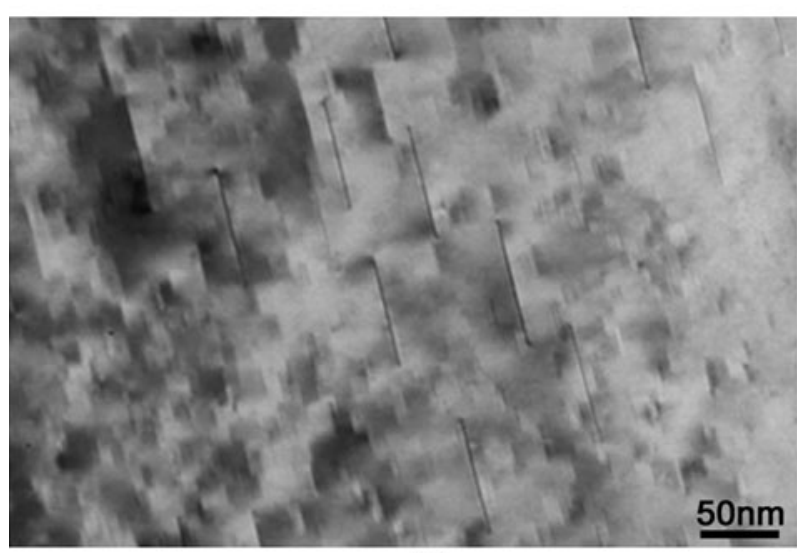

(b)

Fig. 13 - (a) Aging curves of $\mathrm{Mg}$-Ca-Al alloys at $473 \mathrm{~K}\left(200{ }^{\circ} \mathrm{C}\right) .($ b) Transmission electron micrograph showing distribution of basal plates in $\mathrm{Mg}-0.5 \mathrm{Ca}-0.3 \mathrm{Al}$ alloy aged for $1000 \mathrm{~h}$ at $473 \mathrm{~K}\left(200{ }^{\circ} \mathrm{C}\right)$. The alloy compositions are in weight percentage. Reproduced from Ref. [123]. 
attempts have been made in recent years ${ }^{[77,134-136]}$ to refine the distribution of precipitates in $\mathrm{Mg}$-Sn alloys by microalloying additions. As shown in Figures 14(a) and (b) ${ }^{[77,134]}$ ternary additions of $\mathrm{Zn}$ to $\mathrm{Mg}$-Sn alloys can remarkably improve the age-hardening response, and subsequent microalloying additions of $\mathrm{Cu}, \mathrm{Na}, \mathrm{Ag}$, and $\mathrm{Ca}$, and macroalloying additions of $\mathrm{Al}$, to the resultant ternary $\mathrm{Mg}-\mathrm{Sn}-\mathrm{Zn}$ alloys can lead to an even greater age-hardening response. A comparison of microstructures indicates that the $\mathrm{Zn}$ additions can increase the precipitate number density, even thorough the refined precipitates are still the $\beta$ phase, and that quaternary additions of $\mathrm{Na}$ can lead to a much finer distribution of $\beta$ phase (Figures 14(c) through (e)). ${ }^{[134,136]}$ Although the microalloying elements such as $\mathrm{Zn}$ and $\mathrm{Na}$ can apparently enhance the nucleation rates and, thus, the number density of $\beta$ precipitates, as well as change the morphology of the precipitates, it remains to be established whether atoms of such microalloying elements segregate into the precipitate or the precipitate-matrix interface. It is unclear how microalloying elements can enhance the precipitate nucleation rate and change the precipitate morphology, and whether the precipitate morphology change is associated with any change in orientation relationship. Additional work is needed to gain an in-depth understanding of such fundamental issues.

Based on X-ray diffraction and crystallographic analysis in an early study, Derge et al. ${ }^{[137]}$ reported that three orientation relationships (OR) exist between $\beta$ and magnesium phases, namely

$$
\begin{array}{ll}
(111)_{\beta} / /(0001)_{\alpha} \text { and }[1 \overline{1} 0]_{\beta} / /[2 \overline{1} \overline{1} 0]_{\alpha} & (\text { OR-1) } \\
(111)_{\beta} / /(0001)_{\alpha} \text { and }[2 \overline{1} \overline{1}]_{\beta} / /[2 \overline{1} \overline{1} 0]_{\alpha} & (\text { OR-2) } \\
(110)_{\beta} / /(0001)_{\alpha} \text { and }[1 \overline{1} 1]_{\beta} / /[2 \overline{1} \overline{1} 0]_{\alpha} & (\text { OR-3) }
\end{array}
$$

Twenty-five years later, these three orientation relationships were confirmed by Henes and Gerold ${ }^{[138]}$ in their X-ray diffraction observations. They also reported an additional orientation relationship:

$$
(110)_{\beta} / /(0001)_{\alpha} \text { and }[001]_{\beta} / /[2 \overline{1} \overline{1} 0]_{\alpha}
$$

$(\mathrm{OR}-4)$

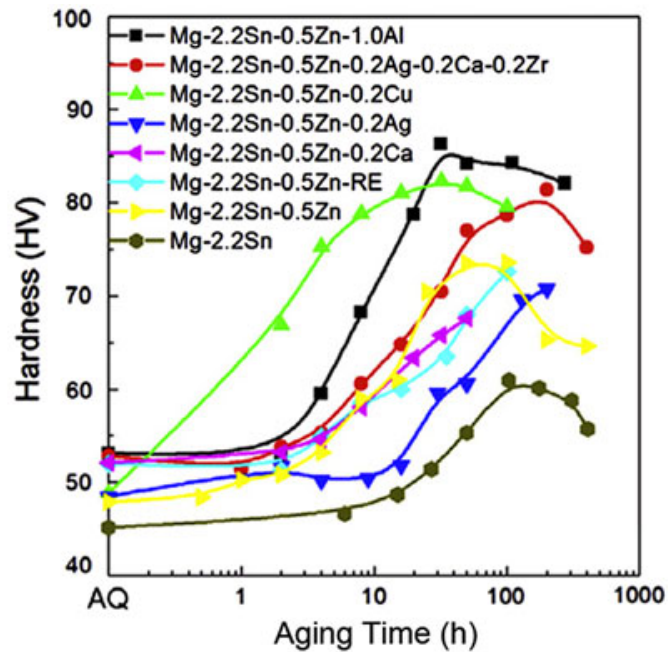

(a)

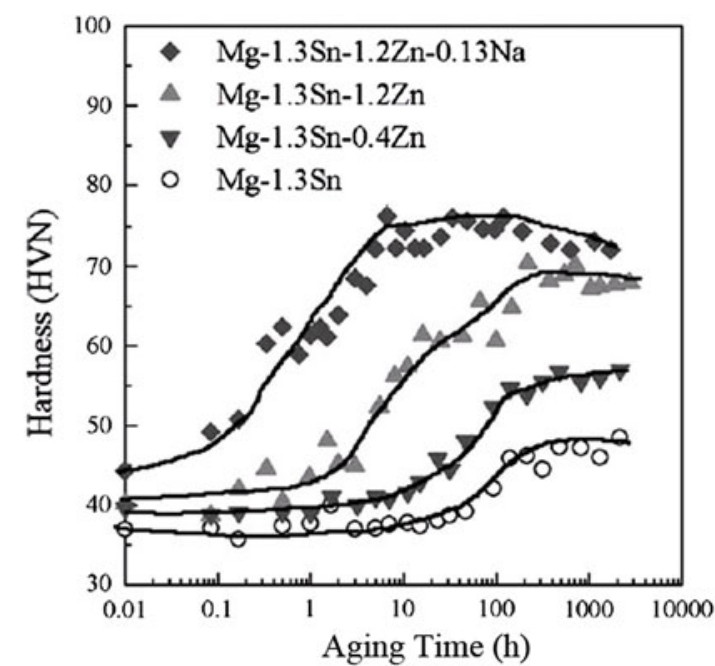

(b)

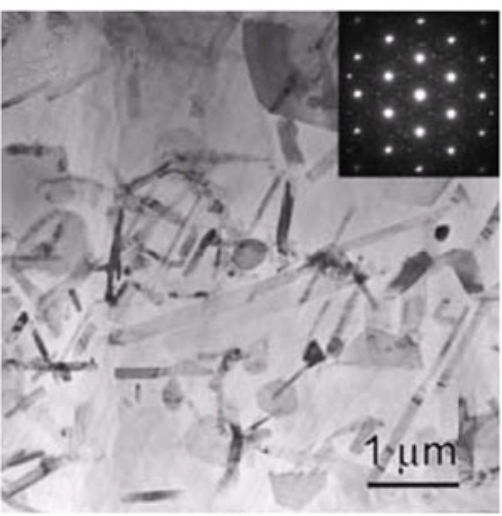

(c)

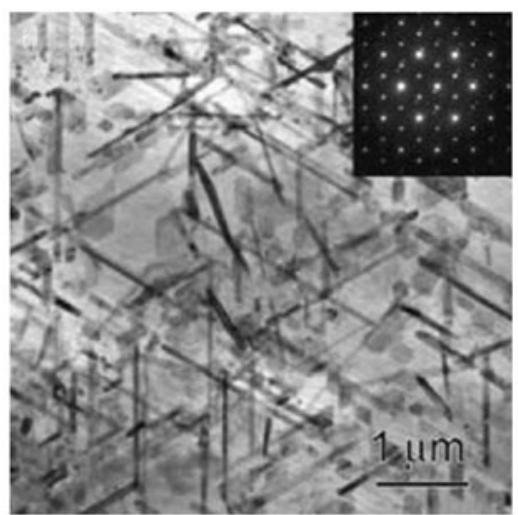

(d)

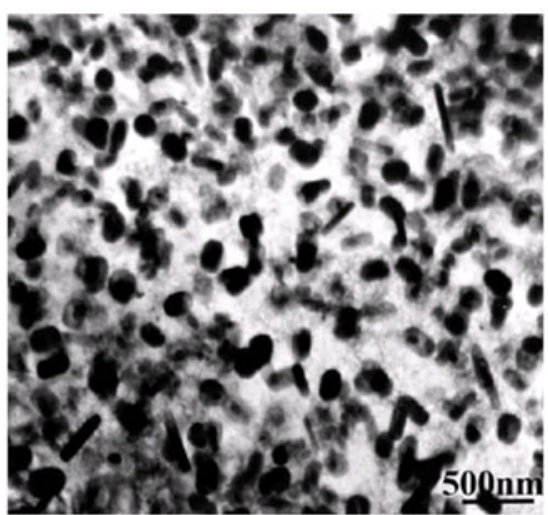

(e)

Fig. $14-(a$ and $b)$ Age-hardening response at $473 \mathrm{~K}\left(200^{\circ} \mathrm{C}\right)$ of $\mathrm{Mg}$-Sn alloys without and with additions of microalloying elements. Transmission electron micrographs showing distribution of precipitates in $(c) \mathrm{Mg}-2.2 \mathrm{Sn},(d) \mathrm{Mg}-2.2 \mathrm{Sn}-0.1 \mathrm{Zn}$, and (e) Mg-1.3Sn-1.2Zn-0.12Na alloys. All alloy compositions are in atomic percentage. (a) and (b) are reproduced from Refs. [77] and [134] respectively, (c) and (d) are from Ref. [136], and (e) are from Ref. [134]. 
and that these four orientation relationships were associated with $\beta$ precipitates that were generated during aging at $433 \mathrm{~K}$ to $573 \mathrm{~K}\left(160{ }^{\circ} \mathrm{C}\right.$ to $\left.300{ }^{\circ} \mathrm{C}\right)$. In these early studies, it was not mentioned which one of the four orientation relationships is most popular and what the precise precipitate morphology is for each of the four orientation relationships. An examination of the orientation relationships reported in recent years ${ }^{[132,134,135,139-141]}$ indicates that even now, this information still remains unclear. Although the most commonly reported orientation relationship in recent years seems to be OR-1, a variety of morphologies has been reported for this OR-1, including the following:

(a) Long laths, which were formed with the broad surface parallel to $(0001)_{\alpha}$ and the long axis parallel to $\langle 2 \overline{1} 10\rangle_{\alpha}$, in a $\mathrm{Mg}-1.9$ at. pct $\mathrm{Sn}$ alloy aged for 240 hours at $473 \mathrm{~K}\left(200{ }^{\circ} \mathrm{C}\right) .{ }^{[135]}$

(b) Short laths, which were formed with the broad surface parallel to $(0001)_{\alpha}$ and the long axis parallel to $\langle 2 \overline{1} 10\rangle$, in $\mathrm{Mg}-1.3 \mathrm{Sn}-1.2 \mathrm{Zn}$ (at. pct) alloy aged for 211 hours at $473 \mathrm{~K}\left(200{ }^{\circ} \mathrm{C}\right)^{[134]}$ and aged samples of $\mathrm{Mg}-2.2 \mathrm{Sn}-0.5 \mathrm{Zn}$ (at. pct) alloy. ${ }^{[136]}$

(c) Short [0001 $]_{\alpha}$ laths in $\mathrm{Mg}-1.3 \mathrm{Sn}-1.2 \mathrm{Zn}$ (at. pct) alloy aged 211 hours at $473 \mathrm{~K}\left(200^{\circ} \mathrm{C}\right) .{ }^{[134]}$

(d) Short rods in Mg-7.8Sn-2.7Al-0.7Si-0.7Zn-0.2Mn (wt pct) alloy produced by die casting. ${ }^{[132]}$

(e) Polygons in Mg-1.3Sn-1.2Zn-0.12Na (at. pct) alloy aged 6.7 hours at $473 \mathrm{~K}\left(200{ }^{\circ} \mathrm{C}\right),{ }^{[134]} \mathrm{Mg}-2.2 \mathrm{Sn}-$ $0.5 \mathrm{Zn}$ (at. pct) alloy peak aged at $473 \mathrm{~K}\left(200^{\circ} \mathrm{C}\right),{ }^{[139]}$ and $\mathrm{Mg}-5.3 \mathrm{Sn}-0.3 \mathrm{Mn}-0.2 \mathrm{Si}$ (wt pct) alloy aged for 10 hours at $523 \mathrm{~K}\left(250^{\circ} \mathrm{C}\right)$. $^{[140]}$

In contrast, the long laths, which were formed on $(0001)_{\alpha}$ and elongated along $\langle 2 \overline{1} 10\rangle_{\alpha}$ in $\mathrm{Mg}-5.3 \mathrm{Sn}-$ $0.3 \mathrm{Mn}-0.2 \mathrm{Si}$ (wt pct) alloy aged for 10 hours at $523 \mathrm{~K}$ $\left(250{ }^{\circ} \mathrm{C}\right),{ }^{[140]}$ and the short laths, formed on $(0001)_{\alpha}$ in $\mathrm{Mg}-2.1 \mathrm{Sn}-1 \mathrm{Zn}-0.1 \mathrm{Mn}$ (at. pet) alloy peak-aged at $473 \mathrm{~K}$ $\left(200{ }^{\circ} \mathrm{C}\right),{ }^{[142]}$ have also been reported to have the OR-4. The polygons in $\mathrm{Mg}-2.2 \mathrm{Sn}-0.5 \mathrm{Zn}$ (at. pct) alloy peak aged at $473 \mathrm{~K}\left(200{ }^{\circ} \mathrm{C}\right),{ }^{[139]}$ the aged samples of $\mathrm{Mg}$ $2.2 \mathrm{Sn}-0.5 \mathrm{Zn}$ (at. pct) alloy ${ }^{[136]}$ and the short laths formed with broad surface parallel to the pyramidal plane of the matrix phase in $\mathrm{Mg}-1.3 \mathrm{Sn}-1.2 \mathrm{Zn}$ (at. pct) alloy aged for 211 hours at $473 \mathrm{~K}\left(200{ }^{\circ} \mathrm{C}\right)^{[135]}$ have been reported to have the OR-3. Furthermore, Zhang et al. ${ }^{[140]}$ reported that the $(0001)_{\alpha}$ plates in their alloy adopt the following orientation relationship:

$$
\begin{aligned}
& (111)_{\beta} / /(0001)_{\alpha} \text { and }[2 \overline{1} \overline{1} 0]_{\alpha} \text { is } \\
& \sim 9 \text { deg away from }[1 \overline{1} 0]_{\beta} \quad(\text { OR-5) }
\end{aligned}
$$

The OR-5 can be related to the OR-1 by a rotation of $9 \mathrm{deg}$ about the $[111]_{\beta} / /[0001]_{\alpha}$ axis. However, Sasaki et al. ${ }^{[139]}$ reported that the basal plates in their alloy have the OR-2. Two other different orientation relationships have also been reported, namely:

$$
\begin{array}{ll}
(110)_{\beta} / /(0001)_{\alpha} \text { and }[31 \overline{1}]_{\beta} / /[1 \overline{1} 00]_{\alpha} & (\text { OR-6) } \\
(111)_{\beta} / /(01 \overline{1} 0)_{\alpha} \text { and }[1 \overline{1} 0]_{\beta} / /[2 \overline{1} \overline{1} 0]_{\alpha} & (\text { OR-7) }
\end{array}
$$

The precipitate morphology is short lath elongated along $\langle 10 \overline{10}\rangle_{\alpha}$ for the OR-6 $6^{[140]}$ and rod elongated in the pyramidal plane of the matrix phase. ${ }^{[136]}$ It is currently unclear why several orientation relationships exist and what microstructural factor dictates the formation of these orientation relationships. It remains to be examined whether the appearance of different orientation relationships and morphologies associated with these orientation relationships is caused by the variation of concentration of $\mathrm{Sn}$ atoms in the solid-solution matrix. Any local segregation of Sn atoms may cause a change in the lattice parameter and, in turn, can promote the formation of a particular orientation relationship.

\section{F. $M g-N d / C e$-Based Alloys}

\section{1. $\mathrm{Mg}-\mathrm{Nd}$ and $\mathrm{Mg}-\mathrm{Ce}$ binary alloys}

The identity of the equilibrium intermetallic phase at the $\mathrm{Mg}$-rich side of the $\mathrm{Mg}-\mathrm{Nd}$ binary phase diagram has been controversial. The early version of the phase diagram $^{[14]}$ indicates that the equilibrium intermetallic phase is $\mathrm{Mg}_{12} \mathrm{Nd}$ that has a tetragonal structure (space group I4 $/ \mathrm{mmm}, a=1.031 \mathrm{~nm}, c=0.593 \mathrm{~nm}$ ). However, more recent studies ${ }^{[143-145]}$ indicate that the equilibrium intermetallic phase is $\mathrm{Mg}_{41} \mathrm{Nd}_{5}$ (space group $\mathrm{I} 4 / \mathrm{m}$, $a=1.474 \mathrm{~nm}, \quad c=1.040 \mathrm{~nm})$ instead of $\mathrm{Mg}_{12} \mathrm{Nd}$ (Figure 15). The maximum solid solubility of $\mathrm{Nd}$ in magnesium varies significantly in the literature, ranging from 0.10 at. pct $(0.59 \mathrm{wt}$ pct $)$ at $821 \mathrm{~K}\left(548{ }^{\circ} \mathrm{C}\right)$ to 0.63 at. pct $(3.62 \mathrm{wt}$ pct $)$ at $825 \mathrm{~K}\left(552{ }^{\circ} \mathrm{C}\right) .{ }^{[14,146]} \mathrm{A}$ recent study using atom probe tomography ${ }^{[147]}$ indicates that the equilibrium solid solubility of $\mathrm{Nd}$ in magnesium is approximately 0.32 at. pet $(1.87 \mathrm{wt}$ pct) at $793 \mathrm{~K}$ $\left(520{ }^{\circ} \mathrm{C}\right)$, and 0.11 at. pct $(0.65 \mathrm{wt}$ pct) at $673 \mathrm{~K}$ $\left(400{ }^{\circ} \mathrm{C}\right)$. The equilibrium solid solubility of $\mathrm{Nd}$ decreases with temperature, down to nearly zero at $473 \mathrm{~K}\left(200{ }^{\circ} \mathrm{C}\right)$, implying a potential for precipitation hardening. The aging curve of a Mg-3 wt pet $\mathrm{Nd}$ alloy at $473 \mathrm{~K}\left(200^{\circ} \mathrm{C}\right)$ is shown in Figure $16(\mathrm{a}) .{ }^{[148]}$

The decomposition of supersaturated solid solution of magnesium in the temperature range of $333 \mathrm{~K}$ to $623 \mathrm{~K}$

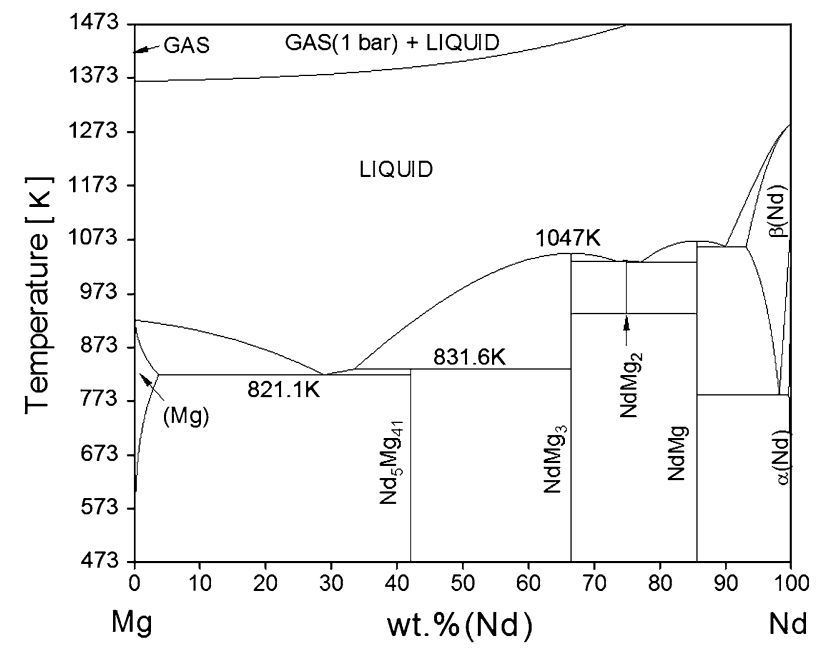

Fig. 15-Mg-Nd binary phase diagram (Courtesy R. Schmid-Fetzer). 
$\left(60{ }^{\circ} \mathrm{C}\right.$ to $350{ }^{\circ} \mathrm{C}$ ) is currently accepted as involving the formation of G.P. zones, $\beta^{\prime \prime}, \beta^{\prime}$, and $\beta$ phases. ${ }^{[5,8,149,150]}$ Whereas the G.P. zones have been reported to form as (1) needles along the $[0001]_{\alpha}$ direction $^{[149]}$ in a Mg-2.9 wt pet $\mathrm{Nd}$ (Mg-0.5 at. pet $\mathrm{Nd}$ ) alloy or as (2) platelets on $\{10 \overline{1} 0\}_{\alpha}$ in a Mg-2.5 wt pct Di (80 pct Nd-20 pet Pr)-0.6 wt pet $\mathrm{Zr}$ alloy, ${ }^{[151]}$ there was a lack of direct experimental evidence, or transmission electron microscopy images, to support the formation of such G.P. zones in these alloys at the early stage of aging. It was not clear whether G.P. zones did form in the Mg-Nd binary alloys and, if so, what morphology they might adopt.

In a very recent study, using HAADF-STEM, of precipitate phases formed in $\mathrm{Mg}-0.5$ at. pct $\mathrm{Nd}$ samples aged at $443 \mathrm{~K}\left(170{ }^{\circ} \mathrm{C}\right),{ }^{[152]}$ some peculiar zigzag arrays of $\mathrm{Nd}$ atoms aligned approximately along $\langle 2 \overline{1} 10\rangle_{\alpha}$ are observed and regarded as G.P. zones. Each zigzag array comprises several $\mathrm{V}$-shaped, or $\mathrm{N}$-shaped, units that are separated by an almost regular spacing. Each V-shaped and $\mathrm{N}$-shaped unit is made of three and four columns of $\mathrm{Nd}$ atoms, respectively. The separation distance between two neighboring columns of $\mathrm{Nd}$ atoms within each unit is invariably $\sim 0.37 \mathrm{~nm}$, and the plane defined by the two neighboring columns of $\mathrm{Nd}$ atoms is invariably parallel to $\{10 \overline{1} 0\}_{\alpha}$.

Some hexagonal rings, defined by six columns of $\mathrm{Nd}$ atoms, are also observed in this latest work. ${ }^{[152]}$ The separation distance between two neighboring columns of $\mathrm{Nd}$ atoms within the hexagonal ring is again approximately $0.37 \mathrm{~nm}$, and the prism plane of the hexagonal ring is parallel to $\{10 \overline{1} 0\}_{\alpha}$. Each hexagonal ring can be regarded as being constructed by linking three variants of the $\mathrm{V}$-shaped unit mentioned in the preceding paragraph. This arrangement of $\mathrm{Nd}$ atoms resembles that in the $\mathrm{D}_{19}$ structure (space group $\mathrm{P}_{3} /$ mmc, $a=0.641 \mathrm{~nm}, c=0.521 \mathrm{~nm}, \mathrm{Mg}_{3} \mathrm{Nd}$ composition), ${ }^{[151]}$ even though Saito and Hiraga did not mention it. Moreover, the area defined by the hexagonal ring is precisely that of the basal plane of the $\mathrm{D} 0_{19}$ unit cell (Figure 16(b)). The $\beta^{\prime \prime}$ phase was originally reported to have a $\mathrm{D}_{19}$ structure and an orientation relationship that is in the form $(0001)_{\beta^{\prime \prime}} / /(0001)_{\alpha}$ and $[2 \overline{1} \overline{10}]_{\beta^{\prime \prime}} / /[2 \overline{1} \overline{1} 0]_{\alpha}$. Therefore, these hexagonal rings may be regarded as the metastable $\beta^{\prime \prime}$ phase. The latest experimental observations made by HAADF-STEM indicate clearly that the $\beta^{\prime \prime}$ precipitates are not $\{2 \overline{1} \overline{1} 0\}_{\alpha}$ plates.

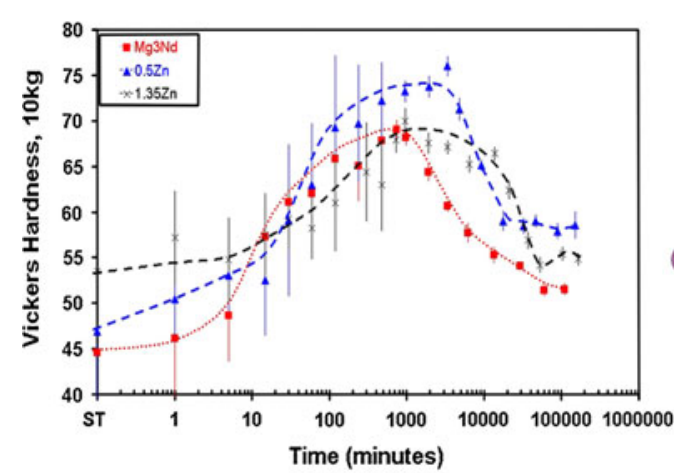

(a)

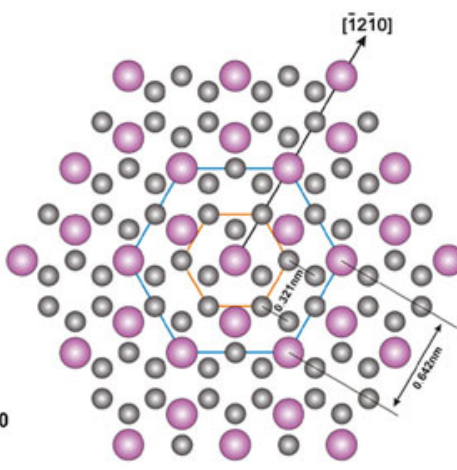

(b)

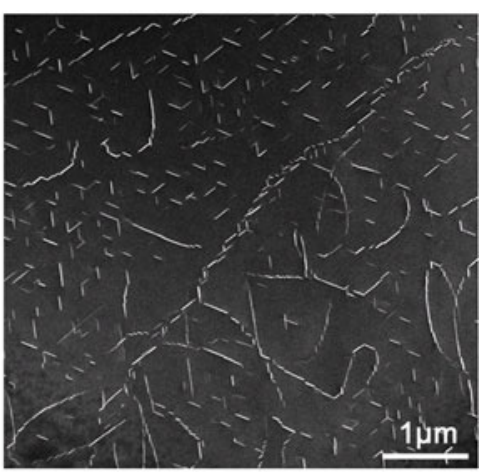

(c)

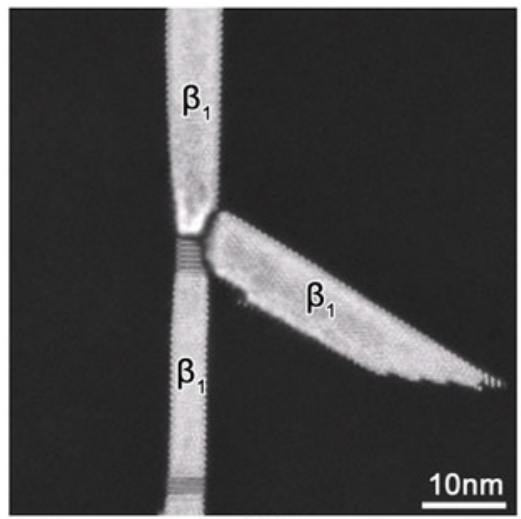

(d)

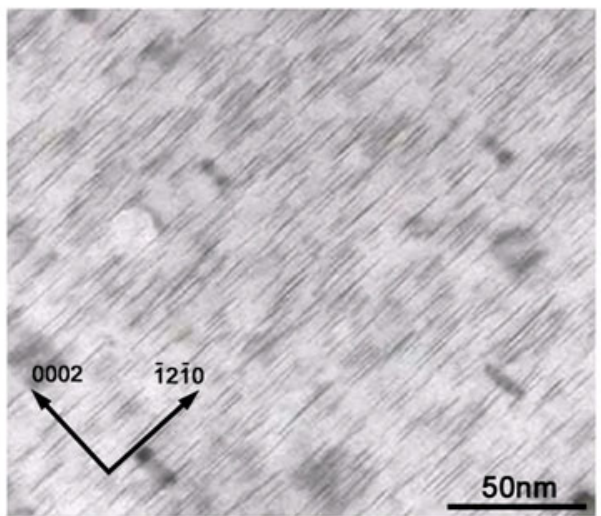

(e)

Fig. 16 - (a) Age-hardening response at $473 \mathrm{~K}\left(200^{\circ} \mathrm{C}\right)$ of $\mathrm{Mg}-3$ wt pct Nd alloys without and with $\mathrm{Zn}$ additions (reproduced from Ref. [148]). (b) Schematic diagram showing D $0_{19}$ structure. The perspective viewing direction is [0001]. Large purple circles and small gray circles represent $\mathrm{Nd}$ and $\mathrm{Mg}$ atoms, respectively. ( $c$ and $d$ ) Transmission electron micrographs showing distribution of $\beta_{1}$ precipitates in $\mathrm{Mg}-3 \mathrm{wt}$ pct $\mathrm{Nd}$ alloy aged for $10 \mathrm{~h}$ at $523 \mathrm{~K}\left(250{ }^{\circ} \mathrm{C}\right){ }^{[153]}$ (e) Transmission electron micrograph showing the distribution of precipitates in $\mathrm{Mg}-3 \mathrm{wt}$ pct $\mathrm{Nd}-$ $1.35 \mathrm{wt}$ pct $\mathrm{Zn}$, aged for $52 \mathrm{~g}$ at $473 \mathrm{~K}\left(200^{\circ} \mathrm{C}\right)$ (reproduced from Ref. [148]). 
The HAADF-STEM work of Saito and Hiraga ${ }^{[152]}$ also revealed the existence of a precipitate phase that has never been reported for the binary Mg-Nd alloys. This phase, designated $\beta^{\prime}$, has an orthorhombic structure $(a=0.64 \mathrm{~nm}, b=1.14 \mathrm{~nm}, c=0.52 \mathrm{~nm}), \mathrm{a} \mathrm{Mg}_{7} \mathrm{Nd}$ composition, and a lenticular morphology. Although it is not mentioned by the authors, the following orientation relationship can be deduced from Figure 7 in their work $^{[152]}:(100)_{\beta^{\prime}} / /\{1 \overline{2} 10\}_{\alpha}$ and $[001]_{\beta^{\prime}} / /[0001]_{\alpha}$. Most of these features are similar to those of the $\beta^{\prime}$ phase in Mg-Gd, Mg-Y, Mg-Gd-Y, and WE54 alloys, as will be discussed in Section II-G.

The $\beta^{\prime}$ phase mentioned in previous studies was reported to form as plates on . Pike and Noble ${ }^{[149]}$ suggested that the $\beta^{\prime}$ phase had a hexagonal structure $(a=0.52 \mathrm{~nm}, c=1.30 \mathrm{~nm})$ and the following orientation relationship with respect to the matrix phases: $(1 \overline{2} 10)_{\beta^{\prime}} / /(10 \overline{1} 0)_{\alpha},(\overline{1} 014)_{\beta^{\prime}} / /\left\langle_{151]}(0001)_{\alpha}\right.$. In contrast, Karimzadeh $^{[150]}$ and Gradwell ${ }^{[151]}$ indicated that $\beta^{\prime}$ had a face-centered cubic structure $(a=0.735 \mathrm{~nm})$ and a composition close to $\mathrm{Mg}_{20} \mathrm{Nd}_{17}$. Karimzadeh ${ }^{[150]}$ also suggested that the orientation relationship between $\beta^{\prime}$ and the matrix was such that $(\overline{1} 12)_{\beta^{\prime}} / /(10 \overline{10})_{\alpha},[110]_{\beta^{\prime}}$ $/ /[0001]_{\alpha}$. The structure, orientation relationship, and morphology proposed by Karimzadeh ${ }^{[150]}$ and Gradwell ${ }^{[151]}$ are essentially the same as those of $\beta_{1}$ phase (space group $\mathrm{Fm} \overline{3} \mathrm{~m}, a=0.74 \mathrm{~nm}$ ) in $\mathrm{Mg}-\mathrm{Gd}$, Mg-Gd-Y, and WE54 alloys. To avoid any confusion and to be consistent with those symbols used for similar structures, it is appropriate to use $\beta_{1}$ to replace $\beta^{\prime}$ used in the previous studies. The $\beta_{1}$ precipitates often form heterogeneously on preexisting dislocations, leading to a nonuniform distribution of these precipitates (Figure 16(c))..$^{[153]}$

The $\beta$ phase, which was originally regarded as the equilibrium phase but is in fact a metastable phase, has a body-centered tetragonal structure $(a=1.031 \mathrm{~nm}$, $c=0.593 \mathrm{~nm})$ and a composition of $\mathrm{Mg}_{12} \mathrm{Nd} \cdot{ }^{[8,149]} \mathrm{It}$ forms as rods with their long axis parallel to [0001] $\alpha$. The cross section of the $\beta$ rods has a hexagonal shape, with the prism facets parallel to $\{10 \overline{1} 0\}_{\alpha}$. The orientation relationship between $\beta$ and the matrix was reported ${ }^{[154]}$ to be the following: $(002)_{\beta} / /(10 \overline{1} 0)_{\alpha}$ and $[100]_{\beta} / /[0001]_{\alpha}$.

Based on the preceding discussion of individual precipitate phases and the fact that the equilibrium precipitate phase is $\mathrm{Mg}_{41} \mathrm{Nd}_{5}$, instead of $\mathrm{Mg}_{12} \mathrm{Nd}$, the part of the whole precipitation sequence in $\mathrm{Mg}-\mathrm{Nd}$ binary alloys is provided in Table I. To preserve the symbols commonly used in the literature for similar structures and to avoid any confusion, in this newly proposed sequence the $\beta^{\prime}$ phase represents the newly reported orthorhombic phase, $\beta_{1}$ phase represents the $\beta^{\prime}$ phase reported in the previous studies, and $\beta_{\mathrm{e}}$ is used as the final precipitate phase, i.e., $\mathrm{Mg}_{41} \mathrm{Nd}_{5}$. It is to be noted that the whole precipitation sequence is far from well established; the early stage precipitation still remains to be unambiguously established, and even the later stage of the precipitation requires more characterization and analysis. For example, the gray contrast regions connecting $\beta_{1}$ precipitates or segments shown in Figure $16(d)^{[153]}$ cannot be attributable to any of the precipitate phases known in the $\mathrm{Mg}-\mathrm{Nd}$ system. The temperature-time-transformation diagrams for various precipitate phases formed in the $\mathrm{Mg}-0.5$ at. pct $\mathrm{Nd}$ alloy were studied and reported by Pike and Noble. ${ }^{[149]}$ Because the identities of the precipitate phases were not unambiguously established in that work, some caution should be taken if such temperature-timetransformation diagrams are to be used.

The age-hardening response and precipitation sequence of $\mathrm{Mg}-\mathrm{Ce}$ binary and $\mathrm{Mg}-\mathrm{MM}$ (MM represents $\mathrm{Ce}$ - or Nd-rich misch-metal) alloys were also studied in the past. ${ }^{[154,155]}$ Because the equilibrium solid solubility of $\mathrm{Ce}$ in magnesium is lower than that of $\mathrm{Nd}$, a lower age-hardening response is expected for the $\mathrm{Mg}-\mathrm{Ce}$ and Mg-MM alloys. Wei et al. ${ }^{[154]}$ and Hisa et al. ${ }^{[155]}$ investigated the precipitation sequence of $\mathrm{Mg}$ 1.3 wt pet $\mathrm{MM}$ (Ce-rich $\mathrm{MM}$ ) and $\mathrm{Mg}-1.3$ wt pct $\mathrm{Ce}$ alloys. The identities and formation mechanisms of the intermediate precipitate phases are controversial in these two studies. Nevertheless, the precipitation in the Mg$\mathrm{Ce}$ and $\mathrm{Mg}-\mathrm{MM}$ alloys is expected to be similar to that in the Mg-Nd alloys.

\section{2. $M g-N d-Z n$ and $M g-C e-Z n$ alloys}

The intermetallic particles formed in the as-cast microstructures of the $\mathrm{Mg}-3 \mathrm{Nd}-0.5 \mathrm{Zn}$ and $\mathrm{Mg}-3 \mathrm{Nd}-$ $1.35 \mathrm{Zn}$ (wt pct) alloys are similar to those in the $\mathrm{Mg}-\mathrm{Nd}$ binary alloys. They have the tetragonal structure of the $\mathrm{Mg}_{12} \mathrm{Nd}$ phase, even though they contain some $\mathrm{Zn}$. The intermetallic particles in the interdendritic regions of a sand cast Mg-2.5 wt pet RE-0.5 wt pct Zn alloy, designated MEZ, have a $\mathrm{Mg}_{12}\left(\mathrm{La}_{0.43} \mathrm{Ce}_{0.57}\right)$ composition and a high density of unidentified planar defects. ${ }^{[156]}$ These intermetallic particles are more difficult to dissolve into the solid-solution matrix phase during the solution treatment, and the volume fraction of the retained such particles increases with the $\mathrm{Zn}$ content in the alloy. The addition of $\mathrm{Zn}$ seems to led to a reduction in eutectic temperature and, therefore, the use of a lower temperature for solution treatment. For example, localized melting in grain boundaries was noted after the $\mathrm{Mg}$ $3 \mathrm{Nd}-1.35 \mathrm{Zn}$ alloy was solution treated for 24 hours at $803 \mathrm{~K}\left(530{ }^{\circ} \mathrm{C}\right),{ }^{[157]}$ and therefore, $783 \mathrm{~K}\left(510^{\circ} \mathrm{C}\right)$ was used for the solution treatment. Whereas the retain intermetallic particles in the Mg-3Nd-1.35Zn alloy still have the structure of the $\mathrm{Mg}_{12} \mathrm{Nd}$ phase after 24 hours solution treatment at $783 \mathrm{~K}\left(510{ }^{\circ} \mathrm{C}\right)$, they gradually decompose and are replaced by the $\gamma$ phase (facecentered cubic, $a=0.72 \mathrm{~nm}$ ) after prolonged heat treatments at $473 \mathrm{~K}$ and $598 \mathrm{~K}\left(200{ }^{\circ} \mathrm{C}\right.$ and $\left.325^{\circ} \mathrm{C}\right) \cdot{ }^{[157]}$ The structure of this $\gamma$ phase is similar to that of the $\mathrm{Mg}_{3} \mathrm{Nd}$ phase, except the lattice parameter is a little smaller. The structures of the equilibrium intermetallic phases at the Mg-rich side of the Mg-Nd-Zn or Mg-Ce$\mathrm{Zn}$ ternary phase diagram have so far not been unambiguously established. ${ }^{[158-161]}$ Therefore, it is difficult to know whether the $\mathrm{Mg}_{3} \mathrm{Nd}$ is an equilibrium phase at the Mg-rich side of the $\mathrm{Mg}-\mathrm{Nd}-\mathrm{Zn}$ alloys and, if so, whether $\gamma$ is the $\mathrm{Mg}_{3} \mathrm{Nd}$ phase.

Ternary additions of $\mathrm{Zn}$ to $\mathrm{Mg}-\mathrm{Nd}$ or $\mathrm{Mg}$-Ce alloys do not lead to any appreciable change in the agehardening response (Figures 16(a) and 17(a)), but they 
lead to a significant improvement in creep resistance. ${ }^{[157]}$ The age-hardening response of the $\mathrm{Mg}-\mathrm{Nd}-\mathrm{Zn}$ alloys is greater than that of the $\mathrm{Mg}-\mathrm{Ce}-\mathrm{Zn}$ alloys because of a higher saturation of solutes in the as-quenched condition and a higher volume fraction of precipitates after aging. As shown in Table II, the tensile yield strength of a $\mathrm{Mg}-\mathrm{Nd}-\mathrm{Zn}$ based alloy, designated NEZ, is much higher than that of a $\mathrm{Mg}-\mathrm{Ce}-\mathrm{Zn}$ based alloy designated MEZ. Quaternary additions of Gd to the resultant $\mathrm{Mg}$ $\mathrm{Nd}-\mathrm{Zn}$ alloys can result in improvement in the agehardening response, ${ }^{[162]}$ and this discovery leads to the development of a commercial alloy designated EV31, which is also known as Elektron 21. The EV31 alloy is age hardenable, and it possesses adequate strength (Table II) and excellent creep resistance at temperatures up to $473 \mathrm{~K}\left(200{ }^{\circ} \mathrm{C}\right)$. The addition of more than 1.35 wt pet $\mathrm{Zn}$ to the $\mathrm{Mg}-3$ wt pet $\mathrm{Nd}$ alloy results in a decreased hardening response. The commercial alloy EZ33 (Mg-3.2 wt pet MM-2.7 wt pet Zn-0.7 wt pet Zr) has a large amount of insoluble intermetallic particles at grain boundaries after casting. This alloy does not have much age-hardening response and therefore is often used in the T5 condition.

The precipitation sequence in a $\mathrm{Mg}-2.8$ wt pet $\mathrm{Nd}$ $1.3 \mathrm{wt}$ pet $\mathrm{Zn}$ alloy was reported to include a lowtemperature reaction and the formation of $\gamma^{\prime \prime}$ and $\gamma$ phases in an early study. ${ }^{[163]}$ The low-temperature reaction was noted during isothermal resistivity measurements at temperatures between $323 \mathrm{~K}$ and $423 \mathrm{~K}$ $\left(50{ }^{\circ} \mathrm{C}\right.$ and $150{ }^{\circ} \mathrm{C}$ ). The nature of this low-temperature reaction was not fully characterized in that study, and it was speculated $^{[163]}$ that it was related to the formation of G.P. zones. In 2003, Ping et al. ${ }^{[125]}$ reported the first 3 DAP result on magnesium alloys. In their study, the transmission electron microscopy and 3DAP were combined to characterize the structure, morphology, and composition of nanoscale precipitates formed in a Mg-2.4RE-0.4Zn-0.6Zr (wt pct, where 2.4 wt pct RE includes 1.3 wt pct $\mathrm{Ce}, 0.6 \mathrm{wt}$ pct $\mathrm{La}, 0.4$ wt pct $\mathrm{Nd}$, and 0.1 wt pet Pr) casting alloy, solution treated for 16 hours at $798 \mathrm{~K}\left(525^{\circ} \mathrm{C}\right)$, cold-water quenched, and then aged for 48 hours at $473 \mathrm{~K}\left(200{ }^{\circ} \mathrm{C}\right)$. Hitherto unreported ordered G.P. zones, which form as (0001) $\alpha$ disks of a single atomic plane thickness, were observed in this alloy. The $\mathrm{RE} / \mathrm{Zn}$ atoms have an ordered hexagonal distribution within individual G.P. zone planes, with $a=0.556 \mathrm{~nm}$. The orientation relationship between the two-dimensionally ordered G.P. zones and $\alpha-\mathrm{Mg}$ matrix phase is that $[10 \overline{1} 0]_{\mathrm{GP}} / /[11 \overline{2} 0]_{\alpha}$. The 3DAP results indicate that the G.P. zones contain approximately 3.2 at. pct $\mathrm{Nd}, 1.0$ at. pet $\mathrm{Ce}$, and 1.2 at. pet $\mathrm{Zn}$ (Figure 17(b)). The presence of both RE and $\mathrm{Zn}$ atoms in the G.P. zones is to reduce the elastic strain associated with individual atoms of RE and $\mathrm{Zn}$ because RE atoms are larger than $\mathrm{Mg}$ whereas $\mathrm{Zn}$ atoms are smaller than $\mathrm{Mg}$.

In the study made by Nuttall et al., ${ }^{[163]}$ the $\gamma^{\prime \prime}$ phase was reported to have a hexagonal structure ( $a=0.556 \mathrm{~nm}, c=1.563 \mathrm{~nm})$, and it formed as plates on the basal plane of $\alpha-\mathrm{Mg}$. The orientation relationship between $\gamma^{\prime \prime}$ and the matrix phase was reported to be such that $(0001)_{\gamma^{\prime \prime}} / /(0001)_{\alpha},[2 \overline{1} \overline{1} 0]_{\gamma^{\prime \prime}} / /[10 \overline{1} 0]_{\alpha}$. In more recent studies ${ }^{[125,148]}$ of peak-aged samples of $\mathrm{Mg}-\mathrm{Nd}$ $\mathrm{Zn}$ and $\mathrm{Mg}-\mathrm{RE}-\mathrm{Zn}$ alloys, most precipitates form as $(0001)_{\alpha}$ plates (Figure 16(e)). They are similar to the $\gamma^{\prime \prime}$ phase but were designated $\gamma^{\prime} .^{[125]}$ In contrary to the early work of Nuttall et al., ${ }^{[163]}$ the basal plates of $\gamma^{\prime \prime}$ were proposed to have a hexagonal structure $(a=0.556 \mathrm{~nm}$, $c=0.521 \mathrm{~nm})$ in these recent studies. This structure is similar to the $\mathrm{Mg}_{5}(\mathrm{Ce}, \mathrm{Zn})$ phase (space group $\mathrm{P} \overline{6} 2 \mathrm{~m}$, $a=0.571 \mathrm{~nm}, \quad c=0.521 \mathrm{~nm}) .{ }^{[164]}$ The precipitates formed in aged samples of a Mg-2.5RE-0.5Zn (wt pct) alloy (MEZ) (Figures 17(c) and (d)) are similar to those in the $\mathrm{Mg}-\mathrm{Nd}-\mathrm{Zn}$ alloys. ${ }^{[156]}$

The equilibrium phase $\gamma$ was reported ${ }^{[163]}$ to have a face-centered cubic structure $(a=0.72 \mathrm{~nm})$ and an orientation relationship (011), // (0001) $\alpha$ and $[\overline{1} 11]_{\gamma} / /[2 \overline{1} \overline{1} 0]_{\alpha}$, and to form as rods with their long axes parallel to $\langle 10 \overline{1} 0\rangle_{\alpha}$ and $\langle 2 \overline{1} \overline{1} 0\rangle_{\alpha}$ directions. A more recent study ${ }^{[157]}$ confirmed the structure and orientation relationship proposed in the early study, but the morphology of the $\gamma$ phase was proposed to be plate. The habit plane of the $\gamma$ plate varies from plate to plate and is, therefore, irrational, but it is always parallel to the moiré plane defined by the intersection of $\{220\}_{\gamma}$ and $\{10 \overline{1} 0\}_{\alpha}$ planes, implying a coherent matching of these two sets of lattice planes within the habit plane. Note that the structure and the orientation relationship of the $\gamma$ phase are similar to those of the $\beta_{1}$ phase in the $\mathrm{Zn}$-free alloys, i.e., $\mathrm{Mg}-\mathrm{Nd}$ binary alloys. The incorporation of $\mathrm{Zn}$ into the precipitates leads to the reduction in the lattice parameter from $\sim 0.74 \mathrm{~nm}$ to $\sim 0.72 \mathrm{~nm}$, and the reduction in the lattice parameter leads to a change of the orientation of the precipitate plates to preserve the matching between the precipitate and matrix lattices.

\section{3. $M g-N d-A g$ alloys}

The ternary phase diagram of the $\mathrm{Mg}-\mathrm{Nd}-\mathrm{Ag}$ system is rather incomplete, ${ }^{[165]}$ and therefore, the equilibrium solid solubility of $\mathrm{Ag}$ in $\mathrm{Mg}$ and the equilibrium intermetallic phases in the $\mathrm{Mg}$-rich end of the $\mathrm{Mg}-\mathrm{Nd}-$ $\mathrm{Ag}$ system are both unclear. According to the $\mathrm{Mg}-\mathrm{Ag}$ binary phase diagram, the maximum equilibrium solid solubility of $\mathrm{Ag}$ in $\mathrm{Mg}$ is $\sim 15 \mathrm{wt}$ pct at the eutectic temperature of $745 \mathrm{~K}\left(472{ }^{\circ} \mathrm{C}\right)$, and it falls to approximately 2 wt pct at room temperature. The intermetallic phase at the $\mathrm{Mg}$-rich side of the phase diagram is $\mathrm{Mg}_{3} \mathrm{Ag}$ (space group $\mathrm{P}_{3} / \mathrm{mmc}, \quad a=0.488 \mathrm{~nm}$, $c=0.779 \mathrm{~nm})$. More than 50 years ago, Payne and Bailey ${ }^{[166]}$ found that the relatively low tensile strength of $\mathrm{Mg}-\mathrm{Nd}$ alloys could be considerably increased by Ag additions. This discovery subsequently led to the development of a commercial alloy designated QE22, Mg2Nd-2.5Ag-0.7Zr (wt pet). The alloy QE22 is age hardenable, and its aging curves at $423 \mathrm{~K}$ to $573 \mathrm{~K}$ $\left(150{ }^{\circ} \mathrm{C}\right.$ to $\left.300{ }^{\circ} \mathrm{C}\right)$ are shown in Figure $18 .^{[167]}$ Within the temperature and time selected, a maximum hardness value of $\sim 85 \mathrm{VHN}$ is obtainable when the alloy is aged at $423 \mathrm{~K}\left(150{ }^{\circ} \mathrm{C}\right)$. After the peak hardness is obtained at each temperature, the prolonged aging leads to only a slight reduction in hardness.

In the temperature range $473 \mathrm{~K}$ to $573 \mathrm{~K}\left(200{ }^{\circ} \mathrm{C}\right.$ to $300{ }^{\circ} \mathrm{C}$ ), the decomposition of the supersaturated solidsolution phase of $\alpha$-Mg in QE22 alloy was reported ${ }^{[5,151]}$ 


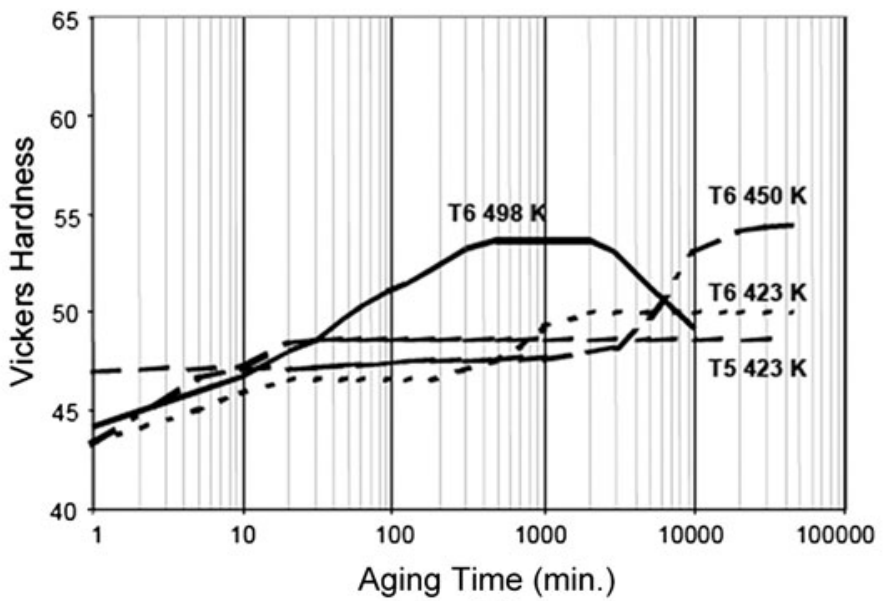

(a)

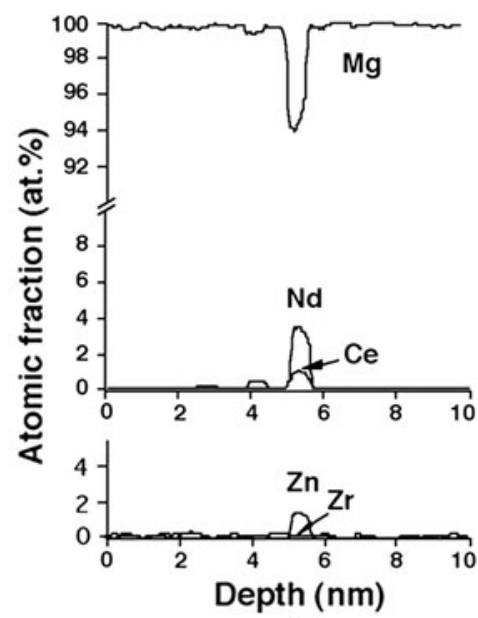

(b)

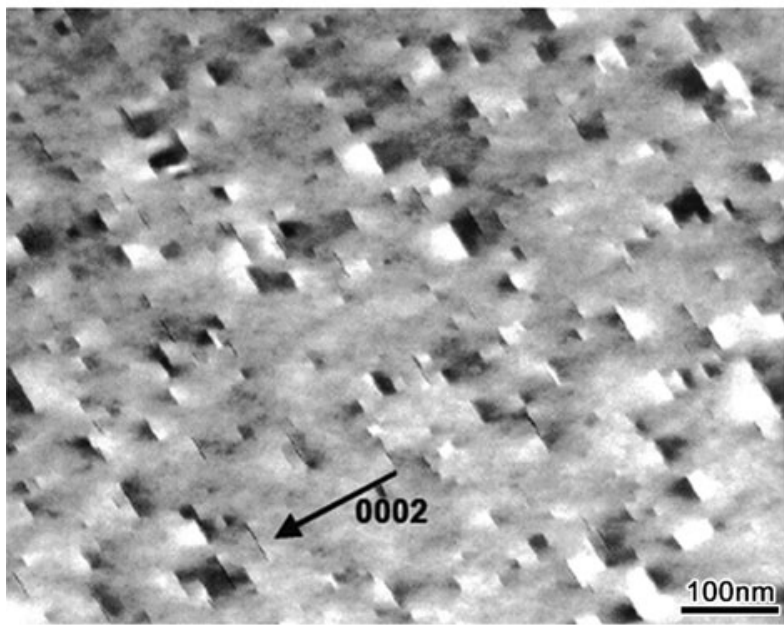

(c)

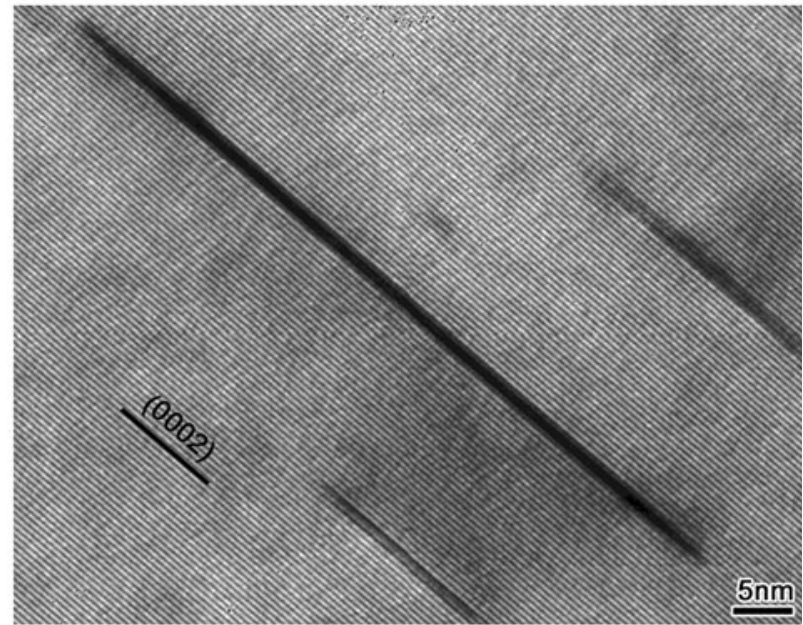

(d)

Fig. 17- (a) Age-hardening response of Mg-2.5 wt pet RE-0.5 wt pet Zn (MEZ) alloy at $423 \mathrm{~K}, 450 \mathrm{~K}$, and $498 \mathrm{~K}\left(150{ }^{\circ} \mathrm{C}, 177{ }^{\circ} \mathrm{C}\right.$, and $225{ }^{\circ} \mathrm{C}$ ). (b) 3DAP composition profile of ordered G.P. zones in a $\mathrm{Mg}-2.4$ wt pet RE- 0.4 wt pct $\mathrm{Zn}-0.6 \mathrm{wt}$ pct $\mathrm{Zr}$ alloy aged for $48 \mathrm{~h}$ at $473 \mathrm{~K}\left(200{ }^{\circ} \mathrm{C}\right)$. $(c$ and $d$ ) Transmission electron micrographs showing distribution and morphology of precipitates in the as-cast microstructure of MEZ alloy produced by sand-casting. (a and c) are reproduced from Ref. [156], and (b) is from Ref. [125].

to occur via two independent precipitation sequences. One sequence involves the formation of G.P. zones, in the form of $[0001]_{\alpha}$ rods, metastable $\gamma$ phase that also forms as $[0001]_{\alpha}$ rods, and the equilibrium phase $\left(\mathrm{Mg}_{12} \mathrm{Nd}_{2} \mathrm{Ag}\right)$ that has a lath morphology and a yet to be determined hexagonal structure. The other sequence has the formation of G.P. zones of an ellipsoid shape, the metastable $\beta$ phase of an equiaxed morphology, and the equilibrium phase $\mathrm{Mg}_{12} \mathrm{Nd}_{2} \mathrm{Ag}$. Gradwell ${ }^{[151]}$ proposed that both types of G.P. zones formed simultaneously during aging at temperatures up to $523 \mathrm{~K}$ $\left(250{ }^{\circ} \mathrm{C}\right)$. Without providing the transformation mechanisms, he further proposed that the rod-like G.P. zones transformed into the rod-shaped $\gamma$ phase, whereas that the ellipsoidal G.P. zones transformed into the equiaxed $\beta$ phase.

The metastable $\gamma$ phase reportedly has a hexagonal structure $(a=0.963 \mathrm{~nm}, c=1.024 \mathrm{~nm})$, but the orientation relationship between $\gamma$ and the magnesium matrix phase has not been reported. The metastable $\beta$ phase also has a hexagonal structure $(a=0.556 \mathrm{~nm}$, $c=0.521 \mathrm{~nm}$ ), and its orientation relationship with $\alpha-\mathrm{Mg}$ phase is such that $(0001)_{\beta} / /(0001)_{\alpha}$ and $[10 \overline{10}]_{\beta} / /[11 \overline{2} 0]_{\alpha}$. The equilibrium phase $\mathrm{Mg}_{12} \mathrm{Nd}_{2} \mathrm{Ag}$ was originally reported to have a complex hexagonal structure. ${ }^{[5,151]}$ But in two separate studies of alloy QE22, ${ }^{[168,169]}$ this equilibrium phase was inferred, without any strong supportive evidence, to be $(\mathrm{Mg}, \mathrm{Ag})_{12} \mathrm{Nd}$ that has a tetragonal structure $(a=1.03 \mathrm{~nm}$ and $c=0.59 \mathrm{~nm})$, i.e., isomorphous to that of $\mathrm{Mg}_{12} \mathrm{Nd}$. To establish the structures of all precipitate phases unambiguously, including that of the equilibrium precipitate phase, in the alloy QE22, it seems necessary to employ modern facilities such as atomic-resolution HAADF-STEM and electron microdiffraction in any efforts to be made in the future studies.

Gradwell ${ }^{[151]}$ studied the precipitation-hardening mechanism in QE22 by examining foils taken from specimens that had been strained 2 pct in tension after aging for various times at $473 \mathrm{~K}\left(200^{\circ} \mathrm{C}\right)$. He concluded that peak hardness coincided with the transition from precipitate cutting to Orowan looping and that 
maximum age hardening was associated with the presence of the $\gamma$ and $\beta$ precipitates. The alloy QE22 in the peak-aged condition has superior tensile properties and creep resistance over many other magnesium alloys. QE22 in its peak-aged condition exhibits a 0.2 pct proof strength of $205 \mathrm{MPa}$ at room temperature, $195 \mathrm{MPa}$ at $373 \mathrm{~K}\left(100{ }^{\circ} \mathrm{C}\right)$, and $165 \mathrm{MPa}$ at $473 \mathrm{~K}\left(200{ }^{\circ} \mathrm{C}\right)$ (Table II). The creep strength, the stress required to produce 0.2 pct creep strain in 500 hours, of this alloy is $135 \mathrm{MPa}$ at $423 \mathrm{~K}\left(150{ }^{\circ} \mathrm{C}\right)$ and $65 \mathrm{MPa}$ at $473 \mathrm{~K}$ $\left(200{ }^{\circ} \mathrm{C}\right) .{ }^{[170]}$ However, this alloy is relatively expensive and, thus, has limited applications only in the aircraft and aerospace industries.

\section{G. Mg-Gd-Based and Mg-Y-Based Alloys}

\section{Mg-Gd binary alloys}

The equilibrium solid solubility of Gd in magnesium is relatively high (4.53 at. pct or $23.49 \mathrm{wt}$ pct) at the eutectic temperature of $821 \mathrm{~K}\left(548{ }^{\circ} \mathrm{C}\right)$ and decreases exponentially with temperature to approximately

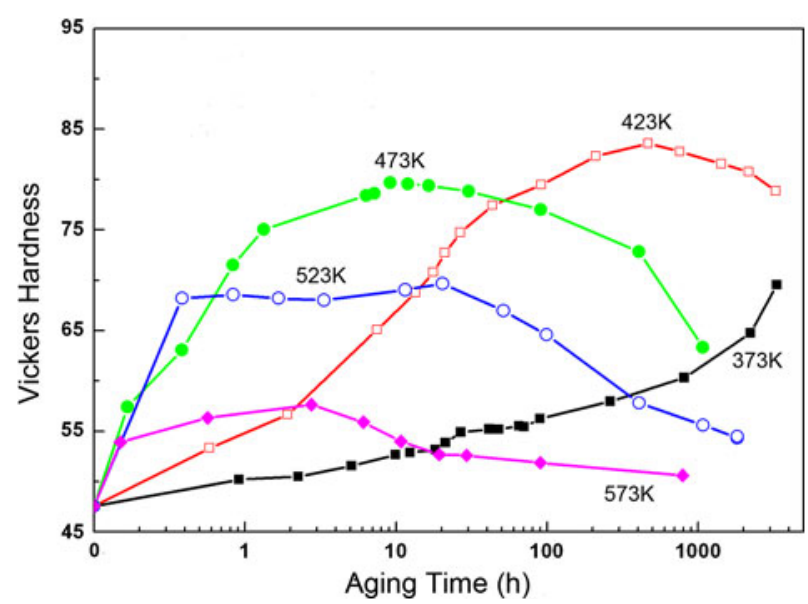

Fig. 18-Age-hardening response of $\mathrm{Mg}-2.1$ wt pct $\mathrm{Nd}-2.5$ wt pct Ag-0.7 wt pet $\mathrm{Zr}$ alloy (QE22) alloy at $373 \mathrm{~K}$ to $573 \mathrm{~K}\left(100{ }^{\circ} \mathrm{C}\right.$ to $\left.300{ }^{\circ} \mathrm{C}\right)^{[167]}$.
0.81 at. pct $\left(5.0 \mathrm{wt}\right.$ pct) at $523 \mathrm{~K}\left(250{ }^{\circ} \mathrm{C}\right)$ and to 0.61 at. pct $(3.82 \mathrm{wt}$ pct $)$ at $473 \mathrm{~K}\left(200^{\circ} \mathrm{C}\right),{ }^{[14]}$ forming an ideal system for precipitation hardening. ${ }^{[171]}$ However, binary $\mathrm{Mg}-\mathrm{Gd}$ alloys containing less than 10 wt pet Gd show little or no precipitation-hardening response during isothermal or isochronal aging of supersaturated solid solutions of these alloys. ${ }^{[172,173]}$ It is often necessary to increase the Gd concentration to the range 10 to $20 \mathrm{wt}$ pct to enhance the precipitationhardening response. ${ }^{[173-176]}$ The aging curve of a $\mathrm{Mg}-$ $15 \mathrm{Gd}-0.5 \mathrm{Zr}$ (wt pct) alloy is shown in Figure 19(a). ${ }^{[177]}$ The hardness value in the as-quenched condition is over $70 \mathrm{VHN}$, which is substantially higher than that of the magnesium alloys described in previous sections. This relatively high value of hardness is the result of solidsolution strengthening in a supersaturated magnesium matrix. It was demonstrated recently ${ }^{[176]}$ that an appreciably high 0.2 pet proof strength of $445 \mathrm{MPa}$ can be achieved in a Mg-14 wt pet Gd-0.5 wt pet $\mathrm{Zr}$ alloy when this alloy is produced by the combined processes of hot extrusion, cold work, and aging (Table II).

The precipitates in $\mathrm{Mg}-\mathrm{Gd}$ binary alloys containing more than $10 \mathrm{wt}$ pct Gd were studied in recent years by conventional transmission electron microscopy ${ }^{[177]}$ and HAADF-STEM. ${ }^{[178,179]}$ The precipitation sequence is now generally accepted ${ }^{[177]}$ to involve the formation of $\beta^{\prime \prime}$, $\beta^{\prime}, \beta_{1}$, and $\beta$ phases, which is similar to that originally proposed for Mg-Y-Nd based alloys. ${ }^{[180]}$ The metastable $\beta^{\prime \prime}$ phase has an ordered D0 ${ }_{19}$ structure $(a=0.641 \mathrm{~nm}$, $c=0.521 \mathrm{~nm})$. The orientation relationship between $\beta^{\prime \prime}$ and $\alpha-\mathrm{Mg}$ phases is such that $[0001]_{\beta^{\prime \prime}} / /[0001]_{\alpha}$ and $\{2 \overline{1} \overline{1} 0\}_{\beta^{\prime \prime}} / /\{2 \overline{1} \overline{1} 0\}_{\alpha}$. The $\beta^{\prime \prime}$ precipitates were originally reported to have a plate-like morphology, with their habit plane almost parallel to $\{2 \overline{1} 10\}_{\alpha}$. However, this morphology is not consistent with experimental observations made by HAADF-STEM images obtained in recent years (Figure 19(b)). ${ }^{[178]}$ The metastable $\beta^{\prime}$ phase usually forms as lenticular particles with their broad surface parallel to $\{2 \overline{1} 10\}_{\alpha}$ (Figure 19(c)). ${ }^{[178]}$ It has a base-centered orthorhombic Bravais lattice ( $a=0.650 \mathrm{~nm}, b=2.272 \mathrm{~nm}$, and $c=0.521 \mathrm{~nm}$ ) and an orientation relationship with respect to the matrix phases: $(100)_{\beta^{\prime}} / /(1 \overline{2} 10)_{\alpha}$ and

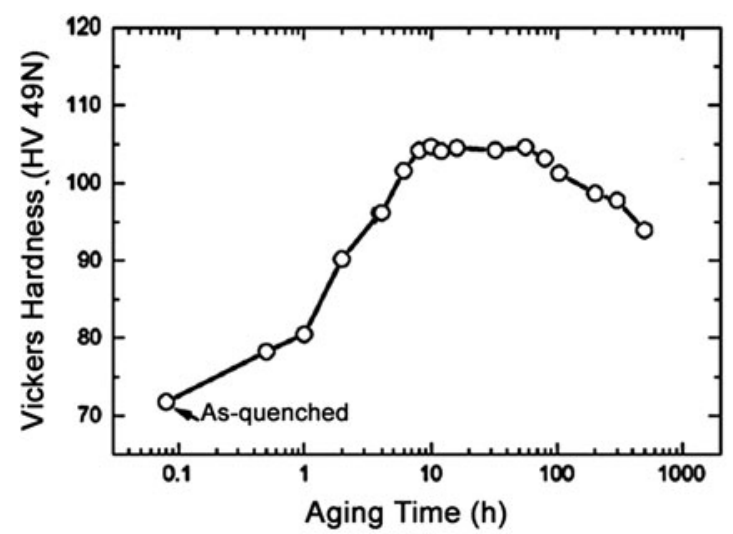

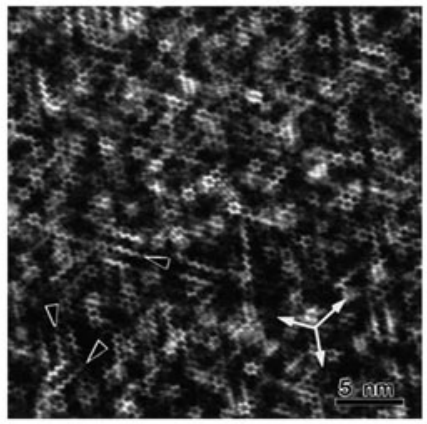

(b)

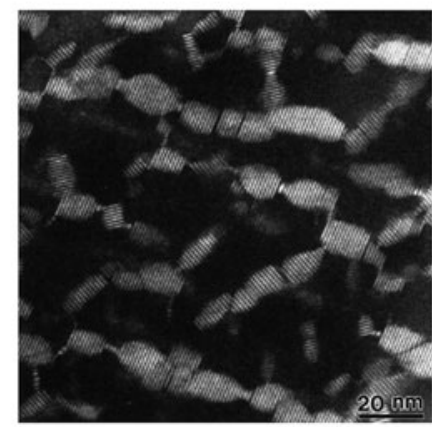

(c)

(a)

Fig. 19-(a) Age-hardening response of Mg-15Gd-0.5Zr (wt pct) alloy at $523 \mathrm{~K}\left(250{ }^{\circ} \mathrm{C}\right)$ (adapted from Ref. [177]). (b and $c$ ) HAADF-STEM images showing distribution and morphology of precipitates in $\mathrm{Mg}-5$ at. pct $\mathrm{Gd}$ alloy aged at $473 \mathrm{~K}\left(200{ }^{\circ} \mathrm{C}\right)$ for $5 \mathrm{~h}$ and $10 \mathrm{~h}$, respectively (reproduced from Ref. [178]). Electron beam is parallel to [0001] $]_{\alpha}$ in (b and c). 
$[001]_{\beta^{\prime}} / /[0001]_{\alpha}$. Based on the analysis made from atomic-resolution HAADF-STEM images (Figure 20(a)), ${ }^{[179]}$ an atomic structure of the $\beta^{\prime}$ phase was proposed, (Figures 20(b) and (c)). ${ }^{[179]}$ The zigzag arrays of $\mathrm{Gd}$ atoms in the unit cell, indicated by dotted line, are consistent with those of bright dots in atomicresolution HAADF-STEM images. The composition of the $\beta^{\prime}$ phase inferred from this model is $\mathrm{Mg}_{7} \mathrm{Gd}$. The $\beta_{1}$ phase $^{[177]}$ has a face-centered cubic structure that is isomorphous to that of the $\beta_{1}$ phase in WE54 alloy, ${ }^{[180]}$ which has the $\mathrm{Mg}_{3} \mathrm{Nd}$ or $\mathrm{Mg}_{3} \mathrm{Gd}$ structure (space group Fm $\overline{3} \mathrm{~m}, a=0.74 \mathrm{~nm}$ ). The orientation relationship is such that $(\overline{1} 12)_{\beta_{1}} / /(10 \overline{1} 0)_{\alpha}$ and $[110]_{\beta_{1}} / /[0001]_{\alpha}$, and its habit plane is parallel to $\{10 \overline{10}\}_{\alpha}$. Precipitates of the equilibrium $\beta$ phase have a face-centered cubic structure (space group F $\overline{4} 3 \mathrm{~m}, a=2.2 \mathrm{~nm}$ ) and a $\mathrm{Mg}_{5} \mathrm{Gd}$ composition. The orientation relationship of the $\beta$ phase with $\alpha-\mathrm{Mg}$ is $(110)_{\beta} / /(0001)_{\alpha}$ and $[1 \overline{1} 1]_{\beta} / /[2 \overline{1} 10]_{\alpha}$. The $\beta$ phase forms as plates parallel to $\{10 \overline{10}\}_{\alpha} \cdot{ }^{[177]}$

\section{2. $M g-Y$ binary alloys}

The Mg-rich part of the Mg-Y binary phase diagram indicates that the maximum solid solubility of $\mathrm{Y}$ in magnesium is 3.75 at. pct (12.5 wt pct) at $839 \mathrm{~K}$ $\left(566^{\circ} \mathrm{C}\right.$ ) (the eutectic temperature), and it decreases to 0.75 at. pet $\left(2.69 \mathrm{wt}\right.$ pct) $\mathrm{Y}$ at $473 \mathrm{~K}\left(200{ }^{\circ} \mathrm{C}\right)$. The equilibrium intermetallic phase $\beta$ has a composition of $\mathrm{Mg}_{24} \mathrm{Y}_{5}$ and a body-centered cubic structure (space group $\mathrm{I} \overline{4} 3 \mathrm{~m}, a=1.128 \mathrm{~nm})$. The equilibrium volume fraction of precipitates achievable at $473 \mathrm{~K}\left(200^{\circ} \mathrm{C}\right)$ is approximately 4.5 pet for a Mg-5 wt pet Y alloy and 10.6 pet for a Mg-8 wt pct Y composition. The age-hardening response of binary $\mathrm{Mg}-\mathrm{Y}$ alloys is remarkable when the $\mathrm{Y}$ concentration in the alloy is at or above $8 \mathrm{wt}$ pct and the aging treatment is carried out at a temperature close to $473 \mathrm{~K}\left(200{ }^{\circ} \mathrm{C}\right)^{[181,182]}$ (Figure 21(a)), even though the hardening kinetics are sluggish during the first 100 hours aging at $473 \mathrm{~K}\left(200{ }^{\circ} \mathrm{C}\right)$.

The precipitate phases formed during isothermal aging of $\mathrm{Mg}-\mathrm{Y}$ binary alloys were reported ${ }^{[5]}$ to include $\beta^{\prime \prime}, \beta^{\prime}$, and $\beta$. The $\beta^{\prime \prime}$ phase has a base-centered orthorhombic lattice $(a=0.64 \mathrm{~nm}, b=2.223 \mathrm{~nm}$, and $c=0.521 \mathrm{~nm})^{[150]}$ and an orientation relationship $(001)_{\beta^{\prime \prime}} / /(0001)_{\alpha},[100]_{\beta^{\prime \prime}} / /\{\overline{2} 110\}_{\alpha}$. Because the structures of $\beta^{\prime}$ and $\beta^{\prime \prime}$ phases were reported to be the same, ${ }^{[5]}$ it is appropriate, at least currently, to merge the $\beta^{\prime \prime}$ and $\beta^{\prime}$ phases into $\beta^{\prime}$ in the precipitation sequence. The morphology of the $\beta^{\prime}$ in a $\mathrm{Mg}-2$ at. pct $\mathrm{Y}$ alloy (Figure 21(b) $)^{[183]}$ is remarkably different from that in a Mg-5 at. pct Gd alloy (Figure 19(a)) even though the structure of $\beta^{\prime}\left(\mathrm{Mg}_{7} \mathrm{Y}\right)$ in the $\mathrm{Mg}-2$ at. pet $\mathrm{Y}$ alloy is reportedly the same as that in the $\mathrm{Mg}-5$ at. pct $\mathrm{Gd}$ alloy (Figures 19(b) and (c)). The difference was attributed to the difference between lattice parameters of $\mathrm{Mg}_{7} \mathrm{Gd}(a=0.650 \mathrm{~nm}, b=2.272 \mathrm{~nm}$, and $c=$ $0.521 \mathrm{~nm}$ ) and $\mathrm{Mg}_{7} \mathrm{Y}$ structures, which results in different lattice misfits with $\mathrm{Mg}$ matrix. ${ }^{[183]}$

Precipitates of the equilibrium phase $\beta$ have a plate shape. The orientation relationship between $\beta$ and magnesium matrix phase is exact Burgers with habit plane of the $\beta$ plates parallel to $\{10 \overline{10}\}_{\alpha}$ or near Burgers

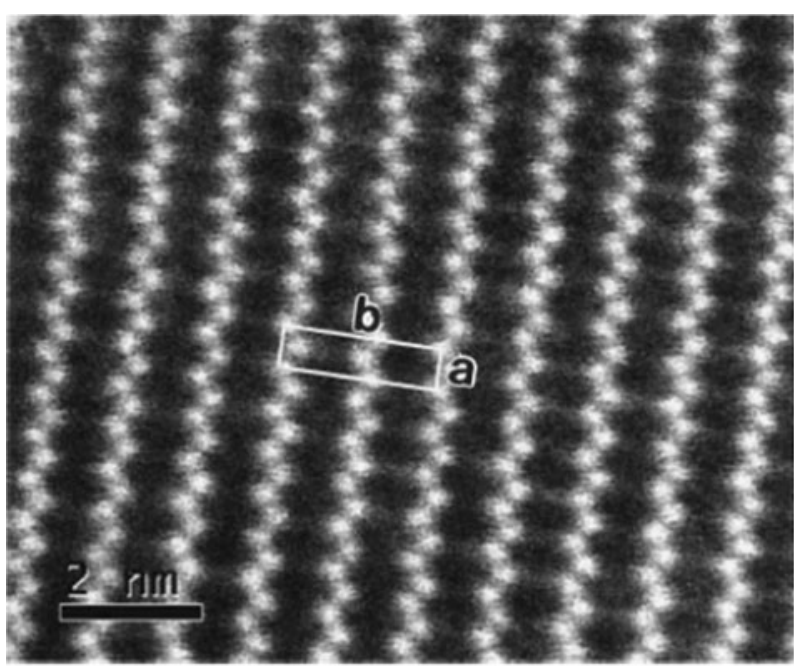

(a)

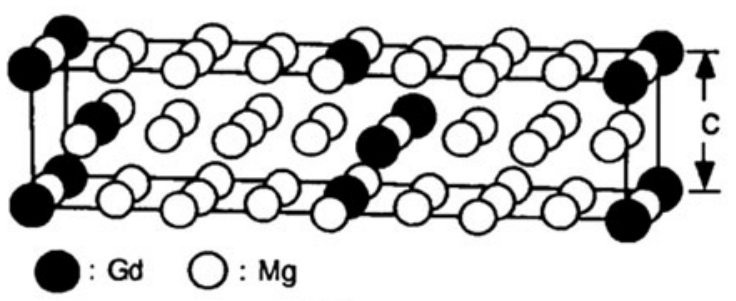

(b)

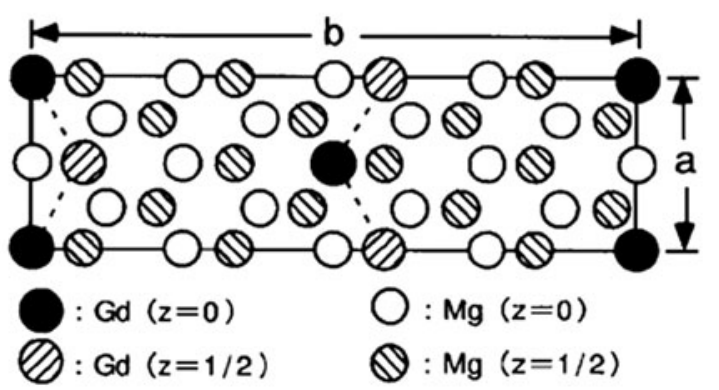

(c)

Fig. 20-(a) [001] Atomic-resolution HAADF-STEM image and $\left(b\right.$ and $c$ ) unit cell of $\beta^{\prime}$ phase in $\mathrm{Mg}-5$ at. pct Gd alloy (reproduced from Ref. [179]).

with the plate habit plane parallel to $\{31 \overline{4} 0\}_{\alpha}$ (Figure 21(c)). ${ }^{[184]}$

\section{3. $M g-Y-N d$ and $M g-G d-N d$ alloys}

The age-hardening response of $\mathrm{Mg}-\mathrm{Y}-\mathrm{Nd}$ alloys is much higher than that of counterpart $\mathrm{Mg}-\mathrm{Y}$ and $\mathrm{Mg}-\mathrm{Nd}$ binary alloys. ${ }^{[185,186]}$ The most successful commercial magnesium alloys developed to date via precipitation hardening, in terms of strength and creep resistance, have been WE54 (Mg-5 wt pet Y-2 wt pet Nd-2 wt pct HRE) and WE43 alloys based on the Mg-Y-Nd system $^{[6,187,188]}$ (Table II). The aging curves of magnesium alloy WE54 at $523 \mathrm{~K}$ and $473 \mathrm{~K}\left(250{ }^{\circ} \mathrm{C}\right.$ and $\left.200{ }^{\circ} \mathrm{C}\right)$ are shown in Figure 22. ${ }^{[189]}$ The hardness value in the as-quenched condition is $68 \mathrm{VHN}$, which is close to that of the $\mathrm{Mg}-15 \mathrm{Gd}-0.5 \mathrm{Zr}$ (wt pet) alloy shown in Figure 19(a), even though the total concentration of 


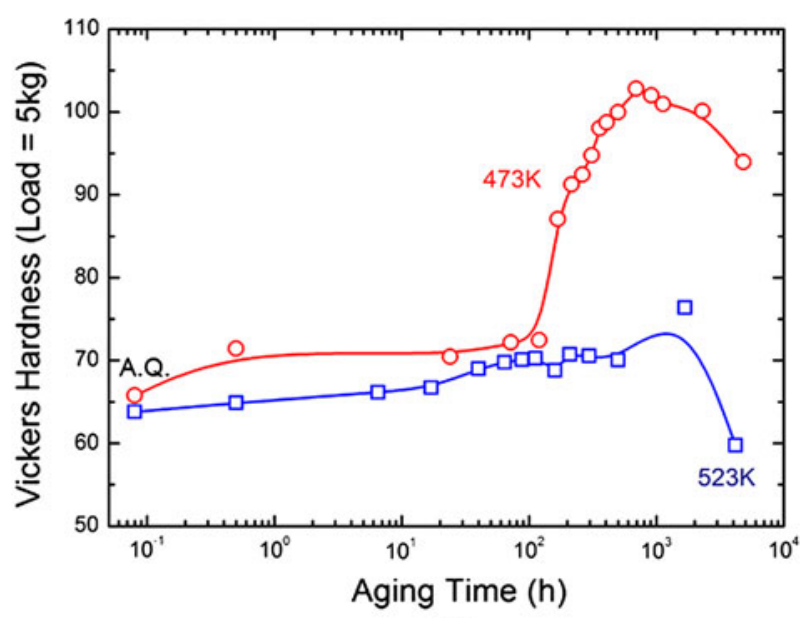

(a)

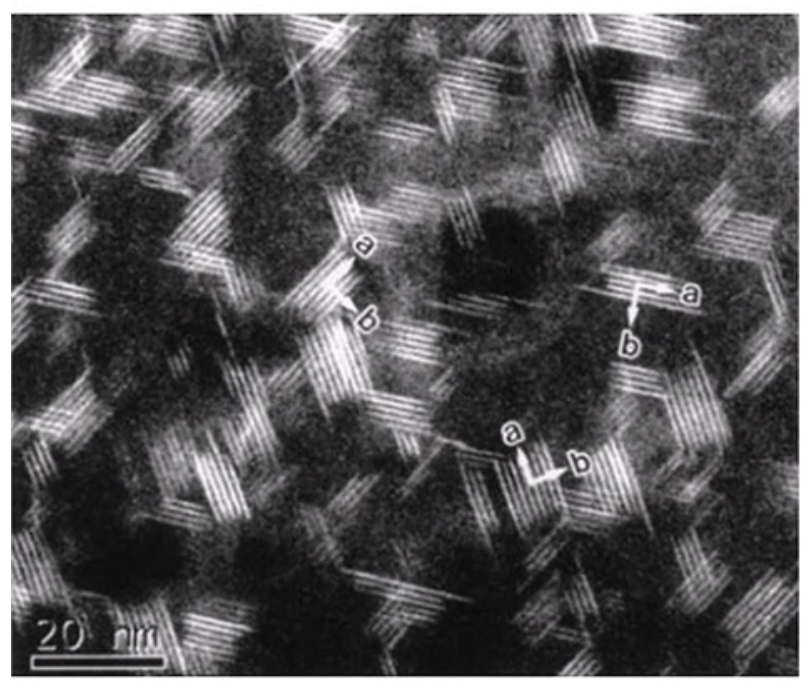

(b)

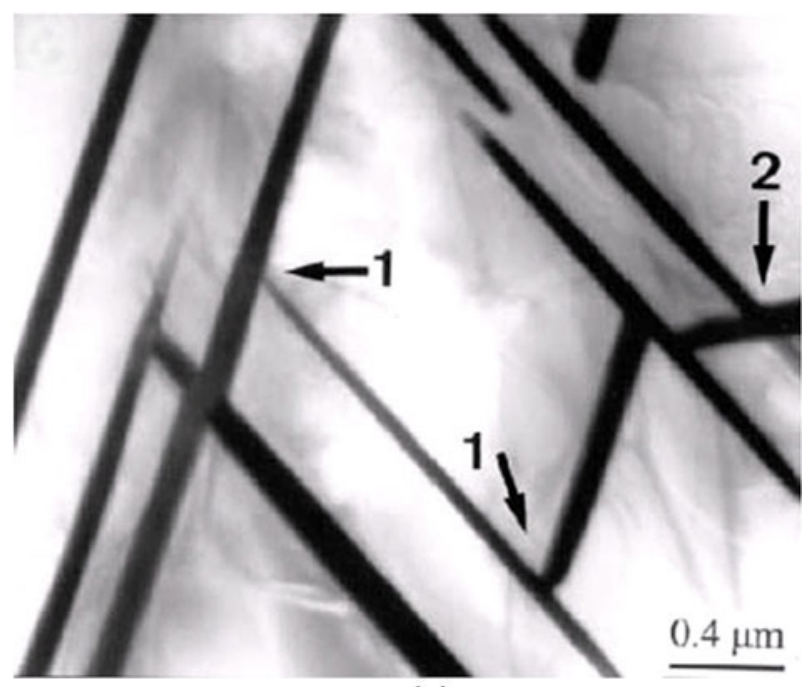

(c)

Fig. $21-(a)$ Aging curve of $\mathrm{Mg}-8 \mathrm{wt}$ pct $\mathrm{Y}$ alloy at $473 \mathrm{~K}$ and $523 \mathrm{~K}\left(200^{\circ} \mathrm{C}\right.$ and $\left.250{ }^{\circ} \mathrm{C}\right)$. (b) HAADF-STEM image of $\beta^{\prime}$ precipitates in $\mathrm{Mg}-2$ at. pct $\mathrm{Y}$ alloy (reproduced from Ref. [183]). (c) TEM image showing $\beta$ precipitate plates in $\mathrm{Mg}-10.2 \mathrm{wt}$ pct $\mathrm{Y}$ alloy, solution treated for $24 \mathrm{~h}$ at $823 \mathrm{~K}\left(550{ }^{\circ} \mathrm{C}\right)$, water quenched, and then aged for 24 hours at $623 \mathrm{~K}\left(350^{\circ} \mathrm{C}\right)$ (reproduced from Ref. [184]). alloying additions is approximately $9 \mathrm{wt}$ pct. Cold work of this alloy by 6 pct, after solution treatment and prior to aging, can raise the hardness of as-quenched samples to 75 VHN. Only a slight increase in hardness is obtained when the level of plastic deformation is increased from 6 pct to 12 pct. During isothermal aging at $523 \mathrm{~K}\left(250{ }^{\circ} \mathrm{C}\right)$, the hardness of the undeformed sample increases gradually to a plateau hardness of 87 VHN after 24 hours. In contrast, the sample with 6 pct deformation reaches a maximum hardness of $\sim 97$ VHN in 8 hours and that with 12 pet deformation achieves a maximum hardness of $\sim 94$ VHN in 4 hours. Therefore, it is possible to obtain higher hardness values in much shorter aging time by cold work. With prolonged aging at $523 \mathrm{~K}\left(250{ }^{\circ} \mathrm{C}\right)$, the difference in hardness between undeformed and deformed samples diminishes gradually. Higher hardness values can be obtained for both undeformed and deformed samples at $473 \mathrm{~K}\left(200{ }^{\circ} \mathrm{C}\right)$ (Figure $\left.22(\mathrm{~b})\right)$. Although the precipitation-hardening response of deformed samples is accelerated, the maximum hardness achievable at $473 \mathrm{~K}$ $\left(200{ }^{\circ} \mathrm{C}\right)$ is not affected significantly by cold work. A maximum hardness between 106 and $110 \mathrm{VHN}$ is achieved at $473 \mathrm{~K}\left(200{ }^{\circ} \mathrm{C}\right)$ for both deformed and undeformed samples.

The microstructure of the undeformed sample aged for 24 hours at $523 \mathrm{~K}\left(250{ }^{\circ} \mathrm{C}\right)$, which is close to the peak-aged condition, is shown in Figure 22(c). It has a relative coarse distribution of $\{1100\}_{\alpha}$ plates of $\beta_{1}$ phase, with globular $\beta^{\prime}$ particles attached to the two ends of each of the prismatic plates. In contrast, the $\{1 \overline{1} 00\}_{\alpha}$ precipitate plates formed samples deformed by 6 pet prior to 4 hours aging at $523 \mathrm{~K}\left(250{ }^{\circ} \mathrm{C}\right)$ have much larger diameter and higher number density, and the number density of globular particles of $\beta^{\prime}$ is significantly reduced (Figure 22(d)). Apparently, the dislocations introduced by the cold work promote the nucleation the growth of the $\{1 \overline{1} 00\}_{\alpha}$ precipitate plates at the expense of $\beta^{\prime}$ phase. Observations made by transmission electron microscopy ${ }^{[189]}$ indicate that $\beta_{1}$ precipitates form heterogeneously on preexisting dislocations, similar to the intermediate precipitate phase $\mathrm{Mg}_{3} X(X=\mathrm{Nd}, \mathrm{Ce}$, or $\mathrm{MM})$ in $\mathrm{Mg}-\mathrm{Nd}, \mathrm{Mg}-\mathrm{Ce}$, and $\mathrm{Mg}-\mathrm{MM}$ alloys that also nucleate preferentially on dislocations. The comparison of the microstructures and aging curves of the undeformed and deformed samples indicates that the remarkable increase in hardness, from $75 \mathrm{VHN}$ in undeformed samples to $93 \mathrm{VHN}$ in deformed samples, is associated with the formation of $\{1 \overline{1} 00\}_{\alpha}$ precipitate plates of larger diameter and higher number density. As discussed in Section III, an increase in the prismatic plate diameter, number density, or a combination of both, can effectively reduce interparticle spacing and, therefore, increase hardness or strength.

The T6 condition of alloy WE54 typically involves a solution treatment of 8 hours at $798 \mathrm{~K}\left(525^{\circ} \mathrm{C}\right)$, a hot water quench, and a subsequent aging treatment of 16 hours at $523 \mathrm{~K}\left(250{ }^{\circ} \mathrm{C}\right) .^{[188,190]}$ The aged microstructure at maximum hardness was initially reported $^{[5,188]}$ to contain metastable $\beta^{\prime}$ and equilibrium $\beta$ phases as dispersed precipitates, and both phases were described to form as plates on $\{1 \overline{100}\}_{\alpha}$ planes of the 


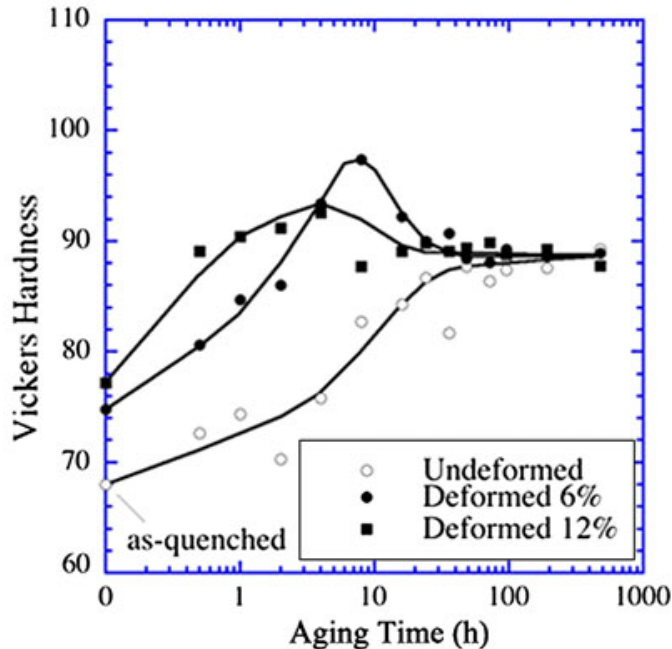

(a)

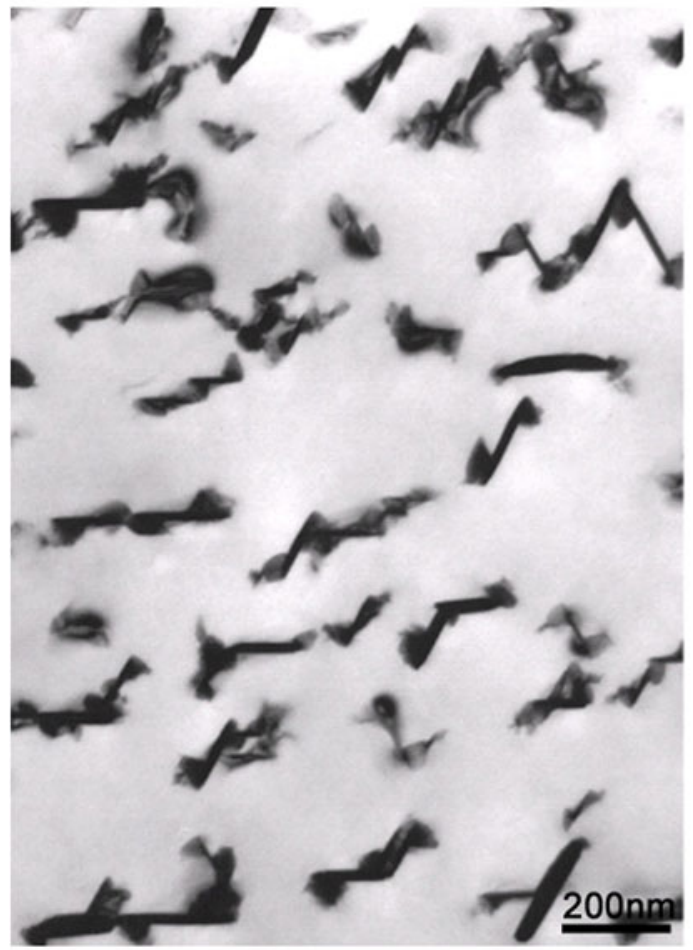

(c)

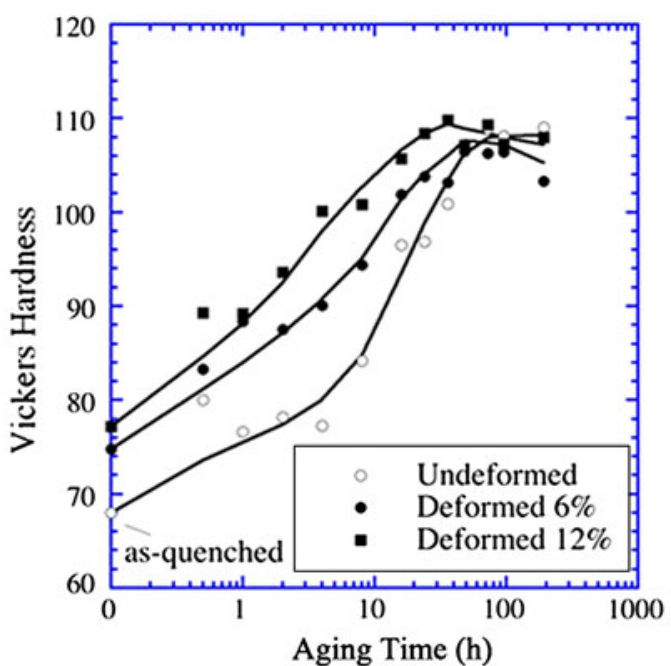

(b)

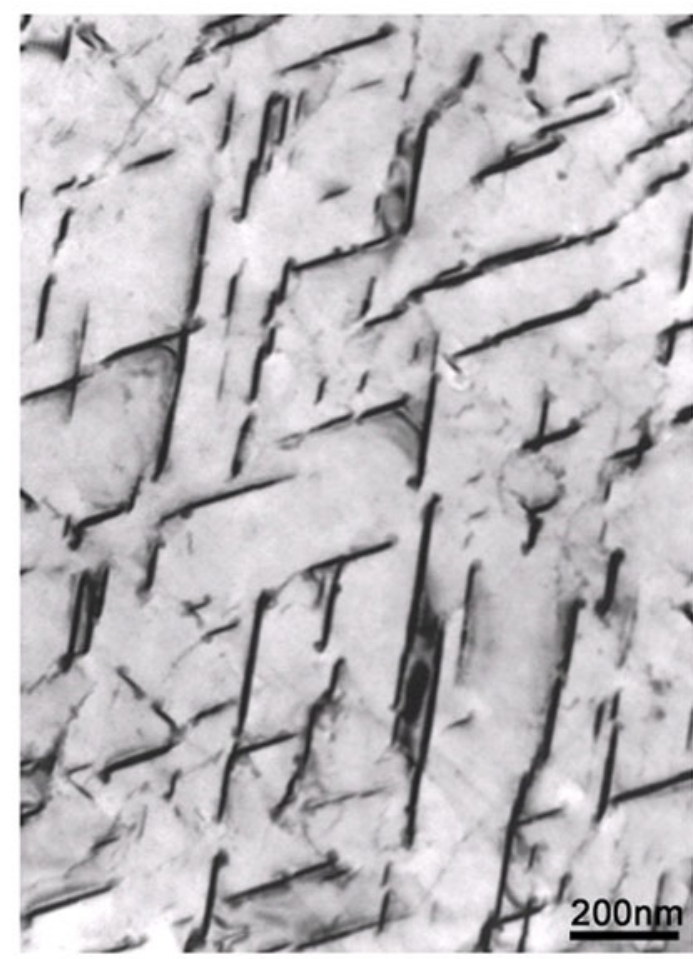

(d)

Fig. 22-Age-hardening response of WE54 alloy at $(a) 523 \mathrm{~K}\left(250{ }^{\circ} \mathrm{C}\right)$ and $(b) 473 \mathrm{~K}\left(200{ }^{\circ} \mathrm{C}\right)$. ( $c$ and $\left.d\right)$ Transmission electron micrographs showing distribution of precipitates in (c) samples peak-aged at $523 \mathrm{~K}\left(250{ }^{\circ} \mathrm{C}\right)$, and (d) samples cold-worked 6 pct after water quench and then aged to peak hardness at $523 \mathrm{~K}\left(250^{\circ} \mathrm{C}\right)$. Reproduced from Ref. [189].

magnesium matrix phase. In early studies, the $\beta^{\prime}$ phase was reported to have a $\mathrm{Mg}_{12} \mathrm{NdY}$ composition ${ }^{[190,191]}$ and a base-centered orthorhombic structure $(a=0.640 \mathrm{~nm}, \quad b=2.223 \mathrm{~nm}, \quad c=0.521 \mathrm{~nm}) .^{[5,150]}$ The orientation relationship of $\beta^{\prime}$ was reported to have the form $(100)_{\beta^{\prime}} / /(1 \overline{2} 10)_{\alpha},[001]_{\beta^{\prime}} / /[0001]_{\alpha}$. The proposed structure and orientation of the $\beta^{\prime}$ phase are similar to those of the $\beta^{\prime}$ formed in binary $\mathrm{Mg}-\mathrm{Y}$ alloys. ${ }^{[5]}$ The $\beta$ phase was reported to have a $\mathrm{Mg}_{14} \mathrm{Nd}_{2} \mathrm{Y}$ composition $^{[191]}$ and a face-centered cubic structure $(a=2.223 \mathrm{~nm}) .^{[5,150]}$ The orientation relationship between $\beta$ and $\alpha-\mathrm{Mg}$ matrix is such that $(\overline{1} 12)_{\beta} / /(1 \overline{1} 00)_{\alpha}$, $[110]_{\beta} / /[0001]_{\alpha}$, which is identical to that observed between $\beta^{\prime}$ and $\alpha-\mathrm{Mg}$ in binary $\mathrm{Mg}-\mathrm{Nd}$ alloys. ${ }^{[150]}$

In the following years, several studies ${ }^{[180,192-195]}$ have been made to use modern facilities to characterize the precipitates in aged samples of WE54 and WE43. It was reported $^{[193,194]}$ that during the early stage of aging of WE43 alloy, monolayer precipitates with a $\mathrm{D}_{19}$ ordering form with two possible habit planes: $\{11 \overline{2} 0\}_{\alpha}$ and $\{1 \overline{100}\}_{\alpha}$, and that the precursor $\{11 \overline{2} 0\}_{\alpha}$ monolayers form the $\beta^{\prime \prime}\left(\mathrm{D} 0_{19}\right)$ phase whereas the precursor $\{1 \overline{1} 00\}_{\alpha}$ monolayers led to the formation of the $\beta^{\prime}$ phase. However, the similarity between these $\mathrm{Mg}-\mathrm{Y}-\mathrm{Nd}$-based 
alloys and $\mathrm{Mg}-\mathrm{Gd}$ alloys suggests that the precipitation in the early stage of the WE alloys is likely to be similar to that in Mg-Gd alloys (Table I). Figure 23(a) shows the microstructure typical of samples aged to maximum hardness (48 hours at $523 \mathrm{~K}\left[250{ }^{\circ} \mathrm{C}\right]$ ). The microstructure contains a dispersion of plate-shaped precipitates in contact with irregular, globular particles. An examination of electron microdiffraction patterns obtained from individual globular precipitate indicates that these particles are $\beta^{\prime}$ phase and that the structure and orientation relationships proposed for the $\beta^{\prime}$ phase in early studies are correct. However, the observed morphology of the $\beta^{\prime}$ phase is clearly different from that from previous suggestions, ${ }^{[5,150]}$ i.e., $\beta^{\prime}$ forms as plates parallel to $\{1 \overline{100}\}_{\alpha}$.
In contrast to the early studies, Nie and Muddle ${ }^{[180]}$ reported that the $\{1 \overline{1} 00\}$, plates have a face-centered cubic structure, with $a \sim 0.74 \mathrm{~nm}$, and an orientation relationship that is of the form $(\overline{1} 12)_{\beta_{1}} / /(1 \overline{1} 00)_{\alpha}$, $[110]_{\beta_{1}} / / /[0001]_{\alpha}$. This phase was designated $\beta_{1}$ because it had not been reported previously in WE alloys. The structure $\beta_{1}$ is similar to that of $\mathrm{Mg}_{3} X$ phase $(X=\mathrm{Nd}$, $\mathrm{La}, \mathrm{Ce}, \mathrm{Gd}, \mathrm{Pr}, \mathrm{Dy}$, and Sm), which has a face-centered cubic structure (space group Fm $\overline{3} \mathrm{~m}, \quad a=0.74 \pm$ $0.01 \mathrm{~nm})$ and form exclusively as $\{1 \overline{1} 00\}_{\alpha}$ plates. ${ }^{[149,153,154]}$ The $\beta_{1}$ phase invariably forms jointly with other particles, either with $\beta^{\prime}$ precipitates such as that shown in Figure 23(a) or with themselves in the form of triads (Figure 23(b)). In the latter case, the magnesium matrix region isolated by the three $\beta_{1}$

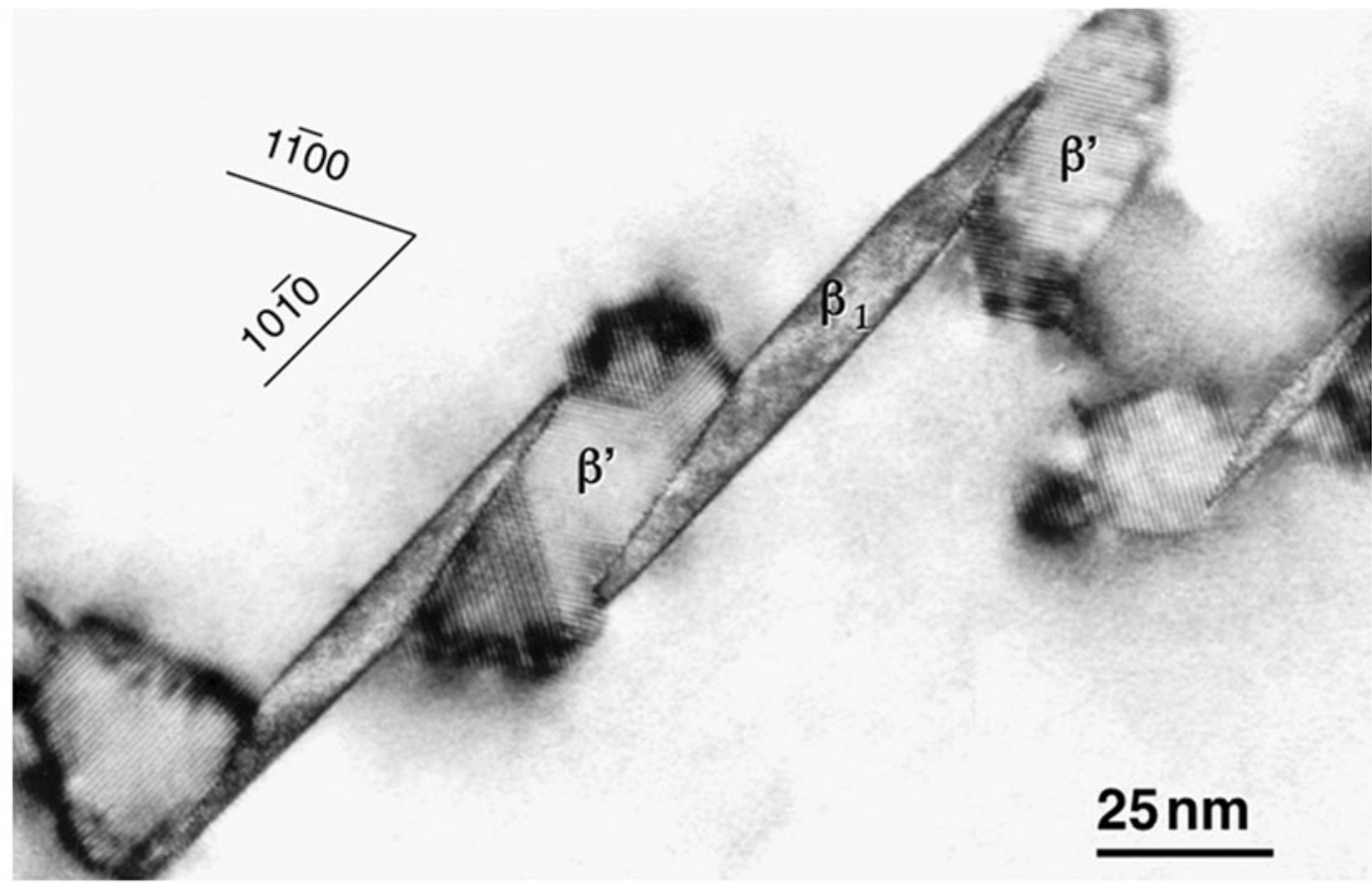

(a)

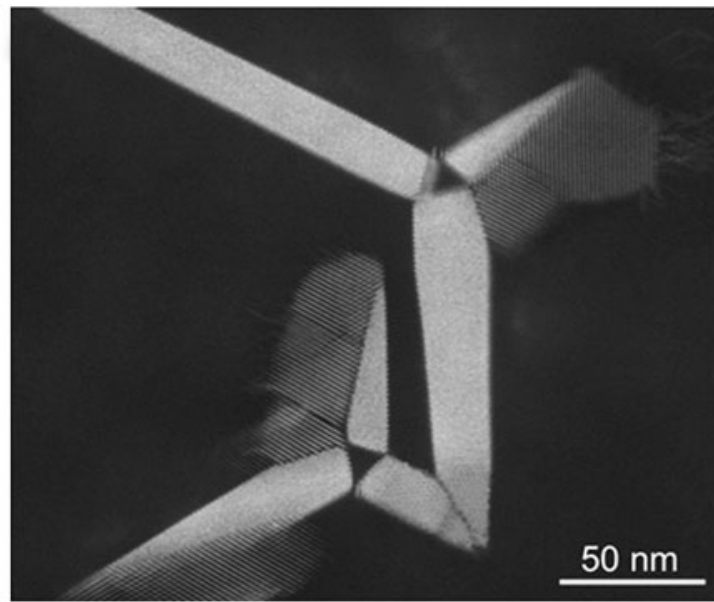

(b)

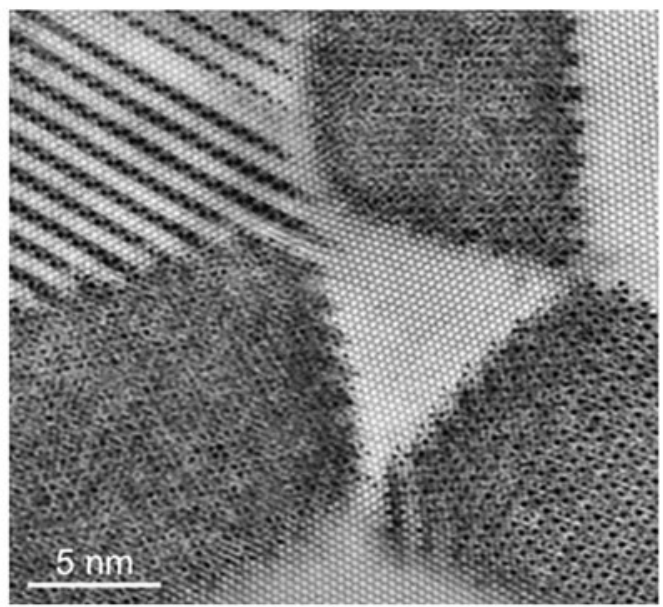

(c)

Fig. 23-(a) Conventional TEM and (b) HAADF-STEM images showing the arrangement of $\beta^{\prime}$ and $\beta_{1}$ precipitates in peak-aged samples of WE54 alloy. (c) HAADF-STEM image showing an enlargement of (b). (a) is reproduced from Ref. [180], and (b and c) is from Ref. [196]. 
variants is rotated by approximately $10.5 \mathrm{deg}$ (Figure 23(c)). ${ }^{[196]}$ These observations indicate that the formation of $\beta_{1}$ phase involves a large shear strain, ${ }^{[180]}$ which will be discussed in Section IV. The $\{1 \overline{100}\}$, plates of $\beta_{1}$ transform in situ to the equilibrium phase $\beta$ during prolonged aging at $523 \mathrm{~K}\left(250^{\circ} \mathrm{C}\right)$. Examination of pattern symmetries in the higher order Laue zone and zero order Laue zone patterns recorded from the $\beta$ plates, together with recognition of absent reflections in the observed electron microdiffraction patterns, indicates a space group of $\mathrm{F} \overline{4} 3 \mathrm{~m}(a=2.2 \pm 0.1 \mathrm{~nm})$. This structure is isomorphous with $\mathrm{Mg}_{5} \mathrm{Gd}$. The orientation relationship is similar to that observed between $\beta_{1}$ and the matrix phase.

The age-hardening response and precipitation in $\mathrm{Mg}$ 7Gd-2.3Nd-0.6Zr and $\mathrm{Mg}-7 \mathrm{Dy}-2.3 \mathrm{Nd}-0.6 \mathrm{Zr}$ (wt pet) alloys have been studied and compared with those in a Mg-4Y-2.3Nd-0.6Zr (wt pct) alloy. ${ }^{[197]}$ Among the three alloys examined, the greatest age-hardening response is found in the Gd-containing alloy. The $\beta_{1}$ phase is also confirmed to occur in the Mg-Gd-Nd-Zr and Mg-Dy$\mathrm{Nd}-\mathrm{Zr}$ alloys, and the structures and morphologies of precipitates and the precipitation sequences in the three alloys are identical.

\section{Mg-Gd-Y-based alloys}

The Mg-Gd-Y alloys have received considerable interest in recent years because of their potential in achieving higher strength and better creep resistance. The Gd:Y atomic ratio in these alloys is important. When the Gd:Y atomic ratio is in the range 3:1 to $1: 1$ and the total concentration of the alloying additions is 2.75 at. pct, the tensile yield strengths of the Mg-Gd-Y alloys are lower than that of the counterpart $\mathrm{Mg}-\mathrm{Gd}$ binary alloy and higher than that of the counterpart Mg-Y binary alloy. ${ }^{[198]}$ The T5 samples of the hot-rolled Mg-Gd-Y alloys have superior tensile strengths to commercial WE54 alloy. The aging curves of two representative alloys in this category are shown in Figures 24(a) and (b). ${ }^{[199,200]}$ The effects of $\mathrm{Zn}$ additions are also shown in Figure 24(b). In general, the additions of $\mathrm{Zn}$ reduce the age-hardening response of these alloys. When the $\mathrm{Zn}$ content is over 1.5 to 2.0 at. pct, the agehardening response of the resultant $\mathrm{Mg}-\mathrm{Gd}-\mathrm{Y}-\mathrm{Zn}$ alloys diminishes completely. ${ }^{[201]}$ However, an impressively high value of $473 \mathrm{MPa}$ has been achieved for the $0.2 \mathrm{pct}$ proof strength in an extruded and aged $\mathrm{Mg}-1.8 \mathrm{Gd}-1.8 \mathrm{Y}$ $0.7 \mathrm{Zn}-0.2 \mathrm{Zr}$ (at. pct) or $\mathrm{Mg}-10 \mathrm{Gd}-5.7 \mathrm{Y}-1.6 \mathrm{Zn}-0.7 \mathrm{Zr}$ (wt pct) alloy ${ }^{[202]}$ (Table II).

The remarkable age-hardening response achieved in the Mg-Gd-Y alloys is attributable to a dense distribution of precipitates in the microstructure. The precipitation sequence in this group of alloys seems to be similar to $\mathrm{Mg}-\mathrm{Gd}$, Mg-Gd-Nd, and Mg-Y-Nd alloys. The $\beta^{\prime}$ precipitates formed in the peak-aged samples have a lenticular shape (Figure 24(c)), which is more effective in impeding dislocation slip than the globular $\beta^{\prime}$ precipitates formed in the WE54 alloy.

\section{5. $M g-G d-Z n$ alloys}

Because the equilibrium solid solubility of $\mathrm{Gd}$ in magnesium is approximately 0.8 at. pct at $523 \mathrm{~K}$

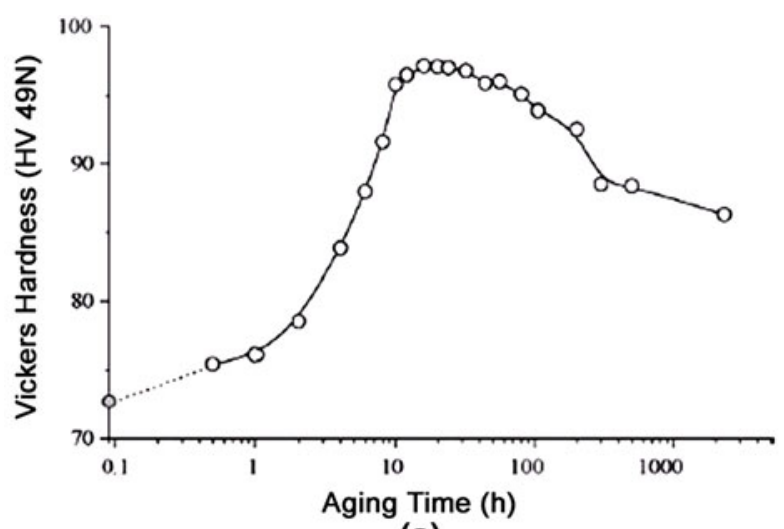

(a)

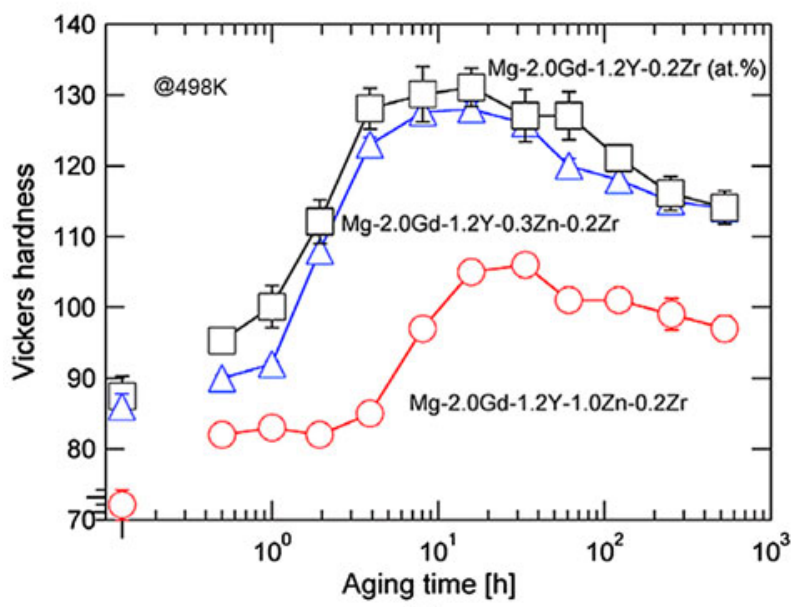

(b)

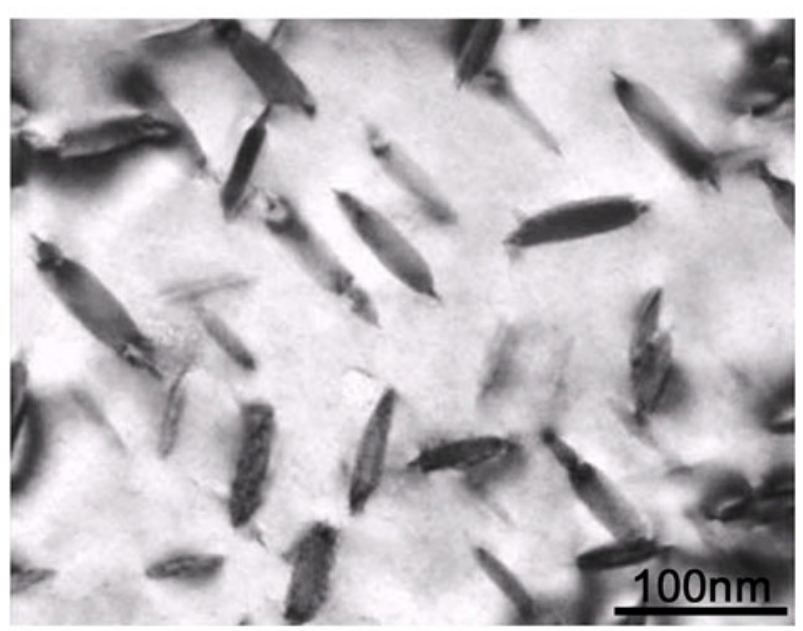

(c)

Fig. 24-Aging curves of (a) Mg-10 wt pct Gd-3 wt pet Y$0.4 \mathrm{wt}$ pet $\mathrm{Zr}$ alloy at $523 \mathrm{~K}\left(250{ }^{\circ} \mathrm{C}\right)$, and (b) $\mathrm{Mg}-2$ at. pct $\mathrm{Gd}-$ 1.2 at. pet $\mathrm{Y}-(0-1)$ at. pet $\mathrm{Zn}-0.2$ at. pet $\mathrm{Zr}$ alloys at $498 \mathrm{~K}\left(225^{\circ} \mathrm{C}\right)$. (c) TEM image showing $\beta^{\prime}$ precipitates in peak-aged samples $(16 \mathrm{~h}$ at $\left.523 \mathrm{~K}\left[250{ }^{\circ} \mathrm{C}\right]\right)$ of $\mathrm{Mg}-10$ wt pet Gd-3 wt pet Y-0.4 wt pet $\mathrm{Zr}$ alloy. (a and c) are reproduced from Ref. [199], and (b) is from Ref. [200].

$\left(250{ }^{\circ} \mathrm{C}\right)$ and 0.6 at. pet at $473 \mathrm{~K}\left(200{ }^{\circ} \mathrm{C}\right)$, Mg-Gd alloys containing less than 1.0 at. pct $(6.1 \mathrm{wt}$ pct) $\mathrm{Gd}$ have a poor age-hardening response at $473 \mathrm{~K}$ to $523 \mathrm{~K}$ $\left(200{ }^{\circ} \mathrm{C}\right.$ to $250{ }^{\circ} \mathrm{C}$ ) because of the low volume fractions of precipitates (Figure 25(a)). For example, the maximum 
volume fraction of precipitates achievable at $523 \mathrm{~K}$ $\left(250{ }^{\circ} \mathrm{C}\right)$ is approximately $1.1 \mathrm{pct}$, according to the level rule calculation, if the precipitates are assumed to have a composition close to that of the equilibrium phase $\mathrm{Mg}_{5} \mathrm{Gd}$. Therefore, it has been of commercial interest to explore the possibility of enhancing the precipitationhardening response of the diluted $\mathrm{Mg}-\mathrm{Gd}$ alloys via the use of microalloying additions of low-cost elements. A recent study ${ }^{[173]}$ reported that additions of 1 to 2 wt pet Zn to a Mg-6 wt pet Gd alloy could considerably enhance the solid-solution strengthening effect and generate a relatively strong precipitation-hardening response (Figure 25(a)).

The 3DAP work $^{[203]}$ did not reveal any detectable clusters of $\mathrm{Gd}$ and/or $\mathrm{Zn}$ atoms in the as-quenched samples of a Mg-6Gd-1Zn-0.6Zr (wt pct) alloy. But the statistical analysis of the 3DAP data suggests that cosegregation of $\mathrm{Gd}$ and $\mathrm{Zn}$ atoms occurs in the as-quenched samples. The co-segregation phenomenon of $\mathrm{Gd}$ and $\mathrm{Zn}$ atoms is attributed to the atomic size difference between the solute and the solvent. The atomic radius is $0.180 \mathrm{~nm}$ for $\mathrm{Gd}, 0.133$ for $\mathrm{Zn}$, and 0.160 for $\mathrm{Mg}$. Therefore, substituting a $\mathrm{Mg}$ atom by a Gd atom leads to a compression strain, whereas replacing a $\mathrm{Mg}$ atom by a $\mathrm{Zn}$ atom causes an extension strain. It is therefore energetically favorable for $\mathrm{Gd}$ and $\mathrm{Zn}$ atoms to segregate to each other to minimize the elastic strain associated with individual $\mathrm{Gd}$ or $\mathrm{Zn}$ atoms. It was further speculated ${ }^{[203]}$ that the $\mathrm{Gd}$ and $\mathrm{Zn}$ atoms form $\mathrm{Gd}-\mathrm{Zn}$ dimers in the $\alpha-\mathrm{Mg}$ solid solution and that these dimers are more effective barriers (than those from individual atoms of $\mathrm{Gd}$ or $\mathrm{Zn}$ ) to the motion of dislocations and therefore contribute to the large hardness increase in the as-quenched condition.

The experimental observations made by TEM indicate that the precipitation process during isothermal aging at $473 \mathrm{~K}$ and $523 \mathrm{~K}\left(200{ }^{\circ} \mathrm{C}\right.$ and $\left.250{ }^{\circ} \mathrm{C}\right)$ of the $\mathrm{Mg}-6 \mathrm{Gd}-1 \mathrm{Zn}-0.6 \mathrm{Zr}$ (wt pct) alloy involves the

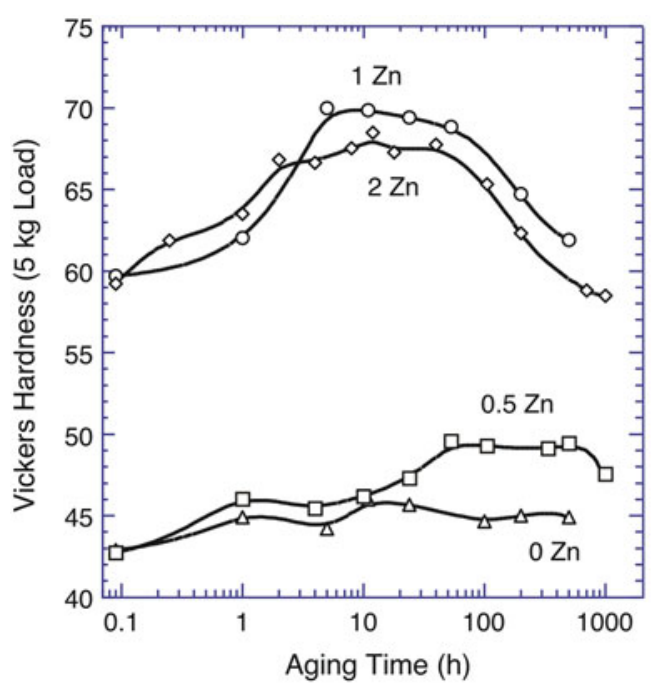

(a)

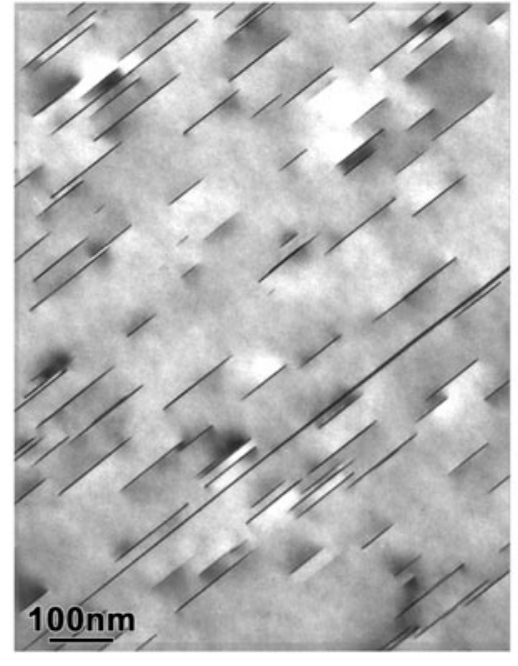

(b)
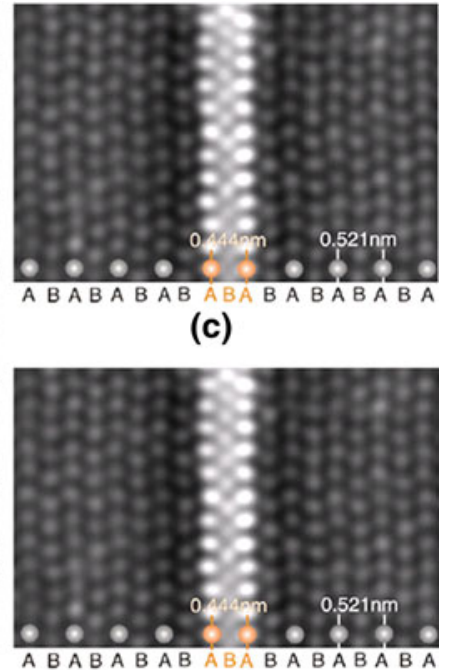

(d)

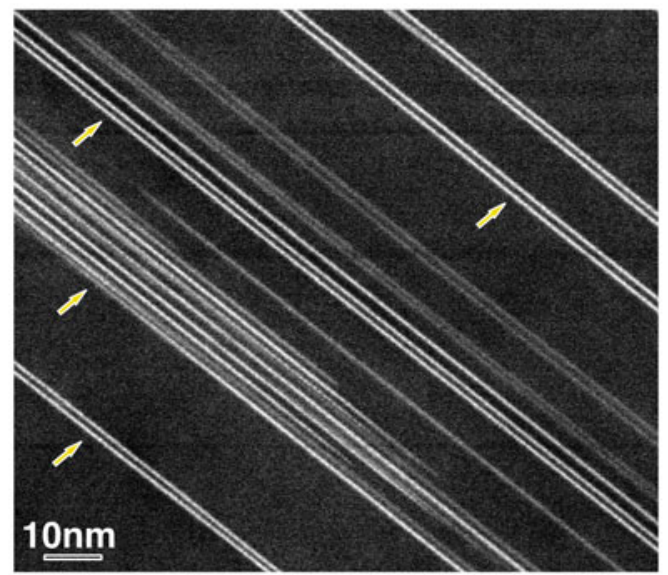

(e)

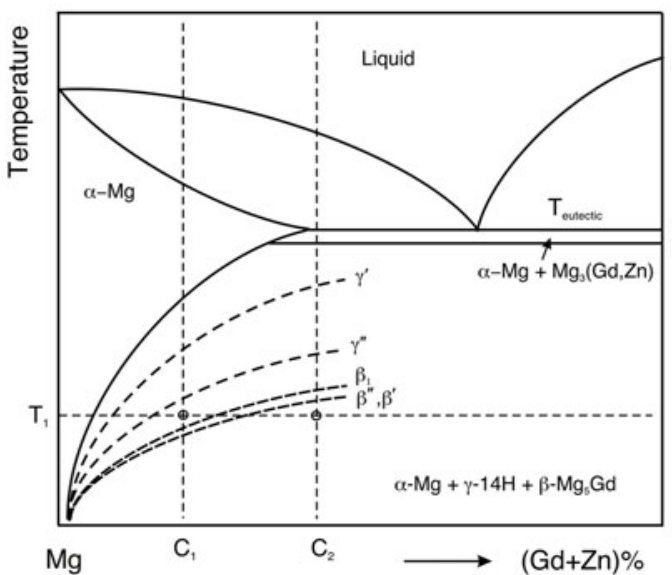

(f)

Fig. 25-(a) $523 \mathrm{~K}\left(250^{\circ} \mathrm{C}\right)$ aging curves of Mg-6 wt pct Gd-Zn alloys. (b) Conventional TEM image showing the distribution of precipitates in peak-aged samples of Mg-6Gd-1Zn-0.6Zr alloy. $\left(c\right.$ and $d$ ) Atomic-resolution HAADF-STEM images showing structures of $\gamma^{\prime \prime}$ and $\gamma^{\prime}$ phases in Mg-6Gd-1Zn-0.6Zr alloy, aged for $2 \mathrm{~h}$ at $523 \mathrm{~K}\left(250^{\circ} \mathrm{C}\right)$. (e) HAADF-STEM image showing precipitates in $\mathrm{Mg}-6 \mathrm{Gd}-1 \mathrm{Zn}-0.6 \mathrm{Zr}$ alloy, aged for $1000 \mathrm{~h}$ at $523 \mathrm{~K}\left(250{ }^{\circ} \mathrm{C}\right)$. Note that the precipitate plates form in pairs or clusters. $(f)$ Schematic diagram showing probable solvus lines of metastable and equilibrium phases. (a and b) are reproduced from Ref. [173], (c through e) are from Ref. [203]. 
formation of metastable $\gamma^{\prime \prime}$ and $\gamma^{\prime}$ phases and that the peak hardness is associated with the $\gamma^{\prime \prime}$ precipitates (Figure 25(b)). Both precipitate phases form as plateshaped particles on $(0001)_{\alpha}$. Most precipitates in the peak-aged condition are $\gamma^{\prime \prime}$ phase that has an ordered hexagonal structure (space group P $\overline{6} 2 \mathrm{~m}, a=0.556 \mathrm{~nm}$ and $c=0.444 \mathrm{~nm}$ ) with an ABA stacking sequence of the close-packed planes (Figure 25(c)) and a composition of $\mathrm{Mg}_{70} \mathrm{Gd}_{15} \mathrm{Zn}_{15}$. ${ }^{[203]}$ This structure is subtly different from that reported for the basal plates in a Mg-2Gd-1Zn (at. pct) alloy ${ }^{[204]}$ in terms of the distribution of $\mathrm{Zn}$ atoms and the $c$ value of the unit cell. The orientation relationship between $\gamma^{\prime \prime}$ and $\alpha-\mathrm{Mg}$ phases is such that $(0001)_{\gamma^{\prime \prime}} / /(0001)_{\alpha}$ and $[1010]_{\gamma^{\prime \prime}} / /[2110]_{\alpha}$. The thickness of the $\gamma^{\prime \prime}$ plates is often of a single unit cell height. This phase is fully coherent with the matrix in its habit plane, but with a relatively large misfit strain $(-0.16)$ in the direction normal to the habit plane. It is to be noted that G.P. zones have been reported ${ }^{[204,205]}$ to form in $\mathrm{Mg}-2 \mathrm{Gd}-1 \mathrm{Zn}$ (at. pct) and $\mathrm{Mg}-1.5 \mathrm{Gd}-1 \mathrm{Zn}$ (at. pct) alloys. However, an inspection of the images of and electron diffraction patterns from these "G.P. zones" indicates that they are actually $\gamma^{\prime \prime}$ phase.

With continued aging at $523 \mathrm{~K}\left(250{ }^{\circ} \mathrm{C}\right)$, the $\gamma^{\prime \prime}$ precipitates are gradually replaced by $\gamma^{\prime}$ precipitates. The $\gamma^{\prime}$ phase has a disordered hexagonal structure (space group $\mathrm{P} \overline{3} \mathrm{~m} 1, a=0.321 \mathrm{~nm}$ and $c=0.780 \mathrm{~nm}$ ) and a $\mathrm{MgGdZn}$ composition. The orientation relationship is such that $(0001)_{\gamma^{\prime}} / /(0001)_{\alpha}$ and $[2 \overline{1} \overline{1} 0]_{\gamma^{\prime}} / /[2 \overline{1} \overline{1} 0]_{\alpha}$. The $\gamma^{\prime}$ plates are perfectly coherent with the matrix phase in their habit plane and in the direction normal to their habit plane. Their thickness is again invariably of a single unit cell height, and their aspect ratio is considerably larger than that of $\gamma^{\prime \prime}$. In contrast to the $\gamma^{\prime \prime}$ plates, the $\gamma^{\prime}$ plates have an ABCA stacking order of their closepacked planes (Figure 25(d)). Therefore, the formation of a $\gamma^{\prime}$ precipitate of a single-unit cell height generates a shear strain of approximately 0.35. This large shear strain can impose a large barrier to the nucleation of $\gamma^{\prime}$ plates. Although $\gamma^{\prime}$ is a metastable phase, it is remarkably resistant to thickening during isothermal aging at $523 \mathrm{~K}\left(250{ }^{\circ} \mathrm{C}\right)$. It is still less than $1 \mathrm{~nm}$ in thickness and remains the dominant precipitate phase in the microstructure of the $\mathrm{Mg}-6 \mathrm{Gd}-1 \mathrm{Zn}-0.6 \mathrm{Zr}$ (wt pct) alloy after long-term aging (1000 hours at $523 \mathrm{~K}\left[250{ }^{\circ} \mathrm{C}\right]$ ) (Figure 25(e)).

Around the same time, Yamasaki et al. ${ }^{[206]}$ studied the precipitation process in a Mg-2Gd-1Zn (at. pct) alloy. The $\mathrm{Gd}$ and $\mathrm{Zn}$ concentrations in their alloy are almost twice of those in the Mg-6 wt pet Gd-1 wt pet $\mathrm{Zn}-0.6$ wt pet $\mathrm{Zr} \quad(\mathrm{Mg}-1$ at. pet Gd-0.4 at. pet Zn0.2 at. pet $\mathrm{Zr}$ ) alloy. The precipitation in the $\mathrm{Mg}-2 \mathrm{Gd}-$ $1 \mathrm{Zn}$ (at. pct) alloy involves the formation of stacking faults and $14 \mathrm{H}$ phase on $(0001)_{\alpha}$ and $\beta^{\prime}, \beta_{1}$, and $\beta$ phases. The stacking faults and $14 \mathrm{H}$ precipitates reportedly form at intermediate and high temperatures $(573 \mathrm{~K}$ to $773 \mathrm{~K}\left[300{ }^{\circ} \mathrm{C}\right.$ to $\left.\left.500{ }^{\circ} \mathrm{C}\right]\right)$, whereas the $\beta^{\prime}, \beta_{1}$, and $\beta$ phases form at low temperatures $\left(\sim 473 \mathrm{~K}\left[200{ }^{\circ} \mathrm{C}\right]\right)$. It was suggested $^{[206]}$ that the 1 at. pct $\mathrm{Zn}$ addition to the Mg-2 at. pct Gd alloy reduced the stacking fault energy and, therefore, promoted the formation of stacking faults and the $14 \mathrm{H}$ phase. The stacking faults in the
Mg-2 at. pct Gd-1 at. pct $\mathrm{Zn}$ alloy were reported to be $I_{1}$ and $I_{2}$ intrinsic stacking faults, and segregation of $\mathrm{Gd}$ and $\mathrm{Zn}$ atoms into the two atomic planes around each single stacking fault was observed. The appearance of these so-called stacking faults resembles that of the $\gamma^{\prime}$ phase in the same alloy system, and to avoid confusion, it is appropriate to call them $\gamma^{\prime}$ precipitates. Otherwise, it would be difficult to understand why these so-called stacking faults form preferentially only at intermediate and high temperatures rather than at both high and low temperatures, i.e., in the temperature range $298 \mathrm{~K}$ to $773 \mathrm{~K}\left(25^{\circ} \mathrm{C}\right.$ to $\left.500{ }^{\circ} \mathrm{C}\right)$. Furthermore, the stacking fault energy would be unrealistically low when the extraordinarily long length (the separation distance between the two Shockley partials binding the stacking fault) is taken into account. The work by Nie et al. ${ }^{[203]}$ suggests that the $I_{1}$ and $I_{2}$ intrinsic stacking faults reported by Yamasaki et al. ${ }^{[206]}$ are in fact two twin-related variants of $\gamma^{\prime}$ precipitate phase.

Although some particles of the equilibrium intermetallic phase $\beta$-Mg5Gd start to form in well overaged samples of the Mg-6Gd-1Zn-0.6Zr (wt pct) alloy, the metastable phases $\beta^{\prime \prime}, \beta^{\prime}$, and $\beta_{1}$, which usually form in Mg-Gd and Mg-Gd-Y alloys, and $\gamma$ phase $(14 \mathrm{H})$ are not observed in the Mg-6Gd-1Zn-0.6Zr (wt pet) or $\mathrm{Mg}$ $1 \mathrm{Gd}-0.4 \mathrm{Zn}-0.2 \mathrm{Zr}$ (at. pct) alloy. In the $\mathrm{Mg}-2$ at. pct Gd1 at. pet $\mathrm{Zn}$ alloy, the $14 \mathrm{H}$ phase can form from the supersaturated solid-solution phase of $\alpha-\mathrm{Mg}$ and from the decomposed primary intermetallic particles $\mathrm{Mg}_{3} \mathrm{Gd}$ (Fm $\overline{3} \mathrm{~m}, a=0.72 \mathrm{~nm}$ ) that have already formed in the as-cast microstructure. The $14 \mathrm{H}$ seems to be an equilibrium phase in this alloy and other alloys of similar compositions. $^{[200,201,206,207]}$ Although Mg-1Gd-0.4Zn$0.2 \mathrm{Zr}, \mathrm{Mg}-2 \mathrm{Gd}-1 \mathrm{Zn}$, and $\mathrm{Mg}-2.5 \mathrm{Gd}-1 \mathrm{Zn}$ (at. pct) alloys have a similar $\mathrm{Gd}: \mathrm{Zn}$ atomic ratio, the precipitate process in these alloys is quite different. It is currently difficult to rationalize the observations in different alloys because of a lack of isotherm sections of the ternary MgGd-Zn phase diagram. Nevertheless, one plausible explanation is that the $473 \mathrm{~K}$ to $523 \mathrm{~K}\left(200{ }^{\circ} \mathrm{C}\right.$ to $250{ }^{\circ} \mathrm{C}$ ) aging temperature range is above the solvus lines of $\beta^{\prime \prime}, \beta^{\prime}$, and $\beta_{1}$ for the $\mathrm{Mg}-1 \mathrm{Gd}-0.4 \mathrm{Zn}-0.2 \mathrm{Zr}$ (at. pct) alloy that has lower contents of $\mathrm{Gd}$ and $\mathrm{Zn}$, but it is below the solvus lines of these metastable phase for the $\mathrm{Mg}-2 \mathrm{Gd}-1 \mathrm{Zn}$ (at. pct) and $\mathrm{Mg}-2.5 \mathrm{Gd}-1 \mathrm{Zn}$ (at. pct) compositions (Figure 25(f)).

\section{6. $M g-Y-Z n$ alloys}

The experimental evidence accumulated thus far indicates that $\mathrm{Zn}$ additions to $\mathrm{Mg}-\mathrm{Y}$ alloys significantly reduce the equilibrium solid solubility of $Y$ in magnesium. Therefore, the volume fraction of solid-state precipitates is quite low in the resultant $\mathrm{Mg}-\mathrm{Y}-\mathrm{Zn}$ alloys, and the $\mathrm{Mg}$ $\mathrm{Y}-\mathrm{Zn}$ alloys exhibit little age-hardening response, as shown in Figure 24(c). Consequently, the Mg-Y-Zn alloys, for example Mg-2 at. pct Y-2 at. pct Zn (Mg6.7 wt pet $\mathrm{Y}-4.9 \mathrm{wt}$ pet $\mathrm{Zn}),{ }^{[208]}$ are usually hot extruded to achieve useful tensile properties (Table II).

It is perhaps for the lack of age hardening that the precipitation sequence in the Mg-Y-Zn alloys has not been well characterized in the past. In the early studies 
of Mg-Y-Zn alloys, ${ }^{[209,210]}$ some planar defects were observed to form on the basal plane of the magnesium matrix phase. Based on the invisibility analysis of the two-beam TEM images obtained from these planar defects, these defects were reported to be $I_{1}$ intrinsic stacking fault bounded by Frank partial dislocations $\left(\mathbf{b}= \pm 1 / 6\langle 20 \overline{2} 3\rangle_{\alpha}, \mathbf{a}+\mathbf{c}\right.$ type $)$. This fault can be generated via the condensation of vacancies onto a single atomic plane, which leads to a dislocation loop bounded by Frank partials with $\mathbf{b}= \pm 1 / 2\langle 0001\rangle_{\alpha}$, and subsequent formation of a Shockley partial loop $\left(\mathbf{b}= \pm 1 / 3\langle 10 \overline{1} 0\rangle_{\alpha}\right)$ within this atomic plane. Similar planar defects are also observed in an early study of $\mathrm{Mg}-\mathrm{Th}-\mathrm{Zn}$ alloys aged at $573 \mathrm{~K}$ to $673 \mathrm{~K}\left(300{ }^{\circ} \mathrm{C}\right.$ to $\left.400{ }^{\circ} \mathrm{C}\right),{ }^{[211]}$ but they were reported to be intrinsic stacking faults $I_{2}$ bounded by Shockley partial dislocations $\left(\mathbf{b}= \pm 1 / 3\langle 10 \overline{1} 0\rangle_{\alpha}\right)$. It is apparent that a wide range of planar features exists in the $\mathrm{Mg}-\mathrm{Y}-\mathrm{Zn}, \mathrm{Mg}-\mathrm{Gd}$ $\mathrm{Zn}$, and $\mathrm{Mg}-\mathrm{Th}-\mathrm{Zn}$ alloys. Some of them have many characteristic features of the stacking faults, but the analysis made did not draw any clear conclusions concerning their identity and relationships.

The stacking faults in magnesium alloys include intrinsic faults $I_{1}$ and $I_{2}$ and extrinsic fault $E{ }^{[212]} \mathrm{An}$ $I_{1}$ fault can be produced by removing the B plane, usually via the condensation of aggregates of vacancies, above an A plane and then shearing the remaining planes above the A plane by a displacement of $1 / 3\langle 10 \overline{1} 0\rangle_{\alpha}$. In this case, the stacking order of the closely packed planes is changed from

\section{ABABABAB}

to

\section{$\operatorname{ABABACAC}\left(I_{1}\right)$}

An $I_{2}$ fault is generated directly by the passage of a Shockley partial dislocation on $(0001)_{\alpha}$ or by directly shearing the hexagonal lattice by a displacement of $1 / 3\langle 1010\rangle_{\alpha}$. The passage of the Shockley partial, or shearing, changes the stacking sequence of closely packed planes from

\section{ABABABAB}

to

\section{$\operatorname{ABABCACA}\left(I_{2}\right)$}

These two types of intrinsic stacking faults can be distinguished by that fact that the $I_{1}$ fault is bound by a pair of Frank partials $\left(\mathbf{b}=1 / 6\langle 20 \overline{2} 3\rangle_{\alpha}\right)$, whereas that the $I_{2}$ fault is bound by a pair of Shockley partial dislocations $\left(\mathbf{b}=1 / 3\langle 1010\rangle_{\alpha}\right)$. The extrinsic fault $E$ can be generated by inserting a $C$ plane into the ...ABAB... stacking sequence. The stacking of the closely packed planes is then changed from

\section{ABABABAB}

to

\section{$\operatorname{ABABCABAB}(E)$.}

Note that the $I_{2}$ fault, rather than $I_{1}$, yields an ABCA stacking that is characteristic of the $\gamma^{\prime}$ structure in
Mg-Gd-Zn and Mg-Y-Zn alloys. Although the $E$ fault can also generate the ABCA stacking, the packing order of closely packed planes outside the ABCA segment is distinguishably different from that associated with the $I_{2}$ fault. If the $\mathrm{ABCA}$ segment is taken as a precipitate plate, then the closely packed planes of the magnesium lattice at both sides of the plate are symmetrically arranged for the $E$ fault, and asymmetrically stacked for the $I_{2}$ fault.

In more recent years, the planar defects in the microstructure of a $\mathrm{Mg}-8 \mathrm{Y}-2 \mathrm{Zn}-0.6 \mathrm{Zr}$ (wt. pet) alloy solution treated for 1 hour at $773 \mathrm{~K}\left(500{ }^{\circ} \mathrm{C}\right)$ and water quenched were characterized in detail using conventional transmission electron microscopy imaging techniques and a modern $\mathrm{Z}$-contrast imaging technique, i.e., atomic-resolution HAADF-STEM. ${ }^{[213]}$ These defects were analyzed using both traditional $\mathbf{g} \cdot \mathbf{b}$ and $\mathbf{g} \cdot \mathbf{R}$ invisibility criteria and computer image simulation.

The alloy microstructure contains three types of planar features on $(0001)_{\alpha}$ (Figure 26(a)). The first type is small ribbons. They are intrinsic stacking faults $I_{2}$, bounded by two Shockley partial dislocations, rather than $I_{1}$. The second type is a precipitate $\gamma^{\prime}$ phase that has a single unit cell height and is always associated with Shockley partial dislocations (Figure 26(b)). ${ }^{[14]}$ The structure of the $\gamma^{\prime}$ phase seems similar to that in the Mg-Gd-Zn alloys (Figure 25(d)). The third type is the $14 \mathrm{H}$ precipitate phase that is again always associated with Shockley partial dislocations. This type of planar features is often inferred to be an intrinsic stacking fault $I_{2}$ bounded by a Frank partial dislocation in the literature. ${ }^{[209]}$ The $14 \mathrm{H}$ phase is an equilibrium phase in the $\mathrm{Mg}-\mathrm{Y}-\mathrm{Zn}$ system. The probable precipitation sequence in the Mg-Y-Zn alloys is given in Table I.

The $14 \mathrm{H}$ phase was originally reported ${ }^{[215]}$ to have a disordered hexagonal structure $(a=0.321 \mathrm{~nm}$ and $c=3.694 \mathrm{~nm}$ ). The close-packed planes of this structure have a long-period stacking order and are arranged in an ACBCBABABABCBCA stacking sequence. But in a more recent study, ${ }^{[216]}$ it was proposed that $14 \mathrm{H}$ has in fact an ordered hexagonal structure $(a=1.112 \mathrm{~nm}$, $c=3.647 \mathrm{~nm}$ ), and a $\mathrm{Mg}_{12} \mathrm{YZn}$ composition that is identical to that of the equilibrium $X$ phase in the Mg-Y$\mathrm{Zn}$ system. ${ }^{[217,218]}$ The stacking sequence of the closepacked planes is ABABCACACACBABA in the $14 \mathrm{H}$ lattice, ${ }^{[203,216]}$ and the orientation relationship between $14 \mathrm{H}$ and $\alpha-\mathrm{Mg}$ is that $(0001)_{14 \mathrm{H}} / /(0001)_{\alpha}$ and $[0 \overline{1} 10]_{14 \mathrm{H}} / /[\overline{1} \overline{1} 20]_{\alpha}$.

The $14 \mathrm{H}$ unit cell is made up of two structural units, or building blocks, that are separated by three $(0001)_{\alpha}$ planes of magnesium (Figure 26(c)). Each structural unit has an ABCA-type stacking sequence, and $\mathrm{Y}$ and $\mathrm{Zn}$ atoms have an ordered arrangement in the $B$ and $C$ layers, i.e., the two middle layers, of each structural unit. The stacking sequence of the close-packed planes in the structural unit is such that each structural unit has a shear component with respect to the matrix phase. The two structural units within the $14 \mathrm{H}$ unit cell are twin-related. Therefore, the joint formation of these two blocks generates a zero net shear relative to the $\alpha-\mathrm{Mg}$ matrix.

In the as-cast microstructures of $\mathrm{Mg}-\mathrm{Y}-\mathrm{Zn}$ alloys, produced by either conventional ingot casting or rapid 

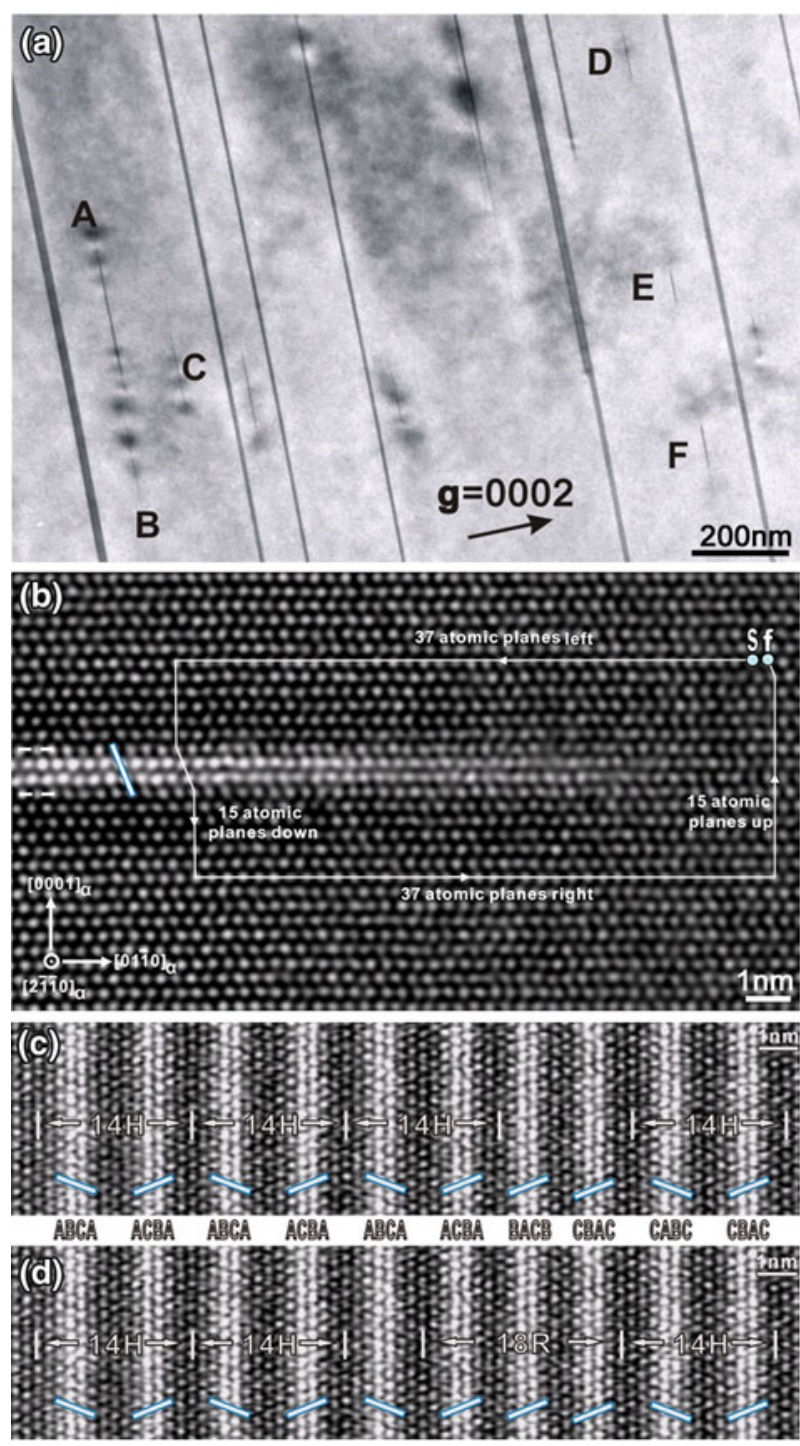

Fig. 26-(a) Conventional TEM image showing the distribution of precipitates in $\mathrm{Mg}-8 \mathrm{Y}-2 \mathrm{Zn}-0.6 \mathrm{Zr}$ (wt pct) alloy solution treated for $1 \mathrm{~g}$ at $773 \mathrm{~K}\left(500^{\circ} \mathrm{C}\right)$ and water quenched. ( $b$ and $c$ ) Atomic-resolution HAADF-STEM images showing $\gamma^{\prime}, 18 \mathrm{R}$, and $14 \mathrm{H}$ phases in $\mathrm{Mg}-8 \mathrm{Y}-2 \mathrm{Zn}-0.6 \mathrm{Zr}$ (wt pct) alloy solution treated for $1 \mathrm{~h}$ or $16 \mathrm{~h}$ at $773 \mathrm{~K}\left(500{ }^{\circ} \mathrm{C}\right)$. Reproduced from Refs. [213] and [214].

solidification processing, it is often to observe primary intermetallic particles of a long-period stacking ordered (LPSO) structure. It seems that this LPSO structure can readily form from the melt, irrespective of the solidification rates in the casting. This LPSO phase can be produced in nanoscales and larger volume fractions when Mg-Y-Zn alloys are produced by the rapid solidification process. For example, the size of the intermetallic particles of the LPSO phase ranges from 50 to $250 \mathrm{~nm}$ in a Mg-2 at. pct $\mathrm{Y}-1$ at. pet $\mathrm{Zn}$ alloy produced by gas atomization, compaction, and hot extrusion. ${ }^{[219]}$ This alloy can have a 0.2 pct proof strength exceeding $600 \mathrm{MPa}$ and an elongation to fracture of 5 pct. ${ }^{[220]}$

In the early studies, ${ }^{[219,221]}$ the intermetallic particles in the Mg-Y-Zn alloys was reported to have a $6 \mathrm{H}$ structure, which has a monoclinic unit cell $(a=$
$0.56 \mathrm{~nm}, b=0.32 \mathrm{~nm}, c=1.56 \mathrm{~nm}$ and $\beta=88 \mathrm{deg}$ ) and an $\mathrm{ABCBCB}^{\prime}$ stacking sequence of the close-packed planes. In the proposed $6 \mathrm{H}$ structure, the $\mathrm{A}$ and $\mathrm{B}^{\prime}$ layers are significantly enriched by $\mathrm{Zn}$ and $\mathrm{Y},{ }^{[221]}$ with the $\mathrm{Y}$ and $\mathrm{Zn}$ content of approximately 10 at. pet and 3 at. pct, respectively, in each of these two layers. ${ }^{[219]}$ In subsequent studies, ${ }^{[215,222]}$ the $6 \mathrm{H}$ structure was regarded as not correct and was superseded by an $18 \mathrm{R}$ structure (hexagonal unit cell, $a=0.321 \mathrm{~nm}, c=$ $4.86 \mathrm{~nm}$ ) with an ACBCBCBACACACBABABA stacking sequence of the close-packed planes. This structure is identical to that of the $X-\mathrm{Mg}_{12} \mathrm{YZn}$ phase proposed by Luo and Zhang. ${ }^{[223]}$ In all such studies, the term "order" refers to the ordered stacking of the close-packed planes rather than ordered arrangement of $\mathrm{Y}$ and $\mathrm{Zn}$ atoms in the close-packed planes.

In a very recent study, ${ }^{[216]}$ the $18 \mathrm{R}$ unit cell was reported to be ordered monoclinic ( $a=1.112 \mathrm{~nm}$, $b=1.926 \mathrm{~nm}, c=4.689 \mathrm{~nm}$, and $\beta=83.25 \mathrm{deg}$ ), with $\mathrm{Y}$ and $\mathrm{Zn}$ atoms occupying some specific positions of the unit cell. The orientation relationship between the $18 \mathrm{R}$ and $\alpha-\mathrm{Mg}$ phases is such that $(001)_{18 \mathrm{R}} / /(0001)_{\alpha}$ and $[010]_{18 \mathrm{R}} / /[1 \overline{2} 10]_{\alpha}$. The $18 \mathrm{R}$ unit cell has an ACACBABABACBCBCBACA stacking sequence of its close-packed planes and is made up of three structural units, with two adjacent units separated by two $(0001)_{\alpha}$ planes of magnesium. Similar to that in the $14 \mathrm{H}$ phase, each structural unit of the 18R phase has an ABCA-type stacking sequence, and $\mathrm{Y}$ and $\mathrm{Zn}$ atoms have an ordered arrangement in the $\mathrm{B}$ and $\mathrm{C}$ layers, i.e., the two middle layers of each structural unit. The experimental measurements and this latter model of $18 \mathrm{R}$ indicate that its stoichiometric composition is $\mathrm{Mg}_{10} \mathrm{YZn}$ rather than $\mathrm{Mg}_{12} \mathrm{YZn}$, which has long been assumed and commonly accepted in previous studies. This error occurred presumably because the $18 \mathrm{R}$ structure was mistakenly taken as the structure of the equilibrium $\mathrm{X}-\mathrm{Mg}_{12} \mathrm{YZn}$ phase in the work of Luo and Zhang. ${ }^{[223]}$ Luo and Zhang $^{[223]}$ did not provide any information on their sample preparation conditions, and it is very likely that the intermetallic particles that they studied are the $18 \mathrm{R}$ phase, rather than the equilibrium $\mathrm{X}-\mathrm{Mg}_{12} \mathrm{YZn}$ phase. The $18 \mathrm{R}$ phase is observed predominantly in the as-cast microstructure of $\mathrm{Mg}-\mathrm{Y}-\mathrm{Zn}$ alloys. Both the accumulated experimental evidence and the calculated $\mathrm{Mg}-\mathrm{Y}$ $\mathrm{Zn}$ phase diagram shown in Figure $27^{[224]}$ indicate that $18 \mathrm{R}$ is not thermodynamically stable at temperatures below $773 \mathrm{~K}\left(500{ }^{\circ} \mathrm{C}\right)$; it is gradually replaced by $14 \mathrm{H}$ after prolonged heat treatment at $623 \mathrm{~K}$ to $773 \mathrm{~K}$ $\left(350{ }^{\circ} \mathrm{C}\right.$ to $\left.500{ }^{\circ} \mathrm{C}\right)$.

It is to be noted that the stacking sequence of the close-packed planes of the structural units of the $14 \mathrm{H}$ and $18 \mathrm{R}$ phases is the same as that of the $\gamma^{\prime}$ phase (Figures 25(d) and 26(b)), even though the $\gamma^{\prime}$ phase is disordered. In two very recent studies of LPSO structures in $\mathrm{Mg}-5$ at. pct $\mathrm{Gd}-3.5$ at. pct $\mathrm{Al}^{[225]}$ and $\mathrm{Mg}$ 2 at. pet $\mathrm{Y}-1$ at. pet Zn, Mg-9 at. pet Y-6 at. pet Zn and $\mathrm{Mg}-2$ at. pet Er-1 at. pct $\mathrm{Zn}^{[226]}$ alloys, the structural unit of the LPSO structures was proposed to have an ordered enrichment of $\mathrm{Y}$ and $\mathrm{Zn}$ atoms in all four layers, instead of the middle two layers, of the ABCA units. In the Mg-5 at. pet Gd-3.5 at. pet Al alloy, the 
HAADF-STEM images obtained indicate that $\mathrm{Gd}$ atoms are arranged with an order in all four layers of the structural unit, with a greater enrichment in the inner two layers of the unit. However, it should be pointed that the SAED patterns recorded from the LPSO phase in this alloy (Figure 2 in Reference 225) are not fully consistent with those obtained from the LPSO phase in the $\mathrm{Mg}-\mathrm{Y}-\mathrm{Zn}$ alloys (Figure 11 in Reference 225), and therefore, more efforts are needed in the future to establish whether the structure reported for the LPSO phase in the $\mathrm{Mg}-\mathrm{Gd}-\mathrm{Al}$ alloy is representative of that of the $\mathrm{Mg}-\mathrm{Y}-\mathrm{Zn}$ alloys.

In the Mg-2 at. pet $\mathrm{Y}-1$ at. pet $\mathrm{Zn}, \mathrm{Mg}-9$ at. pet Y-6 at. pet $\mathrm{Zn}$ and Mg-2 at. pet Er-1 at. pet Zn alloys, ${ }^{[226]}$ the HAADF-STEM images of the 18R and $14 \mathrm{H}$ phases do not show any strong evidence of a systematic ordering of $\mathrm{Y}$ and $\mathrm{Zn}$ atoms in the two outer layers. The SAED patterns obtained from the LPSO phases in these three alloys are not fully self-consistent in terms of the intensity of some reflections. Again, another systematic study is needed in the future to reconcile the HAADF-STEM images and SAED patterns obtained from different alloys and alloys prepared under different processing conditions.

Although $18 \mathrm{R}$ and $14 \mathrm{H}$ are the most frequently observed LPSO structures in $\mathrm{Mg}-\mathrm{Y}-\mathrm{Zn}$ alloys and in many other magnesium alloys such as $\mathrm{Mg}-\mathrm{Gd}-\mathrm{Zn}, \mathrm{Mg}-$ Gd-Y-Zn, Mg-Dy-Zn, Mg-Ho-Zn, Mg-Er-Zn, Mg-Tm$\mathrm{Zn}, \mathrm{Mg}-\mathrm{Tb}-\mathrm{Zn}, \mathrm{Mg}-\mathrm{Y}-\mathrm{Cu}(-\mathrm{Zn})$, and possibly Mg-Gd$\mathrm{Al},{ }^{[200,201,203,206,225,227-231]}$ a few other long-period structures such as $10 \mathrm{H}$ and $24 \mathrm{R}$ have also been reported. ${ }^{[215]}$ However, whether these LPSO structures are also ordered as well as their relationships with the ABCAtype building block and $18 \mathrm{R}$ and $14 \mathrm{H}$ structures, remains to be unambiguously established.

\section{7. $M g-G d-A g$ alloys}

A recent study ${ }^{[232,233]}$ indicates that the addition of 2 wt pet Ag to the Mg-6Gd-0.6Zr (wt pct) alloy can lead to a significant acceleration and increase in the agehardening response in the resultant $\mathrm{Mg}-6 \mathrm{Gd}-2 \mathrm{Ag}-0.6 \mathrm{Zr}$ alloy (Figure 28(a)). When combined with 1 wt pet $\mathrm{Zn}$,

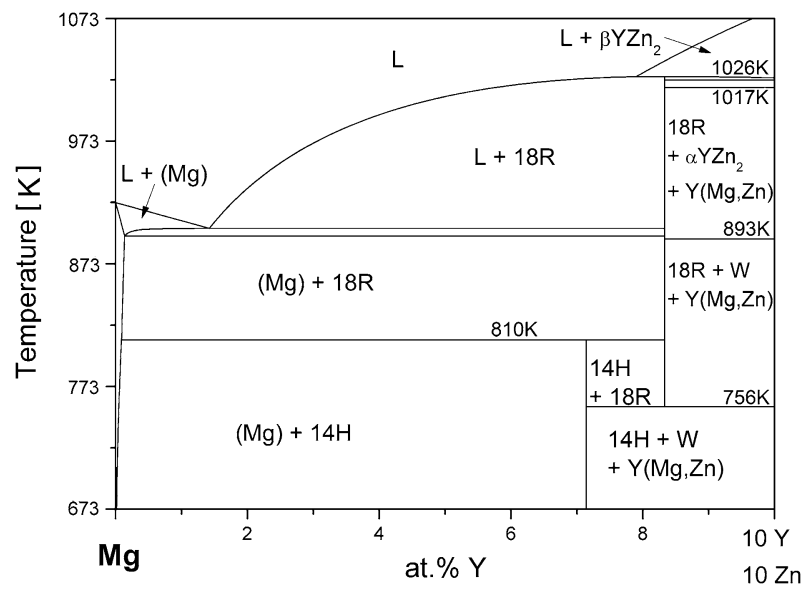

Fig. 27-Vertical section of the Mg-Y-Zn ternary phase diagram from $\mathrm{Mg}$-rich corner to $\mathrm{Mg}_{80} \mathrm{Y}_{10} \mathrm{Zn}_{10}$ through $18 \mathrm{R}$ and $14 \mathrm{H}$ phases (Courtesy R. Schmid-Fetzer). this addition can result in another substantial increase in the peak hardness value, with a maximum hardness value of $\sim 92 \mathrm{VHN}$ obtainable at $473 \mathrm{~K} \quad\left(200{ }^{\circ} \mathrm{C}\right)$ (Figure 28(a)). This improved age-hardening response is associated with the formation of a dense distribution of nanoscale basal precipitate plates that are not available in the Mg-6Gd-0.6Zr alloy. The selected-area electron diffraction patterns recorded from the nanoscale plates indicate they may have a hexagonal structure with lattice parameters $a=0.556 \mathrm{~nm}, c=0,1$, or two times of $c_{\alpha}$ (i.e., $c=0,0.521$, or $1.042 \mathrm{~nm}$ ) and an orientation relationship of $(0001)_{\mathrm{h}} / /(0001)_{\alpha}$, $[10 \overline{1} 0]_{\mathrm{h}} / /[11 \overline{2} 0]_{\alpha}$. Based on what has been reported for similar plates formed in $\mathrm{Mg}-\mathrm{Nd}-\mathrm{Ag}^{[5,151]}$ and $\mathrm{Mg}$ $\mathrm{Y}(-\mathrm{Zn})-\mathrm{Ag}$ alloys, ${ }^{[234]}$ the lattice parameters of the structure of these plates are likely to be $a=0.556 \mathrm{~nm}$ and $c=0.521 \mathrm{~nm}$. An appreciable maximum hardness value of over $130 \mathrm{VHN}$ is obtained when the concentration of $\mathrm{Gd}$ is increased from $6 \mathrm{wt}$ pct to $15 \mathrm{wt}$ pct (Figure 28(b)). ${ }^{[235]}$ When tested at room temperature in the peak-aged condition, the $\mathrm{Mg}-15 \mathrm{Gd}-2 \mathrm{Ag}-0.6 \mathrm{Zr}$ alloy has a 0.2 pct proof strength of $320 \mathrm{MPa}$ and an ultimate strength of $347 \mathrm{MPa} .^{[235]}$

\section{8. $M g-Y(-Z n)-A g$ alloys}

Figure $28(\mathrm{c})$ shows the aging curves at $473 \mathrm{~K}\left(200^{\circ} \mathrm{C}\right)$ of $\mathrm{Mg}-6 \mathrm{Y}-1 \mathrm{Zn}-0.6 \mathrm{Zr}$ alloys with systematic $\mathrm{Ag}$ additions. The Ag-free alloy has a rather poor age-hardening response at $473 \mathrm{~K}\left(200{ }^{\circ} \mathrm{C}\right)$, which is attributable to (1) little precipitation of fine-scale precipitates inside individual magnesium grains, (2) the preferential formation of coarse precipitates of $14 \mathrm{H}$ in grain boundaries, and (3) a relatively high fraction of retained intermetallic particles that formed during solidification. Systematic additions of Ag to the Mg-6Y-1Zn-0.6Zr (wt pct) alloy have been reported ${ }^{[236]}$ to reduce the volume fraction of retained intermetallic particles in the microstructure and to promote the formation of fine-scale precipitates at the expense of coarse precipitates of $14 \mathrm{H}$. The alloy containing 2 wt pct Ag exhibits a remarkable agehardening response during isothermal aging at $473 \mathrm{~K}$ $\left(200{ }^{\circ} \mathrm{C}\right)$. An increase in the Ag content to $3 \mathrm{wt}$ pct leads to another increase in the maximum hardness value achievable. In the peak-aged condition, the Mg-6Y-3Ag$1 \mathrm{Zn}-0.6 \mathrm{Zr}$ (wt pet) alloy has a hardness value of approximately 100 VHN. It should be emphasized that a similar enhancement effect on the age-hardening response is also expected in the counterpart $\mathrm{Mg}-\mathrm{Y}-\mathrm{Ag}$ alloys, i.e., alloys without any $\mathrm{Zn}$ additions. These observations are similar to those observed in $\mathrm{Mg}-\mathrm{Gd}$ $(-\mathrm{Zn})$ alloys containing Ag additions. ${ }^{[232]}$ The enhanced age-hardening response is associated with a dense distribution of fine-scale basal precipitate plates of $\gamma^{\prime \prime}$ (Figure 28(d)), which were not observed in the Ag-free alloy, and the number density of these fine-scale precipitates increases with an increase in the Ag content in the alloy. It is bit puzzling that the $\gamma^{\prime \prime}$ precipitate platelets are invariably of a single unit cell thickness, comprising three atomic planes, irrespective of the aging period that is used (Figures 28(e) and (f)). ${ }^{[234]}$ After prolonged aging (5800 hours) at $473 \mathrm{~K}\left(200{ }^{\circ} \mathrm{C}\right)$, the $\gamma^{\prime \prime}$ platelets remain very thin, with a thickness of a single 
(a)

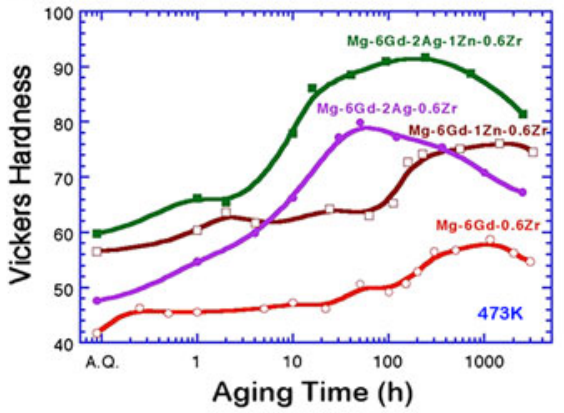

(b)

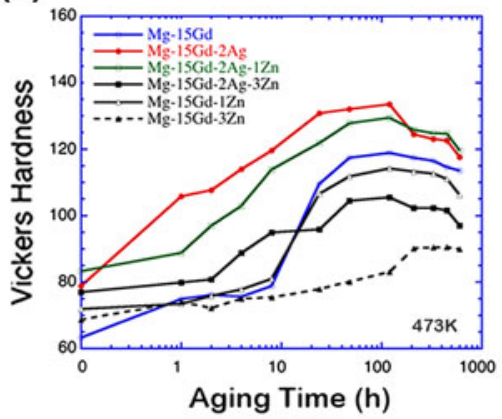

(c)

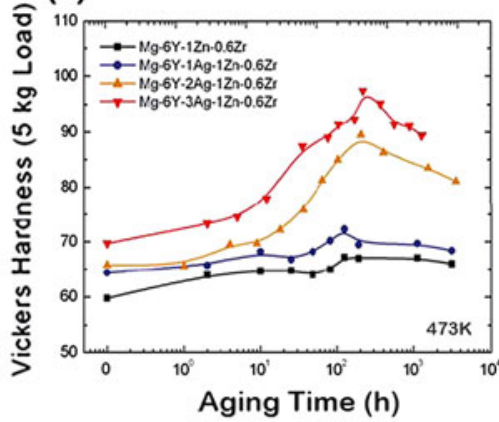

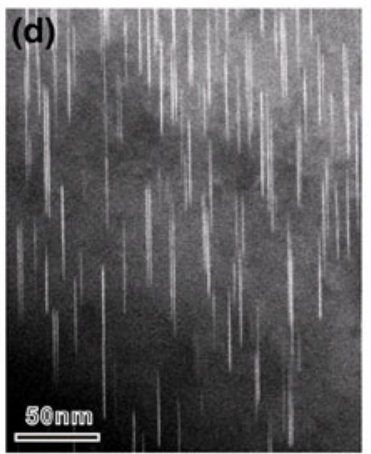
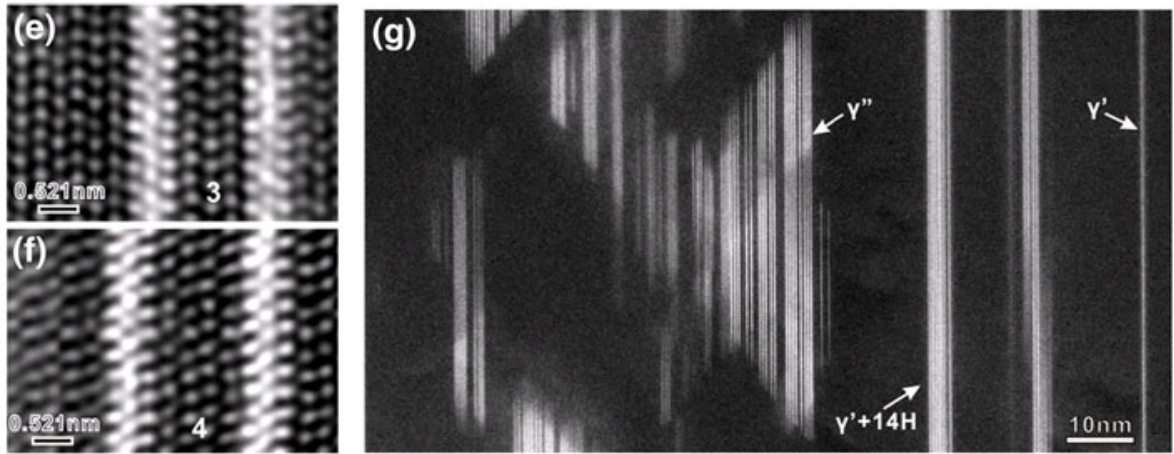

Fig. 28-Aging curves at $473 \mathrm{~K}\left(200{ }^{\circ} \mathrm{C}\right)$ of $(a)$ Mg-6Gd-2Ag-based alloys (reproduced from Ref. [232]), (b) Mg-15Gd-2Ag-based alloys, ${ }^{[235]}$ and (c) Mg-6Y-(1-3)Ag-1Zn-based alloys (reproduced from Ref. [236]). HAADF-STEM images showing the distribution of precipitates in ( $d$ and $f$ ) peak-aged $\left(224\right.$ hours at $\left.473 \mathrm{~K}\left[200{ }^{\circ} \mathrm{C}\right]\right)$, and $(g)$ over-aged $\left(5800 \mathrm{~h}\right.$ at $\left.473 \mathrm{~K}\left[200{ }^{\circ} \mathrm{C}\right]\right)$ samples of $\mathrm{Mg}-6 \mathrm{Y}-2 \mathrm{Ag}-1 \mathrm{Zn}-0.6 \mathrm{Zr}$ alloy $($ reproduced from Ref. [234]). All alloy compositions are in weight percentage.

unit cell. Although they are thermally stable and resistant to thickening, they tend to form clusters in the direction normal to the platelet broad surface, instead of thickening, which are often separated by a few atomic planes (Figure 28(g)). It is currently unclear what factors cause the cluster distribution of the $\gamma^{\prime \prime}$ platelets.

Based on selected-area electron diffraction patterns recorded from regions containing $\gamma^{\prime \prime}$ platelets and atomic-resolution HAADF-STEM images of the $\gamma^{\prime \prime}$ platelets, the structure of the $\gamma^{\prime \prime}$ platelets is proposed to be hexagonal $(a=0.556 \mathrm{~nm}, c=0.450 \mathrm{~nm})$. The precise symmetry of the structure, i.e., the space group and arrangement of individual atoms in the unit cell, remains to be unambiguously established. The orientation relationship between $\gamma^{\prime \prime}$ and $\alpha-\mathrm{Mg}$ phases is that $(0001)_{\gamma^{\prime \prime}} / /$ $(0001)_{\alpha}$ and $[10 \overline{1} 0]_{\gamma^{\prime \prime}} / /[2 \overline{1} \overline{1} 0]_{\alpha}$. The observed structure, orientation relationship, and morphology of the $\gamma^{\prime \prime}$ phase are similar to those of platelets in $\mathrm{Mg}-\mathrm{Gd}-\mathrm{Zn}$, $\mathrm{Mg}-\mathrm{Nd}-\mathrm{Zn}, \mathrm{Mg}-\mathrm{Ce}-\mathrm{Zn}$, and $\mathrm{Mg}-\mathrm{Ca}-\mathrm{Zn}$ alloys.

The aging treatments of a Mg-6Y-2Ag- $1 \mathrm{Zn}-0.6 \mathrm{Zr}$ (wt pct) alloy in the temperature range $473 \mathrm{~K}$ to $623 \mathrm{~K}$ $\left(200{ }^{\circ} \mathrm{C}\right.$ to $350{ }^{\circ} \mathrm{C}$ ) indicate that precipitation in this alloy also involves the formation of G.P. zones, $\gamma^{\prime}$, and $14 \mathrm{H}$ phases. The G.P. zones have a monolayer atomic structure on $(0001)_{\alpha}$, and they form in the early stage of aging at $473 \mathrm{~K}\left(200{ }^{\circ} \mathrm{C}\right)$. These G.P. zones are replaced by $\gamma^{\prime \prime}$ precipitate plates during continued aging at $473 \mathrm{~K}$ $\left(200{ }^{\circ} \mathrm{C}\right)$. The precipitation in the alloy seems to involve the formation of G.P. zone, $\gamma^{\prime \prime}, \gamma^{\prime}, 14 \mathrm{H}$, and $\delta$ (Table I), where $\delta$ is an equilibrium phase (space group $\mathrm{Fd} 3 \mathrm{~m}, a=1.59 \mathrm{~nm}$ ) that forms in grain boundaries. $^{[234,237]}$

\section{H. Other Magnesium Alloy Systems}

\section{Mg-In-Ca alloys}

The equilibrium solid solubility of indium in $\mathrm{Mg}$ is approximately 19.4 at. pct at the peritectic temperature of $757 \mathrm{~K}\left(484{ }^{\circ} \mathrm{C}\right)$, and it decreases only to 18.62 at. pct at $600 \mathrm{~K}\left(327{ }^{\circ} \mathrm{C}\right)$ and 13.95 at. pct at $473 \mathrm{~K}$ $\left(200{ }^{\circ} \mathrm{C}\right) .{ }^{[14]}$ Given the large solid solubility of indium in magnesium at temperatures close to $473 \mathrm{~K}\left(200{ }^{\circ} \mathrm{C}\right)$ and the price of indium, the Mg-In system is by any means not for developing alloys for engineering application. For this reason, the Mg-In alloys have so far received little attention. However, in a recent study, ${ }^{[238]}$ Mendis et al. ${ }^{[238]}$ reported that the addition of 0.3 at. pct $\mathrm{Ca}$ to magnesium alloys containing a very dilute amount ( 0.6 to 1.0 at. pct) of In could lead to a remarkable age-hardening response (Figure 29(a)). This age-hardening response is several folds larger than that of the binary $\mathrm{Mg}-0.3$ at . pct $\mathrm{Ca}$ alloy, and therefore it is not related with formation of precipitates intrinsic of binary $\mathrm{Mg}$-In alloys or $\mathrm{Mg}$-Ca alloys.

An inspection of peak-aged samples of a Mg-1In$0.3 \mathrm{Ca}$ (at. pet) alloy using HAADF-STEM and 3DAP reveals that the this age hardening is associated with the formation of a dense distribution of precipitate platelets forming on $\{10 \overline{1} 0\}_{\alpha}$ planes of the magnesium matrix phase (Figure 29(b)). ${ }^{[238]}$ These prismatic platelets are typically three $\{10 \overline{1} 0\}_{\alpha}$ planes thick and $20 \mathrm{~nm}$ in diameter, and they are fully coherent with the matrix phase. They are comprised of approximately 7.0 at. pct $\mathrm{Ca}$ and 3.5 at. pct In (Figure 29(c)). ${ }^{[238]}$ The structure of these prismatic platelets is yet to be 
determined. The phase equilibria and the precipitation sequence in this alloy are also both unknown.

Nevertheless, the formation of prismatic plates in this alloy system is exciting, and it will be described and discussed in the next section. The prismatic precipitate plates are the most effective barriers to basal dislocations and twins that are operating in the plastic deformation process. Any detailed study in the future of the structure and formation mechanism of the $\{10 \overline{1} 0\}_{\alpha}$ precipitate plates will shed light on the exploration for the principles for generating prismatic precipitate plates in magnesium alloys.

\section{2. $M g-B i-Z n$ alloys}

The maximum equilibrium solid solubility of $\mathrm{Bi}$ in $\mathrm{Mg}$ is 1.12 at. pct (or $8.87 \mathrm{wt}$ pct) at the eutectic temperature $\left(826 \mathrm{~K}\left[553{ }^{\circ} \mathrm{C}\right]\right)$, and it decreases to approximately zero at $473 \mathrm{~K}\left(200^{\circ} \mathrm{C}\right)$. The equilibrium intermetallic phase at the $\mathrm{Mg}$-rich side of the phase diagram is $\alpha-\mathrm{Mg}_{3} \mathrm{Bi}_{2}$ and has a hexagonal structure $(\mathrm{P} 3 \mathrm{ml}, a=0.4671 \mathrm{~nm}$, $c=0.7403 \mathrm{~nm}$ ). The maximum volume fraction of the equilibrium precipitate phase $\alpha-\mathrm{Mg}_{3} \mathrm{Bi}_{2}$ is approximately 3.38 pct if the alloy composition is $\mathrm{Mg}-8.85 \mathrm{wt}$ pct $\mathrm{Bi}$ and if $473 \mathrm{~K}\left(200^{\circ} \mathrm{C}\right)$ is selected as the aging temperature. Although the $\mathrm{Mg}-\mathrm{Bi}$ system is ideal for designing precipitation-hardenable alloys, the age-hardening response of binary $\mathrm{Mg}-\mathrm{Bi}$ alloys is too low to be considered for alloy development. It has been reported recently ${ }^{[239]}$ that the ternary addition of 0.5 at. pet $\mathrm{Zn}$ to a $\mathrm{Mg}-0.8$ at. pct $\mathrm{Bi}$ alloy can enhance the maximum hardness achievable by approximately 40 pct and that an even higher value of the maximum hardness can be obtained when the $\mathrm{Zn}$ concentration is increased from 0.5 at. pet to 1.0 at. pet (Figure 30(a)).

The microstructures of peak-aged samples of $\mathrm{Mg}-0.8 \mathrm{Bi}$ and $\mathrm{Mg}-0.8 \mathrm{Bi}-1.0 \mathrm{Zn}$ alloys are compared in Figures $30(\mathrm{~b})$ and (c). ${ }^{[239]}$ It is apparent that precipitates in the Zn-containing alloy have a denser distribution. These precipitates were reported to be the equilibrium phase $\alpha-\mathrm{Mg}_{3} \mathrm{Bi}_{2}$, and they form as small platelets on $\{11 \overline{2} 0\}_{\alpha}$ planes of the magnesium matrix phase. The orientation relationship between the $\alpha-\mathrm{Mg}_{3} \mathrm{Bi}_{2}$ platelets and the surrounding matrix phase is that $(0001)_{\alpha-\mathrm{Mg}_{3} \mathrm{Bi}_{2}} / /$ $(11 \overline{2} 0)_{\alpha},[11 \overline{2} 0]_{\alpha-\mathrm{Mg}_{3} \mathrm{Bi}_{2}} / /[0001]_{\alpha}$. A fraction of $[0001]_{\alpha}$ rods also forms in the $\mathrm{Mg}-0.8 \mathrm{Bi}-1.0 \mathrm{Zn}$ alloy, and they are often in contact with the $\alpha-\mathrm{Mg}_{3} \mathrm{Bi}_{2}$ platelets. Without making any distinction with the [0001] $\alpha$ rods of $\mathrm{Mg}_{4} \mathrm{Bi}_{7}$ in binary $\mathrm{Mg}-\mathrm{Zn}$ alloys, these rods are designated $\mathrm{MgZn}_{2}$ with the following orientation relationship: $(11 \overline{2} 0)_{\beta_{1}^{\prime}} / /(0001)_{\alpha}$ and $[0001]_{\beta_{1}^{\prime}} / /[11 \overline{2} 0]_{\alpha}$. It was speculated $^{[239]}$ that the $[0001]_{\alpha}$ rods form first during the aging process and then act as heterogeneous nucleation site for the $\mathrm{Mg}_{3} \mathrm{Bi}_{2}$ precipitates. If this speculation is accepted as representative, then any subsequent increase in the nucleation rate of $\alpha-\mathrm{Mg}_{3} \mathrm{Bi}_{2}$ precipitates would require a denser distribution of $[0001]_{\alpha}$ rods. Any detailed characterization in the future of precipitates in the early stages of aging using atomic-resolution HAADF-STEM is expected to provide some insightful results on heterogeneous nucleation and the role of $\mathrm{Zn}$ in the precipitation of $\alpha-\mathrm{Mg}_{3} \mathrm{Bi}_{2}$ in $\mathrm{Mg}-\mathrm{Bi}-\mathrm{Zn}$ alloys.

\section{EFFECTS OF PRECIPITATE SHAPES ON STRENGTHENING}

\section{A. Plastic Deformation by Basal Slip}

1. Mg alloys containing shear-resistant particles

The increment in critical resolved shear stress (CRSS) produced by the need for basal slip dislocations to bypass point obstacles is given by ${ }^{[10,240]}$

$$
\Delta \tau_{\mathrm{p}}=\frac{G b}{2 \pi \lambda \sqrt{1-v}} \ln \frac{d_{\mathrm{p}}}{r_{0}}
$$

where $\Delta \tau_{\mathrm{p}}$ is the increment in CRSS caused by dispersion hardening, $G$ is the shear modulus of the magnesium matrix phase, $b$ is the magnitude of the Burgers vector of the gliding dislocations in magnesium, $v$ is Poisson's ratio, $\lambda$ is the effective planar interparticle spacing, $d_{\mathrm{p}}$ is the mean planar diameter of the particles, and $r_{0}$ is the core radius of the dislocations. Within Eq. [1], the $\lambda$ varies with the shape and orientation of the particles. For spherical particles of uniform

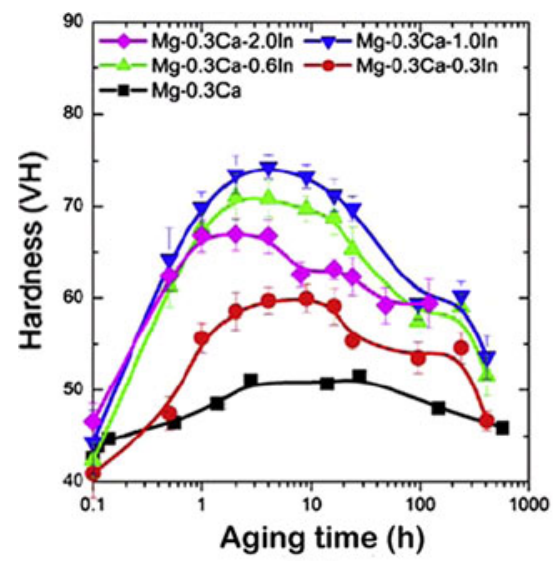

(a)

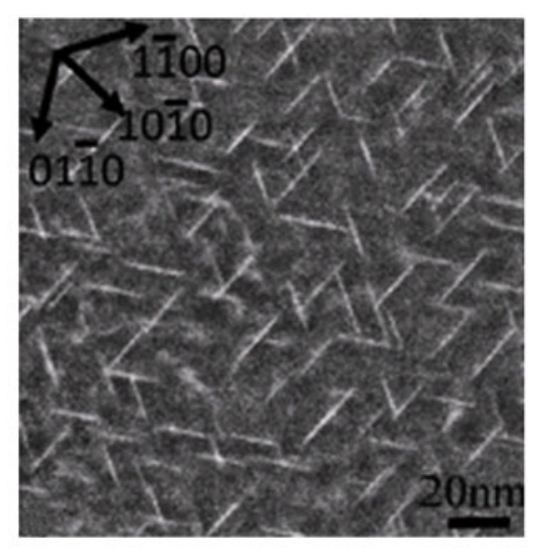

(b)

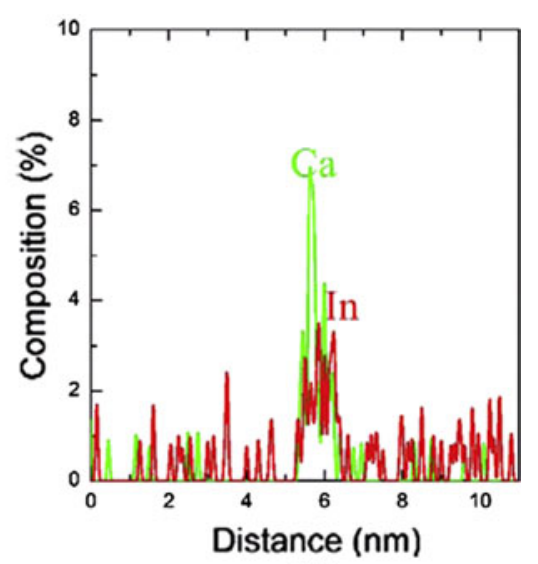

(c)

Fig. 29-(a) Age-hardening response of Mg-In-Ca alloys during isothermal aging at $473 \mathrm{~K}\left(200{ }^{\circ} \mathrm{C}\right)$, (b) HAADF-STEM image showing (c) 3DAP compositional profile of precipitate plates in $\mathrm{Mg}-1 \mathrm{In}-0.3 \mathrm{Ca}$ (at. pct) alloy peak-aged at $473 \mathrm{~K}\left(200{ }^{\circ} \mathrm{C}\right)$. Reproduced from Ref. [238]. 
diameter $d_{\mathrm{t}}$ and distribution in a triangular array on the slip plane, the particle spacing is given by

$$
\lambda=L_{\mathrm{p}}-d_{\mathrm{p}}=\frac{1.075}{\sqrt{N_{\mathrm{v}} d_{t}}}-\frac{\pi d_{t}}{4}=\left(\frac{0.779}{\sqrt{f}}-0.785\right) d_{t}
$$

where $L_{\mathrm{p}}$ is the mean planar center-to-center distance between particles, $N_{\mathrm{v}}$ is the number of particles per unit volume of the matrix phase, and $f$ is the volume fraction of particles.

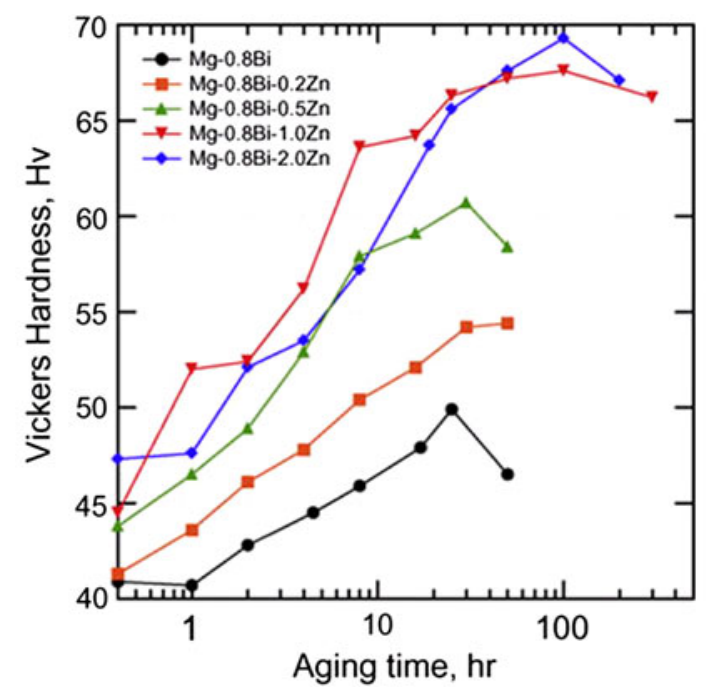

(a)

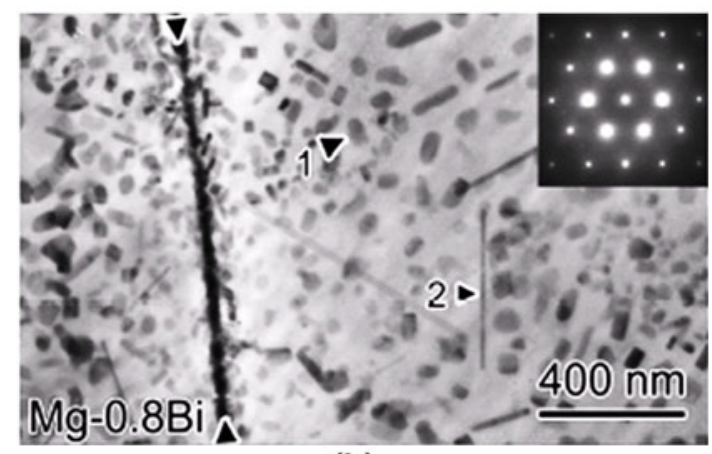

(b)

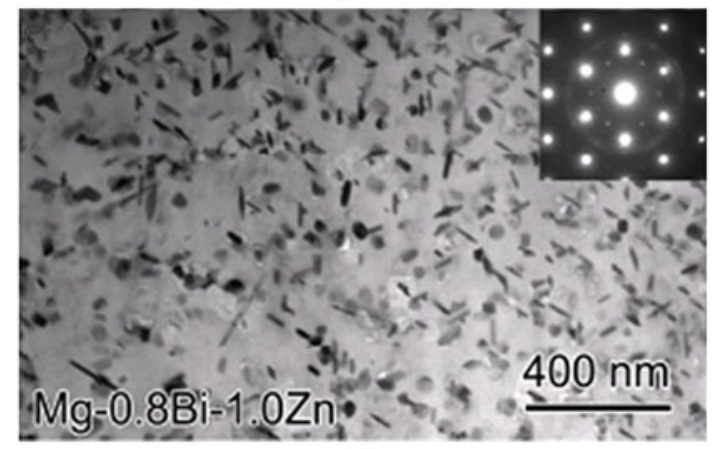

(c)

Fig. 30-(a) Aging curves of Mg-Bi-Zn alloys at $433 \mathrm{~K}\left(160{ }^{\circ} \mathrm{C}\right)$. $(b$ and $c$ ) TEM images showing distribution of precipitates in (b) $\mathrm{Mg}-0.8$ at. Pct $\mathrm{Bi}$ and $(c) \mathrm{Mg}-0.8$ at. pct Bi- 1 at. pet $\mathrm{Zn}$ alloys, both peak aged at $433 \mathrm{~K}\left(160{ }^{\circ} \mathrm{C}\right)$. Reproduced from Ref. [239].
If the particle shape is changed from sphere to plate, then both the effective planar interparticle spacing (Figures 31(a) and (b)) and the dislocation line tension will be changed. For magnesium alloys containing a triangular array of rationally oriented precipitate plates of uniform size, the strengthening effect produced by such particles can be estimated using the equations in Reference 241. These equations are derived under the assumption of a uniform periodic triangular array of particles intersecting the slip plane of the magnesium matrix phase. For fixed volume fractions and number densities of precipitates, the variations in the ratio $\Delta \tau$ (plate) $/ \Delta \tau$ (sphere) with plate aspect ratio are shown in Figure 32(a) for a precipitate volume fraction of 0.03 . For a simplified comparison, the base microstructure is assumed to comprise precipitates in a regular triangular array distribution on the slip plane of the matrix phase. As shown in Figure 32(a), the CRSS increments produced by prismatic plates are invariably larger than those produced by equivalent volume fractions of basal plates or spherical particles, and the difference increases substantially with increasing plate aspect ratio. For a given distribution of precipitate plates, the effective planar interplate spacing $\lambda$ decreases with an increase in

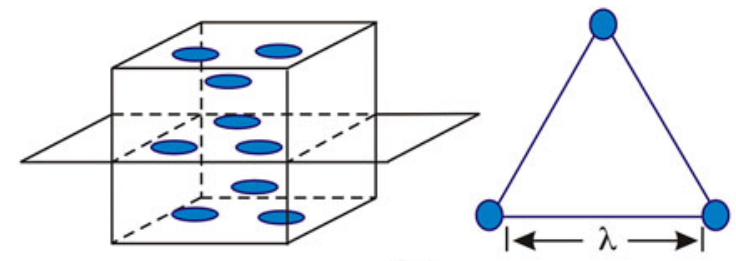

(a)
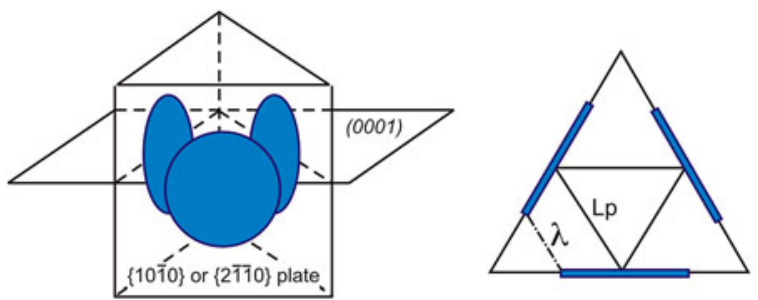

(b)
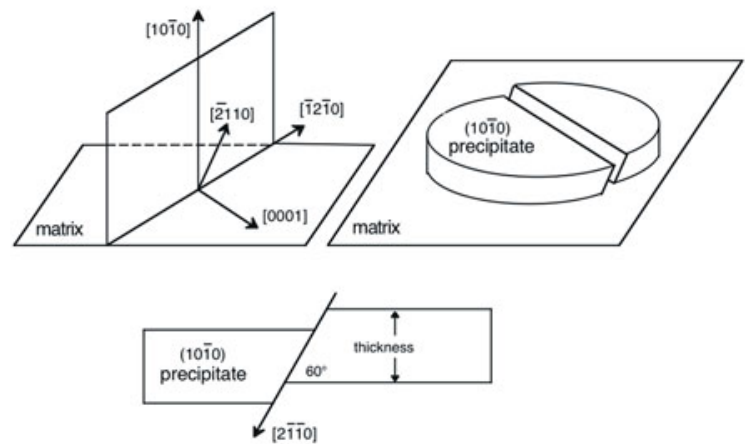

(c)

Fig. 31-Schematic diagrams showing ( $a$ and $b$ ) effects of the orientation of precipitate plates on interparticle spacing for dislocation slip on basal plane of the magnesium matrix phase (adapted from Refs. [20] and [241]), and (c) a prismatic plate sheared by dislocations gliding in basal plane of the magnesium matrix phase (reproduced from Ref. [20]). 
the plate aspect ratio. There is a critical value of aspect ratio for which the effective interparticle spacing becomes zero, and the prismatic plates form closed prismatic volumes, which are defined by prismatic plates. If the plates are assumed to remain resistant to dislocation shearing, then the dislocations generated within the prismatic volumes cannot escape and the theoretical Orowan increment becomes infinitely large. In practice, the accumulation of dislocations may lead to local stress concentrations exceeding the yield strength of precipitates and precipitate shearing.

The effect of number density of precipitates on the variation in the effective interparticle spacing with an increase in the number density of precipitates is shown in Figure 32(b) for a volume fraction of 0.03. For identical volume fractions and number densities of precipitates, the prismatic precipitate plates are much

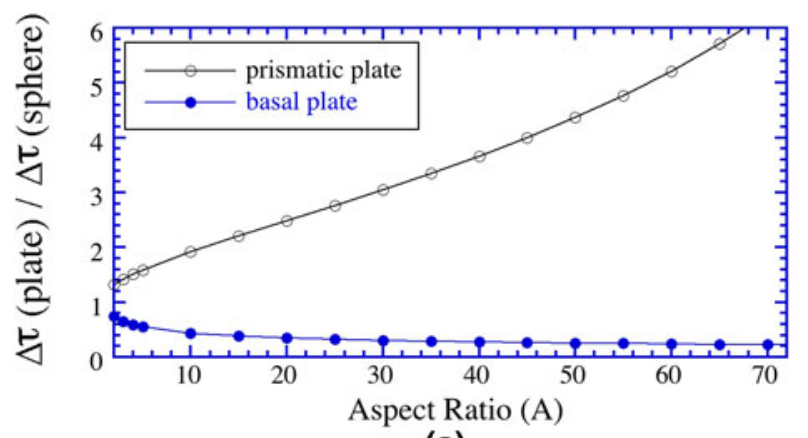

(a)

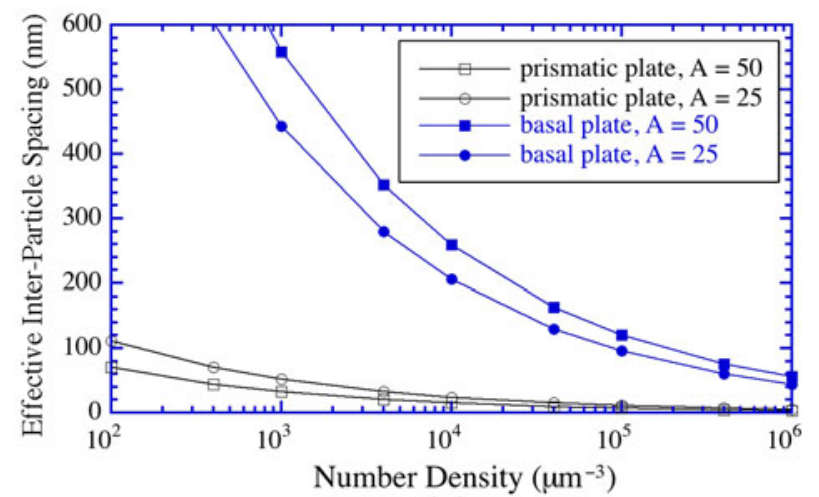

(b)

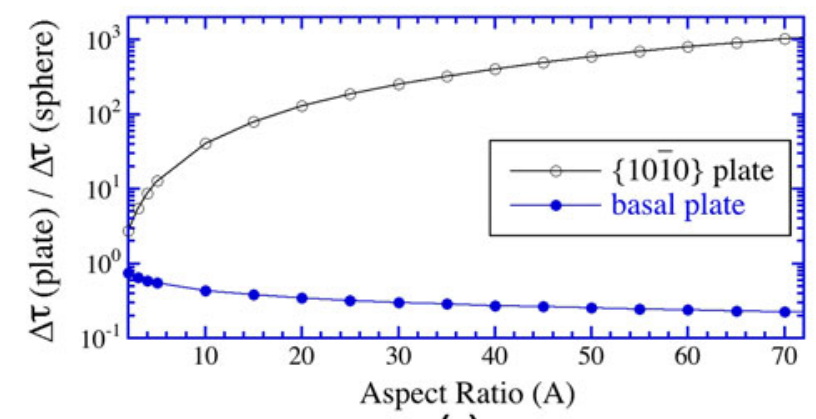

(c)

Fig. 32-Variation of $\Delta \tau_{\mathrm{p}}$ (plate) $/ \Delta \tau_{\mathrm{p}}$ (sphere) with (a) plate aspect ratio and $(b)$ number density for prismatic and basal precipitate plates calculated assuming Orowan strengthening of shear-resistant particles with a volume fraction of 0.03 . (c) Interfacial strengthening from sheared particles. more effective in reducing interparticle spacing than basal plates and spherical particles. For an aspect ratio of either $50: 1$ or $25: 1$, the smallest interparticle spacing is always associated with prismatic plates.

\section{Magnesium alloys containing shearable particles}

Shearable precipitates can impede the movement of gliding dislocations through a variety of dislocation/ particle interaction mechanisms, including those described as interfacial or chemical strengthening, coherency strengthening, stacking-fault strengthening, modulus strengthening, and order strengthening. ${ }^{[10,240]}$ For each such proposed mechanism of strengthening, the contribution of the shearable precipitates to the CRSS of an alloy can be represented by an equation of the following form:

$$
\Delta \tau_{\mathrm{p}}=\frac{2}{L_{\mathrm{p}} b \sqrt{\Gamma}} \cdot\left(\frac{F}{2}\right)^{3 / 2}
$$

where $\Gamma$ is the dislocation line tension in the magnesium matrix and force $F$ is a measure of the resistance of the precipitates to dislocation shearing. Assuming a triangular array distribution of spherical particles of uniform diameter $d_{\mathrm{t}}$, Eq. [3] may be rewritten in the form

$$
\Delta \tau_{\mathrm{i}}=\frac{1.788}{d_{\mathrm{t}}} \cdot\left(\frac{b f}{\Gamma}\right) \gamma^{3 / 2}
$$

for interfacial strengthening, ${ }^{[242]}$ where $\gamma_{i}$ is the specific interfacial energy between the precipitate and magnesium matrix phases.

For precipitates of morphologies other than sphere, it is currently difficult to assess their quantitative contributions to the CRSS increment because there is a lack of appropriate version of the strengthening equations for such precipitate shapes and orientations. Because it has been reported ${ }^{[9,240,242,243]}$ that interfacial strengthening can become a major strengthening mechanism in alloys containing plate-shaped precipitates, it is convenient to restrict the current review to interfacial strengthening. The quantitative contribution of the interfacial strengthening to the CRSS for magnesium alloys containing rationally oriented precipitate plates are given by ${ }^{[244]}$

$$
\begin{gathered}
\Delta \tau_{\mathrm{i}}=\frac{1.461}{d_{\mathrm{t}}} \cdot\left(\frac{b f}{\Gamma}\right) \gamma^{3 / 2} \text { for }(0001)_{\alpha} \text { plate } \\
\Delta \tau_{\mathrm{i}}=\frac{1.359 d_{t}}{t_{t}^{2}} \cdot\left(\frac{b f}{\Gamma}\right) \gamma^{3 / 2} \text { for }\{10 \overline{1} 0\}_{\alpha} \text { plate }
\end{gathered}
$$

These equations are derived based on an ideal regular triangular array of particles in the slip plane. It is also assumed that there is continuity of the slip plane between magnesium matrix and precipitate, and that the magnitude of the Burgers vector of the dislocations in the magnesium matrix is identical to that in the precipitate phase (Figure 31(c)).

For a given value of dislocation line tension, the variations of $\Delta \tau$ (plate) $/ \Delta \tau$ (sphere) with plate aspect ratio as a function of plate aspect ratio are shown in Figure 32(c). It is evident that the contribution of 
interfacial strengthening can become significant when particles take a plate shape on prismatic planes of the magnesium matrix phase. For identical volume fractions and number densities of precipitates per unit volume, the yield stress increments produced by prismatic precipitate plates are orders of magnitude larger than those produced by basal plates and spherical particles. The increments in CRSS produced by prismatic plates increase substantially with an increase in plate aspect ratio and are up to three orders of magnitude larger than that produced by spheres, when the plate aspect ratio is in the range of 10:1 to 70:1.

Many existing magnesium alloys are strengthened by $(0001)_{\alpha}$ precipitate plates. The precipitate plates formed in these alloys are often extraordinarily thin, less than $1 \mathrm{~nm}$, and their aspect ratio is remarkably large. Improvement in alloy strength might be achieved by increasing the number density and/or thickness of the $(0001)_{\alpha}$ plates. Such approaches seem, however, to have limitation because a simultaneous increase in the number density and thickness of precipitate plates or increasing one factor while maintaining the other constant is practically difficult to achieve. Although a much higher number density of $(0001)_{\alpha}$ plates has been produced in many of the alloys discussed in Section II, the age-hardening response and the maximum hardness and strength values of these alloys are still much lower than those obtained in counterpart aluminum alloys. ${ }^{[245]}$ A substantial improvement in strength in these alloys would be difficult to achieve unless prismatic plates of large aspect ratio are introduced to replace, or coexist with, the $(0001)_{\alpha}$ precipitate plates.

\section{B. Plastic Deformation by Twinning}

1. Mg alloys containing shear-resistant particles

It was reported by Clark ${ }^{[15]}$ that twinning becomes difficult to occur when the size and number density of $\mathrm{Mg}_{17} \mathrm{Al}_{12}$ precipitates increase. The precipitate-twin interactions in the $\mathrm{Mg}-\mathrm{Al}$ alloys and effects of precipitate shape on twinning have been studied. ${ }^{[246-248]}$ In the current review and for simplicity, the propagation of twins is considered to involve the motion of twinning dislocations, and only $\{10 \overline{1} 2\}_{\alpha}$ twins are considered in the plastic deformation process. In addition, the lattice parameters of $\mathrm{Mg}$ are taken as $a=0.5200 \mathrm{~nm}$, $c=0.3203 \mathrm{~nm}(c / a=1.6235)$. For a $\{10 \overline{1} 2\}_{\alpha}$ twin to bypass spherical particles of uniform diameter $d_{\mathrm{t}}$ and of a triangular array distribution, the increment in CRSS can be approximated by Eqs. [1] and [2]. For $(0001)_{\alpha}$ plates, of uniform diameter $d_{\mathrm{t}}$ and thickness $t_{\mathrm{t}}$, which are ideally distributed in a triangular array in the (1012) twin plane (Figure 33(a)), the increment in CRSS for $(10 \overline{1} 2)_{\alpha}$ twinning dislocations to bypass $(0001)_{\alpha}$ precipitate plates can be approximated by ${ }^{249]}$

$$
\begin{aligned}
\Delta \tau_{\mathrm{p}}= & \frac{G b}{2 \pi \sqrt{1-v}} \cdot\left\{\frac{1}{\frac{1.327 A t_{\mathrm{t}}}{1.152 \sqrt{A f}+0.785 A f-1.462 f}-1.462 t_{\mathrm{t}}}\right\} . \\
& \ln \frac{1.072 t_{\mathrm{t}} \sqrt{A}}{b}
\end{aligned}
$$

For $\{10 \overline{1} 0\}_{\alpha}$ prismatic plates, with $d_{\mathrm{t}}>>t_{\mathrm{t}}$, outlined in Figure 33(b), if we assume that each of the three plates is ideally distributed at the center of each side of the isosceles triangle, then the increment in CRSS for $\{10 \overline{1} 2\}_{\alpha}$ twinning dislocations to bypass $\{10 \overline{1} 0\}_{\alpha}$ precipitate plates can be approximated by ${ }^{[249]}$ :

$$
\begin{aligned}
\Delta \tau_{\mathrm{p}}= & \frac{G b}{2 \pi \sqrt{1-v}} \cdot\left\{\frac{1}{0.825 t_{\mathrm{t}} \sqrt{\frac{A}{f}}-0.305 A t_{t}-0.981 t_{t}}\right\} . \\
& \ln \frac{0.914 t_{t} \sqrt{A}}{b}
\end{aligned}
$$

Similarly, the increment in CRSS for $(10 \overline{1} 2)_{\alpha}$ twinning dislocations to bypass $\{11 \overline{2} 0\}_{\alpha}$ precipitate plates can be estimated by ${ }^{[249]}$ :
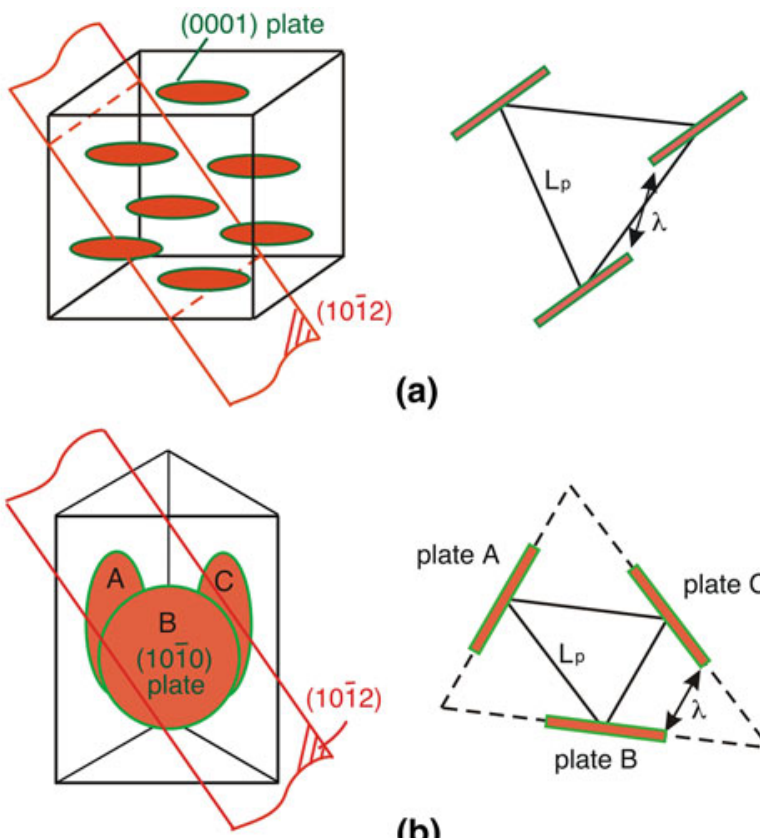

(a)

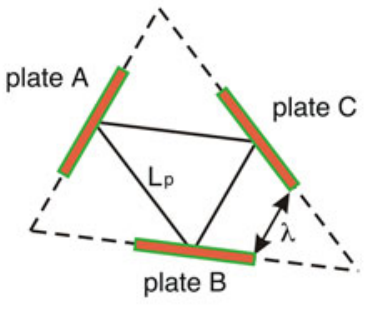

(b)

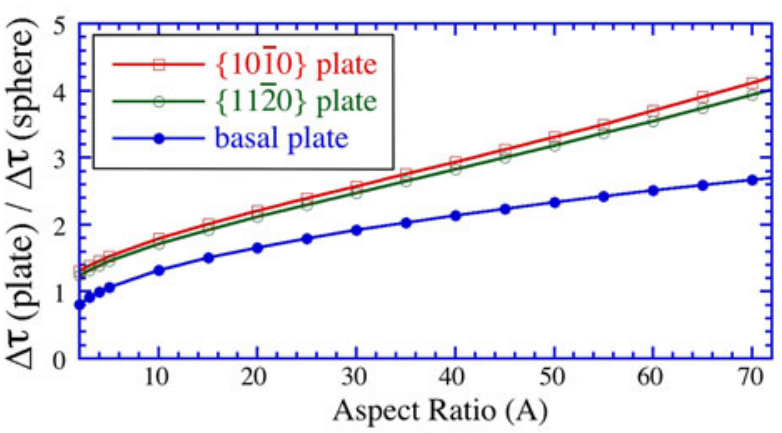

(c)

Fig. 33- Schematic diagrams showing $(a$ and $b$ ) the effects of the orientation of precipitate plates on interparticle spacing for twinning on $\{10 \overline{1} 2\}$ plane of the magnesium matrix phase, and $(c)$ the quantitative effects of the orientation and aspect ratio of precipitate plates on Orowan strengthening. The precipitate volume fraction is $0.03 .^{[249]}$ 


$$
\Delta \tau_{\mathrm{p}}=\frac{G b}{2 \pi \sqrt{1-v}} \cdot\left\{\frac{1}{t_{t} \sqrt{0.752 \frac{A}{f}-\sqrt{\frac{A}{f}}(0.579 A+1.727)+0.117 A^{2}+0.690 A+1.021}}\right\} \cdot \ln \frac{0.886 t_{t} \sqrt{A}}{b}
$$

If the logarithmic terms in Eqs. [8] and [9] are assumed to be identical and in the case of spherical precipitates and basal plates, the base microstructure is assumed to comprise precipitates in a regular triangular array distribution in the $(10 \overline{1} 2)_{\alpha}$ twin plane. For identical volume fractions and number densities of precipitates per unit volume of the matrix phase, the ratio $\Delta \tau_{\mathrm{p}}$ (plate) $/ \Delta \tau_{\mathrm{p}}$ (sphere) is invariably larger than unity, when the plate aspect ratio is in the range 5:1 to $70: 1$, which means that precipitate plates are more effective in impeding twinning dislocation propagation (Figure 33(c)). Furthermore, the ratio $\Delta \tau_{\mathrm{p}}$ (plate)/ $\Delta \tau_{\mathrm{p}}$ (sphere) increases substantially with increasing plate aspect ratio. For a given distribution of prismatic plates, an increase in the plate aspect ratio can lead to significant reduction in effective interparticle spacing. For either $\{10 \overline{1} 0\}_{\alpha}$ or $\{11 \overline{2} 0\}_{\alpha}$ plates, there is again a critical value of plate aspect ratio for which the effective interparticle spacing becomes zero. This implies that, at such a critical plate aspect ratio, the plates will divide a single magnesium grain into many enclosed prismatic volumes. If the plates are assumed to remain shear resistant, then the $(10 \overline{1} 2)_{\alpha}$ twins generated within a prismatic volume are constrained in this prismatic volume.

\section{MICROSTRUCTURAL DESIGN FOR HIGHER STRENGTH}

For precipitation-hardened magnesium alloys, whether particles are sheared or are shear resistant, and whether the deformation mode is basal slip or twinning, the particle strengthening models indicate that precipitate plates formed on prismatic planes of the magnesium matrix phase provide the most effective barrier to gliding dislocations and propagating twins in the magnesium matrix. The models further suggest that a higher strength can be achieved if a high density of intrinsically strong, plate-shaped precipitates with prismatic and basal habit planes and of large aspect ratio can be developed in the microstructure (Figure 34). [249]

Whereas it is now possible to generate a microstructure containing both prismatic and basal plates in some magnesium alloys such as those based on the Mg-Gd-Y$\mathrm{Zn}$ system, and the basal plates in such a microstructure have a large aspect ratio, the aspect ratio and number density of the prismatic plates are much lower than those typical of precipitate plates formed in highstrength aluminum alloys. In high-strength precipitation-hardened aluminum alloys, the maximum hardness and yield strength is commonly associated with microstructures containing a high density of $\{100\}_{\alpha}$ and $\{111\}_{\alpha}$ precipitate plates of large aspect ratio (typically

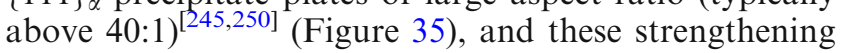
precipitates are often intermediate or equilibrium phases that are intrinsically stronger than G.P. zones and metastable precipitates formed in the early stage of aging. ${ }^{[251]}$ Improvements in the alloy strength thus require an increase in the number density and/or aspect ratio of prismatic plates of intermediate or equilibrium precipitate phases. ${ }^{[252]}$ It is to be noted that the traditional approach to the strength improvement rarely considers the precipitate plate aspect ratio and, instead, puts an emphasis on precipitate number density. The particle-strengthening models suggest that the precipitate plate aspect ratio is an important strengthening factor, as least as important as the precipitate number density, and that a remarkable enhancement in alloy strength could be achieved if the aspect ratio of the prismatic precipitate plates is substantially increased.

How to introduce intrinsically strong, prismatic precipitate plates into the magnesium matrix is currently a difficult question to answer. However, one possible approach may involve consideration of phase equilibria and lattice matching of magnesium and precipitate structures. ${ }^{[33,253,254]}$ The precipitate phase may be selected from the equilibrium or near equilibrium phases that form via reactions among magnesium and/or added alloying elements. These phases are expected to be intrinsically strong and, therefore, more resistant to shearing and plastic deformation. Inspections of the structures of these equilibrium phases and that of magnesium can reveal whether it is possible to have the prismatic plane as an invariant strain plane (habit

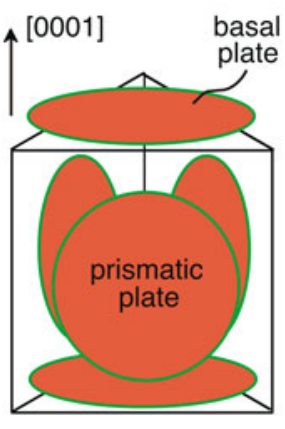

(a)

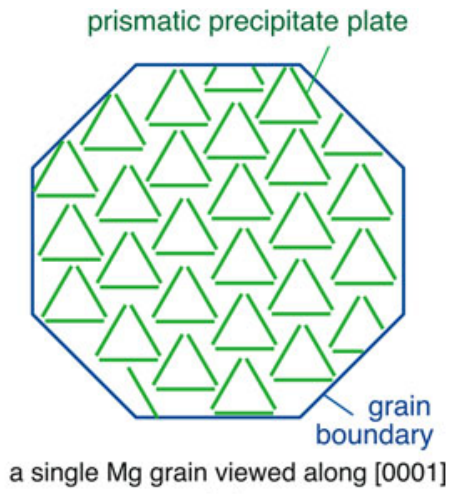

(b)
Fig. 34-Microstructural design for precipitation-hardenable magnesium alloys with a higher strength. A near-continuous network of prismatic and basal precipitate plates in $(a)$ can divide a single magnesium grain into many near-isolated blocks in $(b)$ and therefore effectively impede propagation of dislocations and twins. ${ }^{[249]}$ 
plane) between the precipitate and magnesium structures. One good example is the $\beta_{1}$ phase (space group $\mathrm{Fm} \overline{3} \mathrm{~m}, a=0.74 \mathrm{~nm}$ ) in $\mathrm{Mg}-\mathrm{Nd}$, Mg-Y-Nd, Mg-Gd, $\mathrm{Mg}-\mathrm{Gd}-\mathrm{Y}$, and $\mathrm{Mg}-\mathrm{Gd}-\mathrm{Nd}$ alloys. The structure of this phase can be generated from the magnesium lattice by an invariant plane strain transformation. ${ }^{[180]}$ Therefore, it is fully predictable that the $\mathrm{Mg}_{3} \mathrm{Nd}$ precipitates form as plates on $\{10 \overline{1} 0\}$, even without examining the microstructures using TEM.

It is perhaps also constructive to compare precipitates of $\mathrm{Mg}_{17} \mathrm{Al}_{12}$ in $\mathrm{Mg}$-Al alloys and $\mathrm{Mg}_{24} \mathrm{Y}_{5}$ in $\mathrm{Mg}-\mathrm{Y}$ alloys. ${ }^{[25]}$ Although the $\mathrm{Mg}_{17} \mathrm{Al}_{12}$ and $\mathrm{Mg}_{24} \mathrm{Y}_{5}$ phases

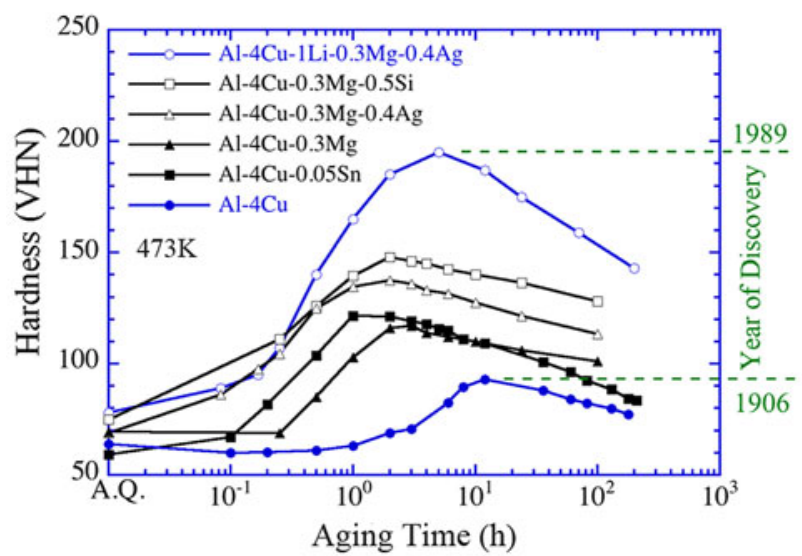

(a)

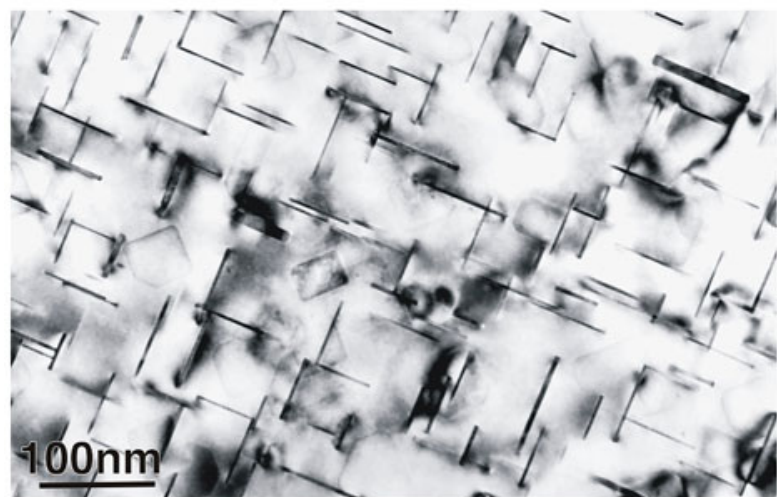

(c)

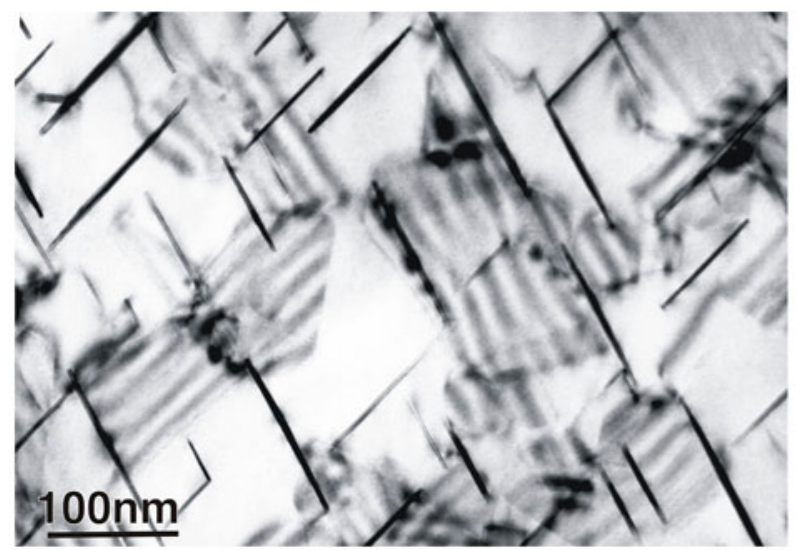

(e)

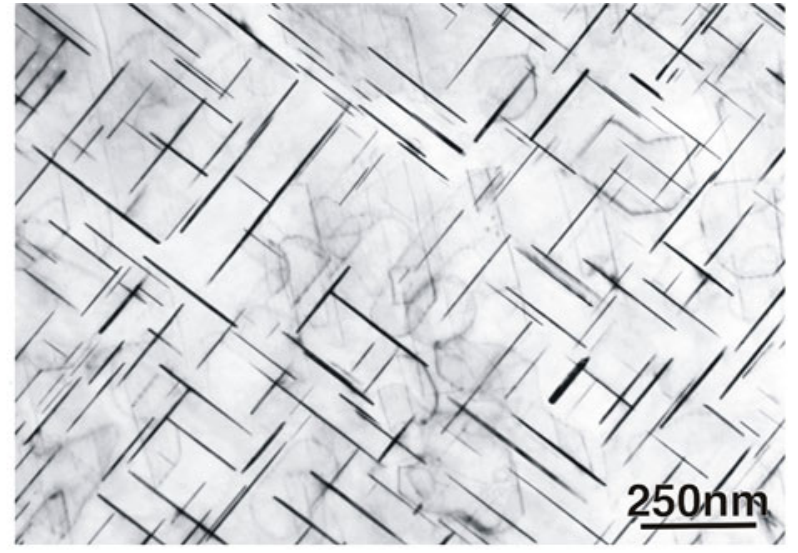

(b)

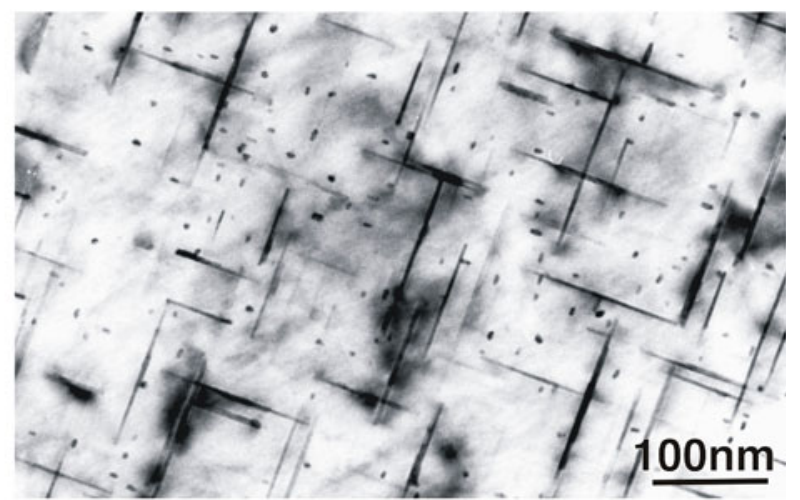

(d)

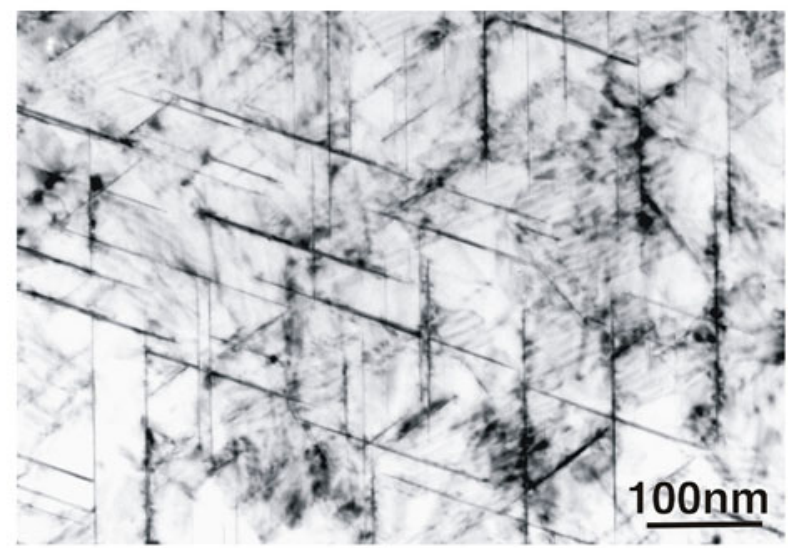

(f)

Fig. 35-(a) Development of precipitation-hardenable Al-Cu based alloy via microalloying and macroalloying additions. The aging temperature is $473 \mathrm{~K}\left(200{ }^{\circ} \mathrm{C}\right)$. Transmission electron micrographs showing $\{100\}_{\alpha}$ precipitate plates of $\theta^{\prime}$ in $(a) \mathrm{Al}-4 \mathrm{Cu}$ alloy aged $24 \mathrm{~h}$ at $473 \mathrm{~K}\left(200{ }^{\circ} \mathrm{C}\right)$, (b) Al-4Cu-0.05Sn alloy aged $3 \mathrm{~h}$ at $473 \mathrm{~K}\left(200^{\circ} \mathrm{C}\right)$, and $(c) \mathrm{Al}-4 \mathrm{Cu}-0.3 \mathrm{Mg}-0.5 \mathrm{Si}$ alloy aged $3 \mathrm{~h}$ at $473 \mathrm{~K}\left(200{ }^{\circ} \mathrm{C}\right)$, and $\{111\}_{\alpha}$ precipitate plates of $(d) \Omega$ phase in Al-4Cu-0.3Mg-0.4Ag alloy aged $100 \mathrm{~h}$ at $473 \mathrm{~K}\left(200{ }^{\circ} \mathrm{C}\right)$, and $(e) \mathrm{T}_{1}$ phase in $\mathrm{Al}-4 \mathrm{Cu}-1 \mathrm{Li}-0.3 \mathrm{Mg}-0.4 \mathrm{Ag}$ alloy aged $5 \mathrm{~h}$ at $473 \mathrm{~K}$ $\left(200{ }^{\circ} \mathrm{C}\right.$ ). Electron beam is parallel to $\langle 001\rangle_{\alpha}$ in (a through c) and $\langle 011\rangle_{\alpha}$ in (d and e). The alloy compositions are in weight percentage. Reproduced from Ref. [245]. 
have same crystal structure (space group $\mathrm{I} \overline{4} 3 \mathrm{~m}$, 58 atoms per unit cell) and similar lattice parameters and orientation relationships, they have drastically different habit planes. The $\mathrm{Mg}_{17} \mathrm{Al}_{12}$ phase has a lattice parameter of $\sim 1.064 \mathrm{~nm}$. For the observed orientation relationship between the $\mathrm{Mg}_{17} \mathrm{Al}_{12}$ phase and the matrix $(1 \overline{1} 0)_{\mathrm{p}} / /(0001)_{\alpha},[111]_{\mathrm{p}} / /[11 \overline{2} 0]_{\alpha}$, the lattice misfit between $(1 \overline{10})_{\mathrm{p}}$ and $(0001)_{\mathrm{m}}$ is $2.7 \mathrm{pct}$ if the lattice parameters of the Mg-9 wt pet Al alloy are taken as the following: $a=0.31699 \mathrm{~nm}, \quad c=0.5155 \mathrm{~nm} .^{[255]}$ The $\mathrm{Mg}_{17} \mathrm{Al}_{12}$ phase adopts a plate shape, with its habit plane parallel to $(1 \overline{1} 0)_{\mathrm{p}}$ and $(0001)_{\mathrm{m}}$. The equilibrium $\mathrm{Mg}_{24} \mathrm{Y}_{5}$ phase has a lattice parameter of $\sim 1.125 \mathrm{~nm},{ }^{[14]}$ which is slightly larger than that of $\mathrm{Mg}_{17} \mathrm{Al}_{12}$. Given that its orientation relationships is also $(1 \overline{10})_{\mathrm{p}} / /$ $(0001)_{\alpha},[111]_{\mathrm{p}} / /[11 \overline{2} 0]_{\alpha}$, the lattice misfit between $(1 \overline{1} 0)_{\mathrm{p}}$ and $(0001)_{\mathrm{m}}$ is -2.9 pct. The $\mathrm{Mg}_{24} \mathrm{Y}_{5}$ phase also adopts a plate shape, but its habit plane is parallel to $\{1010\}$ instead of $(0001)_{\alpha}$. Whereas both $(0001)_{\alpha}$ and $\{1010\}_{\alpha}^{\alpha}$ habit planes are geometrically possible for the Burger's orientation relationship ${ }^{[253]}$ and because a small change in the lattice parameter of the precipitate phase, or the matrix phase, can cause this to happen, it is currently unclear why the $\mathrm{Mg}_{17} \mathrm{Al}_{12}$ precipitates form predominantly on $(0001)_{\alpha}$. If $\mathrm{Al}$ atoms in the $\mathrm{Mg}_{17} \mathrm{Al}_{12}$ unit cell could be partially replaced by $\mathrm{Y}$ atoms, then the lattice parameter of the $\mathrm{Mg}_{17} \mathrm{Al}_{12}$ phase would be modified to reduce the lattice misfit between precipitates and the matrix phase, and it becomes energetically possible to achieve higher nucleation rates and number density of precipitates. Unfortunately, $\mathrm{Y}$ and $\mathrm{Al}$ atoms react strongly in the molten metal to form $\mathrm{Al}_{2} \mathrm{Y}$ particles before alloy casting, leaving few $\mathrm{Y}$ atoms in the magnesium solid solution matrix to form the $\operatorname{Mg}_{17}\left(\mathrm{Al}_{1-x} \mathrm{Y}_{x}\right)_{12}$ phase during the aging process.

It is also to be noted that $\mathrm{Mg}$ - $\mathrm{Th}$ alloys are also strengthened by $\{10 \overline{1} 0\}_{\alpha}$ precipitate plates ${ }^{[256-261]}$ even though these alloys were abandoned many years ago because of the toxicity of $\mathrm{Th}$. The maximum solid solubility of $\mathrm{Th}$ in magnesium is only approximately 0.52 at. pct or $4.75 \mathrm{wt}$ pct at the eutectic temperature of $855 \mathrm{~K}\left(582^{\circ} \mathrm{C}\right) .{ }^{[14]}$ The maximum volume fraction of the equilibrium precipitate phase $\mathrm{Mg}_{23} \mathrm{Th}_{6}$ in a $\mathrm{Mg}$ 3.2 wt pet Th-0.7 wt pet $\mathrm{Zr}$ alloy (HK31) aged at $473 \mathrm{~K}\left(200^{\circ} \mathrm{C}\right)$ is estimated to be $\sim 1.8$ pct. The prismatic precipitate plates formed in this alloy are quite thin. It is worth examining the crystal structure and formation mechanism of the key strengthening precipitate phase in peak-aged Mg-Th alloys. The knowledge to be gained from this alloy can be used to select precipitate phases that can form from nontoxic alloying elements but lead to similar or even better age-hardening effects. Equally, an in-depth knowledge on the structure and formation mechanisms of prismatic precipitate plates formed in Mg-In-Ca alloys (Figure 29(b)) can also provide useful guidelines to the formation and manipulation of prismatic plates in magnesium alloys.

In magnesium alloys that are already strengthened by prismatic plates of intrinsically strong precipitate phases, any subsequent enhancement in yield strength requires an increase in the precipitate plate aspect ratio and/or precipitate number density. Approaches to achieving an increase in plate aspect ratio and number density may lie in the use of (1) microalloying additions, which may partition to either matrix or precipitate phase to improve matching between the precipitate and matrix phase; (2) cold work after solution treatment and prior to aging, which introduces dislocations to provide heterogeneous nucleation sites for intermediate and/or equilibrium precipitate phases; (3) duplex or multiple isothermal aging; and (4) single or multiple nonisothermal aging. Such approaches inevitably involve the consideration of the crystal structure, the orientation relationship, the formation mechanism of strengthening precipitate phases, and the elastic strains associated their nucleation.

Currently, there is a lack of a selection rule for microalloying elements. The establishment of this selection rule inevitably requires an in-depth understanding of the formation mechanisms of the plate-shaped precipitates. It was proposed ${ }^{[180]}$ that the $\beta_{1}$ structure can be generated phenomenologically from the $\alpha-\mathrm{Mg}$ lattice by a shear on the $(1 \overline{1} 00)_{\alpha}$ plane in the $[\overline{1} \overline{1} 20]_{\alpha}$ direction, combined with an expansion in the direction normal to the shear plane, which was confirmed in a recent study using atomic-resolution HAADF-STEM (Figure 23(c)). ${ }^{[196]}$ The transformation strain itself is an invariant plane strain, with the invariant plane parallel to the shear plane $(1 \overline{100})$. This formation mechanism is similar to that proposed for $\gamma^{\prime}$ plates in $\mathrm{Mg}-\mathrm{Gd}-\mathrm{Zn}^{[203]}$ and $\mathrm{Mg}-\mathrm{Y}-\mathrm{Zn}^{[214]}$ alloys, proeutectoid $\alpha$ plates in a Ti$\mathrm{Cr}$ alloy, ${ }^{[262-264]}$ and for precipitate plates of $\gamma^{\prime}$ in Al-Ag alloys, $\theta^{\prime}$ in $\mathrm{Al}-\mathrm{Cu}$ alloys, $T_{1}$ in $\mathrm{Al}-\mathrm{Cu}-\mathrm{Li}(-\mathrm{Mg}-\mathrm{Ag})$ alloys, and $\Omega$ in Al-Cu-Mg-Ag alloys. ${ }^{[265,266]}$ Figure 36 shows schematically an initial $\beta_{1}$ platelet that has a thickness of one unit cell and is constrained within the $\alpha-\mathrm{Mg}$ matrix phase. If the precipitate phase is much stronger than the matrix, then the formation of this platelet will result in regions of expansion (E) and contraction $(\mathrm{C})$ in the matrix surrounding the platelet and to the associated accumulation of significant shear strain energy. ${ }^{[180]}$ A mechanism is thus required to operate to minimize the shear strain energy during nucleation (and growth) of the precipitate phase. One potential approach to accommodating the shear strain energy involves an extrinsic supply of relatively larger solute atoms to the $\mathrm{E}$ regions and of corresponding concentrations of vacancies to the $\mathrm{C}$ regions. Such an environment might be found in the vicinity of clusters combining larger solute atoms with a local excess of vacancies. Although currently there is no evidence for such solute-rich clusters in Mg-Nd, Mg-Gd, Mg-Gd-Y, $\mathrm{Mg}-\mathrm{Gd}-\mathrm{Nd}$, and Mg-Y-Nd alloys, it is to be noted that $\mathrm{Nd}, \mathrm{Gd}$, and $\mathrm{Y}$ atoms have relatively high binding energies with vacancies ${ }^{[180]}$ and are all larger than $\mathrm{Mg}$ atoms. The shear strain associated with an embryo precipitate plate might be reduced or removed if $\mathrm{Nd}$, $\mathrm{Gd}$, or $\mathrm{Y}$ atoms segregate to the extended regions and associated vacancies to the compressed regions during nucleation. If such a mechanism were to operate, then it is plausible that any particles evolved from such soluterich clusters would be expected to form at the end facets rather than the broad surfaces of the $\beta_{1}$ plate. This is in perfect agreement with experimental observations that 


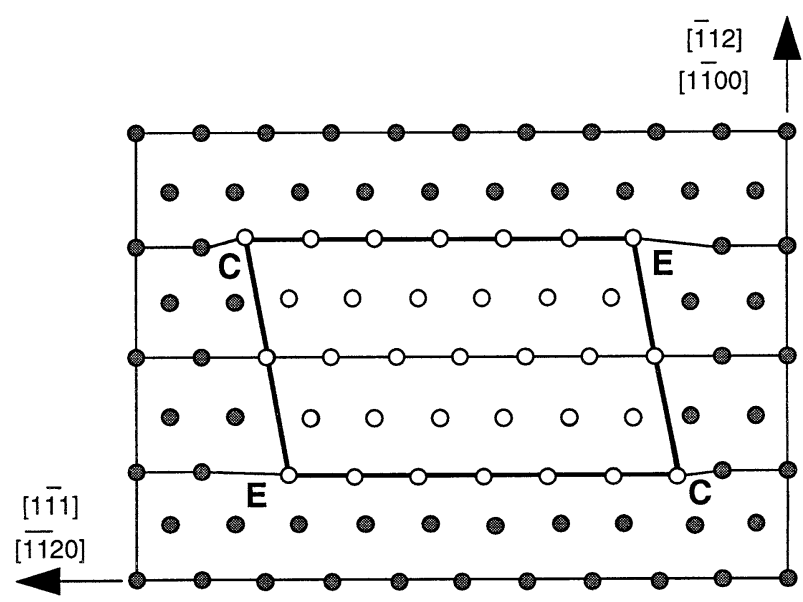

Fig. 36- Schematic diagram showing a $\beta_{1}$ platelet constrained in matrix magnesium lattice. Open and filled circles represent atoms in $\beta_{1}$ and $\mathrm{Mg}$ lattices respectively. Reproduced from Ref. [180].

$\beta_{1}$ plates form invariably in association with $\beta^{\prime}$ particles that are in contact with the end-facets of $\beta_{1}$ plates (Figure 23(a)). It is to be noted that similar phenomena have been documented in $\mathrm{Al}-\mathrm{Cu}-\mathrm{Sn}$ alloys, where the formation of $\theta^{\prime}$ plates involves a large shear $\operatorname{strain}^{[265,266]}$ and Sn particles are invariably located at the end facet of $\theta^{\prime}$ plates when they form in association with the $\theta^{\prime}$ plates. ${ }^{[267,268]}$

The accumulated experimental evidence seems to suggest that the most effective microalloying elements in enhancing nucleation rates of plate-shaped precipitates are those having larger atomic sizes and strong binding energies with vacancies. Although it is a straightforward exercise for the selection of elements with larger atomic sizes, it is currently difficult to judge which elements have large binding energies with vacancies in the matrix of magnesium. There is an urgent need for more theoretical ${ }^{[86,87]}$ and experimenta ${ }^{[269]}$ work on this aspect.

An alternative way to accommodate the shear strain energy involved in the precipitate formation and, therefore, to facilitate the nucleation of $\beta_{1}$ precipitates is to introduce dislocations of appropriate Burgers vectors. As shown in Figure 22, the cold work prior to aging can promote the formation of $\beta_{1}$ phase and the maximum hardness. Although the interaction between preexisting dislocations and the $\beta_{1}$ phase has not been examined in detail using transmission electron microscopy, it is to be noted that in $\mathrm{Al}-\mathrm{Cu}$ alloys, a partial dislocation with a Burgers vector of $a / 2\langle 001\rangle_{\alpha}$ on $\{100\}_{\alpha}$ can cancel the shear strain associated with the formation of a plate of $\theta^{\prime}$ of single unit cell thickness and thus facilitate nucleation of $\theta^{\prime 270]}$; and that in $\mathrm{Al}-\mathrm{Cu}-\mathrm{Li}$ alloys, the shear strain involved in the formation of $T_{1}$ precipitate plates of unit cell thickness may be eliminated if nucleation occurs on a Shockley partial dislocation. ${ }^{[271]}$ It is interesting to note that some prismatic plates of $\beta_{1}$ phase can form a hexagonal-shaped, continuous network in localized regions of the magnesium matrix (Figure 37). ${ }^{[196,272]}$ The formation of such a honeycomb structure of the $\beta_{1}$ plates is likely to be associated with a preexisting hexagonal network of dislocations inside magnesium grains. It is of significance to strengthening if this honeycomb structure could be extensively generated inside individual magnesium grains.

Although the yield strength achieved thus far in magnesium alloys is still much lower than that obtained in counterpart aluminum alloys (Figure 38 and Table II), it is to be noted that a significant progress has been made over the past 12 years. The yield strengths of precipitation-hardenable magnesium alloys were generally less than $200 \mathrm{MPa}$, which are lower than those of aluminum alloys, before year 2000. But around years 2007 to 2009, the yield strength of magnesium alloys approached $320 \mathrm{MPa}$ for casting alloys ${ }^{[235]}$ and $475 \mathrm{MPa}$ for extrusion alloys. ${ }^{[202]} \mathrm{A}$ similar or even faster pace is expected in the development of highstrength magnesium alloys if the level of magnesium research activities enjoyed over the past 12 years can be maintained in the future. The precipitation hardening phenomenon in aluminum alloys was discovered accidentally by Alfred Wilm in $1906,{ }^{[273-275]}$ and the strength of aluminum alloys made at that time was compatible to that of precipitation-hardenable magnesium alloys in year 2000. In the following years, the agehardening response and the strength of the alloys were gradually improved with the additions of microalloying elements, either individually or in combination (Figure 35). In 1989, it was discovered that additions of small amounts of lithium to Al-Cu-Mg-Ag alloys could stimulate an even greater age-hardening response, ${ }^{[276,277]}$ and an Al-Cu-Li-Mg-Ag alloy designated Weldalite 049 (McCook Metals, LLC, McCook, IL) was developed by Pickens et al. ${ }^{[277]}$ Although the composition of this alloy is not too much different from that of the Al- $\mathrm{Cu}$ binary base alloy, this alloy has an extraordinary age-hardening response and has an ultrahigh strength exceeding $700 \mathrm{MPa}$ when tested at room temperature.

\section{UNSOLVED ISSUES AND SUMMARY}

As a consequence of the tremendous efforts made over the past decade, considerable advances have been made in the understanding of precipitation and hardening in magnesium alloys and the development of highstrength magnesium alloys via precipitation hardening. However, as a class of engineering materials, magnesium alloys are still inferior to aluminum alloys in terms of age-hardening response and strength. Further attempts to improve the strength of existing alloys and the development of new high-strength alloys require an insightful understanding of the factors important in controlling the nucleation and growth of precipitates and the strength of the alloys, which inevitably involves consideration of the structure, orientation relationship, morphology, and formation mechanisms of precipitates and the interaction between these precipitates and dislocations and twins during the deformation process. Such understandings form the platform of any rational design and development of magnesium alloys with improved strength. 


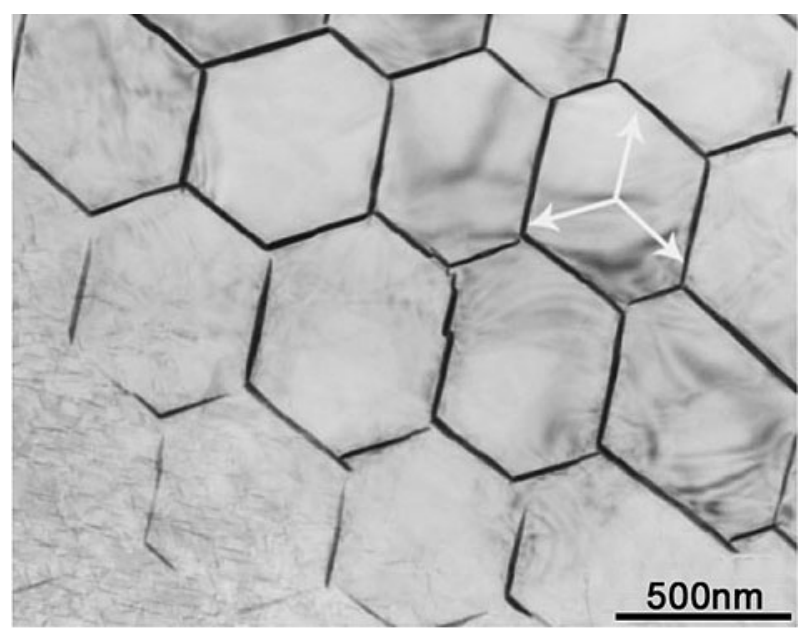

(a)

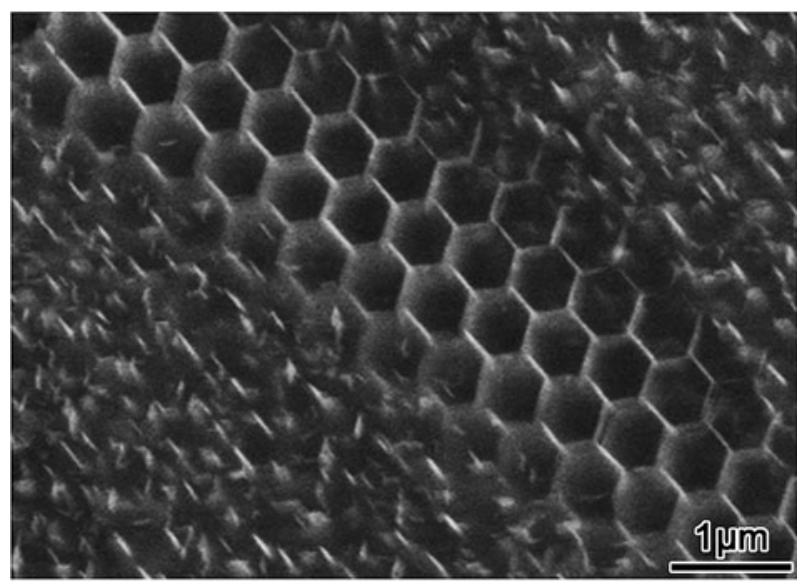

(b)

Fig. 37-(a) Transmission electron micrograph, and (b) scanning electron micrograph showing the formation of a continuous network of prismatic plates of $\beta_{1}$ phase, i.e., honeycomb structure, in $\mathrm{Mg}-0.99$ at. pct Sm and WE54 alloys, respectively. (a) is reproduced from Ref. [272] and (b) is from Ref. [196].

In precipitation-hardened magnesium alloys with multiple alloying elements, the metastable or equilibrium phase equilibria that determine the formation of key strengthening phases have not been examined systematically. Future improvements in the design of magnesium alloys for higher strength will require an improved understanding of the metastable and equilibrium phase equilibria leading to those intermediate or equilibrium phases forming as plate-shaped precipitates on prismatic planes. In particular, there needs to be a concerted systematic effort to understand more completely the role of microalloying additions in determining metastable or equilibrium phase equilibria, especially in promoting the number density and/or aspect ratio of the plate-shaped precipitates outlined in Figure 34. There are still many unsolved and challenging issues on precipitation and hardening in magnesium alloys, which provide ample opportunities for further research in the forthcoming years. These issues include the following:

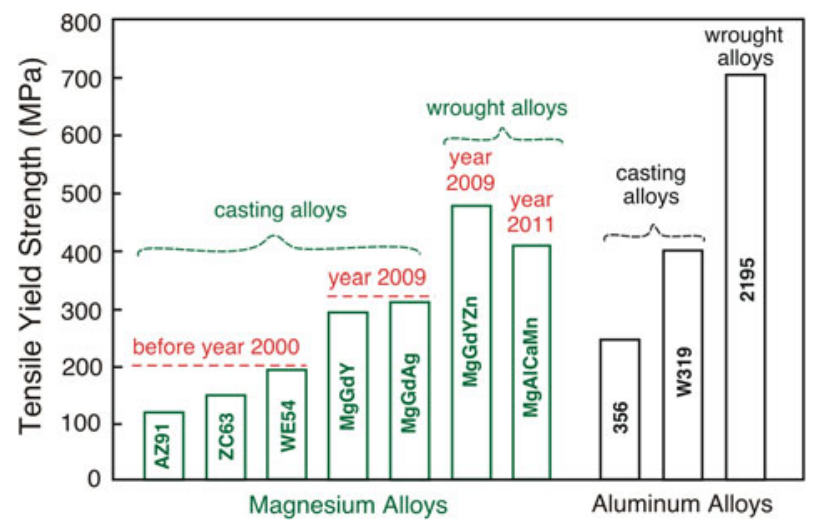

Fig. 38-Development of precipitation-hardenable casting and wrought magnesium alloys. Representative precipitation-hardenable aluminum casting (356 and W319) and wrought (2195) alloys are also provided for the purpose of a comparison of tensile yield strength.

1. The structure and composition of precipitate phases formed in the early stage of isothermal aging are poorly understood in many, if not all, commercial and laboratory alloys. The full spectrum of the precipitation sequence and especially the relationship between adjacent precipitate phases in the whole precipitation sequence remains clear. For example, how does an already formed precipitate phase influence the nucleation of another precipitate phase? It has been demonstrated in recent years that the application of atomic-resolution HAADF-STEM, i.e., Z-contrast imaging technique, can reveal more structural and compositional information at the atomic scale. The use of this imaging technique, combined with 3DAP and other characterization techniques, is expected to resolve this issue.

2. Many of the precipitate phases in magnesium alloys form as basal plates, and often their thickness is of a single unit cell height and remains so even after prolonged aging at elevated temperature. These plates also commonly form in pairs or clusters. It is currently not clear why such precipitate plates resist thickening and why they form in pairs or clusters. These phenomena do not seem to be solely related to the elastic strain effects that are imposed on the precipitates and the surrounding matrix.

3. The particle strengthening models indicate that a combined distribution of intrinsically strong prismatic and basal plates of large aspect ratio is needed for developing higher strength magnesium alloys. Although a rich knowledge has been accumulated for generating basal plates of large aspect ratio, it is currently difficult to know how to generate prismatic plates of the required aspect ratio. The factors determining the habit plane of plateshaped precipitates and the phase equilibria in a multielement system remain largely unknown. The precise role of microalloying elements in the nucleation and growth of strengthening precipitate phases is also largely unknown, and the selection rules of microalloying elements remain empirical. 
4. Magnesium alloys often have a mixture of precipitate phases that have different morphologies, sizes, and distributions instead of having a single precipitate phase of a uniform size. How such precipitates interact with dislocations and twins during the deformation process and therefore influence the alloy strength is an area that has been much less researched.

It is inevitable that any rational design and further development of higher strength magnesium alloys requires a much better understanding of such issues. With modern manufacturing, processing, and characterization facilities as well as modern communication networks, it is foreseeable that it will take a much shorter period for magnesium alloys to achieve the ultrahigh-strength level that is currently enjoyed by precipitation-hardenable aluminum alloys, i.e., much less than the 80-year period experienced by the development of ultrahigh-strength aluminum alloys (Figure 35(a)).

\section{ACKNOWLEDGMENTS}

The author wishes to acknowledge gratefully the generous and continuing support from the Australian Research Council in the past 12 years, as well as the research work done by author's students, postdocs and colleagues, including Mr. Tim Hilditch, Miss Sabine Kallisch, Miss Olga Seremetis, Mr. Bryce Wood, Miss Zheng Ma, Dr. Yuman Zhu, Mr. Zhou Xu, Dr. Matthew Weyland, Dr. Laure Bourgeois, Dr. Xiaoling Xiao, Dr. Chamini Mendis, Dr. Robert Wilson, Mr. Sam Gao, and Dr. Suming Zhu. The author is thankful for the access to the facilities in the Monash Centre for Electron Microscopy, the assistance from Dr. Houwen Chen for formatting some figures and tables of this paper, and helpful discussions with Dr. Allan Morton, Prof. Barry Muddle, Prof. Hub Aaronson, and especially Dr. Kazuhiro Hono during the past 15 years.

\section{REFERENCES}

1. G.V. Raynor: The Physical Metallurgy of Magnesium and its Alloys, Pergamon Press, London, U.K., 1959.

2. C.S. Roberts: Magnesium and Its Alloys, Wiley, New York, NY, 1960.

3. E.F. Emley: Principles of Magnesium Technology, Pergamon Press, London, U.K., 1966.

4. L.L. Rokhlin: Magnesium Alloys Containing Rare Earth Metals, Taylor and Francis, London, U.K., 2003.

5. G.W. Lorimer: Proc. London Conf. on Magnesium Technology, C. Baker, G.W. Lorimer, and W. Unsworth, eds., The Inst. of Metals, London, U.K., 1987, pp. 47-53.

6. I.J. Polmear: Mater. Sci. Technol., 1994, vol. 10, pp. 1-16.

7. I.J. Polmear: Light Alloys, 3rd ed., Arnold, London, U.K., 1995.

8. I.J. Polmear: Light Alloys, 4th ed., Elsevier/Butterworth-Heinemann, Oxford, U.K., 2006.

9. A. Kelly and R.B. Nicholson: Progr. Mater. Sci., 1963, vol. 10, pp. 151-391.

10. A.J. Ardell: Metall. Trans. A, 1985, vol. 16A, pp. 2131-65.
11. B. Reppich: Mater. Sci. Tech.: A Comprehensive Treatment, vol. 6, R.W. Cahn, P. Hassen, and E.J. Kramer, eds., VCH, Weinheim, Germany, 1993, pp. 311-57.

12. E. Nembach: Particle Strengthening in Metals and Alloys, Wiley, Inc., New York, NY, 1997.

13. P. Villars and L.D. Calvert: Pearson's Handbook of Crystallographic Data for Intermetallic Phases, ASM, Materials Park, OH, 1985.

14. A.A. Nayeb-Hashemi and J.B. Clark: Phase Diagrams of Binary Magnesium Alloys, ASM International, Materials Park, $\mathrm{OH}$, 1988.

15. J.B. Clark: Acta Metall., 1968, vol. 16, pp. 141-52.

16. C.R. Hutchinson, J.F. Nie, and S. Gorsse: Metall. Mater. Trans. $A$, 2005, vol. 36A, pp. 2093-2105.

17. B. Lagowski: AFS Trans., 1971, vol. 79, pp. 115-20.

18. C.J. Bettles, P. Humble, and J.F. Nie: Proc. 3rd Int. Magnesium Conf., G.W. Lorimer, ed., The Institute of Materials, London, U.K., 1997, pp. 403-17.

19. S. Celotto: Acta Mater., 2000, vol. 48, pp. 1775-87.

20. J.F. Nie: Proc. Magnesium Technology 2002, H. Kaplan, ed., TMS, Warrendale, PA, 2002, pp. 103-10.

21. D.A. Porter and J.W. Edington: Proc. R. Soc. London A, 1977, vol. 358 , pp. $335-50$.

22. D.B. Williams and E.P. Butler: Int. Metals Rev., 1981, vol. 26, pp. $153-83$.

23. D. Duly, M.C. Cheynet, and Y. Brechet: Acta Metall. Mater., 1994, vol. 42, pp. 3843-54.

24. D. Duly, M.C. Cheynet, and Y. Brechet: Acta Metall. Mater., 1994, vol. 42, pp. 3855-63.

25. D. Duly, J.P. Simon, and Y. Brechet: Acta Metall. Mater., 1995, vol. 43, pp. 101-06.

26. K.N. Braszczynska-Malik: J. Alloys Compd., 2009, vol. 477, pp. $870-76$

27. A.F. Crawley and K.S. Miliken: Acta Metall., 1974, vol. 22, pp. $557-62$.

28. D. Duly, W.Z. Zhang, and M. Audier: Phil. Mag. A, 1995, vol. 71 , pp. $187-204$

29. J.F. Nie, X.L. Xiao, C.P. Luo, and B.C. Muddle: Micron, 2001, vol. 32, pp. 857-63.

30. P.V. Padfield: ASM Handbook, vol. 9, ASM International, Materials Park, OH, 2004, p. 801.

31. M. Zhang, W.Z. Zhang, and F. Ye: Metall. Mater. Trans. A, 2005, vol. 36A, pp. 1681-88.

32. J.F. Nie: Acta Mater., 2004, vol. 52, pp. 795-807.

33. J.F. Nie: Metall. Mater. Trans. A, 2006, vol. 37A, pp. 841-49.

34. J.F. Nie and B.C. Muddle: Metall. Mater. Trans. A, 2002, vol. 33A, pp. 2381-89.

35. J. Gjönnes and T. Östmoe: Z. Metall., 1970, vol. 61, pp. 604-06.

36. A.F. Crawley and B. Lagowski: Metall. Trans., 1974, vol. 5, pp. 949-51.

37. P.G. Partridge: Metall. Review, 1967, vol. 12, pp. 169-94.

38. P.G. Partridge and E. Roberts: The 3rd European Regional Conf. Electron Microscopy, 1964, pp. 213-14.

39. R. Ninomiya, T. Ojiro, and K. Kubota: Acta Metall. Mater., 1995, vol. 43, pp. 669-74.

40. A. Luo, M. Balogh, and B.R. Powell: Metall. Mater. Trans. A, 2002, vol. 33A, pp. 567-74.

41. A. Suzuki, N.D. Saddock, J.W. Jones, and T.M. Pollock: Scripta Mater., 2004, vol. 51, pp. 1005-10.

42. V. Raghavan: J. Phase Equil. Diffusion, 2011, vol. 32, pp. 52-53.

43. A. Suzuki, N.D. Saddock, J.W. Jones, and T.M. Pollock: Acta Mater., 2005, vol. 53, pp. 2823-34.

44. A. Suzuki, N.D. Saddock, J.R. TerBush, B.R. Powell, J.W. Jones, and T.M. Pollock: Metall. Mater. Trans. A, 2008, vol. 39A, pp. 696-702

45. T. Homma, S. Nakawaki, K. Oh-ishi, K. Hono, and S. Kamado: Acta Mater., 2011, vol. 59, pp. 7662-72.

46. I. Higashi, N. Shiotani, and M. Uda: J. Solid State Chem., 1981, vol. 36 , p. 225

47. Y. Khan: J. Mater. Sci., 1989, vol. 24, pp. 963-73

48. X. Gao and J.F. Nie: Scripta Mater., 2007, vol. 57, pp. 655-58.

49. Y.P. Yarmolyuk, P.I. Kripyakevich, and E.V. Mel'nik: Sov. Phys. Crystallogr., 1975, vol. 20, p. 329.

50. Q.B. Yang and K.H. Kuo: Acta Cryst., 1987, vol. A43, pp. 787-95. 
51. J. Gallot and R. Graf: Comptes. Rendus. Acda. Sci., 1966, vol. 262B, p. 1219.

52. J.B. Clark, L. Zabdyr, and Z. Moser: Phase Diagrams of Binary Magnesium Alloys, A.A. Nayeb-Hashemi and J.B. Clark, eds., ASM International, Materials Park, OH, 1988, pp. 353-64.

53. J.B. Clark: Acta Metall., 1965, vol. 13, pp. 1281-89.

54. G. Mima and Y. Tanaka: Trans. Jpn. Inst. Met., 1971, vol. 12, pp. $71-75$.

55. G. Mima and Y. Tanaka: Trans. Jpn. Inst. Met., 1971, vol. 12, pp. 76-81.

56. L.Y. Wei, G.L. Dunlop, and H. Westengen: Metall. Mater. Trans. A, 1995, vol. 26A, pp. 1705-16.

57. J. Buha: Mater. Sci. Eng. A, 2008, vol. 492, pp. 11-19.

58. J. Buha and T. Ohkubo: Metall. Mater. Trans., 2008, vol. 39A, pp. $2259-73$

59. L.L. Rokhlin and A.A. Oreshkina: Fiz. Metal. Metalloved., 1988, vol. 66, p. 559.

60. J. Gallot and R. Graf: Comptes. Rendus. Acda. Sci., 1965, vol. $261 \mathrm{~B}$, p. 728 .

61. J. Gallot, K. Lal, R. Graf, and A. Guinier: Comptes. Rendus. Acda. Sci., 1964, vol. 258B, p. 2818.

62. L. Sturkey and J.B. Clark: J. Inst. Metals, 1959-1960, vol. 88, pp. 177-81.

63. J.S. Chun and J.G. Byrne: J. Mater. Sci., 1969, vol. 4, pp. 861-72.

64. Y. Komura and K. Tokunaga: Acta Crystallogr., 1980, vol. 36B, p. 1548.

65. X. Gao and J.F. Nie: Scripta Mater., 2007, vol. 56, pp. 645-48.

66. A. Singh and A.P. Tsai: Scripta Mater., 2007, vol. 57, pp. 941-44.

67. A. Singh, J.M. Rosalie, H. Somekawa, and T. Mukai: Phil. Mag. Lett., 2010, vol. 90, pp. 641-51.

68. J.M. Rosalie, H. Somekawa, A. Singh, and T. Mukai: Phil. Mag., 2010, vol. 90, pp. 3355-74.

69. J.M. Rosalie, H. Somekawa, A. Singh, and T. Mukai: Phil Mag., 2011, vol. 91, pp. 2634-44.

70. R.I. Mose: Ph.D. Dissertation, The University of Manchester, Manchester, U.K., 1983.

71. J. Geng, X. Gao, X.Y. Fang, and J.F. Nie: Scripta Mater., 2011, vol. 64, pp. 506-09.

72. J. Buha: Mater. Sci. Eng. A, 2008, vol. 491, pp. 70-79.

73. J. Buha: Mater. Sci. Eng. A, 2008, vol. 492, pp. 293-99.

74. J. Buha: Acta Mater., 2008, vol. 56, pp. 3533-42.

75. C.L. Mendis, K. Oh-ishi, Y. Kawamura, T. Honma, S. Kamado, and K. Hono: Acta Mater., 2009, vol. 57, pp. 749-60.

76. K. Oh-ishi, R. Watanabe, C.L. Mendis, and K. Hono: Mater. Sci. Eng. A, 2009, vol. 526, pp. 177-84.

77. K. Hono, C.L. Mendis, T.T. Sasaki, and K. Oh-ishi: Scripta Mater., 2010, vol. 63, pp. 710-15.

78. C.J. Bettles, M.A. Gibson, and K. Venkatesan: Scripta Mater., 2004, vol. 51, pp. 193-97.

79. J.P. Eom, Q.L. Jin, S.G. Lim, B.Y. Hur, and W.W. Park: Mater. Sci. Forum, 2003, vols. 419-422, p. 307.

80. T. Homma, C.L. Mendis, K. Hono, and S. Kamado: Mater. Sci. Eng. A, 2010, vol. 527, pp. 2356-62.

81. S.C. Park, J.D. Lim, D. Eliezer, and K.S. Shin: Mater. Sci. Forum, 2003, vols. 419-422, pp. 159-64.

82. G. Ben-Hamu, D. Eliezer, A. Kaya, Y.G. Na, and K.S. Shin: Mater. Sci. Eng. A, 2006, vols. 435-436, pp. 579-87.

83. C.L. Mendis, K. Oh-ishi, and K. Hono: Scripta Mater., 2007, vol. 57 , pp. $485-88$.

84. C.L. Mendis, K. Oh-ishi, and K. Hono: Mater. Sci. Eng. A, 2010, vol. 527 , pp. $973-80$.

85. C.L. Mendis, J.H. Bae, N.J. Kim, and K. Hono: Scripta Mater., 2011, vol. 64, pp. 335-38.

86. D. Shin and C. Wolverton: Scripta Mater., 2010, vol. 63, pp. 680 85.

87. D. Shin and C. Wolverton: Acta Mater., 2010, vol. 58, pp. 53140.

88. J. Yang, L.D. Wang, L.M. Wang, and H.J. Zhang: J. Alloys Compd., 2008, vol. 459, pp. 274-80.

89. O. Seremetis: Undergraduate Final-Year Research Project Report, Monash University, Melbourne, Australia, 1999.

90. Z.P. Luo, S.Q. Zhang, Y.L. Tang, and D.S. Zhao: Scripta Metall. Mater., 1993, vol. 28, pp. 1513-18.

91. I.J. Kim, D.H. Bae, and D.H. Kim: Mater. Sci. Eng. A, 2003, vol. 359 , pp. $313-18$
92. A. Singh, M. Nakamura, M. Watanabe, A. Kato, and A.P. Tai: Scripta Mater., 2003, vol. 49, pp. 417-22.

93. H. Somekawa, A. Singh, and T. Mukai: Scripta Mater., 2007, vol. 56, pp. 1091-94.

94. D.K. Xu, E.H Han, L. Liu, and Y.B. Xu: Metall. Mater. Trans. $A$, 2009, vol. 40A, pp. 1727-40.

95. H. Liang, S.L. Chen, and Y.A. Chang: Metall. Mater. Trans. A, 1997, vol. 28A, pp. 1725-34.

96. D. Petrov, A. Watson, J. Grobner, P. Rogl, J.C. Tedenac, M. Bulanova, and V. Turkevich: Ternary Alloy Systems, vol. 11A3, G. Effenberg and S. Ilyenko, eds., Springer, Berlin, Germany, 2006, pp. 191-209.

97. Y.P. Ren, G.W. Qin, W.L. Pei, Y. Guo, H.D. Zhao, H.X. Li, M. Jiang, and S.M. Hao: J. Alloys Compd., 2009, vol. 481, pp. 17681.

98. V. Raghavan: J. Phase Equil. Diffusion, 2010, vol. 31, pp. 29394.

99. I.A. Anyanwu, S. Kamado, T. Honda, Y. Kojima, S. Takeda, and T. Ishida: Mater. Sci. Forum, 2000, vols. 350-351, p. 73.

100. Z. Zhang, A. Couture, and A.A. Luo: Scripta Metall., 1998, vol. 39 , pp. $45-53$.

101. Z. Zhang, R. Themblay, D. Dube, and A. Couture: Can. Metall. Q., 2000, vol. 39, pp. 503-12.

102. G. Bergman, J.L.T. Waugh, and L. Pauling: Acta Cryst., 1957, vol. 10 , pp. $254-59$.

103. C.L. Mendis: Masters Thesis, Monash University, Melbourne, Australia, 2000.

104. J.B. Clark and F.N. Rhines: Trans. Am. Soc. Met., 1959, vol. 51, pp. 199-221.

105. P. Donnadieu, A. Quivy, T. Tarfa, P. Ochin, A. Dezellus, M. Harmelin, P. Liang, H.L. Lukas, H.J. Seifert, F. Aldinger, and G. Effenberg: Z. Metallkd., 1997, vol. 88, pp. 911-16.

106. L. Bourgeois, B.C. Muddle, and J.F. Nie: Acta Mater., 2001, vol. 49 , pp. 2701-11.

107. L. Bourgeois, C.L. Mendis, B.C. Muddle, and J.F. Nie: Phil. Mag. Lett., 2001, vol. 81, pp. 709-18.

108. M. Vogel, O. Kraft, G. Dehm, and E. Arzt: Scripta Mater., 2001, vol. 45 , pp. 517-24.

109. T. Rajasekharan, D. Akhtar, R. Gopalan, and K. Muraleedharan: Nature, 1986, vol. 322, pp. 528-30.

110. N.K. Mukhopadhyay, G.N. Subbanna, S. Ranganathan, and K. Chattopadhyay: Scripta Metall., 1986, vol. 20, pp. 525-28.

111. W.A. Cassada, Y. Shen, S.J. Poon, and G.J. Shiflet: Phys. Rev. B, 1986, vol. 34, pp. 7413-16.

112. C.L. Henley and V. Elser: Phil. Mag. B, 1986, vol. 53, pp. L5966.

113. E. Abe and A.P. Tsai: Phys. Rev. Lett., 1999, vol. 83, pp. 753-56.

114. C.L. Mendis, B.C. Muddle, and J.F. Nie: Proc. 4th Pacific Rim Int. Conf. Advanced Materials and Processing (PRICM-4), S. Hanada, Z. Zhong, S.W. Nam, and R.N. Wright, eds., Japan Inst. of Metals, Sendai, Japan, 2001, pp. 1207-10.

115. C.L. Mendis, Ph.D. Dissertation, Monash University, Melbourne, Australia, 2005.

116. K. Oh-ishi, K. Hono, and K.S. Shin: Mater. Sci. Eng. A, 2008, vol. 496 , pp. $425-33$

117. S.S. Park, G.T. Bae, D.H. Kang, I.H. Jung, K.S. Shin, and N.J. Kim: Scripta Mater., 2007, vol. 57, pp. 793-96.

118. M. Vogel, O. Kraft, and E. Arzt: Scripta Mater., 2003, vol. 48, pp. $985-90$.

119. J.F. Nie, X.L. Xiao, and L. Bourgeois: unpublished research, 2000.

120. J.F. Nie and B.C. Muddle: Scripta Mater., 1997, vol. 37, pp. $1475-81$.

121. X. Gao, S.M. Zhu, B.C. Muddle, and J.F. Nie: Scripta Mater., 2005, vol. 53, pp. 1321-26.

122. M. Bamberger, G. Levi, and J.B. Vander Sande: Metall. Mater. Trans. A, 2006, vol. 37A, pp. 481-87.

123. J. Jayaraj, C.L. Mendis, T. Ohkubo, K. Oh-ishi, and K. Hono: Scripta Mater., 2010, vol. 63, pp. 831-34.

124. J.C. Oh, T. Ohkubo, T. Mukai, and K. Hono: Scripta Mater., 2005, vol. 53 , pp. $675-79$.

125. D.H. Ping, K. Hono, and J.F. Nie: Scripta Mater., 2003, vol. 48, pp. 1017-22.

126. P.M. Jardim, G. Solorzano, and J.B. Vander Sande: Microsc. Microanal, 2002, vol. 8, pp. 487-96. 
127. P.M. Jardim, G. Solorzano, and J.B. Vander Sande: Mater. Sci. Eng. A, 2004, vol. 381, pp. 196-205.

128. S.W. Xu, K. Oh-ishi, S. Kamado, F. Uchida, T. Homma, and K. Hono: Scripta Mater., 2011, vol. 65, pp. 269-72.

129. T. Homma, S. Nakawaki, and S. Kamado: Scripta Mater., 2010, vol. 63 , pp. 1173-76.

130. M.A. Gibson, X. Fang, C.J. Bettles, and C.R. Hutchinson: Scripta Mater., 2010, vol. 63, pp. 899-902.

131. D.H. Kang, S.S. Park, and N.J. Kim: Mater. Sci. Eng. A, 2005, vols. 413-414, pp. 555-60.

132. D.H. Kang, S.S. Park, Y.S. Oh, and N.J. Kim: Mater. Sci. Eng. $A, 2007$, vols. 449-451, pp. 318-21.

133. J. van der Planken: J. Mater. Sci, 1969, vol. 4, pp. 927-29.

134. C.L. Mendis, C.J. Bettles, M.A. Gibson, and C.R. Hutchinson: Mater. Sci. Eng. A, 2006, vols. 435-436, pp. 163-71.

135. C.L. Mendis, C.J. Bettles, M.A. Gibson, S. Gorsse, and C.R. Hutchinson: Phil. Mag. Lett., 2006, vol. 86, pp. 443-56.

136. T.T. Sasaki, K. Oh-ishi, T. Ohkubo, and K. Hono: Scripta Mater., 2006, vol. 55, pp. 251-54.

137. G. Derge, A.R. Kommell, and R.F. Mehl: Trans. AIME, 1937, vol. 124 , p. 367

138. V.S. Henes and V. Gerold: Z. Metallkde, 1962, vol. 53, pp. $743-$ 48.

139. T.T. Sasaki, K. Oh-ishi, T. Ohkubo, and K. Hono: Mater. Sci. Eng. A, 2011, vol. 530, pp. 1-8.

140. M. Zhang, W.Z. Zhang, G.Z. Zhu, and K. Yu: Trans. Nonferrous Met. Soc. China, 2007, vol. 17, pp. 1428-32.

141. M. Zhang, W.Z. Zhang, and G.Z. Zhu: Scripta Mater., 2008, vol. 59, pp. 866-69.

142. T.T. Sasaki, J.D. Ju, K. Hono, and K.S. Shin: Scripta Mater., 2009 , vol. 61 , pp. $80-83$.

143. S. Delfino, A. Saccone, and F. Ferro: Metall. Trans. A, 1990 vol. 21 , pp. 2109-14.

144. S. Gorsse, C.R. Hutchinson, B. Chevalier, and J.F. Nie: J. Alloys Compd., 2005, vol. 392, pp. 253-62.

145. H. Okamoto: J. Phase Equil. Diffusion, 2007, vol. 28, p. 405.

146. L.L. Rokhlin: J. Phase Equil., 1995, vol. 16, pp. 504-07.

147. V. Kopp, W. Lefebvre, and C. Pareige: J. Phase Equil. Diffusion, 2011, vol. 32, pp. 298-301.

148. R. Wilson, C.J. Bettles, B.C. Muddle, and J.F. Nie: Mater. Sci. Forum, 2003, vols. 419-422, pp. 267-72.

149. T.J. Pike and B. Noble: J. Less-Common Met., 1973, vol. 30, pp. 63-74.

150. H. Karimzadeh: Ph.D. Dissertation, The University of Manchester, Manchester, U.K., 1985.

151. K.J. Gradwell: Ph.D. Dissertation, University of Manchester, Manchester, U.K., 1972.

152. K. Saito and K. Hiraga: Mater. Trans., 2011, vol. 52, pp. 1860 67.

153. Y.M. Zhu and J.F. Nie: unpublished research, 2012.

154. L.Y. Wei, G.L. Dunlop, and H. Westengen: J. Mater. Sci., 1996, vol. 31, pp. 387-97.

155. M. Hisa, J.C. Barry, and G.L. Dunlop: Phil. Mag. A, 2002, vol. 82, pp. 497-510.

156. C.J. Bettles, K. Venkatesan, and J.F. Nie: Mater. Sci. Forum, 2003, vols. 419-422, pp. 273-78.

157. R. Wilson: Ph.D. Dissertation, Monash University, Melbourne, Australia, 2005

158. C. Zhang, A.A. Luo, L. Peng, D. Stone, and Y.A. Chang: Intermetallics, 2011, vol. 19, pp. 1720-26.

159. H.Y. Qi, G.X. Huang, H. Bo, G.L. Xu, L.B. Liu, and Z.P. Jin: J. Alloys Compd., 2011, vol. 509, pp. 3274-81.

160. M.L. Huang, H.X. Li, H. Ding, Z.Y. Tang, R.B. Mei, H.T Zhou, R.P. Ren, and S.M. Hao: J. Alloys Compd., 2010, vol. 489, pp. 620-25.

161. C.N. Chiu, J. Grobner, A. Kozlov, and R. Schmid-Fetzer: Intermetallics, 2010, vol. 18, pp. 399-405.

162. P. Lyon, T. Wilks, and I. Syed: Magnesium Technology 2005 , N.R. Neelameggham, H.I. Kaplan, and B.R. Powell, eds., TMS, Warrendale, PA, 2005, pp. 303-08.

163. P.A. Nuttall, T.J. Pike, and B. Noble: Metallography, 1980 , vol. 13 , pp. 3-20.

164. M. Nishijima, K. Hiraga, M. Yamasaki, and Y. Kawamura: Mater. Trans., 2007, vol. 48, pp. 476-80.
165. G. Berger and A. Weiss: J. Less-Common Met., 1988, vol. 142, pp. 109-21.

166. R.J.M. Payne and N. Bailey: J. Inst. Metals, 1959-1960, vol. 88, pp. 417-27.

167. S. Kallisch: Undergraduate Final-Year Project Report, Monash University, Australia, 1998

168. J. Kiehn, B. Smola, P. Vostry, I. Stulikova, and K.U. Kainer: Phys. Stat. Sol., 1997, vol. 164, pp. 709-23.

169. G. Barucca, R. Ferragut, D. Lussana, P. Mengucci, F. Moia, and G. Riontino: Acta Mater., 2009, vol. 57, pp. 4416-25.

170. Magnesium Elektron datasheet 463.

171. B. Smola, I. Stulikova, F. von Bush, and B.L. Mordike: Mater. Sci. Eng. A, 2002, vol. 324, pp. 113-17.

172. P. Vostry, B. Smola, I. Stulikova, F. von Buch, and B.L. Mordike: Phys. Stat. Sol. A, 1999, vol. 175, pp. 491-500.

173. J.F. Nie, X. Gao, and S.M. Zhu: Scripta Mater., 2005, vol. 53, pp. 1049-53.

174. S. Kamado, S. Iwasawa, K. Ohuchi, Y. Kojima, and R. Ninomiya: J. Jpn. Inst. Light Metals, 1992, vol. 42, p. 727.

175. L.L. Rokhlin and N.I. Nikitina: Z. Metallkd., 1994, vol. 85, p. 819.

176. R.G. Li, J.F. Nie, G.J. Huang, Y.C. Xin, and Q. Liu: Scripta Mater., 2011, vol. 64, pp. 950-53.

177. X. Gao, S.M. He, X.Q. Zeng, L.M. Peng, W.J. Ding, and J.F. Nie: Mater. Sci. Eng. A, 2006, vol. 431, pp. 322-27.

178. M. Nishijima and K. Hiraga: Mater. Trans., 2007, vol. 48, pp. $10-15$.

179. M. Nishijima, K. Hiraga, M. Yamasaki, and Y. Kawamura: Mater. Trans., 2006, vol. 47, pp. 2109-22.

180. J.F. Nie and B.C. Muddle: Acta Mater., 2000, vol. 48, pp. 16911703.

181. D. Mizer and B.C. Peters: Metall. Trans., 1972, vol. 3, pp. $3262-$ 64.

182. T. Sato, I. Takahashi, H. Tezuka, and A. Kamio: J. Jpn. Inst. Light Met., 1992, vol. 42, pp. 804-09.

183. M. Nishijima, K. Yubuta, and K. Hiraga: Mater. Trans., 2007, vol. 48, pp. 84-87.

184. M.X. Zhang and P.M. Kelly: Scripta Mater., 2003, vol. 48, pp. $379-84$

185. P. Vostry, I. Stulikova, B. Smola, M. Cieslar, and B.L. Mordike: Z. Metallkde, 1988, vol. 79, pp. 340-44.

186. L.L. Rokhlin, T.V. Dobatkina, I.E. Tarytina, V.N. Timofeev, and E.E. Balakhchi: J. Alloys Compd., 2004, vol. 367, pp. 17-19.

187. W. Unsworth and J.F. King: Proc. London Conf. on Magnesium Technology, G.W. Lorimer, ed., The Institute of Metals, London, U.K., 1987, pp. 25-35.

188. R.A. Khosrhoshahi, R. Pilkington, G.W. Lorimer, P. Lyon, and H. Karimzadeh: Proc. 3rd Int. Magnesium Conf., G.W. Lorimer, ed., The Institute of Materials, London, U.K., 1997, pp. 241-56.

189. T. Hilditch, J.F. Nie, and B.C. Muddle: Proc. Magnesium Alloys and Their Applications, B.L. Mordike and K.U. Kainer, eds., Werkstoff-Informationsgesellschaft, Frankfurt, Germany, 1998, pp. 339-44.

190. G.W. Lorimer, R.A. Khosrhoshahi, and M. Ahmed: Proc. Int. Conf. on Solid-Solid Phase Transformations, M. Koiwa, K. Otsuka, and T. Miyazaki, eds., The Japan Inst. of Metals, Tokyo, Japan, 1999, pp. 185-92.

191. M. Ahmed, G.W. Lorimer, P. Lyon, and R. Pilkington: Proc. Magnesium Alloys and Their Applications, B.L. Mordike and F. Hehmann, eds., DGM Informationsgesellschaft, Germany, 1992, pp. $301-08$.

192. J.F. Nie and B.C. Muddle: Scripta Mater., 1999, vol. 40, pp. 1089-94

193. C. Antion, P. Donnadieu, F. Perrard, A. Deschamps, C. Tassin, and A. Pisch: Acta Mater., 2003, vol. 51, pp. 5335-48.

194. C. Antion, P. Donnadieu, C. Tassin, and A. Pisch: Phil. Mag., 2006, vol. 86, pp. 2797-2810.

195. G. Barucca, R. Ferragut, F. Fiori, D. Lussana, P. Mengucci, F. Moi, and G. Riontino: Acta Mater., 2011, vol. 59, pp. 4151-58.

196. Z. Xu, M. Weyland, and J.F. Nie: unpublished research, 2012.

197. P.J. Apps, H. Karimzadeh, J.F. King, and G.W. Lorimer: Scripta Mater., 2003, vol. 48, p. 1023.

198. I.A. Anyanwu, S. Kamado, and Y. Kojima: Mater. Trans., 2001, vol. 42 , pp. $1206-11$ 
199. S.M. He, X.Q. Zeng, L.M. Peng, X. Gao, J.F. Nie, and W.J. Ding: J. Alloys Compd., 2006, vol. 421, pp. 309-13.

200. T. Homma, T. Ohkubo, S. Kamado, and K. Hono: Acta Mater., 2007, vol. 55, pp. 4137-4750.

201. K. Yamada, Y. Okubo, M. Shino, H. Watanabe, S. Kamado, and Y. Kojima: Mater Trans., 2006, vol. 47, pp. 1066-70.

202. T. Homma, N. Kunito, and S. Kamado: Scripta Mater., 2009, vol. 61, pp. $644-47$.

203. J.F. Nie, K. Oh-ishi, X. Gao, and K. Hono: Acta Mater., 2008, vol. 56, pp. 6061-76.

204. M. Nishijima, K. Hiraga, M. Yamasaki, and Y. Kawamura: Mater. Trans., 2008, vol. 49, pp. 227-29.

205. K. Saito, A. Yasuhara, and K. Hiraga: J. Alloys Compd., 2011, vol. 509 , pp. 2031-38.

206. M. Yamasaki, M. Sasaki, M. Nishijima, K. Hiraga, and Y. Kawamura: Acta Mater., 2007, vol. 55, pp. 6798-6805.

207. M. Yamasaki, T. Anan, S. Yoshimoto, and Y. Kawamura: Scripta Mater., 2005, vol. 53, pp. 799-803.

208. S. Yoshimoto, M. Yamasaki, and Y. Kawamura: Mater. Trans., 2006, vol. 47, pp. 959-65.

209. M. Suzuki, T. Kimura, J. Koike, and K. Maruyama: Scripta Mater., 2003, vol. 48, pp. 997-1002.

210. M. Suzuki, T. Kimura, J. Koike, and K. Maruyama: Mater. Sci. Eng. A, 2004, vols. 387-389, pp. 706-09.

211. B. Noble, T.J. Pike, and A. Crook: Phil. Mag., 1971, vol. 23, pp. $543-53$.

212. J.P. Hirth and J. Lothe: Theory of Dislocations, McGraw-Hill Book Company, New York, NY, 1968.

213. Y.M. Zhu, A.J. Morton, M. Weyland, and J.F. Nie: Acta Mater., 2010, vol. 58, pp. 464-75.

214. Y.M. Zhu, M. Wayland, A.J. Morton, K. Oh-ishi, K. Hono, and J.F. Nie: Scripta Mater., 2009, vol. 60, pp. 980-83.

215. M. Matsuda, S. Ii, Y. Kawamura, Y. Ikuhara, and M. Nishida: Mater. Sci. Eng. A, 2005, vol. 393, pp. 269-74.

216. Y.M. Zhu, A.J. Morton, and J.F. Nie: Acta Mater., 2010, vol. 58, pp. 2936-47.

217. E.M. Padezhnova, E.V. Mel'nik, R.A. Miliyevskiy, T.V. Dobatkina, and V.V. Kinzhibalo: Russ. Metall., 1982, vol. 4, p. 185.

218. G. Shao, V. Varsani, and Z. Fan: Comp. Coupling Phase Diag. Thermochem., 2006, vol. 30, pp. 286-95.

219. D.H Ping, K. Hono, Y. Kawamura, and A. Inoue: Phil. Mag. Lett., 2002, vol. 82, pp. 543-51.

220. Y. Kawamura, K. Hayashi, A. Inoue, and T. Masumoto: Mater. Trans., 2001, vol. 42, pp. 1172-76.

221. E. Abe, Y. Kawamura, K. Hayashi, and A. Inoue: Acta Mater., 2002, vol. 50, pp. 3845-57.

222. T. Itoi, T. Seimiya, Y. Kawamura, and M. Hirohashi: Scripta Mater., 2004, vol. 51, pp. 107-11.

223. Z.P. Luo and S.Q. Zhang: J. Mater. Sci. Lett., 2000, vol. 19, pp. 813-15.

224. J. Grobner, A. Kozlov, X.Y. Fang, J. Geng, J.F. Nie, and R. Schmid-Fetzer: Acta Mater., in press.

225. H. Yokobayashi, K. Kishida, H. Inui, M. Yamasaki, and Y. Kawamura: Acta Mater., 2011, vol. 59, pp. 7287-99.

226. D. Egusa and E. Abe: Acta Mater., 2012, vol. 60, pp. 166-78.

227. Y. Kawamura and M. Yamasaki: Mater. Trans., 2007, vol. 48, pp. 2986-92.

228. Y. Kawamura, T. Kasahara, S. Izumi, and M. Yamasaki: Scripta Mater., 2006, vol. 55, pp. 453-56.

229. M. Matsuura, K. Konno, M. Yoshida, M. Nishijima, and K. Hiraga: Mater. Trans., 2006, vol. 47, pp. 1264-67.

230. K. Amiya, T. Ohsuna, and A. Inoue: Mater. Trans., 2003, vol. 44, pp. 2151-56.

231. X. Hui, W. Dong, G.L. Chen, and K.F. Yao: Acta Mater., 2007, vol. 55 , pp. $907-20$.

232. X. Gao and J.F. Nie: Scripta Mater., 2008, vol. 48, pp. 619-22.

233. K. Yamada, H. Hoshikawa, S. Maki, T. Ozaki, Y. Kuroki, S. Kamado, and Y. Kojima: Scripta Mater., 2009, vol. 61, pp. 63639.

234. Y.M. Zhu, Ph.D. Dissertation, Monash University, Australia, 2011.

235. Z. Ma: Undergraduate Final-Year Research Project Report, Monash University, Melbourne, Australia, 2007.

236. Y.M. Zhu, A.J. Morton, and J.F. Nie: Scripta Mater., 2008, vol. 58 , pp. $525-28$
237. Y.M. Zhu, A.J. Morton, and J.F. Nie: Phil. Mag. Lett., 2010, vol. 90, pp. 173-81.

238. C.L. Mendis, K. Oh-ishi, T. Ohkubo, and K. Hono: Scripta Mater., 2011, vol. 64, pp. 137-40.

239. T.T. Sasaki, T. Ohkubo, and K. Hono: Scripta Mater., 2009, vol. 61, pp. 72-75.

240. L.M. Brown and R.K. Ham: Strengthening Methods in Crystals, A. Kelly and R.B. Nicholson, eds., Elsevier Publishing Company Ltd., London, U.K., 1971. pp. 12-135.

241. J.F. Nie: Scripta Mater., 2003, vol. 48, pp. 1009-15.

242. J.F. Nie and B.C. Muddle: J. Phase Equilibria, 1998, vol. 19, pp. $543-51$.

243. J.C. Huang and A.J. Ardell: J. De Phys., 1987, vol. C3(9), pp. 373-83.

244. J.F. Nie and B.C. Muddle: Proc. Magnesium Alloys and Their Applications, B.L. Mordike and K.U. Kainer, eds., WerkstoffInformationsgesellschaft, Frankfurt, Germany, 1998, pp. 229-34.

245. J.F. Nie, H.I. Aarosnon, and B.C. Muddle: Proc. The James T. Staley Honorary Symp. on Aluminium Alloys, Materials Solutions Conf., M. Tiryakioglu, ed., ASM International, Materials Park, $\mathrm{OH}, 2001$, pp. 229-38.

246. M.A. Gharghouri, G.C. Weatherly, and J.D. Embury: Phil. Mag. $A, 1998$, vol. 78, pp. 1137-49.

247. J.D. Robson, N. Stanford, and M.R. Barrnet: Scripta Mater., 2010, vol. 63, pp. 823-26.

248. J.D. Robson, N. Stanford, and M.R. Barrnet: Acta Mater., 2011, vol. 59, pp. 1945-56.

249. J.F. Nie: unpublished research, 2012.

250. S.C. Weakley-Bollin, W. Donlon, C. Wolverton, J.W. Jones, and J.E. Allison: Metall. Mater. Trans. A, 2004, vol. 35A, pp. 240718.

251. B.C. Muddle, S.P. Ringer, and I.J. Polmear: Trans. Mater. Res. Soc. Japan., 1994, vol. 19B, p. 999.

252. J.F. Nie, B.C. Muddle, and I.J. Polmear: Mater. Sci. Forum, 1996, vols. 217-222, pp. 1257-62.

253. J.F. Nie: Acta Mater., 2008, vol. 56, pp. 3169-76.

254. M.X. Zhang and P.M. Kelly: Acta Mater., 2005, vol. 53, pp. 1085-96.

255. R.S. Busk: J. Metals, 1950, vol. 188, pp. 1460-64.

256. J.N. Mushovic and N.S. Stoloff: Trans. TMS-AIME, 1969, vol. 245 , pp. $1449-56$.

257. B. Noble and A. Crook: J. Inst. Met., 1970, vol. 98, pp. 375-80.

258. D.J. Stratford: J. Inst. Met., 1971, vol. 99, pp. 201-08.

259. D.J. Stratford: J. Inst. Met., 1972, vol. 100, pp. 381-84.

260. D.J. Stratford and L. Beckley: J. Met. Sci., 1972, vol. 6, pp. 8389

261. T.J. Pike, P.A. Nuttall, and B. Noble: J. Inst. Met., 1972, vol. 100 , pp. $249-54$

262. T. Furuhara and H.I. Aaronson: Acta Metall. Mater., 1991, vol. 39, pp. 2857-72.

263. T. Furuhara, J.M. Howe, and H.I. Aaronson: Acta Metall. Mater., 1991, vol. 39, pp. 2873-86.

264. J.P. Hirth, G. Spanos, M.G. Hall, and H.I. Aaronson: Acta Mater., 1998, vol. 46, pp. 857-68.

265. J.F. Nie and B.C. Muddle: Mater. Forum, 1999, vol. 23, pp. 2340.

266. J.F. Nie, H.I. Aaronson, and B.C. Muddle: Proc. Int. Conf. on Solid-Solid Phase Transformations, M. Koiwa, K. Otsuka, and T. Miyazaki, eds., The Japan Inst. of Metals, Tokyo, Japan, 1999, pp. $157-60$.

267. X. Gao, J.F. Nie, and B.C. Muddle: Proc. Int. Conf. on SolidSolid Phase Transformations, M. Koiwa, K. Otsuka, and T. Miyazaki, eds., The Japan Inst. of Metals, Tokyo, Japan, 1999, pp. 225-28.

268. L. Bourgeois, C. Dwyer, M. Weyland, J.F. Nie, and B.C. Muddle: Acta Mater., 2012, vol. 60, pp. 633-44.

269. F. Moia, R. Ferragut, A. Calloni, A. Dupasquier, C.E. Macchi, A. Somoza, and J.F. Nie: Phil. Mag., 2010, vol. 90, pp. 2135-47.

270. U. Dahmen and K.H. Westmacott: Scripta Metall., 1983, vol. 17, pp. $1241-46$.

271. W.A. Cassada, G.J. Shiflet, and E.A. Starke: Metall. Trans. A, 1991, vol. 22A, pp. 287-97.

272. M. Nishijima, K. Hiraga, M. Yamasaki, and Y. Kawamura: Mater. Trans., 2009, vol. 50, pp. 1747-52.

273. A. Wilm: DRP 244554, German Patent, 1906. 
274. A. Wilm: Metallurgie, 1911, vol. 8, p. 225.

275. O. Hardouin Duparc: Z. Metallkd, 2005, vol. 96, pp. 398-404.

276. I.J. Polmear and R.J. Chester: Scripta Metall., 1989, vol. 23, pp. 1213-17.
277. J.R. Pickens, F.H. Heubaum, T.J. Langan, and L.S. Kramer, Proc. 5th Int. Conf. on Aluminium-Lithium Alloys, E.A. Starke and T.H. Sanders, eds., Mater and Comp. Eng. Publications, Birmingham, U.K., 1989, pp. 1397-1414. 